\title{
CSIC
}

int

ibfg

UNIVERSIDAD DE SALAMANCA

DEPARTAMENTO DE MICROBIOLOGÍA Y GENÉTICA INSTITUTO DE BIOLOGÍA FUNCIONAL Y GENÓMICA

Función meiótica de

la proteína Ddc2 de

Saccharomyces cerevisiae

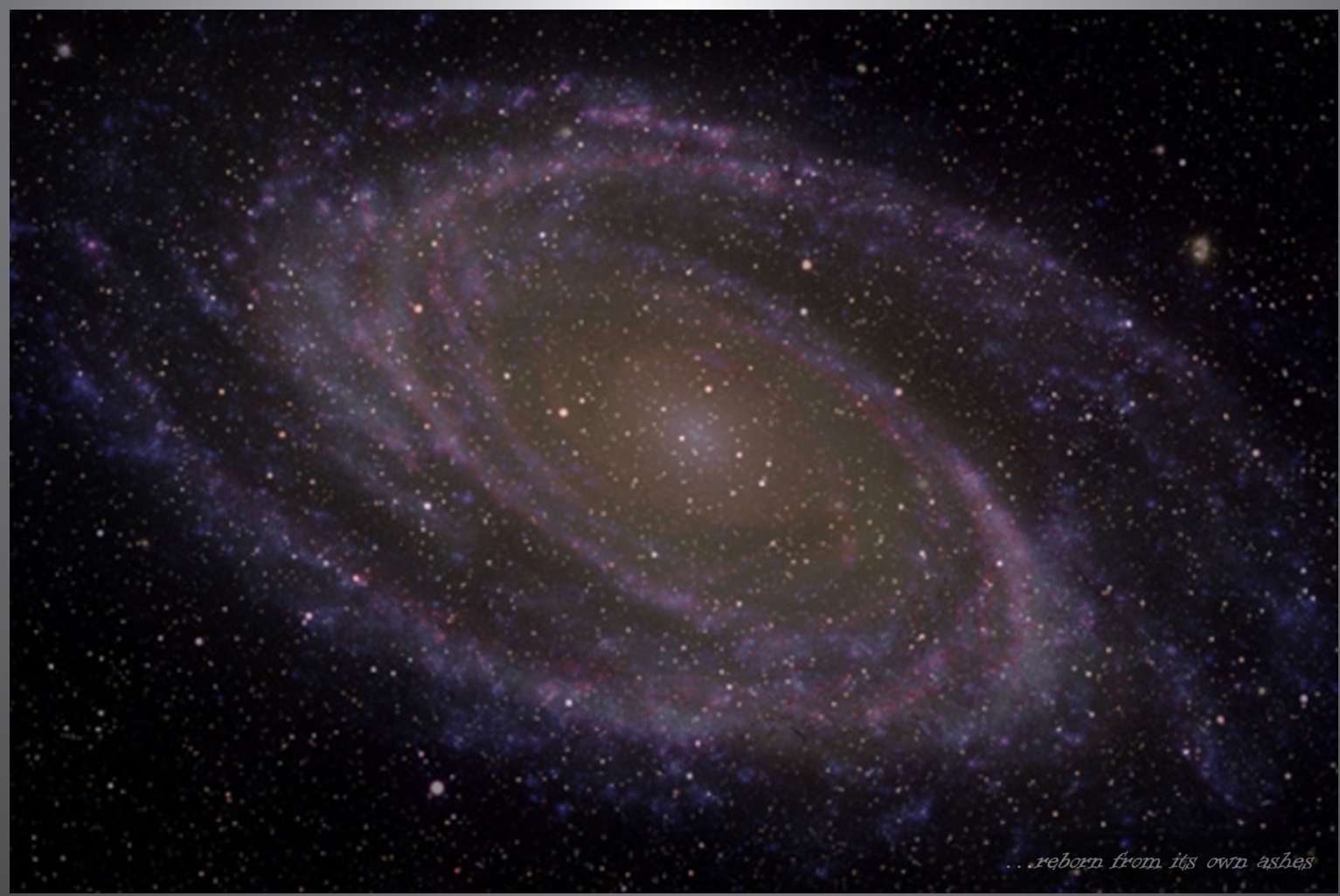

ESTHER H. REFOLIO CARNICERO

Salamanca 2013 

Departamento de Microbiología y Genética Instituto de Biología Funcional y Genómica (USAL/CSIC)

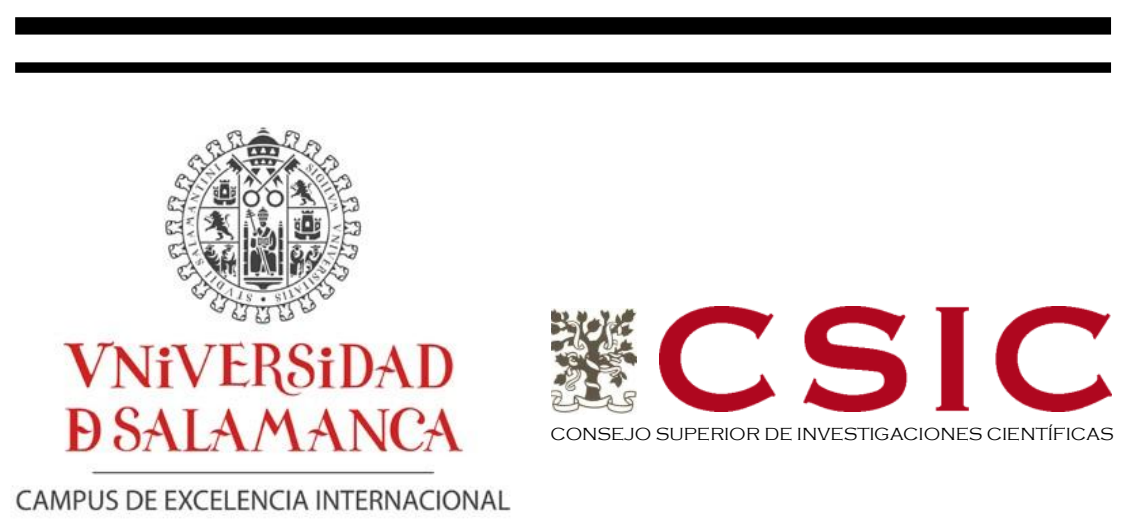

CAMPUS DE EXCELENCIA INTERNACIONAL

TESIS DOCTORAL

\section{Función meiótica de la proteína Ddc2 de Saccharomyces cerevisiae}

Esther H. Refolio Carnicero 

D. LUIS ROMÁN FERNÁNDEZ LAGO, PROFESOR TITULAR DE LA UNIVERSIDAD DE SALAMANCA Y DIRECTOR del DEPARTAMENTO DE MICROBIOLOGÍA Y GENÉTICA de la UNIVERSIDAD DE SALAMANCA,

\section{CERTIFICA:}

Que la memoria titulada "Función meiótica de la proteína Ddc2 de Saccharomyces cerevisiae", presentada Por la licenciada Esther Hortensia Refolio Carnicero ha sido realizada bajo la dirección del Dr. Pedro A. San Segundo Nieto, en el Instituto de Biología Funcional y Genómica (IBFG), centro mixto de la Universidad de Salamanca (Departamento de Microbiología y Genética) y del Consejo Superior de Investigaciones Científicas (CSIC).

Y para autorizar su presentación y evaluación por el tribunal correspondiente, expide el presente certificado en Salamanca, a de de 
D. PEDRo antonio san segundo nieto, Científico titular del CONSEJO SUPERIOR DE INVESTIGACIONES CIENTÍFICAS (CSIC) EN EL INSTITUTO DE BIOLOGÍA FUNCIONAL Y GENÓMICA,

\section{CERTIFICA:}

Que la licenciada Esther Hortensia Refolio Carnicero ha realizado el trabajo titulado "Función meiótica de la proteína Ddc2 de Saccharomyces cerevisiae" bajo mi dirección, en el Instituto de Biología Funcional y Genómica (IBFG), centro mixto de la Universidad de Salamanca (Departamento de Microbiología y Genética) y del Consejo Superior de Investigaciones Científicas (CSIC), para optar al grado de Doctor en Ciencias Biológicas.

Y para autorizar su presentación y evaluación por el tribunal correspondiente, expide el presente certificado en Salamanca, a de de 
D. FRANCISCO DEL REY IGLESIAS, CATEDRÁTICO de MICROBIOLOGÍA DEL DEPARTAMENTO DE MICROBIOLOGÍA Y GENÉTICA de la UNIVERSIDAD DE SALAMANCA,

\section{CERTIFICA:}

Que la memoria titulada "Función meiótica de la proteína Ddc2 de Saccharomyces cerevisiae", presentada Por la licenciada Esther Hortensia Refolio Carnicero ha sido realizada, con mi tutoría, bajo la dirección del Dr. Pedro A. San Segundo Nieto, en el Instituto de Biología Funcional y Genómica (IBFG), centro mixto de la Universidad de Salamanca (Departamento de Microbiología y Genética) y del Consejo Superior de Investigaciones Científicas (CSIC).

Y para autorizar su presentación y evaluación por el tribunal correspondiente, expide el presente certificado en Salamanca, a de de 
Durante los últimos 5 años y medio (ahora ya 7 años), he pensado más de una vez en la llegada de este momento, en cómo me iba a sentir y lo que iba a cambiar mi vida cuando esta etapa tan importante terminase. Estaba convencida de lo fácil que iba a ser para mí escribir esta parte de la tesis, porque es en la que puedes dejar fluir las palabras sin atender a "qué tiempo verbal hay que usar" y si "una frase está escrita de la forma correcta o no", porque al fin y al cabo, son "tus" palabras... pero me equivocaba, porque hay tantas cosas que he vivido en estos años y tanta gente a la que agradecer el haber compartido este camino tan duro, que me va a ser muy difícil explicar en un folio cómo me siento ahora mismo. Como ya podéis imaginaros y a poco que me conozcáis, a lo difícil que está siendo concluir este período se une el hecho de que me es imposible no emocionarme mientras escribo estas líneas recordando. Además, quiero aprovechar este texto para hacer un pequeño homenaje a las personas que más han marcado mi vida. Mi intención no es otra que intentar que mis palabras reflejen mis sentimientos y que os lleguen muy dentro.

La primera persona que debo mencionar es Pedro, el cual, hizo posible tanto el inicio como el fin de esta bonita historia y al que debo el estar hoy aquí. Gracias por confiar en aquella chica "tímida" de la primera planta. Gracias por no sólo darme la oportunidad de entrary descubrir este mundo, si no por todo lo que me has enseñado. Tu continuo empeño por rozar la perfección en todo lo que haces y tu afán de superación es de admirar. Te agradezco muchísimo todo lo que has hecho por mí, tanto a nivel profesional como personal, que al final es lo verdaderamente importante. Gracias a ti, en este "mundo" siempre hay una recompensa por tanto trabajo y tanto esfuerzo. Gracias de verdad.

Hace 7 años me acogieron en Bioquímica, donde di mis primeros pasos en investigación bajo la tutela de Carmen y Jesús. Gracias por esos casi 2 años en los que empecé a cogerle el "gustillo" a los westerns. Mi maestra fue Nancy, con la que desde el principio tuve una relación muy especial, llena de confidencias, pero sobre todo, de amistad. A Nieves le tengo que agradecer lo mucho que aprendí con ella de otro campo que me apasiona, los viajes. A todos, muchísimas gracias por todo y por seguir sintiéndoos cerca estos últimos años.

Del lab.316, mi segunda casa...donde se cuece de todo y en tan poco espacio (eso sí que tiene mérito, qué apañados somos!) Como nos hemos llevado tan bien, quizás no soy capaz de apreciar la suerte que he tenido trabajando largas horas de trabajo con gente tan maravillosa. Suena pedante, pero es la verdad. Paco ya no estás y se nota. Aún me acuerdo de esos tiempos en los que estábamos tú y yo solitos. Si no hubiera sido por ti, no puedo imaginarme cómo hubieran ido las cosas. Te debo mucho. Mi pupilo David, que es una de las personas que más admiro, por cómo es y por todo lo que sabe....jes que sabe de todo el tío! Nuestra relación pasó muy pronto de ser compis a ser amigos y te voy a echar mucho de menos (¿con quién vas a "estrumpir" los embalajes?). Isa ha sido mi gran aliada entre tanto hombre, me has ayudado muchísimo en momentos muy importantes y te agradezco que me escucharas y me comprendieras tan bien. Te has comportado como una verdadera amiga y te admiro por lo luchadora que eres. Y a Santi, el último en llegar, pero el más grande. En todo, jeh! Gracias por esos consejos tan valiosos y por volcarte en ayudarme a dar consistencia a este trabajo. No puedo olvidarme de Berta y Rocío, dos compañeras que ya no están pero de las que guardo muy buenos recuerdos y a las que tengo mucho cariño.

Continúo con la gente del IMB, especialmente con los becarios, pero sin olvidar a la gente de Secretaría e informática (Alegría, Paco Soriano, Javier Tola y Miguel, gracias por la ayuda final), a Carmen Castro (mil gracias), Paco A. y Carlos Belinchón. A todos deciros que sois geniales. Gracias por formar parte de este grupo y por tratarme tan bien. Los becarios somos el alma del centro y ojalá que este buen rollo dure siempre porque aunque eso no hace que "lo difícil" se haga "fácil", ni que empiecen a salir los westerns...por lo menos algo mejor se lleva, ¿no? Todos necesitamos un hombro en el que llorar o en el que apoyarte, y aquí yo he encontrado a muy buenas personas, de una calidad humana increíble y que se preocupan verdaderamente por ti. Algunas de estas personas son: Sandrine, Cristina M., Olga, Ana J., Mercedes T., Joana, María G., Ana Y., Ramón S., Jorge, Fernando L., Carlos, Jose Ángel, Bea S., Mario, Toñi, Pilar P., Talía, Laura A., Civi, Laura D., Nagore, Patri, Eli, Laura M., Cristina C., Rebeca, Paco A., Carlos V. y Paco del R. De forma especial quería agradecer a Nacho, Alicia y Javi E. esas palabras de ánimo, por su tiempo y su interés tan sincero por mí. A Javi, Alberto y Naza os deseo lo mejor, ha sido un placer poder compartir estos últimos días con vosotros porque nos ha servido para estrechar lazos mientras compartíamos mesa peleándonos con la escritura. Las últimas palabras de este párrafo se las dedico a mi niña, por cómo es ella y porque se lo merece....Mariona, me has demostrado todo, gracias porque siempre que lo he necesitado has estado ahí para mí (fuiste mi gran apoyo en USA) y eres uno de los tesoros que he descubierto en este período de mi vida y que me llevo para siempre. 
Quiero dar las gracias también (aunque estén lejos y no puedan leer estas líneas) a la gente que ha formado parte de los laboratorios de Luis Aragón y Michael Lichten donde realicé mis dos estancias en el extranjero (Londres y Bethesda, respectivamente). Gracias especialmente a ellos por ser tan buenos profesionales y mejores personas, y a Sarah, Pranav, Violeta y Rober por ofrecerme su ayuda siempre. Aquí, tengo que mencionar a Nerri, mi "sister" hebrea, con la que compartí 3 meses en Bethesda y que se volcó conmigo en el que hasta ahora ha sido el momento más duro de mi vida. Gracias por ser tan buena amiga en tan poco tiempo.

Una de las mayores suertes que he tenido en mi vida ha sido formar parte del Grupo Scout Pléyades porque allí conocía a la mayor parte de mis amigos. Este hecho fundamental se lo debo a mis padres. Ellos son los verdaderamente responsables de mi naturaleza y mi forma de ser (lo siento papá, pero el físico es de mamá). Gracias por confíar siempre en mí y por apoyarme incondicionalmente en todo lo que hago. Gracias por estar orgullosos de mí y por quererme tanto. A ellos va dedicada esta Tesis, porque sé que son los que más valoran mi esfuerzo y empeño. Rubén nunca olvides que yo te quiero tanto o más que tú a mí. No te rindas, ¿vale? Y no puedo olvidarme del resto: mis abuelos/as, mis tíos/as (mi tita Manoli siempre tan pendiente de mí), mis primos/as (Silvi eres mi hermanita pequeña)... gracias porque me siento orgullosa de formar parte de una familia así. Y a los que ya no están, duele no teneros aquí conmigo...os echo de menos y os tengo muy presente... a todos, os quiero muchísimo.

Éramos un grupo de amigos inseparables y lo compartíamos "todo"...pero la vida nos lleva por caminos diferentes. Aunque nos sea difícil, todos queremos mantener esa "esencia" que nos dio tantos momentos buenos, la mayoría de los cuales, han sido inolvidables e irrepetibles. ¡Os echo de menos y os quiero tanto! sois parte de mí y sin vosotros no sería la misma. Los "jinetes" y las "nenas" lo han compartido todo y eso nos quedará para siempre. Hay una frase de una canción que lo describe bastante bien: "la amistad se convirtió en amor". Nati, mi hermanita, eres la persona que más me ha dado y que menos me ha pedido, la que nunca me ha fallado y a la que he confiado todo. ¡Es que no concibo mi vida sin ti!. Nadie me conoce como tú y nunca podré agradecerte todo lo que has hecho por mí. Julia, Beíta y Ana Cris sois mis niñas, llevamos toda una vida juntas... iy lo que nos queda por compartir! Gracias por estar ahí siempre, iqué suerte tengo de teneros como amigas! Alberto, sabes de sobra lo que has significado en mi vida y te agradezco todo lo bueno que me has dado. Gracias también por todos esos momentos difíciles, quizás demasiados, en los que has sido mi apoyo y mi seguridad. (Ah, y gracias además por sufrir conmigo la interminable lista de findes acompañándome al lab y, sobre todo, por no rechistar "mucho" por ello). Sergio, David y Álex sois mis niños y siempre lo seréis, gracias por haberme hecho tan feliz. A Alsi, Aning, Anita, Ana B., Beota, Helena, Juani, María, Mariví, Miri, Nerry, Terce, Yoli...gracias por convertiros en amigas imprescindibles y por preocuparos tanto por mí. A todos, os quiero de corazón y sabed que aquí me tenéis para lo que necesitéis. Al resto de amigos de scout, que son muchos (Juanpy, Marta, Moreno, Morocho, M. Elena, Patri...), gracias de corazón por todos y cada uno de esos momentos compartidos en las acampadas, las cuales, echo muchísimo de menos. Al crecer y madurar juntos tenemos un vínculo tan especial que durará para siempre. A mis amigos de la Facultad, gracias por esos momentos de risas en los viajes y en las "fiestecitas" en San Alberto. Sólo por conoceros ya ha merecido la pena haber elegido esta Carrera y no otra. La verdad es que, sin vosotros, llegar a la "meta" habría sido mucho más difícil.

He dejado para el final la persona que llena mi corazón y mi vida en estos momentos, la que me ha devuelto la ilusión y la que me hace sonreír cuando me levanto cada mañana. Jose, conocerte ha cambiado mi vida y soy muy feliz. La vida es una "caja" de sorpresas a tu lado y te agradezco que quieras compartirla conmigo. Gracias por hacerme sentir. Me das todo lo que necesito y eres la suerte de mi vida. Te quiero.

Por fin acabo, y no quiero hacerlo sin decir que aunque durante esta larga temporada he aprendido mucho a nivel científico, lo que realmente me llevo son, sobre todo, personas y vivencias que me han hecho crecery han moldeado a la Esther de hoy. El fin de esta etapa tan importante en mi vida me llena de satisfacción pero también me entristece porque sé que voy a dejar atrás muchas cosas y muy buenas personas. En fin... (suspiro)... c'est la vie, ¿no?

Espero no haber aburrido a nadie con tantos párrafos y mucho menos, haber deufradado a alguien con mis palabras. Si lo he hecho lo siento, porque la verdad es que todos vosotros os mereceríais, al menos, un folio entero. Bueno, iiestoy que no me lo creo!! ¡iQué bien!! iiLlegó el momento!! Ya puedo pronunciar esa frase tan "ansiada" por todos los becarios pre-doctorales: "iilo conseguí!! ¡iPor fin soy DOCTORA!!" $Y$ termino con una frase perfecta para los tiempos que corren porque contiene "demasiada" verdad: "No es más rico el que más tiene, si no el que menos necesita". 
INTRODUCCIÓN 3

1.- MECANISMOS DE VIGILANCIA DEL CICLO CELULAR O CHECKPOINTS 3

1.1.- Los checkpoints de integridad del genoma 4

1.1.1.- Componentes del checkpoint de daño en DNA 5

1.1.1.1.- Sensores 6

1.1.1.2.- Efectores

1.1.1.3.- Adaptadores

1.1.1.4.- Dianas

1.2.- El checkpoint de ensamblaje del huso 9

1.3.- El checkpoint de orientación del huso 9

2.- LAMEIOSIS 10

2.1.- Etapas de la meiosis 11

2.1.1.- La replicación premeiótica del DNA 11

2.1.2.- La profase meiótica 11

2.1.2.1.- El apareamiento y la sinapsis: Formación del Complejo Sinaptonémico (SC) 11

2.1.2.2.- La recombinación meiótica 12

2.1.3.- Segregación de los cromosomas en meiosis 14

2.2.- Formación de las esporas 15

2.3.- El checkpoint de recombinación meiótica o de paquitene en S.cerevisiae 15

2.4.- Alteraciones de la meiosis 19

OBJETIVOS 21

RESULTADOS 23

CAPITULO 1.- Caracterización de la función de la proteína Ddc2 en meiosis 23

1.1.- La proteína Ddc2 participa en el checkpoint de recombinación meiótica 23

1.2.- En ausencia de $D D C 2$, las células entran en meiosis I sin haber reparado $\begin{array}{ll}\text { los intermediarios de recombinación } & 27\end{array}$

1.3.- La producción de Ddc2 se induce en la profase meiótica 31

1.4.- Fosforilación de Ddc2 durante la meiosis 33

1.5.- Los sitios consenso de fosforilación por Mec1 no son necesarios para la función de checkpoint de Ddc2 
1.6.- Ddc2 se localiza en los cromosomas meióticos y se acumula en mutantes bloqueados por el checkpoint de paquitene 35

1.7.- Localización in vivo de Ddc2 durante la meiosis 35

1.8.- La localización de Ddc2 en meiosis depende de RPA 39

1.9.- Ddc2 se acumula en DSBs meióticas sin reparar 41

CAPÍTULO 2.- Interacción de Ddc2 con el huso meiótico 44

2.1.- Localización alternativa de Ddc2 independiente de la recombinación meiótica 44

2.2.- Ddc2 colocaliza con el huso meiótico 45

2.3.- Ddc2 interacciona con el huso de la profase meiótica: ensayo BiFC 46

2.4.- La localización de Ddc2 en el huso depende de Mec1 46

2.5.- Los mutantes $d d c 2$ y mec1 presentan sensibilidad a benomilo 48

CAPÍTULO 3.- Detección y señalización de los intermediarios de recombinación meiótica en el mutante sae2 $\quad 50$

3.1.- Localización de Ddc2 en el mutante sae2 50

3.2.- Localización de Ddc2 en el mutante rad50S 52

3.3.- Ddc2 colocaliza con RPA en los mutantes sae2 y rad50S 52

3.4.- En el mutante sae2 se genera ssDNA durante la meiosis 53

3.5.- El ssDNA generado en el mutante sae2 activa el checkpoint de recombinación meiótica 54

3.6.- Spo11 y Ddc2 no colocalizan en el mutante sae2 56

3.7.- Requerimientos genéticos para la localización de Ddc2 en sae2 58

3.8.- En el mutante sae2 existe una leve acumulación de Ddc2 en algunas DSBs 59

$\begin{array}{ll}\text { DISCUSIÓN } & 65\end{array}$

$\begin{array}{ll}\text { CONCLUSIONES } & 73\end{array}$

MATERIALES Y MÉTODOS

1.- CONSTRUCCIÓN DE CEPAS DE Saccharomyces cerevisiae 75

1.1.- Deleción de genes $\quad 75$

1.2.- Marcaje de proteínas con epítopos $\quad 79$

1.3.- Otras construcciones $\quad 85$

2.- MEDIOS Y CONDICIONES DE CULTIVO

2.1.- Medios de cultivo para Saccharomyces cerevisiae 85

2.2.- Condiciones de crecimiento y esporulación para S. cerevisiae 86

2.3.- Ensayos de sensibilidad a MMS, luz UV y benomilo 86 
3.- TÉCNICAS DE TRANSFORMACIÓN

3.1.- Transformación de S.cerevisiae 88

3.2.- Transformación de E.coli 88

4.- MICROSCOPÍA

4.1.- Microscopía de contraste de fases 88

4.2.- Microscospía de fluorescencia y de contraste interdiferencial (DIC) 88

5.- ÁNALISIS DE ÁCIDOS NUCLEICOS 90

5.1.- Extracción de DNA plasmídico de E.coli 90

5.2.- Extracción de DNA total de S. cerevisiae 90

5.3.- Digestión de moléculas de DNA con enzimas de restricción 90

5.4.- Separación de moléculas de DNA en geles de agarosa 90

5.5.- Amplificación de DNA: reacción en cadena de la polimerasa (PCR) 91

5.6.- Inmunoprecipitación de cromatina y PCR cuantitativa 91

5.7.- Tinción de DNA con DAPI 93

5.8.- Análisis de incorporación de BrdU 93

6.- ANÁLISIS DE PROTEÍNAS 94

6.1.- Obtención de extractos proteicos en condiciones desnaturalizantes 94

6.2.- Separación de proteínas en geles de poliacrilamida 94

6.3.- Transferencia de proteínas tipo Western 95

6.4.- Inmunoprecipitación de proteínas y tratamiento con $\lambda$-fosfatasa 95

6.5.- Inmunofluorescencia de extensiones de núcleos 97

7.- OTRAS TÉCNICAS 98

7.1.- Estudios de ditirosina 98

7.2.- Cálculos de estadística 98

$\begin{array}{ll}\text { BIBLIOGRAFÍA } & 99\end{array}$

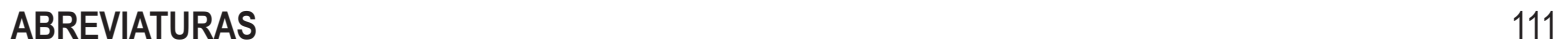


En la mayoría de los organismos eucariotas con reproducción sexual, la recombinación meiótica es un proceso crucial para la correcta producción de gametos. La recombinación meiótica se inicia con roturas de doble cadena en el DNA (DSBs) que, aún siendo necesarias para la correcta segregación de los cromosomas en la meiosis, suponen un elevado riesgo para el mantenimiento de la integridad del genoma. Si las células inician la segregación cromosómica antes de que estas roturas hayan sido reparadas, los cromosomas o fragmentos de éstos pueden perderse o segregar incorrectamente.

En los organismos eucariotas, existen unos mecanismos de vigilancia o checkpoints que responden a la presencia de DSBs y detienen la progresión del ciclo celular para dar tiempo a la célula para repararlas. Por tanto, los checkpoints tienen un papel crucial en proteger la integridad genómica. Existe un mecanismo de vigilancia específico de la meiosis, denominado checkpoint de recombinación meiótica o de paquitene, que bloquea la progresión de la meiosis en respuesta a fallos meióticos, como por ejemplo la presencia de DSBs sin reparar, y asegura la segregación correcta de los cromosomas. Los errores en la segregación meiótica de cromosomas originan gametos aneuploides que pueden causar diversas patologías.

La finalidad de este proyecto de tesis ha consistido en entender mejor los mecanismos moleculares que controlan la función del checkpoint de recombinación meiótica en la levadura de gemación Saccharomyces cerevisiae. Para ello, hemos estudiado la función de la proteína Ddc2 en el checkpoint de recombinación meiótica. Ddc2 junto con Mec1 constituyen un complejo sensor del daño en el DNA en células vegetativas,. Hemos determinado que Ddc2 participa en el checkpoint de recombinación meiótica puesto que su deleción suprime el bloqueo meiótico que sufren diferentes mutantes de sinapsis y/o recombinación, como sae2, dmc1, hop2 y zip1, originando productos meióticos inviables. La producción de Ddc2 se induce en la profase meiótica y la proteína se hiperfosforila en respuesta a la acumulación de DSBs sin reparar. Sin embargo, los sitios consenso de fosforilación por Mec1 (S/T-Q) no son necesarios para su función de checkpoint. Mediante estudios de microscopía de fluorescencia y de inmunoprecipitación de cromatina, hemos demostrado que Ddc2 se localiza en forma de focos múltiples, que se acumulan en los mutantes meióticos de forma dependiente de RPA señalizando la presencia de intermediarios de recombinación sin reparar. Además, hemos detectado una localización alternativa de Ddc2, independiente de la recombinación, en el huso de la profase meiótica.

Se ha descrito que en el mutante sae2 de $S$. cerevisiae no existe procesamiento nucleolítico de las DSBs meióticas; sin embargo, inesperadamente, hemos observado focos meióticos de Ddc2 en sae2 lo que, en principio, implicaría la existencia de regiones de ssDNA. Diversas evidencias, como la generación de focos de RPA y de BrdU, así como la activación de la kinasa efectora Mek1 de forma dependiente de Spo11, confirman la formación de ssDNA derivado de DSBs meióticas en sae2. Proponemos que una fracción de las DSBs meióticas generadas se procesa por un mecanismo alternativo independiente de Sae2 y de otras proteínas descritas hasta el momento implicadas en la resección de DSBs, como Exo1 y Sgs1.

Nuestros resultados con el estudio de Ddc2 durante la meiosis en levaduras nos han permitido avanzar en el conocimiento de cómo el checkpoint de recombinación meiótica es capaz de detectar la existencia de errores y detener la progresión de la meiosis. Puesto que ATRIP, la proteína homóloga de Ddc2 en mamíferos, se localiza en cromosomas meióticos es probable que esta función esté conservada en la evolución. 


\section{1.- MECANISMOS DE VIGILANCIA DEL CICLO CELULAR O CHECKPOINTS}

Para asegurar la viabilidad de los organismos y de sus descendientes debe haber una fina coordinación entre las distintas etapas del ciclo celular mitótico y meiótico. La supervivencia de todos los organismos depende de la completa duplicación de la información genética y de la correcta transmisión de ésta a las células hijas cuando se produce la división celular.

El genoma de las células es relativamente estable pero es atacado constantemente de forma espontánea por factores endógenos y exógenos tales como especies reactivas de oxígeno (resultantes del metabolismo celular) o agentes físicos y químicos como la radiación ultravioleta (UV), la radiación ionizante y compuestos ambientales derivados de la actividad del hombre. Todos estos factores pueden alterar la estructura química del genoma, produciendo en ocasiones roturas en el mismo. Si las lesiones en el DNA son DSBs, ya se hayan producido de forma accidental o de forma programada, éstas se reparan gracias a dos mecanismos: la unión de extremos no homólogos (№n- $\underline{H}$ omologous Ennd-Joining o NHEJ) y la recombinación homóloga (바omologous Recombination o HR). El daño en el DNA no sólo se produce de forma accidental por los agentes mencionados, sino que también puede producirse de forma programada, como ocurre en la recombinación $V(D) J$ y de cambio de clase durante la diversificación de inmunoglobulinas en mamíferos (Gellert, 1996; Maizels, 2005), en el cambio de tipo sexual en levaduras (Haber, 1998) y en la meiosis al iniciarse la recombinación meiótica entre cromosomas homólogos mediante la inducción de DSBs (Roeder, 1997).

Para mantener la integridad en el genoma, las lesiones en el genoma deben ser reparadas. Para ello, además de múltiples sistemas de reparación, los organismos eucariotas cuentan con unos sistemas de control muy conservados en la evolución que se denominan checkpoints. El término de "checkpoint" fue introducido a finales de los años 80 por Weinert y Hartwell estudiando la interdependencia de una serie de procesos que tenían lugar durante el ciclo celular. Los checkpoints son rutas de señalización que monitorizan la progresión del ciclo celular asegurando la correcta finalización de cada una de sus etapas de modo que no se inicia un evento tardío hasta que se ha completado con éxito uno más temprano (Hartwell and Weinert, 1989). Cuando se producen lesiones en el genoma, la activación del checkpoint de daño en DNA o del checkpoint de recombinación meiótica bloquea o retrasa la progresión del ciclo celular mitótico o meiótico, respectivamente, otorgando a las células un tiempo adicional para la reparación del DNA dañado (Hochwagen and Amon, 2006; Longhese et al., 2006; Longhese et al., 2008).

De este modo, los mecanismos de checkpoint contribuyen al mantenimiento de la estabilidad genómica y, en el caso de humanos, reducir el riesgo de predisposición, inicio y desarrollo de varios tipos de cáncer y de enfermedades genéticas hereditarias (Aguilera and Gomez-Gonzalez, 2008).

A pesar de que existen algunas diferencias que se acentúan a medida que el organismo es más complejo, los mecanismos de checkpoints de integridad de DNA están muy conservados en la evolución y los estudios en organismos modelo como la levadura Saccharomyces cerevisiae ha aportado información muy valiosa acerca de su funcionamiento (Melo and Toczyski, 2002; Harrison and Haber, 2006). En los siguientes apartados se describen los aspectos más relevantes de estos procesos centrándonos en $S$. cerevisiae, que es el organismo utilizado en este trabajo. 


\section{1.- Los checkpoints de integridad del genoma}

En S. cerevisiae, se pueden distinguir diferentes checkpoints de daño en el DNA dependiendo del momento en el que se produzcan las lesiones en el genoma, como el que retrasa la transición G1/S, bloquea la transición $\mathrm{G} 2 / \mathrm{M}$, o el checkpoint intra-S que ralentiza la progresión por fase $\mathrm{S}$. Además, el checkpoint de replicación detiene la progresión del ciclo celular e inhibe la activación de orígenes de replicación tardíos en respuesta a estrés replicativo para evitar la entrada en mitosis sin haber replicado totalmente el material genético (Figura 1) (Nyberg et al., 2002). El mantenimiento de la integridad del genoma depende también de la existencia de otros checkpoints, como el checkpoint de ensamblaje del huso, que monitoriza la correcta unión de los cromosomas a los microtúbulos del huso durante la mitosis y detiene la progresión del ciclo celular hasta que los cromosomas están correctamente alineados en la placa metafásica (Figura 1) (Musacchio and Salmon, 2007).

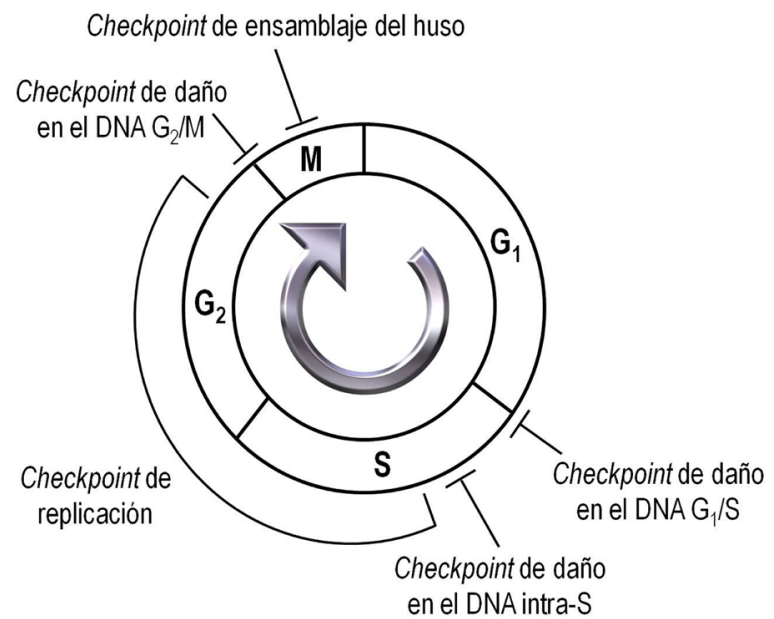

Figura 1. Los checkpoints de integridad del genoma. Se representan esquemáticamente los diferentes mecanismos de vigilancia que existen dependiendo de la fase del ciclo mitótico en la que se encuentre la célula y de las alteraciones que disparan el checkpoint.

Además, en mitosis existe un checkpoint dependiente de la proteína Bub2, la cual, forma un complejo con Bfa1 (Alexandru et al., 1999; Fesquet et al., 1999; Fraschini et al., 1999; Li, 1999) que monitoriza la posición del huso (Hoyt, 2000) e inhibe la salida de mitosis a través de la regulación negativa de MEN (Mitotic Exit Network) (Fesquet et al., 1999). Por último, existe un mecanismo de vigilancia que es específico de meiosis, el checkpoint de recombinación meiótica o de paquitene que impide la entrada en meiosis I hasta que se hayan completado correctamente procesos como el apareamiento de los cromosomas homólogos, la sinapsis y la recombinación (Figura 2) (Roeder and Bailis, 2000; Hochwagen and Amon, 2006).

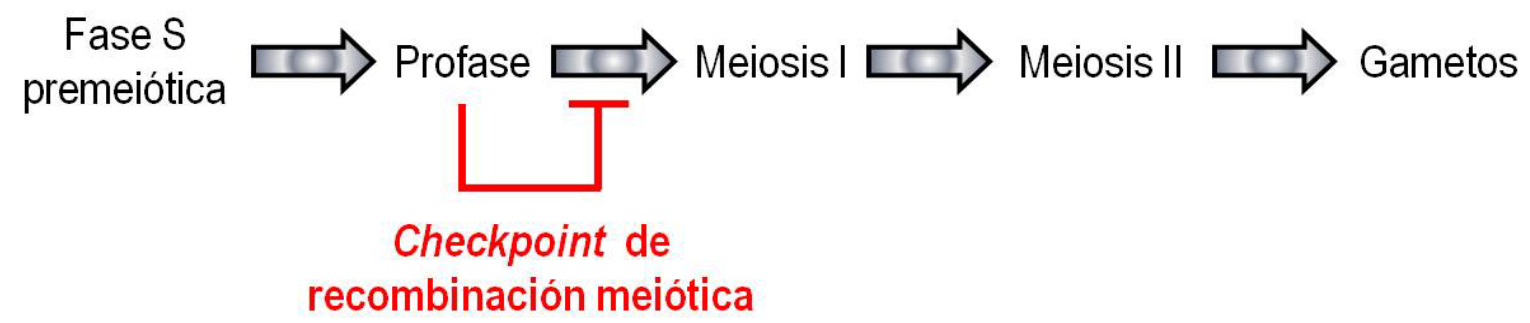

Figura 2. El checkpoint de recombinación meiótica. Se indican diferentes eventos de la meiosis. Cuando hay defectos 0 errores en la profase de la meiosis el checkpoint de recombinación meiótica bloquea o ralentiza la entrada en meiosis I. 


\subsection{1.- Componentes del checkpoint de daño en DNA}

Los componentes clave de las rutas de checkpoint del DNA incluyen proteínas que detectan los errores y el daño en el DNA, proteínas mediadoras que transmiten la señal y proteínas efectoras que actúan sobre las correspondientes dianas celulares produciendo la respuesta biológica adecuada. Esta respuesta, como ya hemos mencionado, puede ser una parada o un retraso en el ciclo celular y la activación o represión de otras rutas que son necesarias para la completa recuperación de la célula. A continuación, se describen los diferentes grupos de proteínas que actúan en las rutas del checkpoint de daño en el DNA en $S$. cerevisiae que en su mayoría están conservadas en otros organismos (Tabla 1).

Tabla 1.- Proteínas del checkpoint de respuesta al daño en el DNA

\begin{tabular}{|c|c|c|c|c|}
\hline Clase & Función & S. cerevisiae & S. pombe & Mamíferos \\
\hline \multirow[t]{5}{*}{ Sensores } & \multirow[t]{5}{*}{ Detección del daño } & Mre11/Rad50/Xrs2 & Rad32/Rad50/Nbs1 & MRE11/RAD50/NBS1 \\
\hline & & Rfa1/Rfa2/Rfa3 & Rfa1/Rfa2/Rfa3 & Rpa1/Rpa2/Rpa3 \\
\hline & & Rad24/Rfc2-5 & Rad17/RFC3 & Rad17/RFC2-5 \\
\hline & & Ddc1/Mec3/Rad17 & Rad9/Hus1/Rad1 & Rad9/Hus1/Rad1 \\
\hline & & Elg1 & - & - \\
\hline \multirow{2}{*}{$\begin{array}{l}\text { Sensores/ } \\
\text { Transductores }\end{array}$} & \multirow{2}{*}{ Se unen a los sitios de daño } & Mec1/Ddc2 & Rad3/Rad26 & ATR/ATRIP \\
\hline & & Tel1 & Tel1 & ATM \\
\hline \multirow[t]{4}{*}{ Adaptadores } & \multirow{4}{*}{$\begin{array}{l}\text { Median la activación de } \\
\text { las kinasas efectoras }\end{array}$} & Mrc1 & Mrc1 & Claspina \\
\hline & & Rad9 & Crb2/Rph9 & 53BP1 \\
\hline & & Dpb11 & Cut5/Rad4 & TopBP1 \\
\hline & & - & - & BRCA1 y MDC1 \\
\hline \multirow{2}{*}{$\begin{array}{l}\text { Kinasas } \\
\text { efectoras }\end{array}$} & \multirow{2}{*}{$\begin{array}{l}\text { Inducen respuesta global de } \\
\text { la célula frente a agresiones } \\
\text { mediante fosforilación de } \\
\text { sustratos diana }\end{array}$} & Rad53 & Cds1 & Chk2 \\
\hline & & Chk1 & Chk1 & Chk1 \\
\hline \multirow[t]{10}{*}{ Dianas } & \multirow{10}{*}{$\begin{array}{l}\text { Responsables directas de } \\
\text { la respuesta global de la } \\
\text { célula frente a agresiones }\end{array}$} & Pds1 & & Securina \\
\hline & & Cdc20 & & $\mathrm{p} 55^{\mathrm{CDC}} / \mathrm{CDC} 20$ \\
\hline & & & & p53 \\
\hline & & & Cdc25 & Cdc25A-C \\
\hline & & & & PLK1 \\
\hline & & Bfa1 & & \\
\hline & & Rad55 & & \\
\hline & & Dun1 & & \\
\hline & & Scc1 & Rad21 & \\
\hline & & & & SMC1/SMC3 \\
\hline
\end{tabular}

Los huecos en blanco indican que o bien la proteína homóloga no es diana del checkpoint o no se conoce que lo sea. El guión indica que no hay hómologo conocido. 


\subsubsection{1.- Sensores}

Dependiendo del tipo de lesión detectada se activan unos mecanismos sensor u otros. Cuando el daño que se produce en el genoma son DSBs, el mecanismo sensor que las detecta es el complejo MRX que

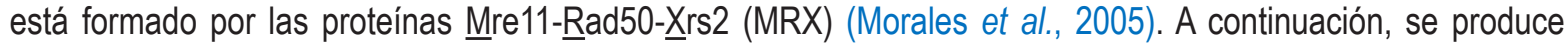
la degradación exonucleolítica de la DSB a partir de sus extremos $5^{\prime}$ generando ssDNA con extremos $3^{\prime}-\mathrm{OH}$ libres. Recientemente, se han realizado estudios que han revelado que el procesamiento de los extremos implica múltiples pasos y que se puede dividir en dos estadíos: un procesamiento inicial seguido de un procesamiento más prolongado e intensivo necesario para alcanzar los niveles adecuados de ssDNA. En el procesamiento inicial a ssDNA participan el complejo MRX mediante la exonucleasa Mre11 y la endonucleasa Sae2 (Lengsfeld et al., 2007). El procesamiento más activo está compuesto por dos rutas redundantes que están por debajo del procesamiento iniciado por MRX y Sae2. La primera consta de la proteína Exo1 (una exonucleasa 5'-3') y la segunda consta de un conjunto de proteínas formado por la nucleasa Dna2, y el complejo que desenrolla el DNA y que está formado por la helicasa Sgs1 y las proteínas Rmi1 y Top3 (Gravel et al., 2008; Liao et al., 2008; Mimitou and Symington, 2008; Zhu et al., 2008; Budd and Campbell, 2009).

Una vez que se ha generado el ssDNA, se une el complejo multiproteico RPA (ㄹeplication $\underline{\text { Protein }} \underline{A}$ ). La unión de RPA hace posible el reclutamiento de los complejos Rad24-RFC y "9-1-1" a los sitios de daño (Kim and Brill, 2001; Lisby et al., 2004; Majka et al., 2006). El complejo Rad24-RFC está formado por la proteína Rad24, que es estructuralmente similar a la subunidad mayor (Rfc1) del factor de replicación (RFC) implicado en la replicación del DNA, y por otras cuatro subunidades del RFC (Rfc2, Rfc3, Rfc4 y Rfc5). En la levadura de gemación, el complejo Rad24-RFC atrae al complejo conocido como "9-1-1" a la zona dañada, el cual, en S. cerevisiae está formado por las proteínas Ddc1, Mec3 y Rad17. Este trímero se parece estructuralmente al

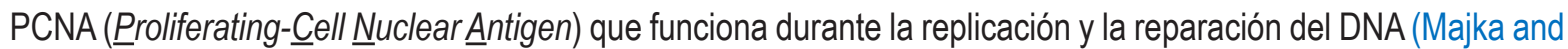
Burgers, 2003). El complejo "9-1-1" necesita de Rad24-RFC para unirse a los sitios de daño, al igual que ocurre con RFC, el cual, es necesario para cargar PCNA durante la replicación (Melo et al., 2001; Lisby et al., 2004).

En los lugares donde se están produciendo las lesiones, no sólo se reclutan los complejos sensor que acabamos de mencionar, sino que de forma independiente también son atraídas dos kinasas de la familia PI3KK

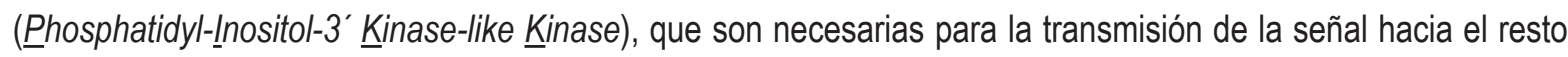
de componentes de la ruta de checkpoint (Falck et al., 2005). En S. cerevisiae estas kinasas son Mec1 y Tel1. La kinasa sensor Mec1 se asocia a la subunidad reguladora Ddc2, la cual, es fosforilada por Mec1 cuando hay daño en el DNA (Paciotti et al., 2000). Mec1 se activa en repuesta a horquillas de replicación colapsadas, DSBs y lesiones generadas por agentes genotóxicos. Aunque Ddc2 se une a los sitios de daño en DNA independientemente de Mec1, es necesaria para el reclutamiento de Mec1 a las lesiones. Este reclutamiento de Mec1 por Ddc2 es crucial para la respuesta al daño en el DNA (Rouse and Jackson, 2002). La proteína Ddc2 tiene una gran afinidad por RPA que como ya hemos dicho, se une al ssDNA, lo que sugiere que el complejo formado por Mec1/Ddc2 se une a través de RPA a los sitios de daño o a intermediarios de recombinación que contienen regiones con SsDNA (Zou and Elledge, 2003). Se ha visto que para que la unión de Mec1/Ddc2 al DNA sea estable, es necesario que se produzca la interacción entre RPA y Ddc2 (Ball et al., 2007). La unión de Mec1/Ddc2 a RPA durante la fase G1 depende además del complejo "9-1-1". Además, durante las fases S y G2, el complejo "9-1-1" y la kinasa dependiente de ciclina Cdc28 cooperan independientemente junto con RPA en el reclutamiento de Mec1/Ddc2. 
Por tanto, la colocalización del complejo Mec1/Ddc2 y el complejo "9-1-1" junto con la actividad kinasa de Cdc28 son necesarias para la activación completa de Mec1, independientemente de la fase en la que se encuentre la célula (Barlow et al., 2008). Además se ha visto que la colocalización de la proteína Ddc1 (del complejo "9-1-1") junto con Mec1/Ddc2 es suficiente para activar la respuesta al daño en el DNA (Bonilla et al., 2008). El encargado de reclutar la otra kinasa de la familia PI3KK, Tel1, a las DSBs, es el complejo MRX a través de la subunidad Xrs2. Aunque en S. cerevisiae la activación del checkpoint de daño en el DNA depende casi exclusivamente de la kinasa Mec1, se ha observado que la interacción de MRX-Tel1 es suficiente para estimular la respuesta en circunstancias específicas, como en ausencia de Mec1 o en presencia de múltiples lesiones (Mantiero et al., 2007). La explicación de que Tel1 sea menos importante en levaduras puede ser debido a que el procesamiento de las DSBs a ssDNA es muy eficiente y conduce a una activación del checkpoint mediada por Mec1. En cambio, el complejo MRX-Tel1 es necesario principalmente para mantener la longitud de los telómeros (Lydall, 2003; Viscardi et al., 2005).

\subsubsection{2- Efectores}

Las PI3KKs Mec1 y Tel1 regulan las proteínas diana a través de la activación de proteínas efectoras a las que fosforilan en residuos serina/treonina que preceden a residuos de glutamina, los denominados motivos S/T-Q. Las kinasas efectoras son intermediarios esenciales en las rutas de checkpoint en levaduras y actúan al final de éstas induciendo el bloqueo del ciclo celular mediante la fosforilación de sus sustratos diana que son los encargados de regular el ciclo. En S. cerevisiae existen dos cascadas de señalización mediadas por las kinasas efectoras Chk1 y Rad53 (Pellicioli and Foiani, 2005).

Los miembros de la familia Chk1 tienen un dominio kinasa característico en el extremo amino terminal y ciertas regiones de homología en su extremo carboxilo terminal. Rad53 pertenece a la familia de kinasas de Chk2, cuyas características estructurales son un domino FHA (ㅌorkㅐㅡead-Associated) en su extremo amino terminal y un dominio kinasa carboxilo terminal (McGowan, 2002). Rad53 fue la primera proteína de la familia que se describió y es la única que porta dos dominios FHA, cada uno en un extremo de la proteína (Sun et al., 1998). Como ya hemos mencionado, las rutas de checkpoint están muy conservadas evolutivamente, pero existen diferencias importantes con respecto a la relevancia de las kinasas efectoras en las fases del ciclo celular. Chk1 participa fundamentalmente en el checkpoint G2/M y aunque tiene un papel relevante en el mantenimiento de la estabilidad de las horquillas de replicación cuando hay daño en el DNA (Segurado and Diffley, 2008), su función en la respuesta celular al daño en S. cerevisiae no es tan importante como el que tiene Rad53. La kinasa Rad53 tiene un papel esencial en todas las rutas de integridad genética de la célula pero en su ausencia, es Chk1 la que previene el colapso de las horquillas de replicación. La redundancia entre las kinasas proporciona a la célula la capacidad de responder ante lesiones en el DNA garantizando así su supervivencia.

\subsubsection{3- Adaptadores}

Las proteínas adaptadoras o mediadoras se encargan de promover la interacción entre las kinasas sensor (PI3KKs) y las kinasas efectoras (Chk1 y Rad53). Los adaptadores no sólo determinan qué ruta de checkpoint se va a activar dependiendo de la naturaleza de la señal, sino que, además favorecen la amplificación de ésta. El mecanismo general consiste en que los sensores activados reclutan los adaptadores que son 
fosforilados. De esta forma, éstos pueden atraer los efectores a los sitios de daño, los cuales, a su vez también se activan mediante fosforilación.

Las proteínas adaptadoras mejor estudiadas en las levaduras son:

- Mrc1: está implicada en el checkpoint de fase $\mathrm{S}$ y en la señalización de horquillas de replicación colapsadas. El complejo sensor Mec1/Ddc2 fosforila Mrc1 y la activa, lo cual, es necesario para la activación de la kinasa efectora Rad53 durante el checkpoint de fase S (Alcasabas et al., 2001; Osborn and Elledge, 2003). Mrc1, aunque no es esencial, se requiere también para la replicación normal del DNA en ausencia de estrés replicativo (Szyjka et al., 2005).

- Proteínas adaptadoras con dominios BRCT: son un grupo de proteínas que tienen en su extremo carboxilo el domino BRCT (BRCA1 C-Terminus). Las proteínas que contienen dominios BRCT participan en varios aspectos de la respuesta al daño en el DNA, tanto en los mecanismos de checkpoint como en las rutas de reparación. Los dominios BRCT pueden mediar las interacciones proteína-proteína dependientes de fosforilación en esos procesos. En este grupo se incluye la proteína Rad9 que es necesaria para la activación del checkpoint de daño permitiendo la fosforilación de Rad53 por Mec1 (Schwartz et al., 2002; Sweeney et al., 2005). Rad9 es esencial para la señalización del daño en el DNA durante las fases del ciclo celular G1 y G2/M, mientras que en la fase $\mathrm{S}$, su función en el checkpoint de replicación no es necesaria, siendo Mrc1 la que la sustituye. En la respuesta al daño en DNA juegan un papel muy importante factores que regulan la estructura de la cromatina, como los modificadores de histonas y los remodeladores de la cromatina. En las células mitóticas, la proteína Dot1 lleva a cabo la metilación de la histona H3 en la lisina 79 (H3K79) (van Leeuwen et al., 2002). Esta metilación mediada por Dot1 está implicada en la activación de la kinasa Rad53 a través del adaptador Rad9 (Giannattasio et al., 2005; Wysocki et al., 2005). Además, se ha comprobado que el reclutamiento de cohesina a una DSB depende de tanto Dot1 como Rad9 (Conde et al., 2009). Esta carga de cohesina facilitaría la reparación de DSBs mediante la recombinación con la cromátida hermana al mantener las cromátidas hermanas unidas (Unal et al., 2004; Cortes-Ledesma and Aguilera, 2006). En el grupo de proteínas adaptadoras con dominios BRCT se encuentra también la proteína Dpb11, la cual, activa directamente la kinasa Mec1 que fosforila Rad53 (Navadgi-Patil and Burgers, 2008). Dpb11 interacciona con la subunidad Ddc1 del complejo "9-1-1" y participan en el inicio de la replicación y en la reparación por recombinación homóloga (Araki et al., 1995; Kamimura et al., 1998; Ogiwara et al., 2006). Aunque Dpb11 y el complejo "9-1-1" activan independientemente a Mec1, se ha sugerido que en su función en el checkpoint podría existir una compensación parcial entre ellas (Navadgi-Patil and Burgers, 2008).

Los mediadores en mamíferos son Brca1, MCD1, 53BP1 (homóloga a Rad9), TopBP1 (homóloga a Dpb11) y la proteína claspina (homóloga a la proteína Mrc1).

\subsubsection{4- Dianas}

Las kinasas efectoras juegan un papel clave en los checkpoints que regulan la parada o retraso del ciclo celular mediante la fosforilación de múltiples dianas. Chk1 fosforila la securina Pds1 retrasando la degradación de las cohesinas que mantienen unidas a las cromátidas hermanas, impidiendo así su segregación (Cohen-Fix and Koshland, 1997; Wang et al., 2001). Además, tanto Rad53 como Chk1 parecen suprimir la última fase de la salida de mitosis impidiendo la liberación de la fosfatasa Cdc14 del complejo que forma con Net1 en el nucleolo. Así,

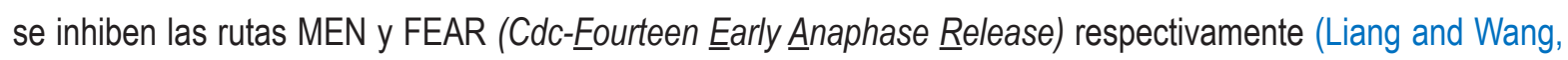


2007). La liberación de Cdc14 marca el final de la mitosis a través de la defosforilación de las dianas de Cdk1, conduciendo a la degradación de las ciclinas mitóticas, la inducción de la transcripción del gen SIC1 que codifica el inhibidor de Cdk1 y la estabilización de la proteína Sic1 (Visintin et al., 1998). La activación del checkpoint también también afecta a la la kinasa dependiente de Dbf4 (DDK), la cual, activa orígenes de replicación. En la levadura de gemación, Dbf4 es fosforilada por Mec1 cuando persiste el daño en el DNA (Cheng et al., 1999).

En respuesta al daño en el DNA durante la transición $\mathrm{G} 1 / \mathrm{S}$, el bloqueo del ciclo celular producido por la activación del checkpoint se debe al descenso en la expresión de las ciclinas CLN1 y CLN2 promovido por la fosforilación de los factores de transcripción Swi4 y Swi6 por la kinasa Rad53 (Sidorova and Breeden, 1997).

\section{2.- El checkpoint de ensamblaje del huso}

El complejo proteico de cohesinas es el encargado de mantener la unión entre las cromátidas hermanas (Michaelis et al., 1997). En anafase, la proteasa encargada de la eliminación de las cohesinas es la separasa Esp1, la cual, es activada en la transición de metafase a anafase a través de la degradación su inhibidor, la securina

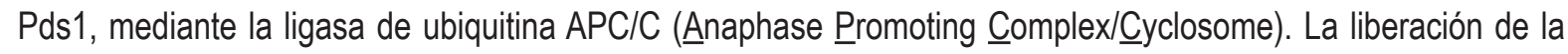
separasa permitirá que ésta elimine las cohesinas produciendo así la separación de las cromátidas hermanas.

Existe un mecanismo de vigilancia denominado checkpoint de ensamblaje del huso o SAC (S्Spindle

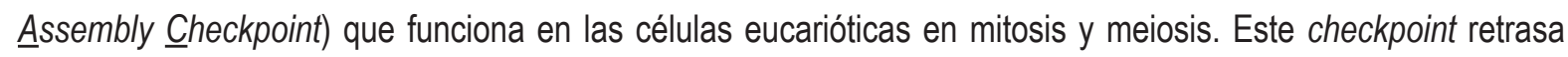
el comienzo de la separación de las cromátidas hermanas hasta que todas ellas estén ancladas correctamente al huso previniendo así la separación precoz de éstas (Amon, 1999). La señalización del SAC en prometafase

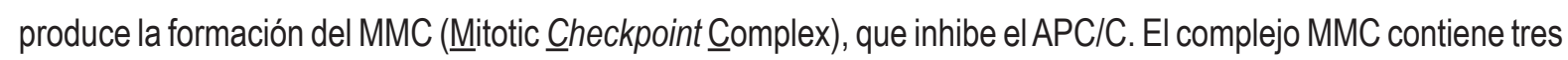
proteínas del SAC: Mad2, Mad3 y Bub3 que, junto con Cdc20 podrían ser los efectores del SAC. El SAC regula negativamente la capacidad de Cdc20 para activar el APC/C impidiendo la poliubiquitilación de dos sustratos clave, la ciclina B y la securina Psd1. Al controlar la actividad de Cdc20, el SAC prolonga la prometafase hasta que los cromosomas estén bi-orientados en la placa metafásica hacia polos opuestos del huso (Musacchio and Salmon, 2007).

\section{3.- El checkpoint de orientación del huso}

En las células de levadura la unión de la madre con la yema determina el lugar donde va a tener lugar la citoquinesis (Segal and Bloom, 2001). La ruta MEN (Mitotic Exit Network) es una cascada de señalización que determina la salida de mitosis, que es la transición final del ciclo celular que conduce a la generación de dos células hijas genéticamente idénticas. Las proteínas Bfa1 y Bub2 son componentes de la ruta MEN y son activadores (GAP) de de la GTPasa Tem1 que actúa al principio de la ruta. Bfa1 y Bub2 mantienen Tem1 en su forma inactiva unida a GDP durante la mayor parte del ciclo celular (Stegmeier and Amon, 2004). Además de ser componentes claves de la ruta MEN, las proteínas Bfa1 y Bub2 son componentes esenciales del de orientación del huso o SPOC (Spindle POSsitioning Checkpoint) (Valerio-Santiago and Monje-Casas, 2011), un mecanismo de vigilancia que regula la fidelidad en la transmisión del material genético a través del control de posicionamiento del núcleo. EI SPOC retrasa la salida de mitosis o MEN cuando el huso en anafase no está correctamente colocado en la célula madre, evitando así la generación de células aneuploides. Por tanto, este checkpoint detecta los defectos en orientación del huso e inhibe la ruta MEN en las células con un huso de anafase que no 
está correctamente alineado en el eje célula madre-célula hija.

\section{2.- LA MEIOSIS}

En los organismos eucariotas que se reproducen sexualmente tiene lugar la meiosis, un proceso de división celular especializada. En la meiosis se parte de una célula madre en la que tiene lugar una única fase de replicación del DNA seguida de dos rondas consecutivas de segregación de los cromosomas, consiguiendo así reducir a la mitad la dotación cromosómica de las células hijas resultantes. Por tanto, a partir de una célula diploide (2n) se obtienen cuatro células haploides ( $n$ ) que son los gametos. La meiosis tiene la particularidad de que en la primera segregación cromosómica las cromátidas hermanas permanecen unidas, a diferencia de lo que ocurre en mitosis, y segregan los cromosomas homólogos, uno procedente del padre y otro de la madre. La meiosis es necesaria para mantener el número de cromosomas correcto cuando los gametos haploides se fusionan para dar lugar a la formación de un zigoto.

La dinámica que siguen los cromosomas a lo largo de la meiosis es muy compleja. La meiosis comienza con una fase $\mathrm{S}$ o de replicación premeiótica del DNA en la que se establece la cohesión entre las cromátidas hermanas. Después de la replicación del DNA tiene lugar la profase meiótica, en la se producen procesos como el apareamiento, la sinapsis y la recombinación entre los cromosomas homólogos. A continuación, se produce la segregación de los cromosomas homólogos en la meiosis I hacia polos opuestos de la célula seguida de la separación de las cromátidas hermanas durante la meiosis II, tal y como ocurre en la mitosis. En la meiosis tienen lugar tres procesos únicos y diferenciados, que son esenciales para una distribución correcta de los cromosomas a los gametos. El primero es que como resultado del proceso de recombinación meiótica entre cromosomas homólogos, se producen entrecruzamientos entre las cromátidas no hermanas que generan unas conexiones físicas entre los homólogos denominadas quiasmas, las cuales, son necesarias para la segregación correcta de los cromosomas en la meiosis I. El segundo es que para que las cromátidas hermanas migren al mismo polo de la célula en la meiosis I también se necesita la orientación monopolar de los cinetocoros hermanos asociados a los microtúbulos, lo que, junto con los quiasmas entre homólogos generan la tensión necesaria para que los cromosomas se orienten en la placa metafásica y segreguen correctamente (Figura 3). Y el tercero es que durante la meiosis, la cohesión entre las cromátidas hermanas se elimina de una forma secuencial, primero a lo largo de los brazos de los cromosomas durante la meiosis I y, segundo en las regiones pericentroméricas durante la meiosis II.
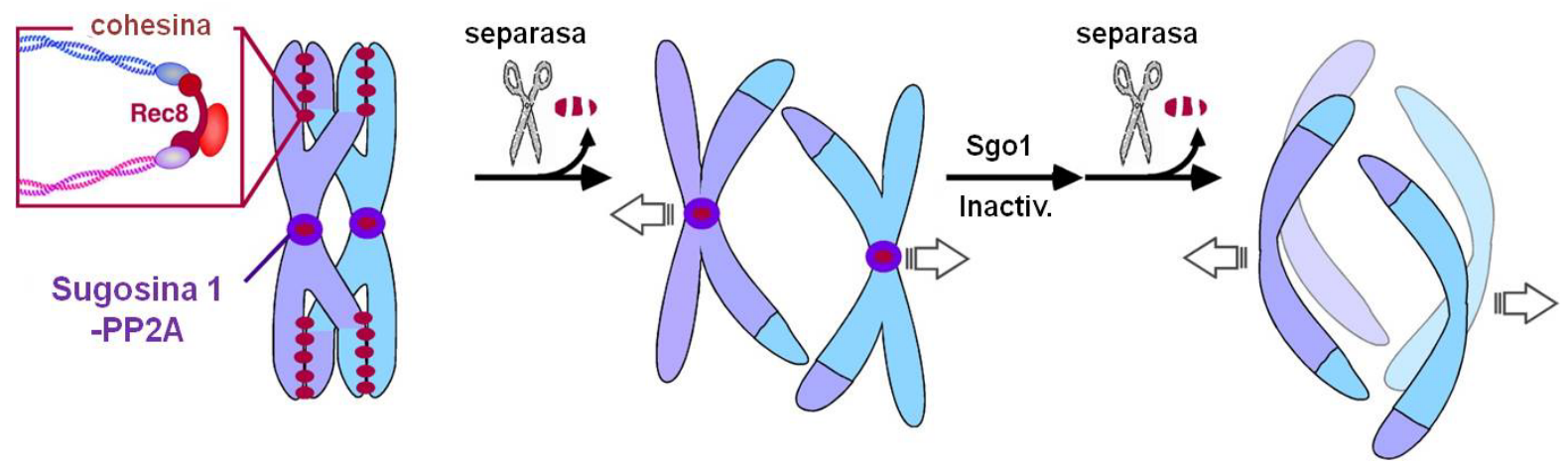

Figura 3. Segregación meiótica de los cromosomas. Se representa la unión física de los cromosomas a través de los quiasmas, los cuales, son necesarios para la correcta segregación de los cromosomas. Se observa como las cohesinas se mantienen a lo largo de los brazos de los cromosomas hasta la meiosis I, momento en el cual, son eliminadas por la separasa y quedan protegidas en las regiones pericentroméricas por la sugosina hasta la meiosis II donde ya se elimina. 
2.1.- Etapas de la meiosis.

A continuación se describen brevemente los principales eventos meióticos. Aunque es un proceso tremendamente conservado, se hace referencia fundamentalmente a la levadura $S$. cerevisiae.

\subsection{1.- La replicación premeiótica del DNA}

La primera de la etapas de la meiosis es la fase S premeiótica donde tiene lugar la replicación del DNA. Se ha comprobado que la mayoría de las proteínas que son necesarias para la replicación del DNA en mitosis, también lo son para la fase $S$ de la meiosis. En esta fase premeiótica se produce la asociación entre las cromátidas hermanas mediante el complejo de cohesina, en el que se incorpora Rec8, una cohesina específica de meiosis. La regulación de la síntesis y degradación de esta cohesina será un elemento clave para que se produzcan correctamente las segregaciones de los cromosomas durante la meiosis I y II.

Además, se ha demostrado que la replicación y la recombinación del DNA meiótico son procesos que están estrechamente relacionados y regulados tanto a nivel espacial como temporal. La actividad CDK

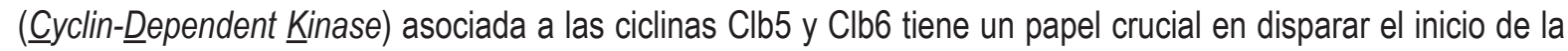
replicación y la activación de Spo11 durante la meiosis, existiendo una estrecha coordinación entre la replicación premeiótica del DNA y la formación de las DSBs (Dirick et al., 1998; Stuart and Wittenberg, 1998; Smith et al., 2001; Henderson et al., 2006). Así, recientemente, se ha demostrado que la actividad CDK regula directamente la formación de las DSBs a través de la fosforilación de la proteína Mer2 (Henderson et al., 2006). Por otro lado, se ha demostrado que la eliminación de todas las secuencias de replicación autónomas (ARSs) del brazo izquierdo del cromosoma III confiere un retraso en la replicación del DNA y la formación de las DSBs específicamente en dicho brazo, lo que sugiere que existe una regulación coordinada de ambos procesos a nivel cromosómico. Tal control aseguraría que las DSBs no se formaran antes de la completa replicación del DNA (Borde et al., 2000; Murakami et al., 2003).

\subsection{2.- La profase meiótica}

Después de que las células hayan replicado el DNA entran en la etapa siguiente que corresponde a la fase G2 del la primera división meiótica, pero que habitualmente se conoce como profase meiótica. La profase es la etapa de mayor duración de la meiosis y en la que tienen lugar procesos cruciales como el apareamiento, la sinapsis y la recombinación.

\subsubsection{1.- El apareamiento y la sinapsis: formación del Complejo Sinaptonémico (SC)}

Se conoce como apareamiento meiótico de los cromosomas al proceso por el que los homólogos se encuentran entre sí dentro del núcleo y se alinean en la distancia. La agrupación de los telómeros en una zona de la envoltura nuclear juega un papel importante en este proceso.

El apareamiento culmina con la sinapsis, que es la unión física de los cromosomas homólogos a través de una estructura proteica denominada complejo sinaptonémico (SC). En estudios previos del ensamblaje del $\mathrm{SC}$ en la levadura de gemación se ha sugerido que la sinapsis se inicia en los lugares donde se producen los entrecruzamientos, pero más recientemente se ha visto que es en los centrómeros donde se produce más frecuentemente el inicio de la misma (Tsubouchi et al., 2008). 
El SC está formado por dos elementos laterales y los cromosomas meióticos se disponen formando bucles de cromatina cuyas bases se asocian a estos ejes estructurales (Moens and Pearlman, 1988). Los elementos laterales se conectan a lo largo de su longitud por unos elementos transversales que constituyen la región central del SC. El ensamblaje del SC ocurre de forma paralela a la recombinación, de modo que los elementos laterales, se forman a la vez que las DSBs (Padmore et al., 1991) y se conectan mediante los elementos transversales del SC coincidiendo con la invasión de la cadena homóloga (ver más abajo) (Hunter and Kleckner, 2001).

En la levadura de gemación, Red1, Hop1 y Mek1 son componentes estructurales de los elementos laterales y, además, participan en el checkpoint de recombinación meiótica. Por su parte, la proteína Zip1 es el principal componente de la región central del SC (Sym et al., 1993). Esta proteína es necesaria para la sinapsis correcta de los cromosomas homólogos y, además, participa en la resolución de los entrecruzamientos. Al final de la profase (diplotene), el SC se desensambla pero los cromosomas permanecen ligados debido a los quiasmas.

\subsubsection{2.- La recombinación meiótica}

Dentro de la profase, concretamente en el estadío denominado leptotene, comienza la recombinación meiótica, la cual, ha sido especialmente estudiada en S. cerevisiae. La recombinación meiótica se inicia la formación de DSBs catalizadas por Spo11 (Keeney, 2001), una topoisomerasa específica de meiosis que en S. cerevisiae actúa junto con, al menos, otras nueve proteínas más: Rec102, Rec104, Rec114, Mei4, Mer2, Rad50, Mre11, Xrs2 y Ski8/Rec103. En la levadura de gemación se inducen una media de 200 DSBs meióticas por célula que tienen que ser procesados para generar ssDNA con extremos 3'-OH libres. Esto sirve como substrato de Dmc1 y Rad51, que son proteínas homólogas a la proteína RecA de Escherichia coli (Bishop, 1994; Hunter and Kleckner, 2001) y catalizan la invasión por parte de una de las cadenas sencillas que se ha generado en la cadena de una cromátida intacta procedente del cromosoma homólogo para así, poder ser reparada (Figura 4). Dmc1 se produce exclusivamente en meiosis y es la responsable de la mayoría de la recombinación homóloga que tiene lugar en ella. Rad51 actúa tanto en la reparación de DSBs en células vegetativas como en la recombinación meiótica. Después de la invasión se produce la síntesis del DNA utilizando como molde la cadena de la cromátida del cromosoma homólogo. Esta síntesis termina cuando la cadena desplazada de la cromátida no hermana se enfrenta con el extremo 3'-OH del lado opuesto del DSB y comienza a sintetizarse DNA del mismo. Cuando finaliza la síntesis, los extremos 3'-OH se ligan. Si el intermediario que se ha generado se procesa según el modelo de reparación de las DSBs o DSBR (double strand break repair) (Szostak et al., 1983), el resultado es la formación de una estructura denominada unión de Holliday doble (dHJ, double Holliday Junction, en honor a su descubridor Robin Holliday en 1964). Las dHJ pueden ser resueltas como entrecruzamientos recíprocos (crossovers o COs) o no recíprocos (noncrossovers o NCOs). Los COs dan lugar a unas estructuras denominadas quiasmas. En mutantes en los que las dHJs no se pueden resolver ( $n d t 80, c d c 5)$, se reduce el número de COs pero la formación de NCOs no se ve afectada (Allers and Lichten, 2001; Clyne et al., 2003) (Figura 4). Esto se explica mediante una nueva ruta que se denomina reasociación de cadenas dependiente de síntesis o SDSA

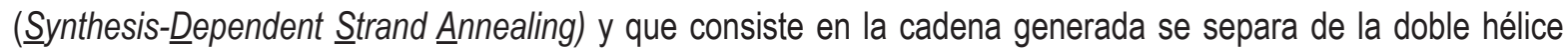
homóloga y anilla con el otro extremo libre de la DSB. Por último, la síntesis se completa y los extremos se ligan. Por tanto, a partir de esta ruta alternativa como se acaba de detallar sólo podrán formarse NCOs. En la meiosis la 
frecuencia de formación de COs puede llegar a un $66 \%$. Esta frecuencia es mucho más elevada que en mitosis, dónde tan sólo llega a un 20\% (Prado et al., 2003).

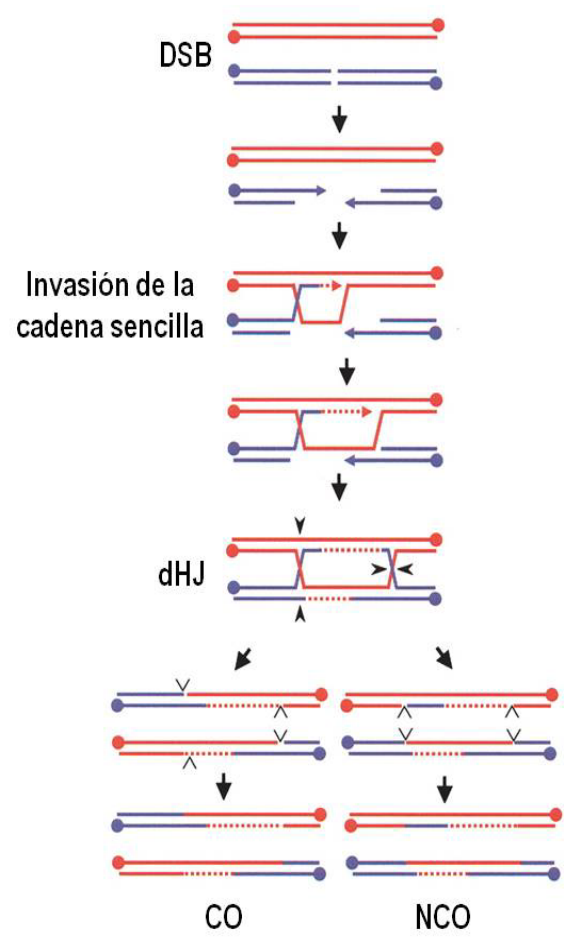

Figura 4. La recombinación meiótica. Los DSBs generados por la proteína Spo11 se reparan mediante su resección a cadena sencilla (ssDNA) y la invasión de este ssDNA en la cromátida intacta del cromosoma homólogo dando lugar a uniones doble de Holliday (dHJ), cuya resolución puede dar lugar a entrecruzamientos (COs) o no (NCOs).

Los eventos de recombinación meiótica no están distribuidos uniformemente a través del genoma. De hecho, la frecuencia de intercambio meiótico por unidad de distancia física cambia en varios órdenes de magnitud de una región a otra. En S. cerevisiae generalmente los DSBs se generan a una distancia media de $5 \mathrm{~kb}$ y la recombinación ocurre en un intervalo de 1-2 kb alrededor de ellos (Lichten and Goldman, 1995) pero excepcionalmente, también puede producirse recombinación meiótica alejada de los cortes (Baudat and Nicolas, 1997). Para el mapeo de las DSBs a lo largo de todo el genoma de la levadura de gemación se han utilizado tradicionalmente mutantes que acumulan DSBs sin procesar ni reparar, como el mutante rad50S, en el cual, la proteína Spo11 permanece covalentemente unida a los extremos del DNA roto (Keeney et al., 1997) y se han detectado regiones en el genoma donde existen niveles elevados de recombinación (hotspots) y otras en las que las DSBs apenas se producen (coldspots). Sin embargo, estudios más recientes en los que han mapeado las DSBs meióticos en todo el genoma mediante la detección del ssDNA que se genera en su procesamiento, han revelado un paisaje mucho más homogéneo en la distribución de las DSBs que el inicialmente previsto (Buhler et al., 2007; Buhler et al., 2009)

En S. cerevisiae, la recombinación meiótica y la sinapsis son dos procesos que ocurren simultáneamente.y muestran cierta interdependencia (Padmore et al., 1991). Se ha demostrado que la sinapsis no es necesaria para que se inicie la recombinación meiótica. Por ejemplo, se ha visto que en cepas haploides de S. cerevisiae, manipuladas para hacerlas capaces de entrar en meiosis, no es necesaria la presencia del cromosoma homólogo para que las DSBs se formen (De Massy et al., 1994). Además, se ha demostrado que estas DSBs (en ausencia del homólogo) tienen lugar con una frecuencia, temporalidad y posición normales (Gilbertson and Stahl, 1994). 
No obstante, la sinapsis contribuye a que la recombinación entre los homólogos ocurra eficientemente. Por otro lado, en mutantes como spo11 donde no se generan DSBs, no tiene lugar la sinapsis.

En definitiva, la recombinación es un evento de gran importancia en la meiosis, no sólo porque genera variabilidad genética, sino porque es necesaria para los cromosomas segreguen correctamente. Al final de la profase meiótica y como resultado de los entrecruzamientos entre las cromátidas de los cromosomas homólogos se forman unas estructuras denominadas quiasmas que son las que aseguran la unión de los homólogos y la correcta segregación de éstos a polos opuestos de la célula en la meiosis I.

\subsection{3.- Segregación de los cromosomas en meiosis}

En la meiosis I, que es una división reduccional, las cromátidas hermanas permanecen asociadas, por lo que son los cromosomas homólogos los que se separan debido a que cada uno se ancla a microtúbulos del mismo polo (mono-orientación). Poco después de que se desmantela el huso de meiosis I, se ensambla un segundo huso. En la meiosis II, que es ecuacional, las cromátidas hermanas se separan una de la otra porque ahora se unen a microtúbulos procedentes de polos opuestos (bi-orientación) (Petronczki et al., 2003; Marston and Amon, 2004).

Como ya se ha mencionado, los entrecruzamientos entre homólogos se producen durante la profase y son los que constituyen los quiasmas, que son conexiones estables que unen los cromosomas homólogos. La segregación correcta de los cromosomas durante el ciclo meiótico depende de una serie de mecanismos que aseguran la correcta orientación de las cromátidas hermanas en meiosis I. Estos mecanismos se basan en modificaciones en los propios cromosomas y son claves porque si se producen fallos en ellos se generaría una progenie aneuploide. Los cinetocoros son estructuras proteicas cuya función es la asociación de los cromosomas a los microtúbulos del huso. En la primera división meiótica lo que ocurre es que los cinetocoros de las cromátidas hermanas se anclan a los microtúbulos del mismo polo. Esta mono-orientación de los cinetocoros depende de unas proteínas específicas, llamadas monopolinas, las cuales, evitan la bi-orientación que tiene lugar en la segunda división meiótica. Entre las múltiples funciones meióticas de la kinasa polo Cdc5 (Clyne et al., 2003; Lee et al., 2003; Sourirajan and Lichten, 2008; Acosta et al., 2011), una de ellas es la regulación de la localización del complejo monopolina en los cinetocoros, siendo la encargada de liberar del nucleolo a dos componentes del complejo monopolina, las proteínas Csm1 y Lrs4 (Rabitsch et al., 2003). Después de su liberación, Csm1 y Lrs4 forman un complejo con la proteína específica de meiosis Mam1 y se unen a los cinetocoros. Mam1 es esencial para asegurar la co-orientación de estos cinetocoros (Toth et al., 2000) y recluta la caseína kinasa Hrr25, la cual, es también necesaria para la co-orientación de los cinetocoros hermanos durante la meiosis I (Rabitsch et al., 2003; Petronczki et al., 2006). La kinasa Ipl1/Aurora B colabora con el complejo monopolina en promover la correcta segregación de los homólogos en la primera división meiótica (Monje-Casas et al., 2007) y además se ha visto que se localiza en forma de focos en los cromosomas meióticos que están en profase I y en los cinetocoros en metafase I (Monje-Casas et al., 2007; Yu and Koshland, 2007). Ipl1 tiene además otras funciones en meiosis, como la coordinación del desemsamblaje del SC y la formación de los entrecruzamientos (Jordan et al., 2009).

Los complejos de cohesinas son otros elementos clave para que se produzca la correcta segregación de los cromosomas. Las cohesinas mantienen unidas a las cromátidas hermanas desde que se produce la replicación de DNA hasta su segregación durante mitosis o meiosis. El complejo de cohesinas mitóticas está formado por un 
núcleo de 4 proteínas: Scc3, Smc1, Smc3 y Scc1/Mcd1 (Uhlmann, 2003). El complejo de cohesinas meióticas contiene las mismas proteínas, sustituyendo Scc1/Mcd1 por Rec8, subunidad específica de meiosis (Klein et al., 1999). Como ya se ha comentado anteriormente, los homólogos permanecen unidos a través de los quiasmas y las cohesinas mantienen unidas las cromátidas hermanas. Para que los cromosomas homólogos segreguen durante la meiosis I, las cohesinas deben ser eliminadas a lo largo de los brazos de los cromosomas (para permitir la resolución de estos quiasmas), pero permanecen en las regiones centroméricas permitiendo que las cromátidas hermanas continúen unidas hasta la transición metafase II-anafase II (Figura 3). Las cohesinas son eliminadas mediante la proteasa específica Esp1 denominada separasa. La cohesina centromérica no se elimina en meiosis I porque permanece asociada (hasta anafase II) a la shugosina (Sgo1), la cual la protege de la acción de la separasa (Katis et al., 2004; Kitajima et al., 2004; Marston et al., 2004). Existe otro factor en S. cerevisiae, Spo13, que también es necesario para retener el complejo de cohesinas meióticas en los centrómeros durante la anafase I (Shonn et al., 2002).

En levaduras, el SAC tiene una función esencial en la meiosis porque evita que los homólogos se separen durante la meiosis I cuando éstos no están anclados a los cinetocoros y, por tanto, no existe la tensión necesaria para que segreguen correctamente (Shonn, 2000; Bernard et al., 2001). La proteína Mad2 es la mediadora entre el SAC y los mecanismos que regulan la proteólisis de la securina. Además, Mad2 es importante en la orientación de los cromosomas durante la primera división meiótica (Shonn, 2000; Shonn et al., 2003) contribuyendo a la fidelidad en la segregación de los cromosomas durante meiosis I y de las cromátidas hermanas durante meiosis II (Cheslock et al., 2005).

\section{2.- Formación de las esporas}

En S. cerevisiae, la meiosis culmina con un proceso de diferenciación que es la morfogénesis de las esporas. Así, los cuatro núcleos haploides resultantes se empaquetan en esporas, que son capaces de resistir a condiciones ambientales adversas y protegen al genoma del daño inducido por estrés físico o químico (Smits et al., 2001). La morfogénesis de las esporas ocurre en dos etapas: primero se forman las membranas de las pro-esporas o PSMs (마oS pore Membranes) alrededor de cada núcleo haploide y después las pro-esporas son rodeadas por una pared que protege a las esporas maduras.

En la meiosis II temprana, los cuerpos polares del huso (SPBs) duplicados sufren modificaciones y sus superficies citoplasmáticas (las placas meióticas) se convierten en lugares de formación de la PSM reclutando vesículas que se fusionan para formar la cápsula inicial de la PSM (Moreno-Borchart and Knop, 2003; Neiman, 2005). Cuando finaliza la meiosis II, cada PSM se cierra de modo que cada núcleo haploide queda encapsidado junto con los orgánulos y el material citoplasmático dentro de una PSM doble. Entre las dos capas de las PSMs se ensambla de novo la pared de la espora (Neiman, 2005). La pared de la espora madura consiste en cuatro capas que van de dentro hacia fuera siguiendo este orden: $\beta-1,3-$ glucano, quitosán y ditirosina. Las dos capas más exteriores se encargan de asegurar la resistencia de las esporas a los factores ambientales.

\section{3.- El checkpoint de recombinación meiótica o de paquitene en S. cerevisiae}

Aunque están muy relacionados, existen diferencias entre la ruta de transducción de la señal de DSBs específicas de meiosis y el checkpoint activado por DSBs en células mitóticas, lo que sugiere que existen 
requisitos específicos para el reconocimiento de diferentes tipos de daño en el DNA en células meióticas, células mitóticas y durante la replicación para así prevenir la activación de un checkpoint inapropiado (Caspari and Carr, 2002).

En meiosis existe un mecanismo específico que vigila la integridad del genoma y que se denomina checkpoint de recombinación meiótica o de paquitene. Este checkpoint monitoriza la profase meiótica, más concretamente, procesos como la sinapsis y la recombinación y bloquea las células antes de la entrada en meiosis I mientras dichos procesos no se hayan completado correctamente (Figura 5). Así, las células se aseguran de haber generado los entrecruzamientos entre homólogos, necesarios para la correcta orientación de los cromosomas en la placa metafásica y su posterior segregación a polos opuestos de la célula (Roeder and Bailis, 2000).

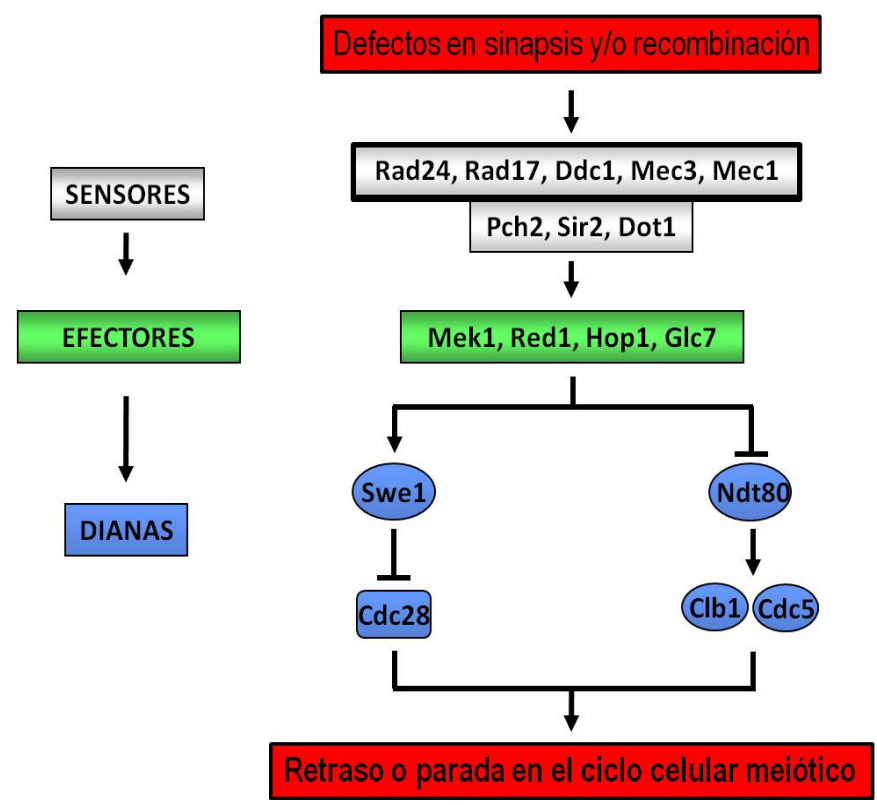

Figura 5. El checkpoint de recombinación meiótica de S.cerevisiae. Representación esquemática de los diferentes componentes de este checkpoint y las principales proteínas implicadas.

El organismo modelo en el que más y mejor se ha estudiado este mecanismo de vigilancia es la levadura de gemación S. cerevisiae aunque la mayoría de sus componentes estén conservados a lo largo de la evolución (Tabla 2). El checkpoint de recombinación meiótica se ha investigado principalmente en mutantes que carecen de factores necesarios para la invasión de la cadena homóloga, tales como dmc1 y hop2, en mutantes defectivos en procesamiento de las DSBs, como rad50S y sae2, y en mutantes defectivos en sinapsis y recombinación, como zip1. Todos estos mutantes presentan un retraso en la progresión meiótica durante la profase debido a la activación del checkpoint. (Bishop et al., 1992; Sym et al., 1993; Leu et al., 1998; Borner et al., 2004).

Los intermediarios de recombinación generados por DSBs meióticas sin reparar son los que disparan el checkpoint de paquitene. Al igual que en el checkpoint de daño en el DNA, los complejos Rad24/RFC y "9-1-1" (Ddc1-Rad17-Mec3), participan en el reconocimiento inicial de las DSBs meióticas (Figura 5) (Hochwagen and Amon, 2006), así como en la elección del cromosoma homólogo para su reparación (Grushcow et al., 1999).

Ddc1 colocaliza con Rad51, y un análisis de dos híbridos con Rad24 como gancho ha desvelado que hay interacción con Sae1, Sae2, Rad57 y Msh5 (Hong and Roeder, 2002). Rad24 y Ddc1 actúan como moduladores 
de Mek1, la kinasa específica de meiosis que se activa por el inicio de la recombinación meiótica (Hochwagen and Amon, 2006). Mek1 es el parálogo específico de meiosis de la proteína Rad53 y, además de su función en el checkpoint meiótico, junto con Red1 y Hop1 asegura la recombinación homóloga dependiente de DMC1

Tabla 2.- Proteínas del checkpoint meiótico y sus homólogos.

\begin{tabular}{|c|c|c|c|c|}
\hline Clase & Función & S. cerevisiae & S. pombe & Mamíferos \\
\hline \multirow{20}{*}{$\begin{array}{l}\text { Factores } \\
\text { del } \\
\text { checkpoint }\end{array}$} & Factor de carga parecido a RFC & Rad24 & Rad17 & Rad17 \\
\hline & Clamp parecido a PCNA & Rad17 & Rad1 & Rad1 \\
\hline & Clamp parecido a PCNA & $\operatorname{Mec3}$ & Hus1 & Hus1 \\
\hline & Clamp parecido a PCNA & Ddc1 & Rad9 & Rad9 \\
\hline & Kinasa parecida a la fosfo-inositol kinasa 3 & Mec1 & Rad3 & ATR \\
\hline & Kinasa meiótica (parálogo de Rad53) & Mek1 & Mek1 & - \\
\hline & Proteína cromosómica meiótica & Red1 & Red10 & - \\
\hline & Proteína cromosómica meiótica & Hop1 & Hop1 & $\begin{array}{l}\text { HORMA D1 } \\
\text { HORMA D2 }\end{array}$ \\
\hline & Metiltransferasa de histonas & Dot1 & - & Dot1L \\
\hline & Kinasa con dominio FHA & Rad53/Mek1 & Cds1/Mek1 & Chk2 \\
\hline & Kinasa parecida a la fosfo-inositol kinasa 3 & Tel1 & Tel1 & ATM \\
\hline & Proteína adaptadora con dominio BRCT & Rad9 & Crb2 & 53BP1 \\
\hline & Nucleasa, componente del complejo MRX & Mre11 & Rad32 & Mre11 \\
\hline & Componente del complejo MRX & Xrs2 & $\mathrm{Nbs} 1$ & $\mathrm{Nbs} 1$ \\
\hline & Componente del complejo MRX & Rad50 & Rad50 & Rad50 \\
\hline & Desacetilasa de histonas & Sir2 & Sir2 & varios \\
\hline & ATPasa & Pch2 & - & TRIP13 \\
\hline & Proteína con dominio BRCT & Dpb11 & Cut5 & TopBP1 \\
\hline & Proteína de unión a DNA & Tel2 & - & - \\
\hline & Proteín kinasa & (Chk1) & Chk1 & Chk1 \\
\hline \multirow[t]{11}{*}{ Dianas } & Histona deacetilasa 2 & $\mathrm{H} 2 \mathrm{~A}$ & - & $\mathrm{H} 2 \mathrm{AX}$ \\
\hline & Proteína de la envuelta nuclear & Mps3 & Sad1 & SUN1, SUN2 \\
\hline & Proteína del filamento transversal del SC & Zip1 & - & SYCP1 \\
\hline & Endonucleasa & Sae2 & Ctp1 & CtIP \\
\hline & Kinasa dependiente de ciclina & Cdc28 & Cdc2 & Cdc2 \\
\hline & Tirosín kinasa de Cdc28 & Swe1 & (Wee1) & Wee1 \\
\hline & Tirosín fosfatasa de Cdc28 & (Mih1) & Cdc25 & varios \\
\hline & Desacetilasa de histonas & Ndt80 & - & - \\
\hline & Factor de transcripción & Sum1 & - & - \\
\hline & Represor transcripcional & - & - & p53 \\
\hline & Factor de iniciación de la traducción & varios & varios & varios \\
\hline \multirow[t]{2}{*}{ Adaptación } & Proteína fosfatasa 1 & Glc7 & varios & varios \\
\hline & Proteína de unión a FK506 & Frp3 & Fkbp39 & varios \\
\hline
\end{tabular}

Los nombres que aparecen entre paréntesis indican factores para los que los experimentos realizados no indicaron un papel en el checkpoint meiótico.

RFC - Factor de replicación C (Replication Factor C)

PCNA - Antígeno de proliferación celular (Proliferating Cell Nuclear Antigen)

FHA domain - Dominio asociado a horquillas (Forkhead Associated domain)

BRCT domain - Dominio carboxi-terminal de Brca1 (Brca1 Carboxy Terminal domain)

complejo MRX- complejo Mre11/Rad50/Xrs2 
impidiendo el uso de la cromátida hermana como molde para la reparación de las DSBs (Niu et al., 2007).

La activación de Mek1 depende de la fosforilación de la proteína Hop1, la cual, es mediada por Mec1 y Tel1 (Carballo et al., 2008). Además, Red1, que interacciona con Hop1 (Hollingsworth and Ponte, 1997; Bailis and Roeder, 1998; de los Santos and Hollingsworth, 1999), es necesaria para que Mek1 alcance su máxima actividad kinasa (Wan et al., 2004). Recientemente, se ha descrito que Red1 se asocia con SUMO (Ś MOdifier) para promover la fosforilación de Hop1 dependiente de Mec1/Tel1 así como el ensamblaje del SC (Lin et al., 2010). Además, la unión de Red1 al complejo "9-1-1" es crucial para la activación del checkpoint meiótico (Eichinger and Jentsch, 2010).

Además de en mutantes como dmc1 o hop2 que acumulan DSBs sin reparar, el checkpoint de paquitene también se activa en el mutante zip1 que carece de la región central del SC, si bien no está muy clara la naturaleza de la señal que dispara el checkpoint en estos mutantes provocando el bloqueo meiótico. El checkpoint de zip1 requiere Pch2, una ATPasa específica de meiosis (San-Segundo and Roeder, 1999). La inactivación de PCH2 elimina el retraso o bloqueo en la progresión de la meiosis de los mutantes zip1, zip2 y mms4 (San-Segundo and Roeder, 1999; de los Santos et al., 2001), pero no en los mutantes hop2, mnd1 y sgs1 (Roeder and Bailis, 2000; Rockmill et al., 2003; Zierhut et al., 2004). Pch2 se localiza en el nucleolo y esta localización parece ser importante para su función. La localización de Pch2 en el nucleolo depende de la metiltransferasa Dot1 y de la desacetilasa de histonas Sir2 (San-Segundo and Roeder, 1999; San-Segundo and Roeder, 2000). Dot1 es una proteína conservada en la evolución que cataliza la metilación de H3K79 (Feng et al., 2002; Ng et al., 2002; van Leeuwen et al., 2002). Además de su función en el checkpoint meiótico, Dot1 participa en múltiples aspectos de la respuesta al daño en el DNA en células vegetativas (Game et al., 2006; Toh et al., 2006; Bostelman et al., 2007; Conde and San-Segundo, 2008).

De modo general, los factores de checkpoint activados transmiten su señal a las proteínas diana que controlan la progresión del ciclo celular, la reparación del DNA, la muerte celular programada y, en algunos casos, el desarrollo. Entre las dianas más importantes de los mecanismos de checkpoint del ciclo celular están las kinasas dependientes de ciclina, proteínas kinasas compuestas por una subunidad kinasa catalítica o CDK y una subunidad reguladora, la ciclina. En el caso del programa meiótico en S. cerevisiae, las ciclinas Clb1, 3 o 4, junto con la CDK Cdc28, conducen a las células a entrar en meiosis (Marston and Amon, 2004). Cuando se activa el checkpoint de recombinación meiótica, tanto Cdc28 como las ciclinas meióticas están sometidas a inhibición (Figura 5). Así, la activación del checkpoint da lugar a la hiperfosforilación y estabilización de la kinasa Swe1 que, a su vez fosforila a Cdc28 en la tyrosina 19 inhibiendo su actividad (Leu and Roeder, 1999; Pak and Segall, 2002; Acosta et al., 2011). Además, la activación del checkpoint mantiene bajos los niveles del transcrito (y de proteína) de las ciclinas meióticas de tipo B (Chu and Herskowitz, 1998; Hepworth et al., 1998). Los promotores de CLB1, CLB3 y CLB4, que se expresan en meiosis, contienen un elemento de DNA de pequeño tamaño denominado elemento de esporulación medio o MSE (Medium S Sporulation Element) que se encuentra en muchos otros genes medios cuya expresión se induce una vez que las células salen de la G2/profase meiótica y entran en meiosis I. La expresión de la ciclinas meióticas está controlada por dos factores, Ndt80 y Sum1. Ndt80 es un factor transcripcional que se une al MSE e induce la expresión de los genes medios (Chu and Herskowitz, 1998; Hepworth et al., 1998); El mutante ndt80 está bloqueado en la profase meiótica (Xu et al., 1995). Sum1 es un represor transcripcional que reconoce un elemento del DNA que se solapa con el MSE, y por tanto, compite 
con Ndt80 para unirse a un subconjunto de genes medios (Xie et al., 1999; Lindgren et al., 2000; Pierce et al., 2003). Tanto Ndt80 como Sum1 están bajo el control del checkpoint. Los niveles de expresión de NDT80 se mantienen bajos durante la activación del checkpoint y la sobreexpresión de NDT80 permite una supresión parcial del bloqueo meiótico inducido por el checkpoint (Tung et al., 2000; Pak and Segall, 2002). Además, la fosforilación de Ndt80 se reduce de forma dependiente del checkpoint (Hepworth et al., 1998; Tung et al., 2000; Shubassi et al., 2003). Se ha visto que la fosforilación de Ndt80 depende en parte de la kinasa meiótica Ime2 y de la polo kinasa Cdc5 (Benjamin et al., 2003; Clyne et al., 2003; Acosta et al., 2011). Por el contrario, Sum1 parece estar regulada a nivel de estabilidad de la proteína. Los niveles de Sum1 descienden a medida que las células meióticas pasan de la G2/profase a meiosis I, a pesar del incremento en los niveles de mRNA de SUM1 (Lindgren et al., 2000). Además, Sum1 se acumula cuando las células están detenidas en G2/profase, y Sum1 se requiere para el bloqueo meiótico de los mutantes dmc1 (Lindgren et al., 2000; Pak and Segall, 2002).

\subsection{Alteraciones de la meiosis}

A pesar de los estrictos mecanismos de control comentados anteriormente, la meiosis es un proceso que no siempre funciona correctamente. Una de las principales causas de las enfermedades genéticas que se producen en los humanos es la existencia de errores en la formación de los gametos. En una célula, durante la meiosis, lo que ocurre normalmente es que las cuatro cromátidas de una tétrada se separen por completo dirigiéndose cada una de ellas a una de las cuatro células hijas resultantes. En cambio, cuando las cromátidas no se separan, se producen desórdenes genéticos en los que uno de los gametos resultantes recibe una copia extra del mismo cromosoma. El ejemplo más común para este error meiótico es el defecto conocido como síndrome de Down, en el cual, una persona posee una copia extra del cromosoma 21 procedente de uno de los padres. Otro ejemplo bastante común de no separación de las cromátidas hermanas ocurre cuando los cromosomas sexuales $(X X, X Y)$ no se separan correctamente, lo que da lugar a dos tipos de síndromes, el síndrome de Klinefelter o el sindrome de Turner.

Además de estos errores de aneuploidía, también se pueden producir otros errores durante la meiosis tales como la translocación cromosómica, en la cual, parte del fragmento de un cromosoma se une a otro y la deleción, en la que parte de un cromosoma se pierde por completo. La severidad de los efectos de estos desórdenes siempre depende del tamaño del cromosoma y de la información que contiene.

La tecnología moderna puede detectar precozmente estas anormalidades genéticas cuando el feto se está desarrollando, pero actualmente, poco se puede hacer para corregir o tratar las enfermedades que resultan de estos errores que se producen durante la meiosis. Por ello, estudios en organismos modelos como las levaduras nos pueden ayudar a conocer con más detalle cómo funciona la ruta del checkpoint de recombinación meiótica y así, poder entender mejor las causas de errores meióticos. 
OBJETIVOS 
Los mecanismos de vigilancia del ciclo celular o checkpoints son esenciales para el mantenimiento de la integridad genómica; en particular, aquellos checkpoints que responden a lesiones en el genoma. Durante la meiosis se genera daño en el DNA, si bien de forma programada o fisiológica, puesto que las DSBs meióticas son necesarias para iniciar la recombinación. Aunque algunos de los componentes del checkpoint que responde al daño en el DNA durante la mitosis son comunes con el checkpoint que monitoriza la recombinación meiótica, el hecho de que las DSBs meióticas se generen en un contexto cromosomal específico implica que haya diferencias entre ambas rutas. Por ello, en este trabajo nos hemos planteado el profundizar en el estudio de los mecanismos moleculares por lo que se detectan los intermediarios de recombinación meiótica y se detiene la progresión de la meiosis cuando existen alteraciones en la recombinación y/o sinapsis entre los cromosomas homólogos. Para ello, nos hemos centrado en el análisis de la proteína Ddc2 de Saccharomyces cerevisiae que, junto con la kinasa Mec1, constituyen un complejo sensor de daño en el DNA.

Por tanto, el objetivo principal de este trabajo ha sido la caracterización funcional de Ddc2 durante la meiosis en S. cerevisiae. 
RESULTADOS 


\section{CAPÍTULO 1.- Caracterización de la función de la proteína Ddc2 en meiosis}

\section{1.- La proteína Ddc2 participa en el checkpoint de recombinación meiótica}

El checkpoint de recombinación meiótica bloquea o retrasa la entrada en meiosis I cuando existen alteraciones en los procesos de sinapsis y/o recombinación (ver Introducción) (Roeder and Bailis, 2000). Por tanto, en este trabajo, como herramienta genética para disparar este checkpoint meiótico se han utilizado diversos mutantes (zip1, sae2, dmc1, hop2) defectivos en diferentes aspectos de esos procesos, y que muestran un retraso o parada en el estadío de paquitene de la profase como resultado de la activación del checkpoint (Bishop et al., 1992; Sym et al., 1993; McKee and Kleckner, 1997; Prinz et al., 1997; Leu et al., 1998). Para iniciar el análisis funcional de Ddc2, se llevó a cabo la deleción del gen DDC2. Puesto que la ausencia de Ddc2 es letal para las células de S. cerevisiae, dicha deleción se realizó en un fondo genético sml1, ya que la falta de Sml1 suprime la letalidad del mutante $d d c 2$ sin alterar sus efectos en el checkpoint de daño en DNA (Zhao et al., 1998; Paciotti et al., 2000). No obstante, en primer lugar, se confirmó que la ausencia de Sml1 no afecta a la meiosis, ya que el mutante sml1 mostró una cinética de progresión meiótica normal (Figura $6 \mathrm{~A}$ ) y una elevada viabilidad de las esporas (>85\%). Además, la falta de Sml1 no alteraba el bloqueo meiótico mediado por el checkpoint en los mutantes zip1, dmc1 y hop2 (Figuras 6B-6D). Por tanto, puesto que la falta de Sml1 no confiere ningún efecto meiótico, para simplificar, las cepas 'sml1 dddc2' se denominarán a partir de ahora ' $d d c 2$ ' a lo largo de esta memoria. Por otro lado, se observó que el mutante $s m / 1 d d c 2$ tenía una progresión de la meiosis normal (Figura $6 \mathrm{~A}$ ), pero mostraba una viabilidad de las esporas reducida (27\%), lo cual indica un papel de la proteína Ddc2 en un ciclo meiótico sin perturbar.

Para determinar si Ddc2 se requiere para el checkpoint de recombinación meiótica, combinamos la deleción de $D D C 2$ con los mutantes meióticos zip1, dmc1, hop2 y sae2 y se estudiaron varios eventos meióticos (Figuras 7-11). En concreto, se analizó la cinética de las divisiones meióticas mediante tinción nuclear con DAPI y, en algunos casos, la monitorización de la elongación del huso meiótico. Por otro lado, se determinó la eficiencia de esporulación en placa mediante el contaje microscópico de ascas maduras e inmaduras y se utilizó un ensayo de fluorescencia de ditirosina como indicador específico de la presencia de esporas maduras (Briza et al., 1986). Por último, mediante disección de tétradas, se analizó la viabilidad de las esporas, que refleja la fidelidad en la segregación cromosómica y la integridad del genoma en los productos meióticos de la levadura.

Elmutantezip1,queposee defectosen sinapsis decromosomasyenlaresolucióndelosentrecruzamientos, muestra una parada muy marcada en paquitene (Sym et al., 1993) (Figura 7B). Cuando delecionamos el gen DDC2 en el mutante zip1, lo que observamos fue una supresión de este bloqueo meiótico, es decir, el mutante zip1 ddc2 mostraba un cinética de progresión de la meiosis similar a la cepa silvestre dando lugar a la formación de ascas con 4 esporas maduras y con núcleos aparentemente intactos en la mayoría de los casos (Figuras 7B, 7D). Sin embargo, la viabilidad de las esporas del doble mutante zip1 ddc2 estaba significativamente reducida (Figura 7A) y el patrón de muerte de las esporas cambiaba en comparación con el de los pocos productos meióticos formados en el mutante sencillo zip1 después de una incubación prolongada en medio de esporulación (Figura 7C).

El mutante dmc1 acumula DSBs hiper-procesadas sin reparar debido a su defecto en invasión de la cadena homóloga durante la recombinación meiótica, por lo que presenta un retraso en la progresión de la meiosis debido a la activación del checkpoint (Bishop et al., 1992; Rockmill et al., 1995). Sin embargo, eventualmente, el mutante $d m c 1$ completa la meiosis y esporulación, incluso formando esporas maduras que contienen ditirosina 
A

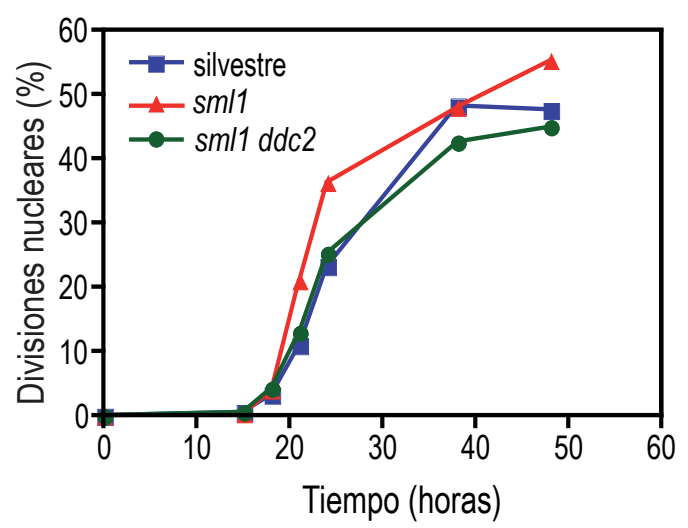

C

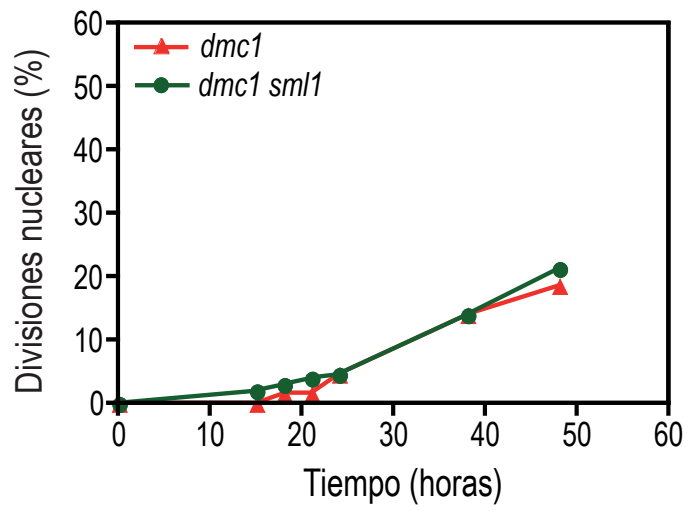

B

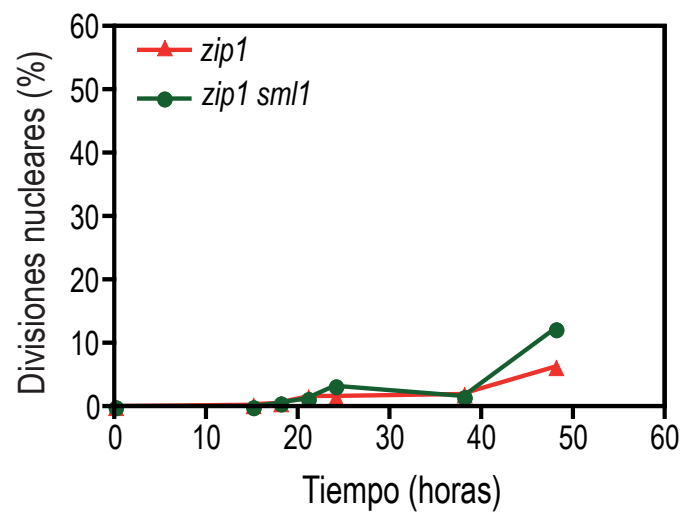

D

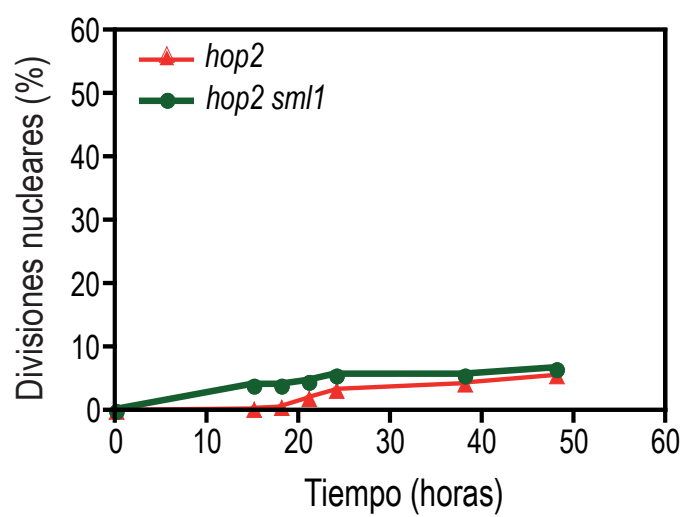

Figura 6. La ausencia de Sml1 no afecta ni la progresión de la meiosis (A) ni la función del checkpoint de paquitene (B, C, D). Se representa la cinética de la progresión de la meiosis mediante el porcentaje de células que contienen más de dos núcleos. Las cepas son BR1919-2N (silvestre), DP455 (sm/1), DP454 (sml1 ddc2), DP422 (zip1), DP452 (zip1 sm/1), DP456 (dmc1), DP467 (dmc1 sm/1), DP470 (hop2) y DP471 (hop2 sml1).

(Figuras 8A, 8B). No obstante, la viabilidad de las esporas de dmc1 era baja $(10,4 \%)$. La deleción de $D D C 2$ suprimía, al menos parcialmente, el retraso meiótico de $d m c 1$, pero los núcleos de los productos meióticos generados estaban fragmentados y disgregados, formándose muy pocas esporas maduras, la mayoría de ellas inviables (Figuras 8A, 8B, 8D). Al analizar la progresión de la meiosis mediante tinción de núcleos con DAPI y debido a que el material genético estaba muy disgregado, podríamos estar infravalorando el número de células que estaban realizando meiosis I y II. Por ello, decidimos seguir la elongación del huso a lo largo de la meiosis como marcador alternativo de la progresión meiótica y, de hecho, comprobamos que la deleción de $D D C 2$ suprimía totalmente el retraso meiótico de dmc1 (Figura 9A). La interpretación más sencilla para estas observaciones es que, durante el retraso meiótico impuesto por el checkpoint en el mutante $d m c 1$, las DSBs se podrían reparar eventualmente usando la cromátida hermana en lugar del cromosoma homólogo, dando lugar a la formación de núcleos intactos y a la generación de esporas maduras, aunque inviables debido a la segregación defectiva de los cromosomas al no haberse producido conexiones entre los homólogos. Sin embargo, cuando el retraso meiótico de $d m c 1$ es suprimido por $d d c 2$, las células llevarían a cabo las divisiones meióticas con DSBs sin reparar, dando como resultado núcleos fragmentados incapaces de promover la morfogénesis de las esporas. Para verificar esta posibilidad, se introdujo la mutación rad54, que evita la recombinación entre cromátidas hermanas (Arbel et al., 1999). El mutante sencillo rad54 no mostraba un retraso meiótico significativo y la viabilidad de las 
A

\begin{tabular}{|r|c|c|c|}
\hline Genotipo relevante & Fluorescencia de ditirosina & Eficiencia de esporulación(\%) & Viabilidad de las esporas (\%) \\
\hline Silvestre & & 63 & 96,2 \\
zip1 & & 6 & 44,0 \\
zip1 ddc2 & & 50 & 6,9 \\
\hline
\end{tabular}

B

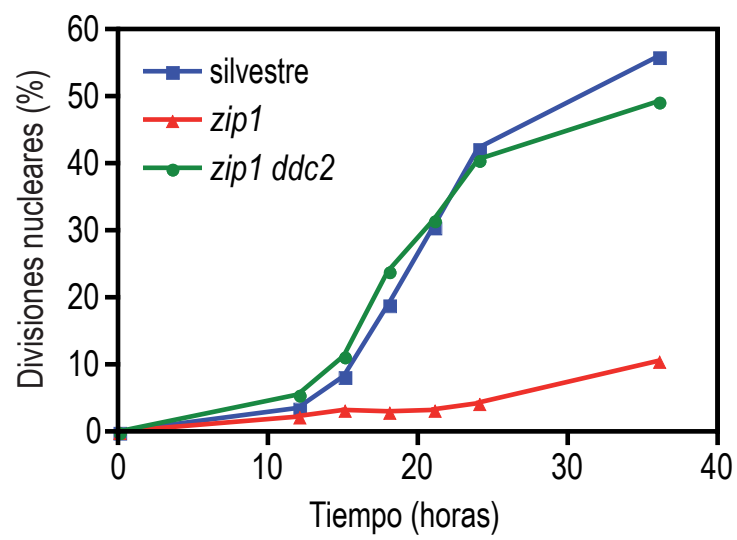

\section{C}

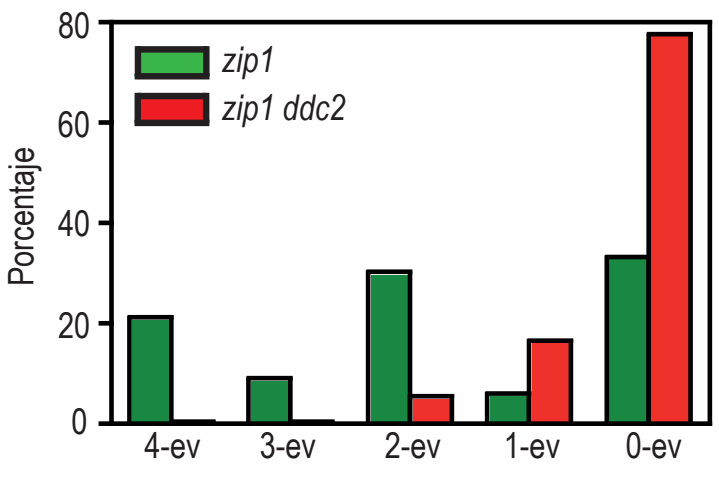

D
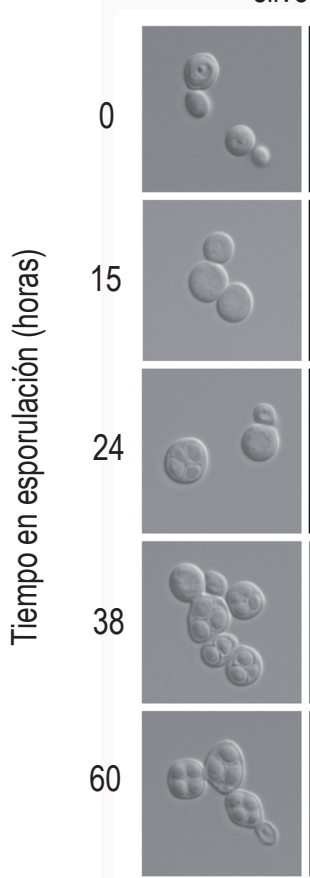

DIC silvestre
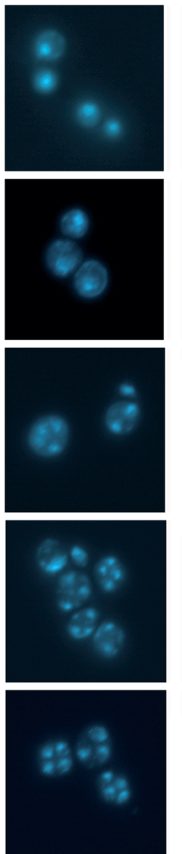

DAPI

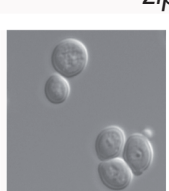

zip1
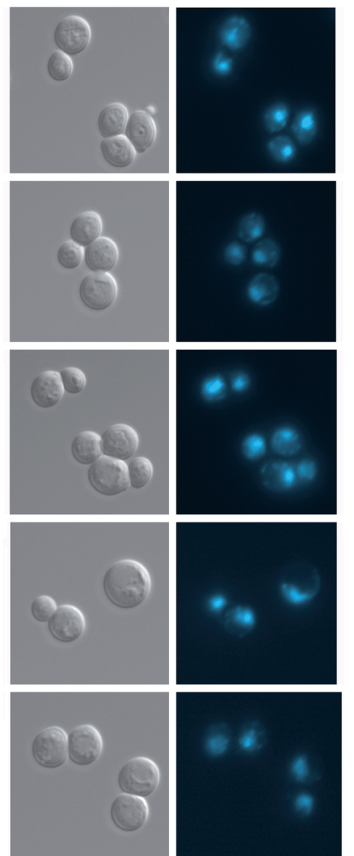

DIC

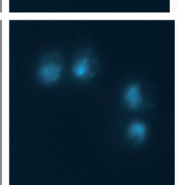

DAPI zip1 ddc2
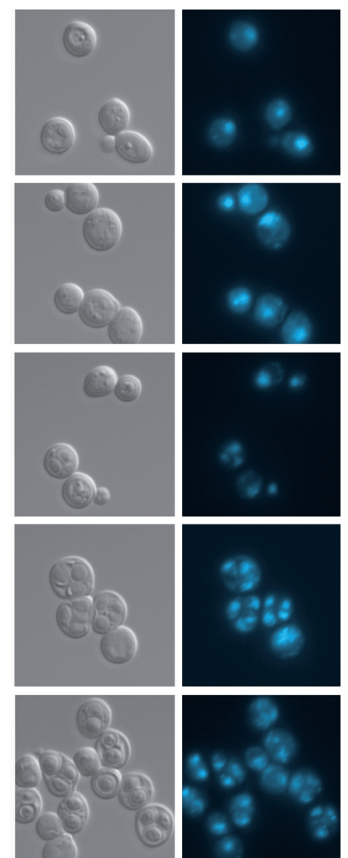

DIC

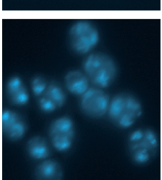

DAPI

Figura 7. Ddc2 se requiere para el bloqueo meiótico inducido por el checkpoint en el mutante zip1. (A) Se examinaron diferentes eventos meióticos como la fluorescencia de ditirosina, la eficiencia de esporulación y la viabilidad de las esporas después de 3 días de esporulación en placa. (B) Cinética de las divisiones nucleares meióticas. Se representa el porcentaje de células con más de dos núcleos. (C) Distribución de los tipos de tétrada. Se representa el porcentaje de tétradas con 4, 3, 2, 1 y 0 esporas viables (4-ev, 3-ev, 2-ev, 1-ev y 0 -ev, respectivamente). (D) Imágenes representativas de células/ascas (DIC) y morfologías nucleares (DAPI) a diferentes tiempos de la meiosis. Las cepas son BR1919-2N (silvestre), DP452 (zip1) y DP451 (zip1 ddc2). 
A

\begin{tabular}{|r|c|c|c|}
\hline Genotipo relevante & Fluorescencia de ditirosina & Eficiencia de esporulación(\%) & Viabilidad de las esporas (\%) \\
\hline silvestre & & 63 & 96,2 \\
$d m c 1$ & & 9 & 10,4 \\
$d m c 1 d d c 2$ & & 10 & 3,5 \\
rad54 & & 66 & 60,4 \\
rad54 dmc1 & & 26 & 11,1 \\
rad54 dmc1 ddc2 & & & 3,5 \\
\hline
\end{tabular}

B

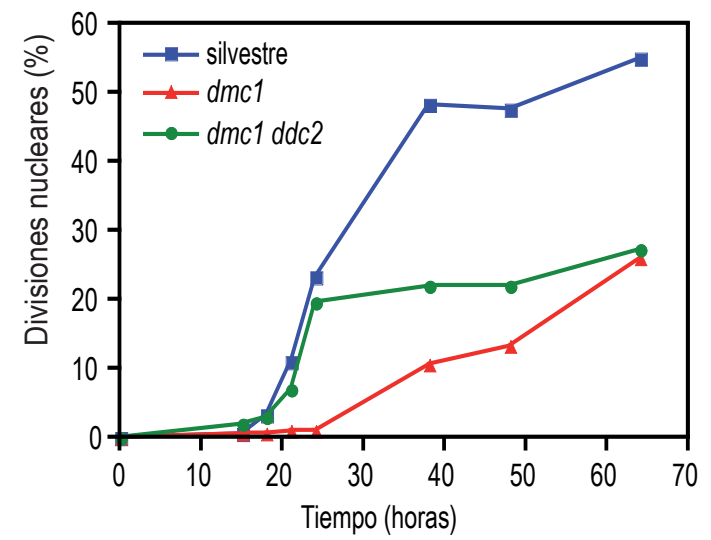

C

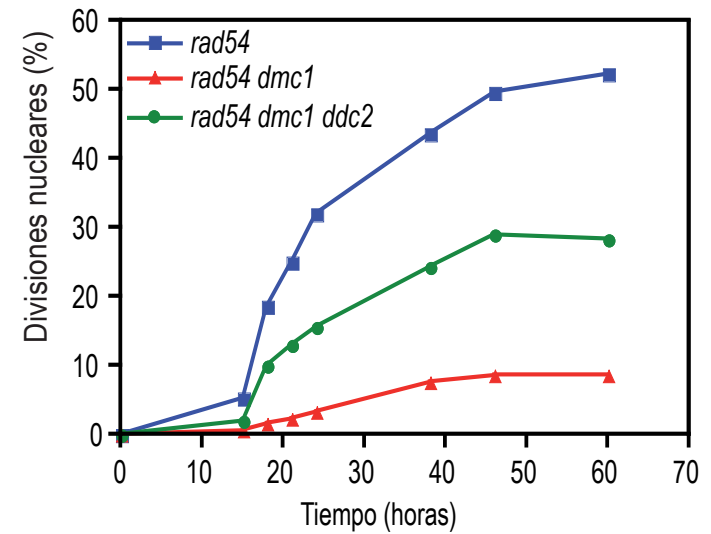

D

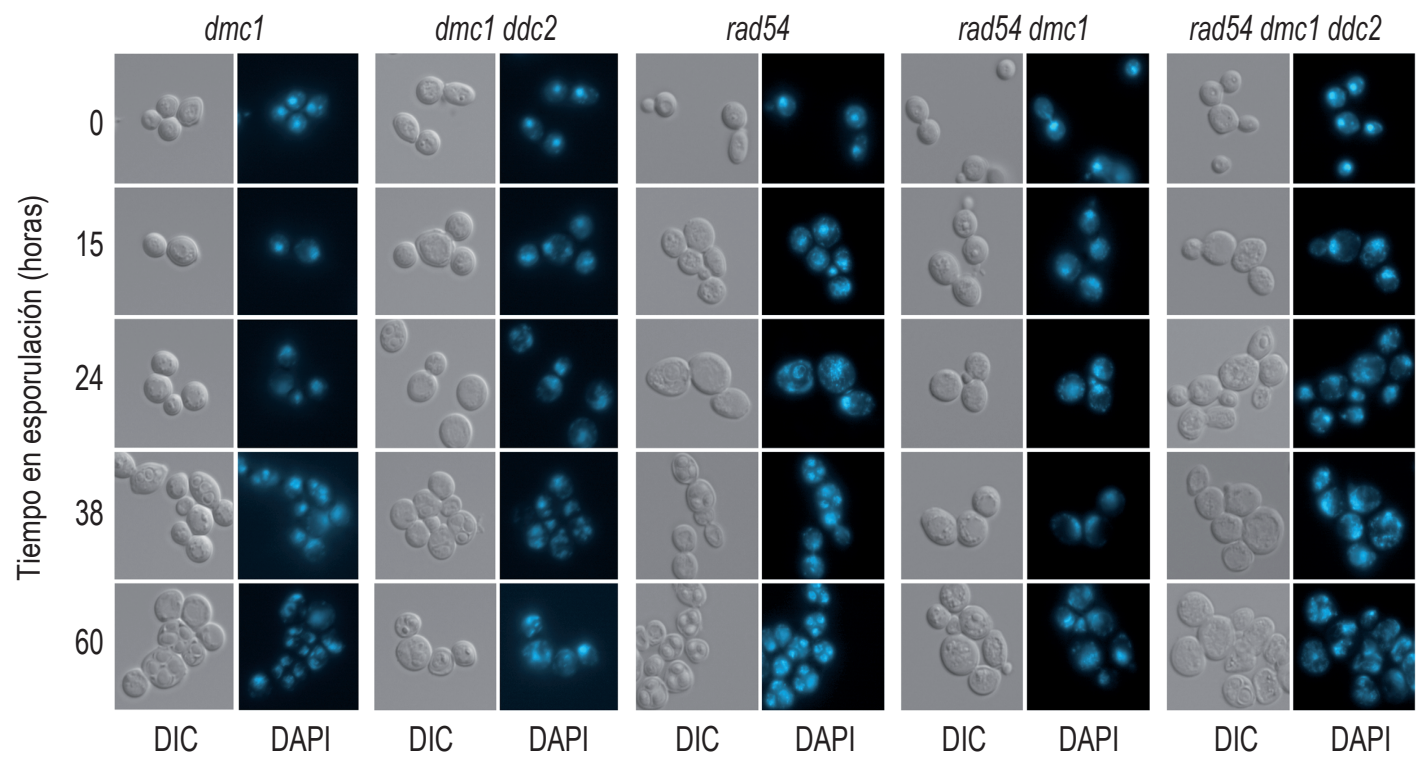

Figura 8. Ddc2 se requiere para el retraso meiótico inducido por el checkpoint en el mutante dmc1 y el bloqueo en dmc1 rad54. (A) Se examinaron diferentes eventos meióticos como la fluorescencia de ditirosina, la eficiencia de esporulación y la viabilidad de las esporas después de 3 días de esporulación en placa. $(B, C)$ Cinética de divisiones nucleares meióticas. Se representa el porcentaje de células con más de dos núcleos. (D) La deleción de DDC2 suprime el retraso o parada de los mutantes dmc1 o dmc1 rad54 respectivamente, generando esporas aberrantes. Se muestran imágenes representativas de células/ascas (DIC) y morfologías nucleares (DAPI) a diferentes tiempos de la meiosis. Las cepas son BR1919-2N (silvestre), DP467 (dmc1), DP468 (dmc1 ddc2), DP473 (rad54), DP475 (rad54 dmc1) y DP481 (rad54 dmc1 ddc2). 
esporas no estaba muy afectada, pero el mutante doble rad54 dmc1 estaba casi completamente bloqueado en la meiosis (Figura 8A, C, D), lo que era consistente con la acumulación de DSBs que ya no pueden ser reparadas ni con la hermana ni con el homólogo. Además, este bloqueo meiótico se suprimía, al menos parcialmente, al delecionar DDC2 (Figura 8C), conduciendo a la formación de productos meióticos inviables (Figura 8A).

El mutante hop2 está afectado en el mismo paso de la recombinación meiótica que dmc1 y, además, presenta sinapsis entre cromosomas no homólogos, dando lugar a una parada en la profase de la meiosis dependiente del checkpoint de paquitene (Leu et al., 1998). Esta parada se suprimía cuando delecionamos el gen $D D C 2$, resultando en productos meióticos inviables (Figuras 9B y 10).

A

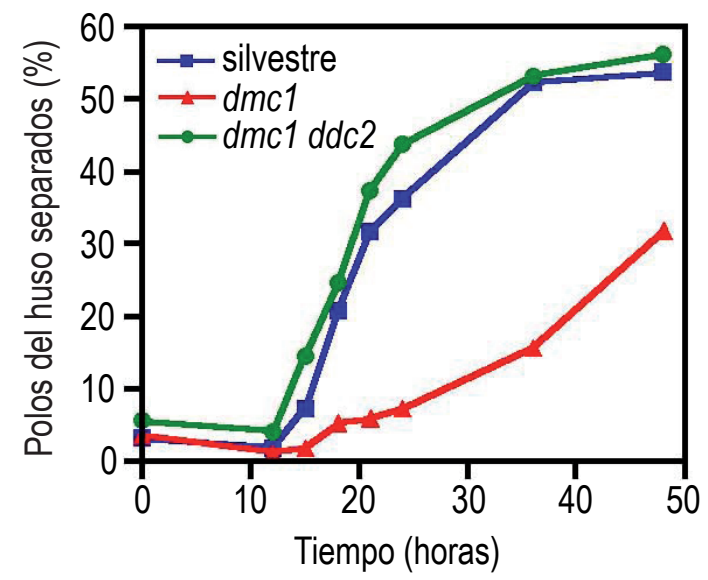

B

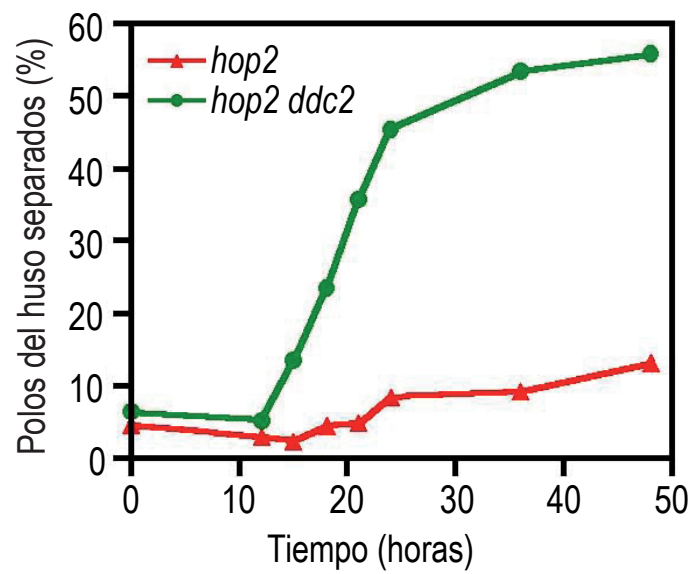

Figura 9. La deleción de DDC2 suprime por completo el retraso meiótico de los mutantes dmc1 y hop2. (A) Análisis de la separación de los polos del huso a lo largo de la meiosis mediante la observación de Tubulina-GFP en las cepas silvestre (DP778), dmc1 (DP779) y dmc1 ddc2 (DP781). (B) Análisis de la separación de los polos del huso en las cepas hop2 (DP780) y hop2 ddc2 (DP782). Se realizaron contajes de 150-400 células por cada cepa y tiempo de meiosis representado en la cinética.

El mutante sae2 es defectivo en la eliminación de la proteína Spo11 de los extremos 5 ' de las DSBs meióticas, que permanecen sin procesar ni reparar (McKee and Kleckner, 1997; Wu and Burgess, 2006) disparando así el checkpoint meiótico (Wu and Burgess, 2006) y produciendo un retraso en la progresión meiótica, aunque eventualmente se producen esporas inviables (Figura 11A, B). Por el contrario, el mutante doble sae2 ddc2 exhibía cinéticas de meiosis más rápidas y una eficiencia de esporulación más elevada comparado con sae2, pero las esporas seguían siendo inviables y mostraban una distribución aberrante del material genético (Figura 11C). En conjunto, todos estos resultados muestran que la proteína Ddc2 es necesaria para mantener el bloqueo meiótico inducido por el checkpoint en mutantes alterados en distintos pasos de los procesos de sinapsis y recombinación.

\section{2.- En ausencia de $D D C 2$, las células entran en meiosis I sin haber reparado los intermediarios} de recombinación

El hecho de que la deleción de DDC2 suprima el retraso o parada en profase de varios mutantes originando productos meióticos defectivos, sugiere que las células llevan a cabo las divisiones meióticas sin haber completado la recombinación; es decir, se pierde la coordinación entre un evento tardío (la segregación de los cromosomas) y otro más temprano (la recombinación). Estas observaciones están de acuerdo con que Ddc2 


\begin{tabular}{|r|c|c|c|}
\hline Genotipo relevante & Fluorescencia de ditirosina & Eficiencia de esporulación(\%) & Viabilidad de las esporas (\%) \\
\hline silvestre & & 63 & 96,2 \\
hop2 & & 7 & 0,7 \\
hop2 $d d c 2$ & & 39 & 0 \\
\hline
\end{tabular}

\section{B}

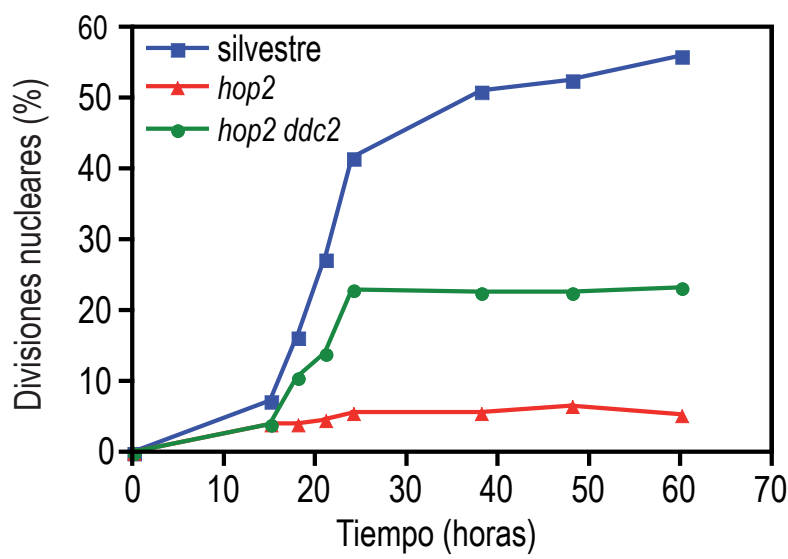

C

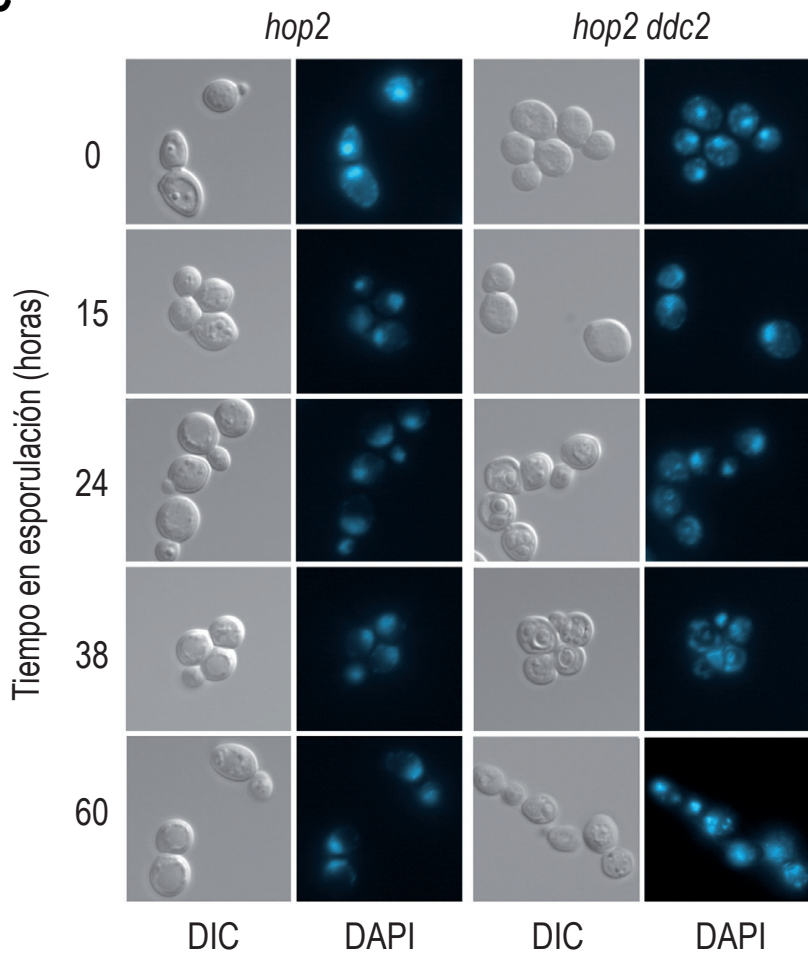

Figura 10. Ddc2 se requiere para el bloqueo meiótico inducido por el checkpoint en el mutante hop2 (A) Se examinaron diferentes eventos meióticos como la fluorescencia de ditirosina, la eficiencia de esporulación y la viabilidad de las esporas después de 3 días de esporulación en placa. (B) Cinética de divisiones nucleares meióticas. Se representa el porcentaje de células con más de dos núcleos. (C) Imágenes representativas de células/ascas (DIC) y morfologías nucleares (DAPI) a diferentes tiempos de la meiosis. Las cepas son BR1919-2N (silvestre), DP471 (hop2) y DP472 (hop2 ddc2). 
A

\begin{tabular}{|r|c|c|c|}
\hline Genotipo relevante & Fluorescencia de ditirosina & Eficiencia de esporulación(\%) & Viabilidad de las esporas (\%) \\
\hline silvestre & & 63 & 96,2 \\
sae2 & & 33 & 0 \\
sae2 ddc2 & & 52 & 0 \\
\hline
\end{tabular}

B

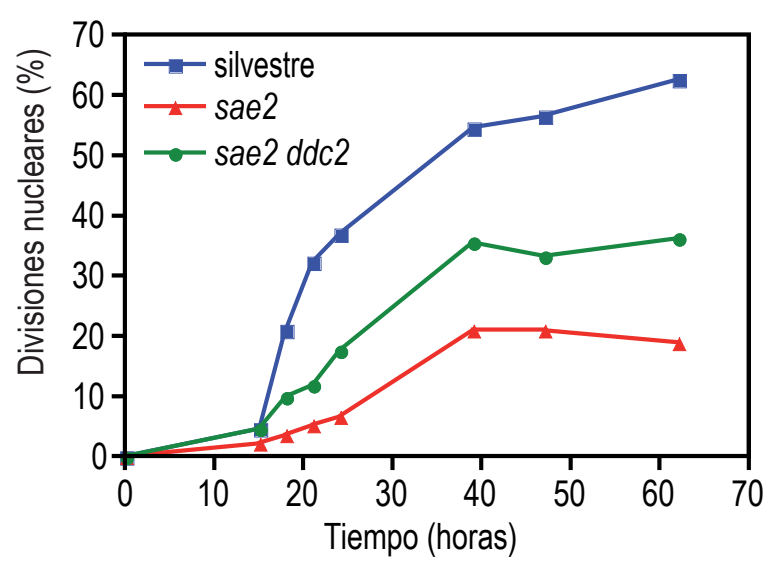

C

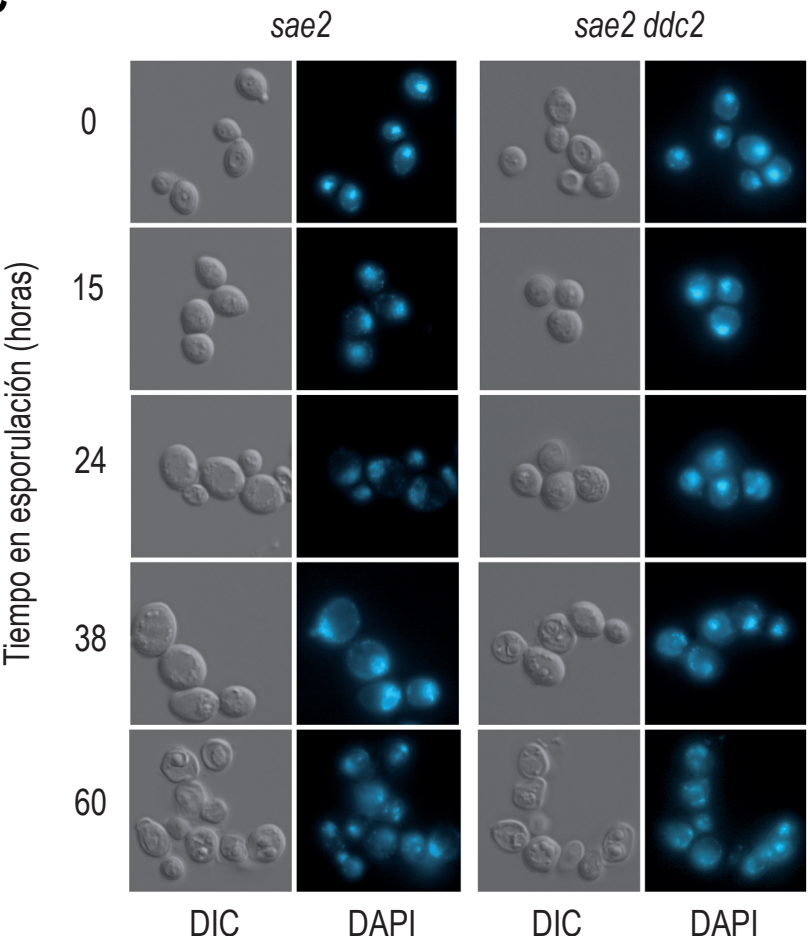

Figura 11. Ddc2 se requiere para el bloqueo meiótico inducido por el checkpoint en el mutante sae2 (A) Se examinaron diferentes eventos meióticos como la fluorescencia de ditirosina, la eficiencia de esporulación y la viabilidad de las esporas después de 3 días de esporulación en placa. (B) Cinética de divisiones nucleares meióticas. Se representa el porcentaje de células con más de dos núcleos. (C) Imágenes representativas de células/ascas (DIC) y morfologías nucleares (DAPI) a diferentes tiempos de la meiosis. Las cepas son BR1919-2N (silvestre), DP485 (sae2) and DP489 (sae2 ddc2). 
sea un componente crucial para el checkpoint de paquitene. Para confirmarlo, usamos la presencia de focos de la proteína Rad51 como marcador de los intermediarios de recombinación meiótica y la tinción de la tubulina para monitorizar la elongación del huso en extensiones de cromosomas meióticos (Lydall et al., 1996; San-Segundo and Roeder, 2000). Como se esperaba, el mutante hop2 presentaba numerosos focos de Rad51 que representan las DSBs sin reparar y el huso no se elongaba debido a que el checkpoint detiene las células en profase impidiendo la entrada en meiosis I (Figura 12A). En la cepa silvestre, los focos de Rad51 sólo están presentes durante profase, cuando se está produciendo la recombinación meiótica, pero no en núcleos en meiosis I o meiosis II identificados por el huso meiótico elongado (Figura 12A). De hecho, en el silvestre, 23 de 25 núcleos en meiosis I examinados, no contenían señal de Rad51, y sólo 2 núcleos presentaban un único foco de Rad51, probablemente inespecífico.

A
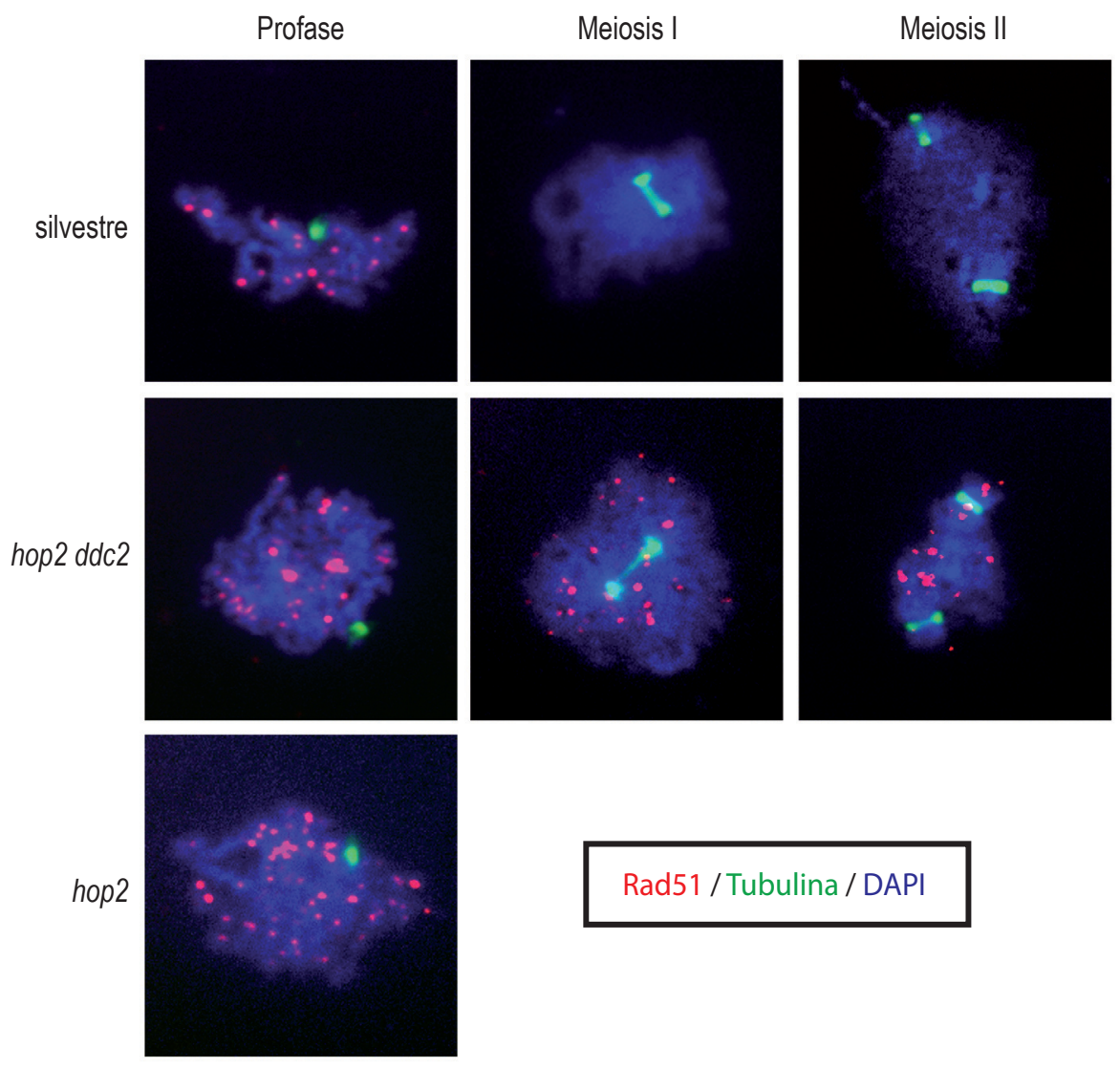

B

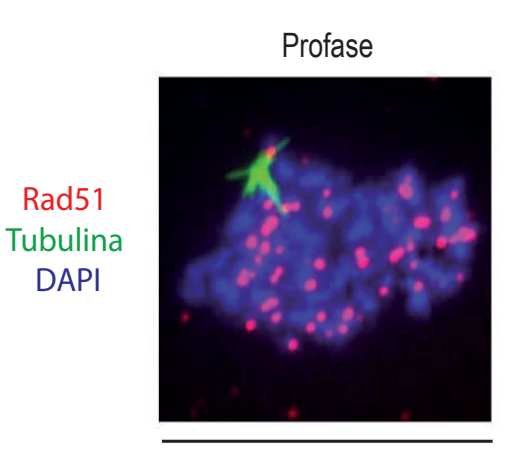

$d m c 1$

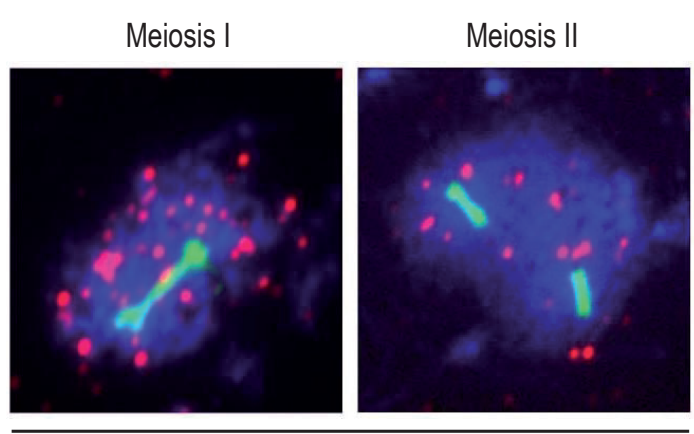

$d m c 1 d d c 2$

Figura 12. Ddc2 impide la segregación cromosómica en presencia de intermediarios de recombinación. (A y B) Extensiones de núcleos meióticos teñidos con DAPI (azul) y anticuerpos anti-Rad51 (rojo) y anti-tubulina (verde). Se muestran imágenes representativas de cada estadío meiótico. Las cepas son BR1919-2N (silvestre), DP471 (hop2), DP472 (hop2 ddc2), DP467 (dmc1) y DP468 (dmc1 ddc2). 
En cambio, el mutante doble hop2 ddc2 llevaba a cabo las segregaciones meióticas a pesar de la presencia de intermediarios de recombinación; así, múltiples focos de Rad51 (18.1 $\pm 5.1, n=28)$ coexistían con los husos meióticos elongados en meiosis I y II (Figura 12A). Estas observaciones no eran exclusivas del mutante hop2 ddc2, puesto que también encontramos el mismo fenotipo, es decir, la presencia de focos de Rad51 junto con los husos alargados, en el doble mutante $d m c 1 d d c 2$ (Figura 12B). Por tanto, Ddc2 se requiere para el checkpoint meiótico que bloquea la segregación cromosómica hasta que la recombinación se haya completado correctamente.

\section{3.- La producción de Ddc2 se induce en la profase meiótica}

Para estudiar la dinámica de la proteína Ddc2 durante la meiosis, el gen DDC2 se marcó en su propio locus genómico con la proteína verde fluorescente (GFP), o con tres copias del epítopo HA. Se comprobó que las proteínas resultantes son funcionales porque las cepas portadoras de estas versiones etiquetadas no eran sensibles a MMS (datos no mostrados), no tenían alterada la parada o retraso meiótico de los mutantes zip1, dmc1, hop2 y sae2 (Figura 13) y tenían altos niveles de viabilidad de las esporas ( $92 \%$ y $96 \%$ para las cepas silvestres DDC2-GFP y DDC2-HA, respectivamente).

A

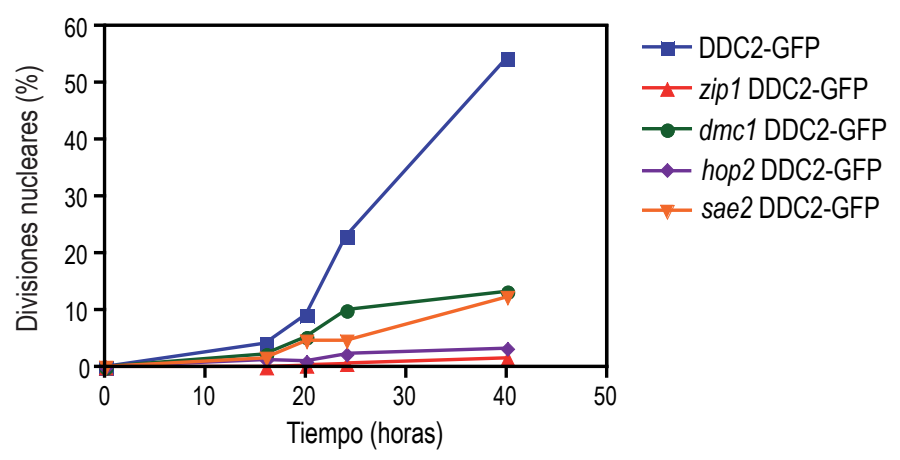

B

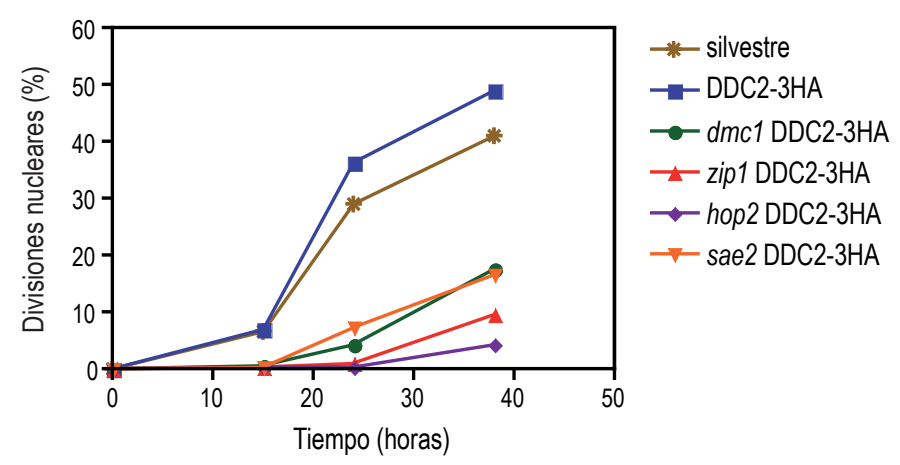

Figura 13. Las versiones de Ddc2 marcadas con los epítopos HA y GFP son completamente funcionales. (A y B) Cinética de las divisiones nucleares meióticas. Se representa el porcentaje de células que contienen más de dos núcleos. Se realizó un contaje de al menos 300 células para cada tiempo representado en la cinética. Las cepas son BR1919-2N (silvestre), DP487 (DDC2-HA), DP490 (zip1 DDC2-HA), DP488 (dmc1 DDC2-HA), DP491 (hop2 DDC2-HA), DP492 (sae2 DDC2-HA), DP448 (DDC2-GFP), DP449 (zip1 DDC2-GFP), DP450 (dmc1 DDC2-GFP), DP480 (hop2 DDC2-GFP) y DP484 (sae2 DDC2-GFP).

La producción de la proteína Ddc2 se analizó mediante western blot en células en crecimiento vegetativo $(\mathrm{t}=0 \mathrm{~h})$ y a diferentes tiempos a largo de la meiosis (Figura 14A, 14B). En la cepa silvestre, se detectó una banda débil de $D d c 2$ en células vegetativas ( $t=0)$; los niveles de Ddc2 se incrementaban en la profase meiótica, y después esta expresión caía gradualmente a medida que 
se iban reparando los intermediarios de recombinación y la meiosis progresaba. Como control, se analizaron en paralelo los niveles de la kinasa específica de meiosis Mek1, que se induce en la profase meiótica (Rockmill and Roeder, 1991). Las proteínas Ddc2 y Mek1 muestran el mismo perfil de expresión (Figura 14A, 14B), excepto que Mek1 es exclusiva de meiosis, mientras que Ddc2 se detecta (aunque a niveles más bajos) en células vegetativas y durante la formación de las esporas, lo cual es consistente con su papel en el checkpoint de daño en DNA en células mitóticas. En contraste con la cepa silvestre, cuando el checkpoint de paquitene se dispara en los mutantes zip1, dmc1, hop2 y sae2, la proteína Ddc2 se acumulaba hasta tiempos tardíos

A

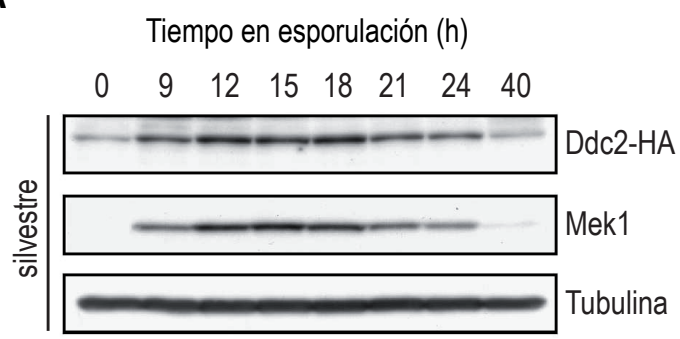

C

Tiempo en esporulación ( $h$ )
B

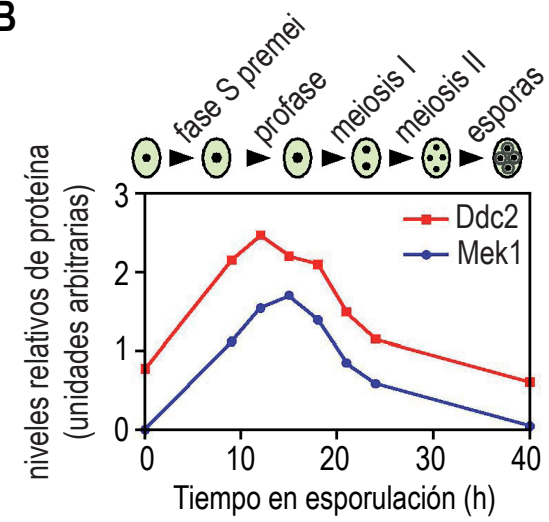

D

Tiempo en esporulación (h)

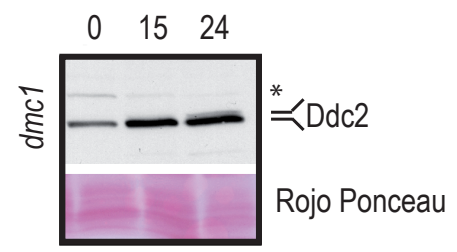

$\mathbf{E}$

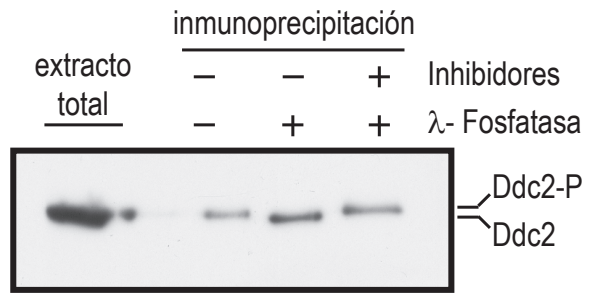

Figura 14. Análisis de la producción y fosforilación de Ddc2. (A) Análisis mediante western blot de Ddc2-HA y Mek1 a lo largo de la meiosis en una cepa silvestre (DP697). Como control de carga se usó la tubulina. (B) Se representa la cuantificación de los niveles relativos de Ddc2 y Mek1 normalizados con la tubulina. Se muestra esquemáticamente la cinética aproximada de los eventos meióticos más importantes en las cepas BR. (C) Ddc2 se acumula en los mutantes bloqueados por el checkpoint. Análisis mediante western blot de Ddc2-HA a lo largo de la meiosis en las cepas silvestre (DP487), zip1 (DP490), dmc1 (DP488), hop2 (DP491) y sae2 (DP492). Se utilizó como control de carga la tinción con Rojo Ponceau. (D) Análisis mediante western blot de Ddc2-GFP durante la meiosis en el mutante dmc1 (DP450) donde se detecta una banda de Ddc2 de menor intensidad y movilidad electroforética. Como control de carga se utilizó la tinción con Rojo Ponceau. El asterisco marca una banda inespecífica. (E) Inmunoprecipitación de Ddc2-GFP en el mutante dmc1 y análisis mediante western blot. Se trató la muestra con la enzima $\lambda$-fosfatasa y con la enzima más inhibidores de fosfatasa. La cepa es el mutante dmc1 (DP450). 
después de que se hubiese inducido la meiosis (Figura 14C). Así, podemos afirmar que la produción de Ddc2 se induce en la profase meiótica y se acumula en mutantes que están bloqueados por el checkpoint.

\section{4.- Fosforilación de Ddc2 durante la meiosis}

En células vegetativas sometidas a daño en el DNA, Ddc2 es fosforilada por la kinasa Mec1 dando lugar a un cambio en la movilidad electroforética (Paciotti et al., 2000). Durante la meiosis, observamos que existía una acumulación significativa de la proteína Ddc2 en mutantes deficientes en la reparación de las DSBs (Figura 14C); sin embargo, a pesar de probar diferentes condiciones electroforéticas, no pudimos detectar de manera reproducible un cambio claro en la movilidad de Ddc2. No obstante, de forma ocasional, éramos capaces de detectar una banda de menor intensidad y de menor movilidad electroforética que podría ser reflejar una forma fosforilada de Ddc2 (Figura 14D; ver también mutante sae2 en Figura 14C).

Para confirmar esta posibilidad, inmunoprecipitamos la proteína Ddc2 de células meióticas del mutante dmc1 y tratamos la muestra con la enzima $\lambda$-fosfatasa. Como se observa en la Figura 14E, el tratamiento con $\lambda$-fosfatasa originó una mayor migración de Ddc2 en el gel. Sin embargo, este aumento de movilidad no ocurrió cuando la misma muestra se trató, además, con inhibidores de fosfatasa. Por tanto, y aunque no éramos capaces de detectar fácilmente las dos formas de la proteína, podíamos afirmar que Ddc2 se fosforila durante la meiosis, al menos en mutantes que activan el checkpoint de recombinación meiótica.

\section{5.- Los sitios consenso de fosforilación por Mec1 no son necesarios para la función de checkpoint de Ddc2}

Ddc2 contiene tres sitios consenso (S/T-Q) de fosforilación por la kinasa Mec1 en las treoninas 29 y 40 y en la serina 636. Para averiguar la relevancia de la fosforilación en estos sitios para la función del checkpoint, mutamos estos sitios a alanina en un plásmido centromérico que contenía el gen DDC2 marcado con el epítopo myc (Rouse and Jackson, 2002), creando el alelo ddc2-3AQ que lleva los siguientes cambios de aminoácidos: T29A, T40A y S636A. Para determinar si la fosforilación de Ddc2 en estos sitios se requiere para el checkpoint de paquitene analizamos la progresión meiótica en el diploide zip1 ddc2 transformado con el vector vacío (pRS316) o con los plásmidos expresando la versión silvestre de $D D C 2$ o la versión mutante $d d c 2-3 A Q$. Como controles adicionales, se analizaron en paralelo la cepa silvestre y el mutante zip1 transformados con el vector vacío. Aunque, debido a fenómenos de pérdida de plásmido en los cultivos, la expresión de $D D C 2$ procedente del plásmido reestablecía sólo parcialmente la parada meiótica del mutante zip1 ddc2 (Figura 15A), la cinética de progresión de la meiosis era indistinguible de la del mutante zip1 $d d c 2$ transformado con el alelo ddc2-3AQ (Figura 15A). Estos resultados indican que la fosforilación de Ddc2 en las posiciones T29, T40 y S636 no es necesaria para su función en el checkpoint de paquitene. Puesto que Ddc2 también participa de forma crucial en la respuesta al daño en el DNA durante el ciclo mitótico, decidimos estudiar si, a diferencia de la meiosis, estos sitios consenso de fosforilación por Mec1 podrían ser importantes para la función de Ddc2 en el checkpoint de daño en DNA en células vegetativas. Para ello, realizamos ensayos de sensibilidad a agentes genotóxicos como el MMS y la luz UV. Como se observa en la Figura 15B, el mutante $d d c 2$ (transformado con vector vacío) mostró sensibilidad a dichos agentes. Sin embargo, el mutante ddc2 transformado con plásmidos portadores de DDC2, DDC2-myc ó 
A

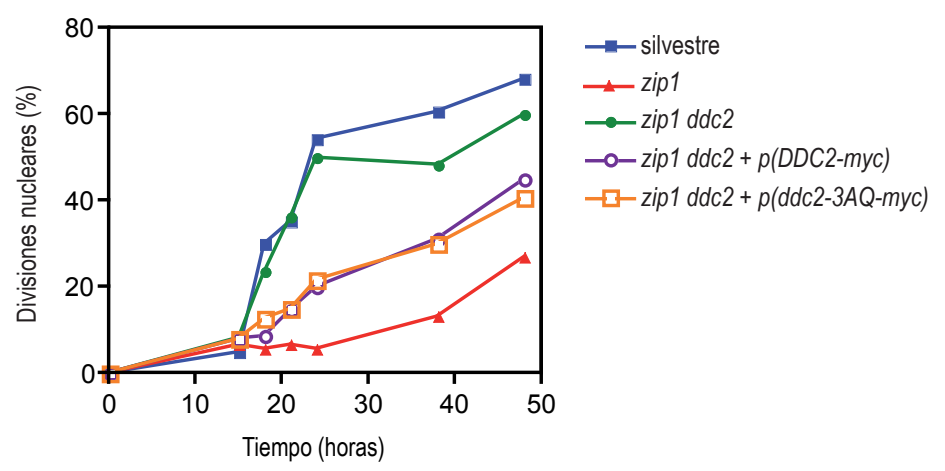

B

YPDA

$0.02 \% \mathrm{MMS}$

40J/m2 UV
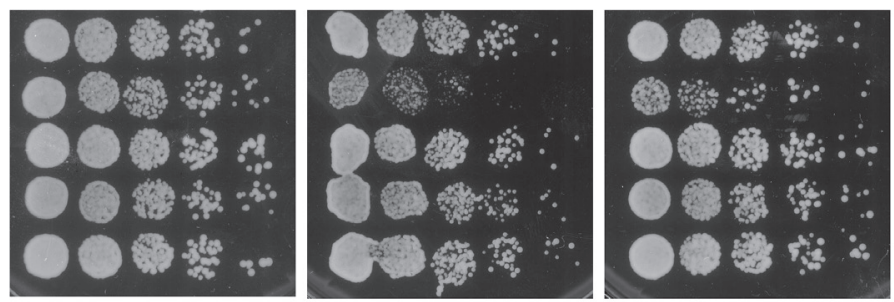

silvestre

$d d c 2 \Delta$

$d d c 2 \Delta+p(D D C 2)$

$d d c 2 \Delta+p(D D C 2-m y c)$

$d d c 2 \Delta+p(D D C 2-3 A Q-m y c)$

$48 \mathrm{~h}$

C

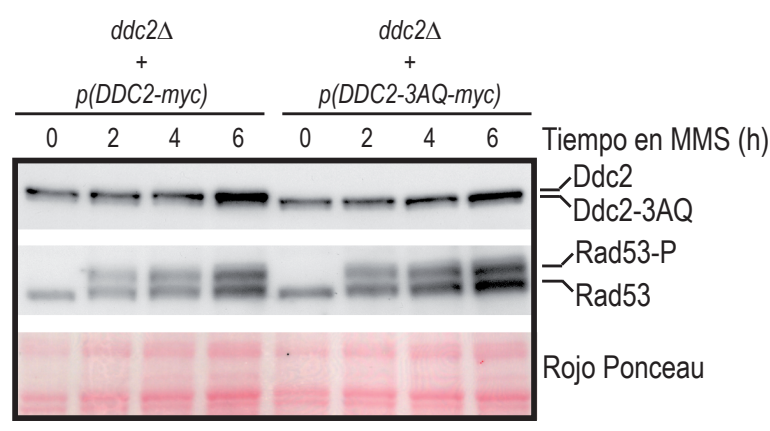

Figura 15. La fosforilación de Ddc2 en los sitios $\mathrm{S} / \mathrm{T}-\mathrm{Q}$ no es necesaria para su función de checkpoint (A) Cinética de las divisiones nucleares meióticas. Se representa el porcentaje de células que contienen más de dos núcleos. Las cepas son DP455 + pRS316

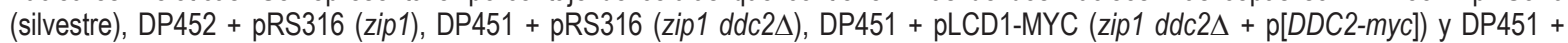
pLCD1-MYC (zip1 ddc2 $\Delta+$ p[ddc2-3AQ-myc]). (B) Diluciones seriadas (1:5) de células creciendo exponencialmente se sembraron sobre una placa control de YPDA, un placa de YPDA con $0,02 \%$ de MMS y una placa de YPDA irradiada con $40 \mathrm{~J} / \mathrm{m}^{2}$ de luz UV. Las placas se incubaron a $30^{\circ} \mathrm{C}$ durante 2 dias. Las cepas son DP471 + pRS316 (silvestre), DP472 + pRS316 (ddc2 $\Delta$ ), DP472 + pLCD1 (ddc2 $\Delta$ $+p[D D C 2]), D P 472+p L C D 1-M Y C(d d c 2 \Delta+p[D D C 2-m y c])$ y DP472 + pSS136 (ddc2 $\Delta+p[d d c 2-3 A Q-m y c])$. Aunque algunas de estas cepas llevan la deleción de HOP2, ésta es irrelevante para los ensayos de sensibilidad al daño en DNA en células vegetativas, porque HOP2 se expresa exclusivamente en meiosis (Leu et al., 1998). (C) Análisis mediante western blot de Ddc2 (marcada con el epítopo myc) y Rad53 en células haploides en crecimiento exponencial tratadas con $0.04 \%$ de MMS. Las cepas son YP1027 (ddc2 + p[DDC2-myc]) y YP1028 (ddc2 $\Delta+\mathrm{p}[d d c 2-3 A Q-m y c])$.

ddc2-3AQ-myc presentaron el mismo nivel de resistencia a MMS y UV, que la cepa silvestre. Por tanto, estos resultados sugerían que, sorprendentemente, estos sitios consenso para la kinasa Mec1 tampoco son necesarios para la función de Ddc2 en respuesta a lesiones en el genoma durante el ciclo vegetativo.

No obstante, quisimos profundizar más en este aspecto y, para ello, examinamos si se estaba produciendo una activación correcta del checkpoint de daño en DNA utilizando la fosforilación de la kinasa efectora Rad53 como marcador de dicha activación. Células creciendo exponencialmente del mutante $d d c 2$ transformado con el plásmido que lleva la versión silvestre de DDC2-myc o con el plásmido que lleva el alelo ddc2-3QA-myc se 
trataron con MMS al $0.4 \%$ y se tomaron muestras a diferentes tiempos que se analizaron mediante western blot. En ambas cepas se produjo una activación de la proteína Rad53 inducida por MMS que se manifiesta por un retraso en la movilidad electroforética (Figura 15C). Por tanto, este resultado confirma que la fosforilación de Ddc2 en los sitios consenso por Mec1 no es necesaria para la activación del checkpoint de daño en el DNA.

\section{6.- Ddc2 se localiza en los cromosomas meióticos y se acumula en mutantes bloqueados por el checkpoint de paquitene}

Para investigar más acerca del papel que tiene Ddc2 en la meiosis, se examinó la localización de la proteína mediante inmunofluorescencia indirecta en extensiones de cromosomas meióticos de cepas DDC2-GFP o DDC2-HA usando anticuerpos anti-GFP o anti-HA, respectivamente. Además, se emplearon anticuerpos que reconocen la proteína Zip1 (componente de la región central del SC) que nos permite identificar las diferentes fases de la profase meiótica y, en este caso, diferenciar si los núcleos están en zigotene (Zip1 aparece punteado y parcialmente lineal) o en paquitene (Zip1 aparece completamente lineal indicando que se ha completado la sinapsis de los homólogos). Como se observa en la Figura 16 en las extensiones cromosómicas de la cepa silvestre se observó un gran número de focos de Ddc2 en el estadío de zigotene, que es cuando está ocurriendo la recombinación meiótica, mientras que el número de focos disminuía o incluso, en algunos casos, estos desaparecían en paquitene, cuando la mayoría de las DSBs ya han sido reparadas. Por el contrario, en mutantes deficientes en la reparación de las DSBs, como hop2y dmc1, los focos de Ddc2 se acumulan durante toda la profase meiótica (Figuras 16 y 17), lo que sugiere que Ddc2 se localiza en los lugares donde tiene lugar la recombinación.

Para confirmar esta posibilidad realizamos una doble tinción para Ddc2 y Rad51 en extensiones de cromosomas meióticos puesto que, como se comentó anteriormente, Rad51 marca la presencia de intermediarios de recombinación sin reparar. Como se presenta en la Figura 18 existe una colocalización parcial de ambas proteínas en los mutantes hop2 y dmc1, que acumulan DSBs sin reparar, que se manifiesta como focos amarillos en la imagen resultante de la fusión de Ddc2-HA y Rad51 (Figura 18A y 18B; paneles superiores). No obstante, esta colocalización parcial es significativa $(P<0,001)$, puesto que es mucho más elevada que la colocalización fortuita que resulta de la superposición de las imágenes al azar girando una de ellas $180^{\circ}$ (Figura 18Ay 18B; paneles inferiores). Además, se observó que existía una variabilidad acusada en la intensidad relativa de los focos de Rad51 y Ddc2.

\section{7.- Localización in vivo de Ddc2 durante la meiosis}

Para estudiar in vivo la dinámica meiótica de la localización de Ddc2 utilizamos las diferentes cepas (silvestre y mutantes sae2, dmc1, hop2 y zip1) portadoras de la versión funcional de la proteína Ddc2 marcada con GFP. A partir de cultivos en esporulación de todas estas cepas se tomaron muestras a lo largo del tiempo y se examinaron mediante microscopía de fluorescencia. Tanto en la cepa silvestre como en los mutantes meióticos, existía una pequeña proporción de células que presentaban focos de Ddc2 a tiempo cero (Figura 19), probablemente debidos al daño espontáneo que se genera durante el crecimiento mitótico previo a la inducción de la meiosis. En el silvestre, el número de células con señal de Ddc2-GFP aumentaba a medida que las células entraban en meiosis, alcanzando niveles máximos que coincidían con el intervalo en que la mayoría de células del cultivo se encuentran en profase (Figura 19A); después, la fracción de células con focos disminuía a medida que los intermediarios de recombinación van reparándose, las divisiones meióticas 


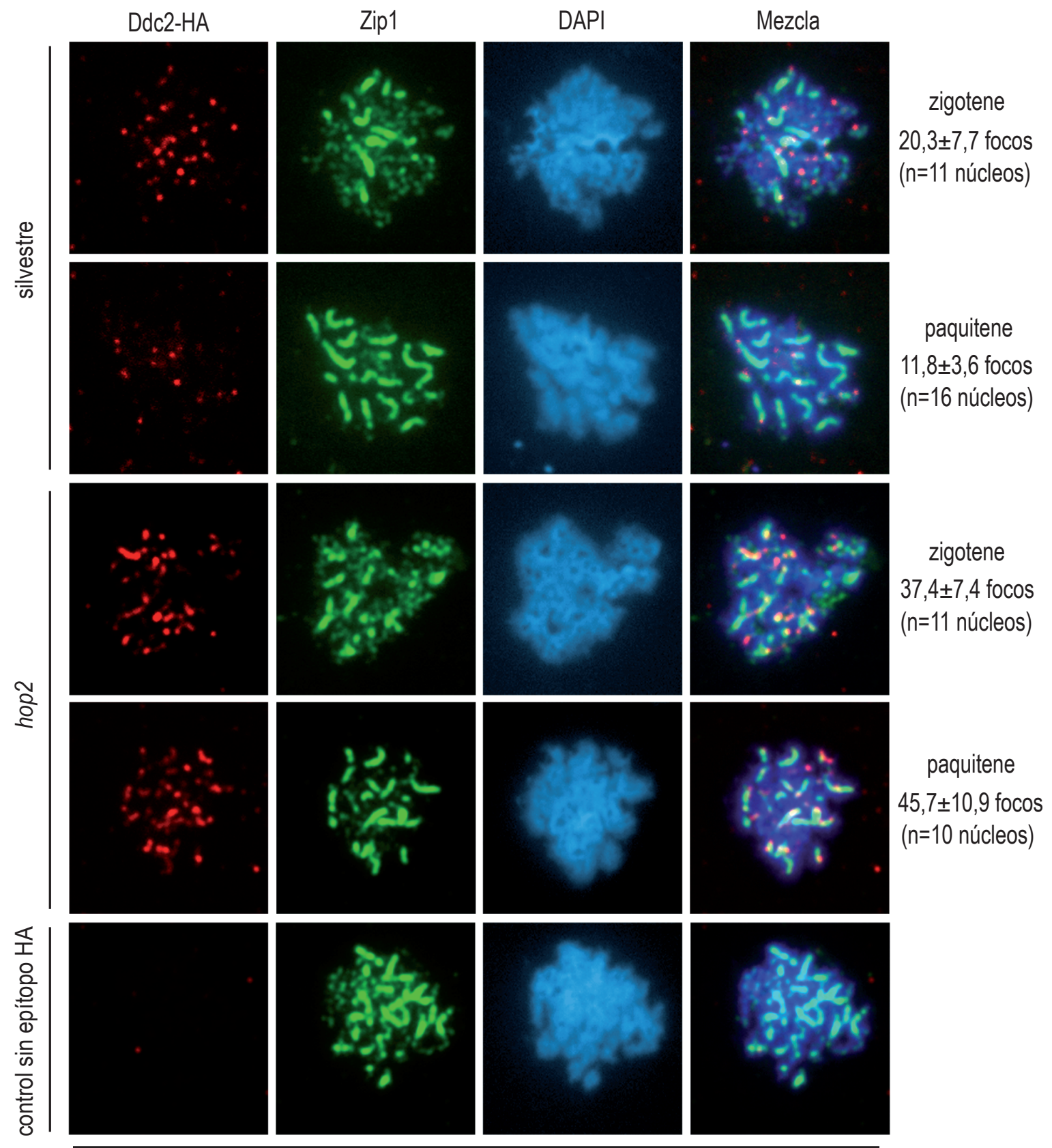

15 horas en meiosis

Figura 16. Localización de Ddc2 en cromosomas meióticos. Inmunofluorescencia de extensiones de núcleos meióticos teñidos con DAPI (azul), y anticuerpos anti-HA (rojo) y anti-Zip1 (verde). Se muestran núcleos representativos de zigotene y paquitene basados en la tinción con Zip1. La cuantificación del número de focos de Ddc2 se presenta a la derecha. Las cepas son DP487 (silvestre), DP491 (hop2), ambas portadoras de DDC2-HA, y DP471 (control sin epítopo). Las extensiones se prepararon a las $15 \mathrm{~h}$ después de la inducción meiótica.

se completan y se forman las esporas. Por el contrario, en los mutantes que disparan el checkpoint de recombinación meiótica (sae2, hop2, zip1 y dmc1) la fracción de células con señal de Ddc2-GFP alcanzaba niveles más elevados que, además, se mantenían hasta tiempos tardíos de meiosis (Figuras 19A y 19B).

El examen detallado de la localización de Ddc2-GFP reveló diferentes patrones de focos de Ddc2GFP en células meióticas (Figura 20). A tiempo cero, es decir, antes de entrar en meiosis, la mayoría de las células con señal de Ddc2-GFP exhibían un solo foco brillante, similar a los que se forman de modo espontáneo durante la fase $S$ o en respuesta al daño en el DNA en células vegetativas (Lisby et al., 2004). Sin embargo, cuando las células entraban en el programa meiótico, se observaba otro patrón de localización de Ddc2-GFP 
control sin epítopo
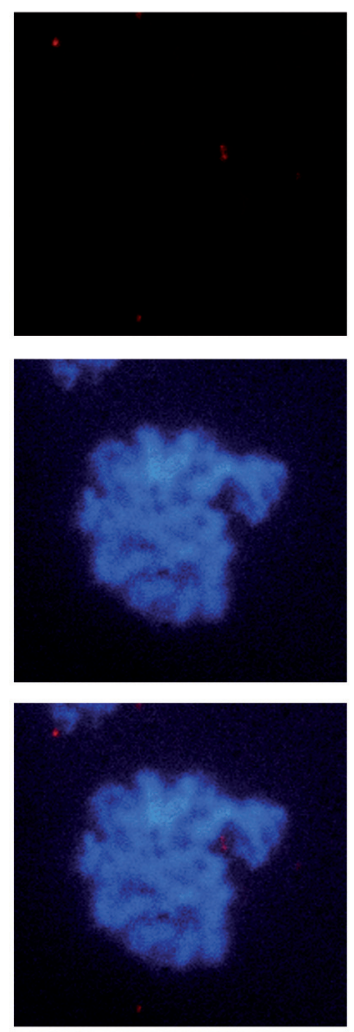

DDC2-GFP

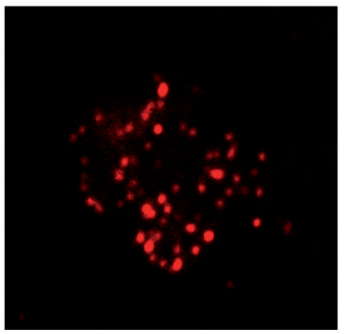

anti-GFP

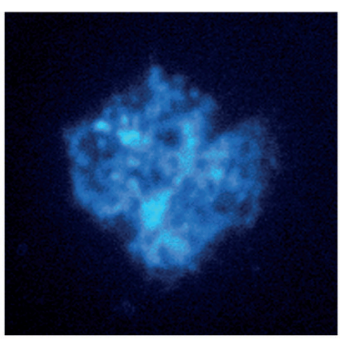

DAPI

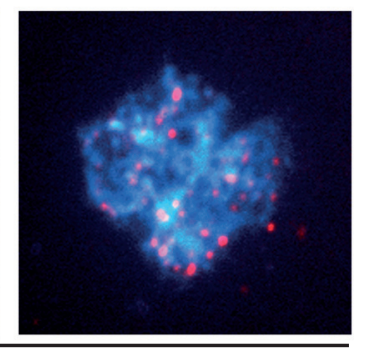

Mezcla

dmc1

Figura 17. Ddc2 localiza en forma de focos múltiples en los cromosomas del mutante dmc1. Inmunofluorescencia de las extensiones nucleares meióticas teñidas con DAPI (azul) y anticuerpo anti-GFP (rojo). Las cepas son DP456 (dmc1; control sin epítopo) y DP608 (dmc1 DDC2-GFP). Las extensiones se prepararon después de 15h en medio de esporulación.

que consistía en pequeños focos múltiples que a menudo se organizaban en estructuras con forma de hilera o de anillo. Cabe destacar que, mientras que en la cepa silvestre esta organización de los focos de Ddc2 disminuía a medida que la meiosis progresaba, en el mutante zip1 se acumulaba un considerable fracción de células con múltiples focos de Ddc2 a tiempos tardíos y, en el caso de los mutantes dmc1, hop2 o sae2, la mayoría de las células presentaban numerosos focos de Ddc2 a tiempos finales de la meiosis (Figura 20).

En resumen, estas observaciones sugieren que los focos de Ddc2 individuales presentes en todas las cepas a tiempos tempranos de meiosis probablemente representen daño espontáneo que ha tenido lugar durante el crecimiento vegetativo previo a la meiosis y/o durante la replicación premeiótica del DNA. Por el contrario, los focos múltiples presentes de forma transitoria en el silvestre y que se acumulan en los mutantes, reflejarían la presencia de Ddc2 en los lugares donde están las DSBs meióticas sin reparar. Para explorar esta posibilidad, examinamos la señal de Ddc2-GFP en ausencia de recombinación meiótica, en concreto, en mutantes spo11 y spo11 dmc1 en los que no se generan DSBs meióticas (Keeney, 2001). En el mutante spo11, los focos múltiples de Ddc2 desaparecían y la señal de Ddc2-GFP se detectaba únicamente como focos sencillos. Además, la acumulación de células que presentaban numerosos focos de Ddc2 a tiempos tardíos en dmc1 desaparecía en el doble mutante spo11 dmc1 (Figuras 19B y 20). Así, estas observaciones indican que el patrón de localización de Ddc2 en forma de focos múltiples es específico de las DSBs meióticas involucradas en el proceso de recombinación. 
A

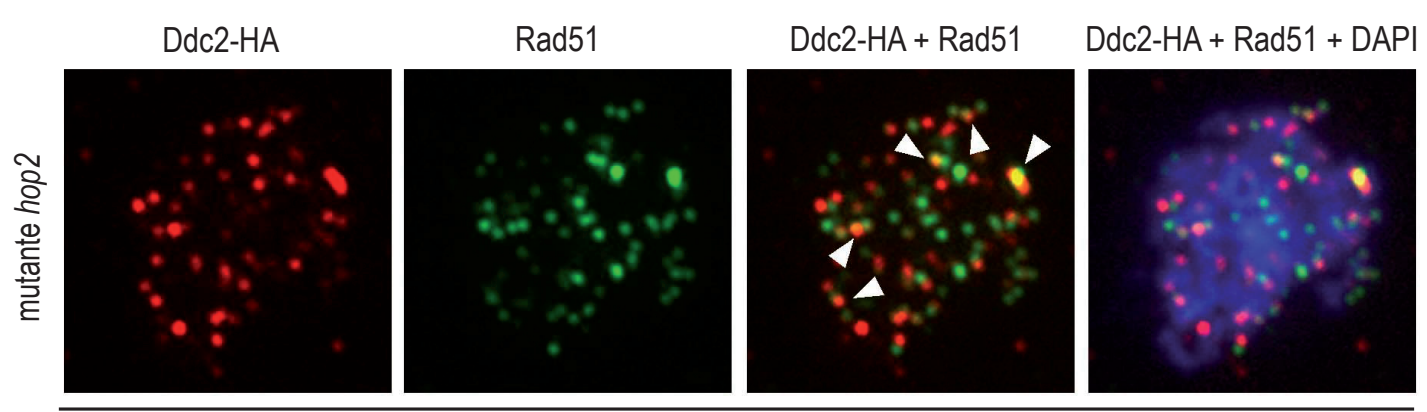

19 horas en meiosis

focos de Ddc2 que contienen Rad51

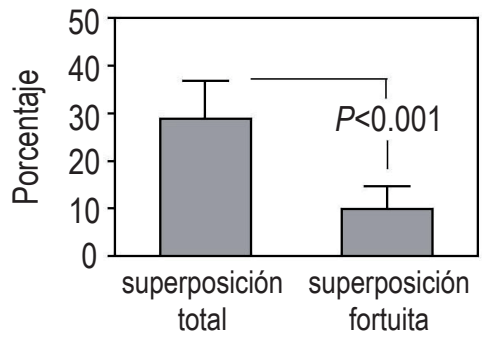

focos de Rad51 que contienen Ddc2

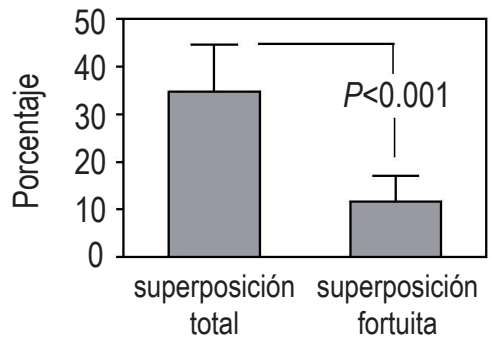

B

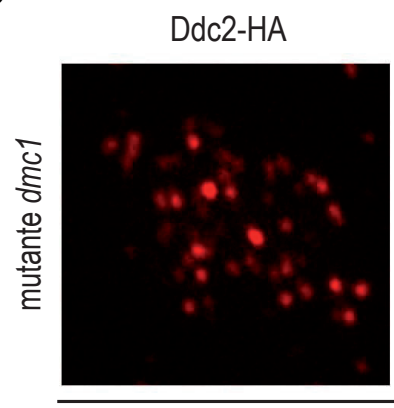

$\operatorname{Rad51}$

Ddc2-HA + Rad51

$\mathrm{Ddc2}-\mathrm{HA}+\mathrm{Rad} 51+\mathrm{DAPI}$
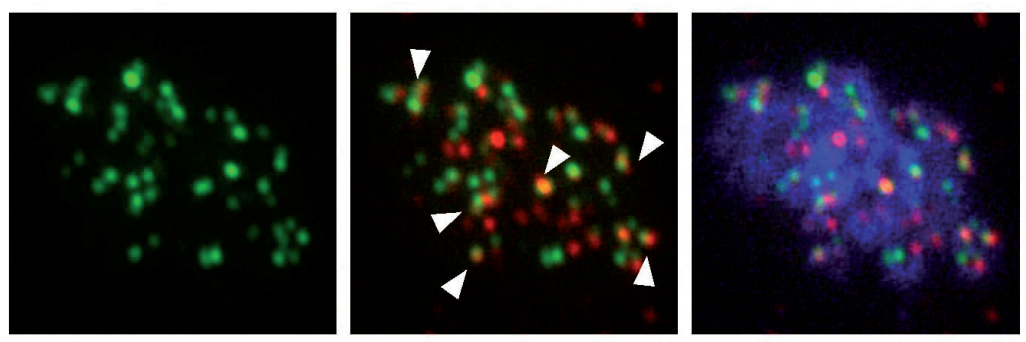

24 horas en meiosis

focos de Ddc2 que contienen Rad51

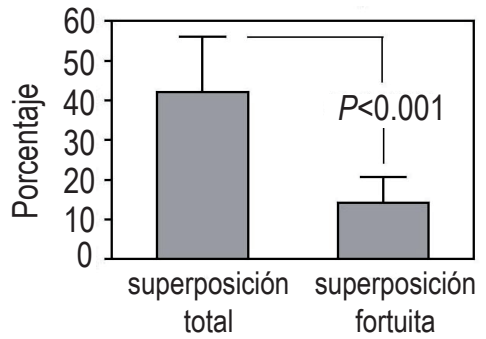

focos de Rad51 que contienen Ddc2

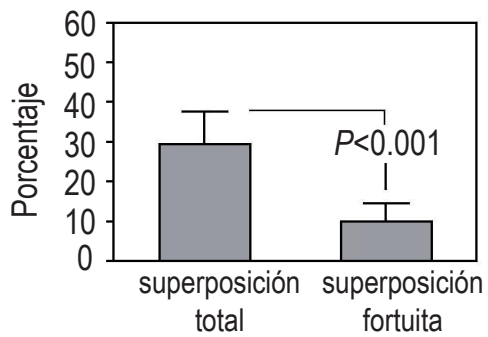

Figura 18. Ddc2 colocaliza parcialmente con Rad51. Las extensiones de los cromosomas corresponden al mutante hop2 (A) y al mutante dmc1 (B) portadores de DDC2-HA (DP491 y DP488, respectivamente), preparadas después de 20-24h en meiosis, teñidas con DAPI (azul) y anticuerpos anti-HA (rojo) y anti-Rad51 (verde). Las flechas señalan algunos de los focos de Ddc2-HA y Rad51 que se solapan, los cuales aparecen en amarillo. No obstante, el amarillo está infrarepresentado en las imágenes debido a las diferentes intensidades de los focos de Ddc2-HA y Rad51. Se muestra la cuantificación de la colocalización entre los focos de Ddc2 y Rad51. La colocalización fortuita se calculó rotando $180^{\circ}$ la imagen de Ddc2-HA ó Rad51, como se ha descrito en Gasior et al., 1998. Se realizó un contaje de 20 núcleos para cada cepa. Las barras de error representan las desviaciones éstandar. Se muestran los valores $P$ de las comparaciones estadísticas. 
A

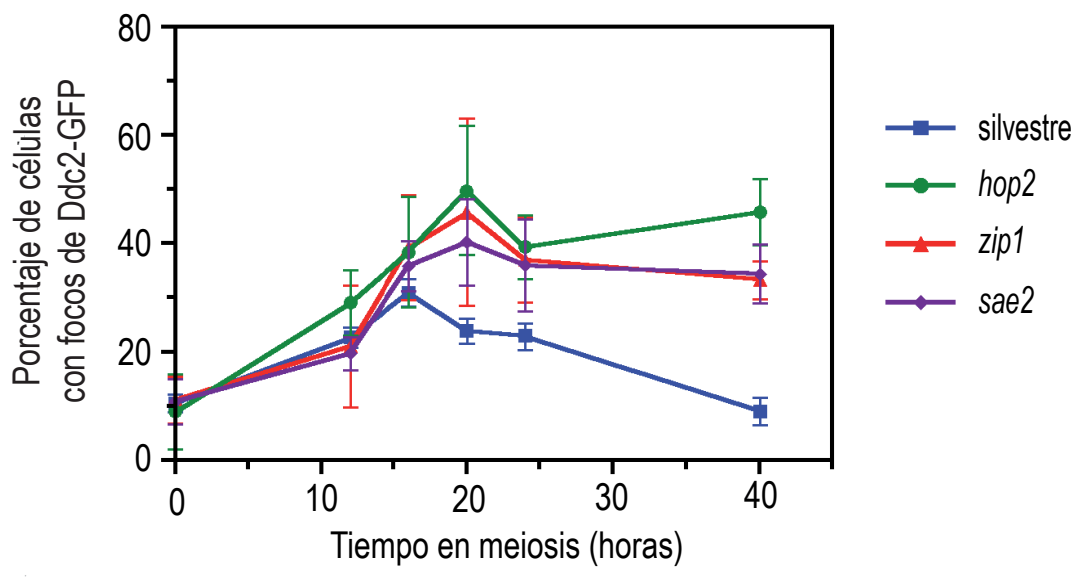

B

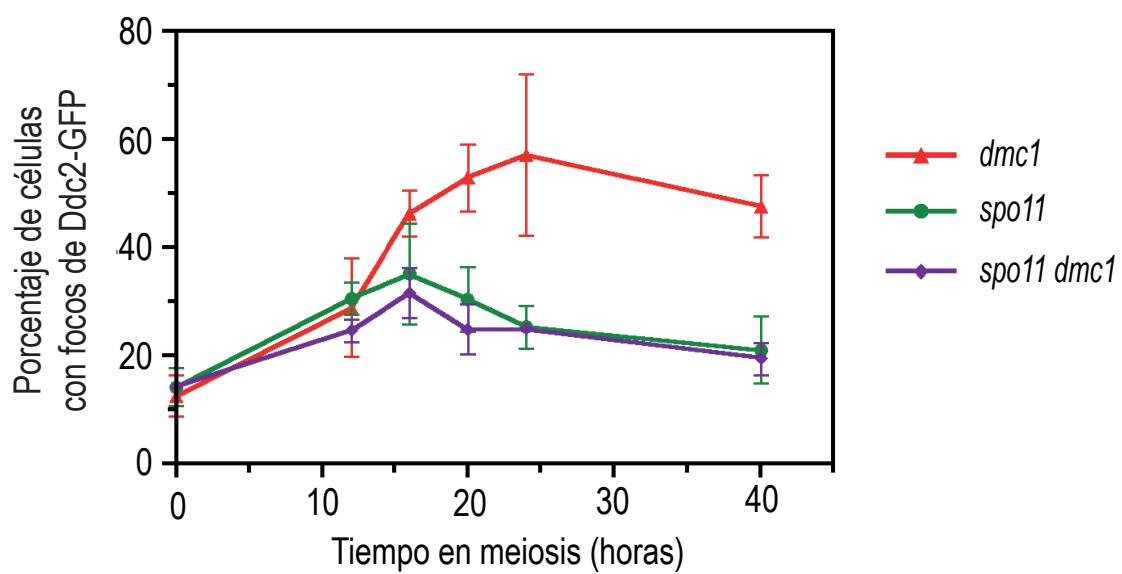

Figura 19. Análisis de la localización de Ddc2-GFP en células meióticas vivas. (A y B) Se representa el porcentaje de células que contienen señal de Ddc2-GFP a diferentes tiempos de meiosis. Se representan los valores de la media y desviación estándar de 2 a 6 experimentos. Se realizó un contaje de entre 150-500 células para cada cepa y cada tiempo en cada experimento. Las cepas son DP448 (silvestre), DP480 (hop2), DP449 (zip1), DP484 (sae2), DP450 (dmc1), DP465 (spo11) y DP469 (spo11 dmc1).

\section{8.- La localización de Ddc2 en meiosis depende de RPA}

En células vegetativas, el reclutamiento de Ddc2 a las DSBs depende de RPA, un complejo heterotrimérico (Rfa1-Rfa2-Rfa3) que se une a regiones de ssDNA y que participa en múltiples aspectos del metabolismo de los cromosomas (Sakaguchi et al., 2009). Puesto que el complejo RPA es esencial para la célula, para investigar su posible papel en la localización meiótica de Ddc2, empleamos el alelo hipomórfico rfa1-t11 que mantiene la función esencial de RPA en replicación pero es defectivo es la respuesta al daño en el DNA, al menos en células mitóticas (Zou and Elledge, 2003). Cuando analizamos la localización de Ddc2GFP durante la meiosis en células vivas observamos que mientras que el mutante dmc1 presentaba el patrón característico de acumulación de focos múltiples de Ddc2 descrito anteriormente, en el doble mutante dmc1 rfa1-t11 la cantidad de focos de Ddc2 se reducía drásticamente y la intensidad de los mismos era muy débil (Figura 21A). Esta localización imperfecta de Ddc2 originaba una respuesta defectiva del checkpoint porque la mutación rfa1-t11 confería una supresión parcial del retraso meiótico que tiene el mutante dmc1 (Figura 21B). Además, para corroborar que la reducida localización de Ddc2 cuando la función de RPA está alterada da lugar a una respuesta defectiva del checkpoint analizamos marcadores moleculares de la activación del 


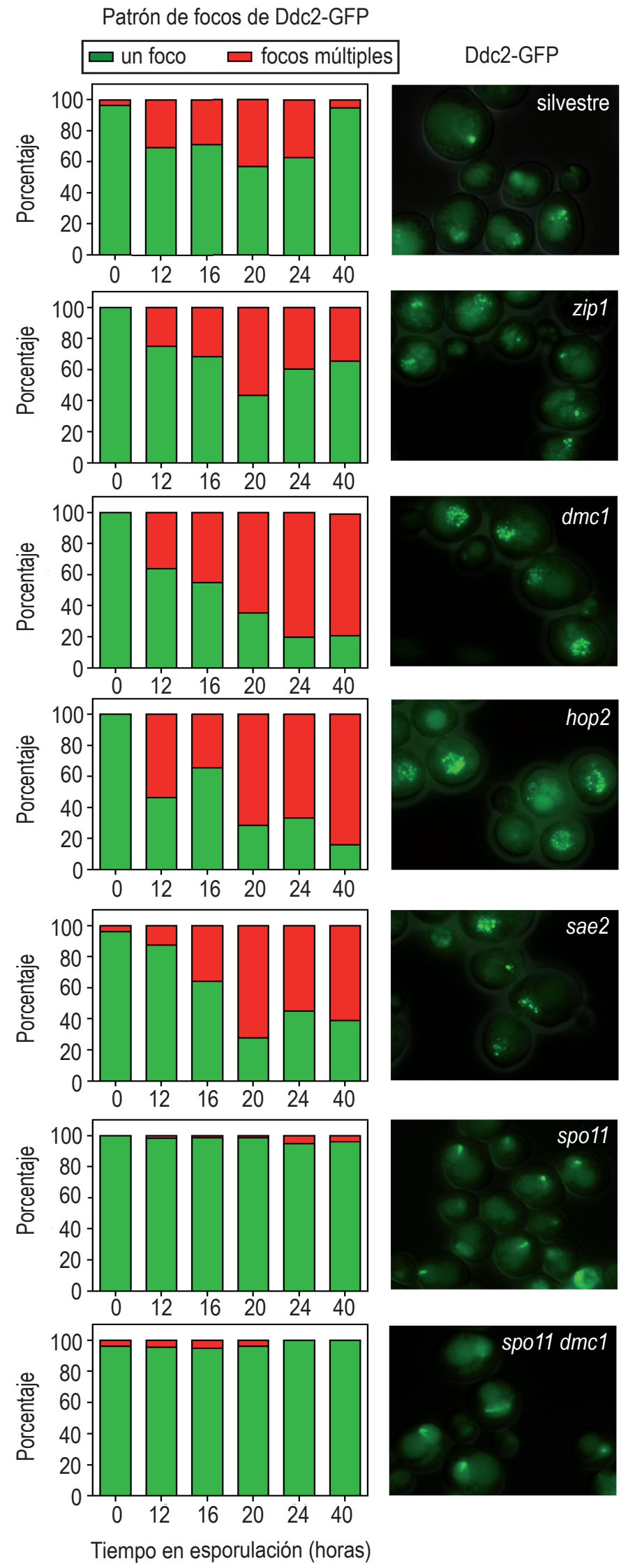

Figura 20. Ddc2 se localiza en forma de focos múltiples en mutantes que acumulan intermediarios de recombinación. Se realizó un recuento del patrón de localización de Ddc2-GFP a lo largo de la meiosis (un solo foco o focos múltiples, como está indicado) en células que tenían señal de Ddc2-GFP. Las gráficas (paneles de la izquierda) representan el porcentaje de cada patrón de localización. También se muestran imágenes representativas de cada cepa (paneles de la derecha). Las cepas utilizadas son las mismas que en la Figura 19. 
checkpoint de paquitene, como la fosforilación de la kinasa efectora Mek1 (Bailis and Roeder, 2000) y la inhibición de la producción de la kinasa polo Cdc5 que es una diana terminal de la ruta. Así, observamos que la fuerte activación de Mek1 que ocurre en dmc1 estaba muy atenuada en el doble mutante dmc1 rfa1-t11 que, además, presentaba una inducción de Cdc5 que marca la salida de profase (Figura 21C), de acuerdo con la supresión parcial del retraso meiótico del mutante dmc1 (Figura 21B). Por tanto, es necesario que el complejo RPA sea funcional para que Ddc2 realice de forma correcta su papel en el checkpoint de recombinación meiótica.

A

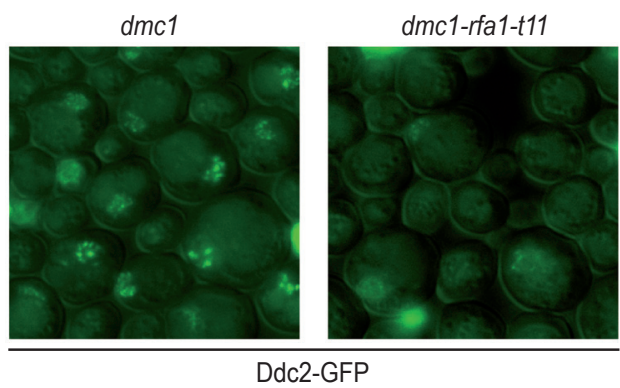

B

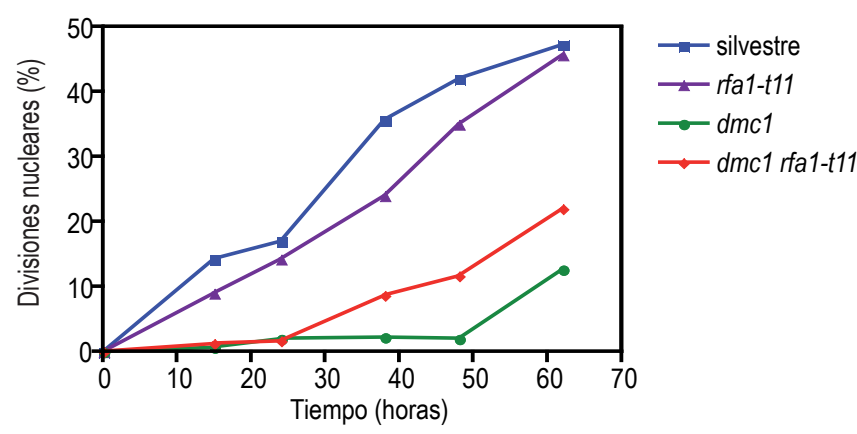

C
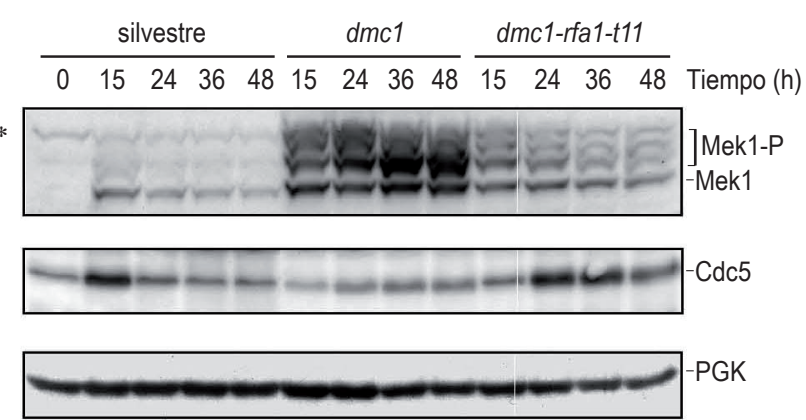

Figura 21. La función de RPA es necesaria para la formación eficiente de focos meióticos de Ddc2 y para el checkpoint meiótico. (A) Imágenes representativas la localización de Ddc2-GFP en células vivas de los mutantes dmc1 y dmc1 rfa1-t11 a las $24 \mathrm{~h}$ de meiosis. (B) Análisis de la cinética de las divisiones nucleares meióticas. Se representa el porcentaje de células que contienen más de dos núcleos. (C) Análisis de Mek1 y Cdc5 mediante western blot. Como control de carga se utilizó PGK. El gel de Mek1 contenía Phos-tag para resolver las bandas de fosforilación. El asterisco marca una banda inespecífica. Las cepas son DP433 (silvestre), DP506 (rfa1-t11), DP434 (dmc1) y DP505 (dmc1 rfa1-t11).

\section{9.- Ddc2 se acumula en DSBs meióticas sin reparar}

Los estudios de la localización meiótica de la proteína Ddc2 tanto en extensiones de cromosomas como en células vivas son consistentes con que Ddc2 esté actuando como un sensor de los intermediarios de recombinación meióticos. Para confirmar esto, analizamos mediante inmunoprecipitación de cromatina (ChIP) la unión de Ddc2-HA a dos sitios calientes (hotspots) de DSBs meióticas (BUD23 y ERG1). Como 
control de referencia, se utilizó la región del DNA ribosomal ( $\mathrm{rDNA})$, donde no se producen DSBs meióticas.

Se analizaron por ChIP la cepa silvestre y el mutante dmc1 antes de que las células entraran en meiosis ( $t=0)$ y a las 24 horas de meiosis, cuando los focos de Ddc2 se acumulan en dmc1. En la cepa silvestre, sólo se produce un leve enriquecimiento meiótico de Ddc2 en los hotspots, de acuerdo con el hecho de que las DSBs sin reparar son transitorias en una meiosis normal. Por el contrario, en el mutante dmc1 se observó un enriquecimiento relativo (aproximadamente 3 veces) de Ddc2 en ambos hotspots a las $24 \mathrm{~h}$ de meiosis (Figura 22A). Para comprobar que la unión de Ddc2 a los sitios de recombinación depende

A
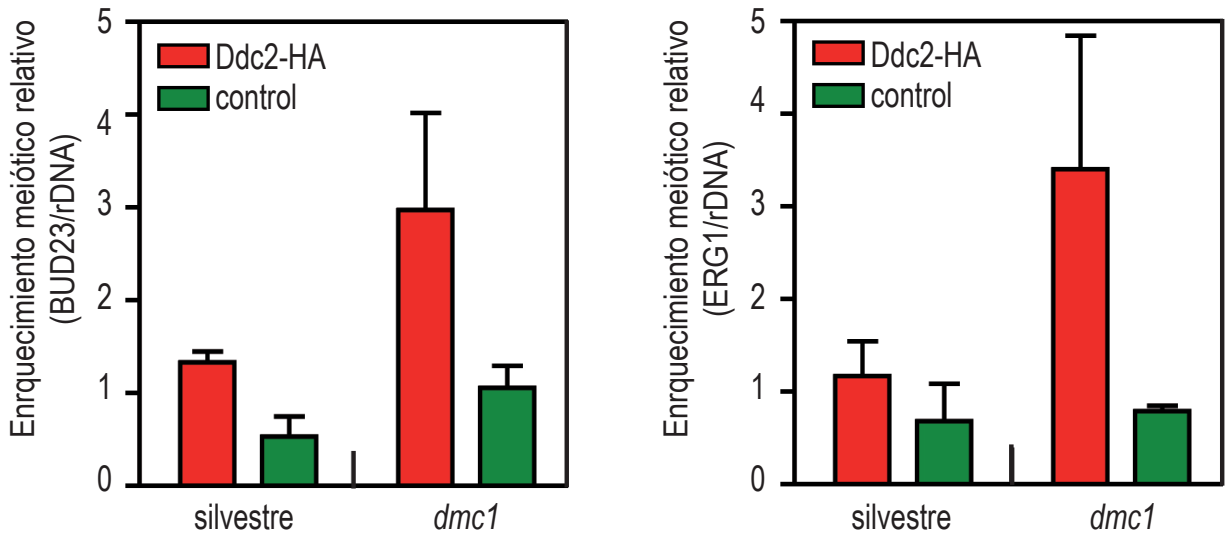

B
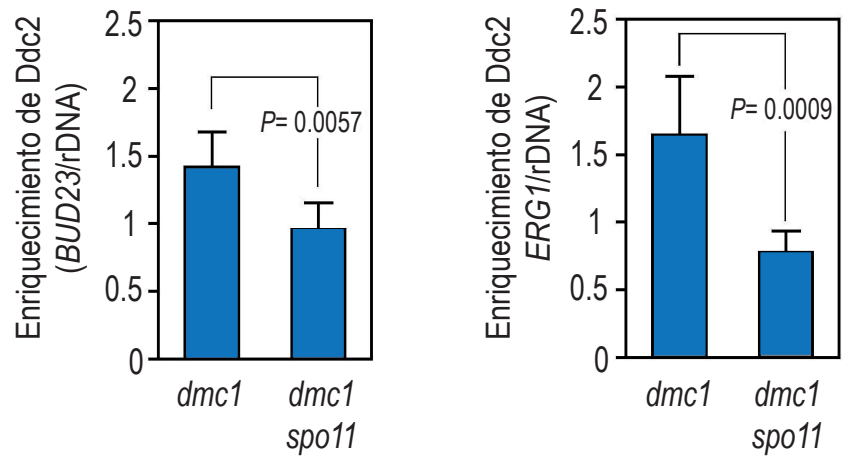

Figura 22. Ddc2 se une a los sitios de recombinación meiótica. (A) Análisis por ChIP del reclutamiento de Ddc2 a los hotspots de DSBs BUD23 y ERG1 en las cepas silvestre (DP487) y dmc1 (DP488) que expresan DDC2-HA, utilizando anticuerpos anti-HA. Se analizaron por PCR cuantitativa el DNA del extracto total y del inmunoprecipitado procedentes de muestras recogidas a las oh y $24 \mathrm{~h}$ de meiosis. Se utilizaron parejas de oligonucleótidos que estaban localizados en el hotspot y en el rDNA, que se usó como control de una región cromosómica sin DSBs meióticas. Se calculó el enriquecimiento de Ddc2 en cada hotspot como se describe en Materiales y Métodos. Se representa el enriquecimiento de la unión de Ddc2-HA a las DSBs durante la meiosis ( $\mathrm{t}=24 \mathrm{~h}$ ) relativo a la unión en células vegetativas $(t=0)$. El control representa inmunoprecipitaciones paralelas de los mismos extractos totales de cromatina, pero utilizando anticuerpos antimyc. Se representan las medias y las desviaciones estándar de tres experimentos independientes. (B) Análisis por ChIP del reclutamiento de Ddc2-HA en los hotspots BUD23 y ERG1 relativo al rDNA en células dmc1 (DP693) y dmc1 spo11 (DP695) a las 24h de meiosis. Hay que mencionar que las cepas son también ndt80 para que se produzca la parada de la progresión meiótica en profase. Se muestran las medias, las desviaciones estándar y los valores $P$ de las comparaciones estadísticas de seis experimentos independientes.

de la generación de DSBs meióticas se llevaron a cabo análisis de ChIP en el mutante spo11. Como se observa en las Figura 22B el enriquecimiento de Ddc2 fue significativamente menor $(P<0,01)$ en ausencia de Spo11, lo que indica que Ddc2 se recluta en los lugares donde tiene lugar la recombinación meiótica.

Para verificar que cuando Ddc2 se une a las DSBs meióticas sin reparar actúa como sensor del checkpoint de paquitene, monitorizamos los procesos que tienen lugar más abajo en la ruta del checkpoint. Como 
se muestra en la Figura 23, la hiperfosforilación de Mek1 que se induce en el mutante dmc1 fue completamente eliminada en ausencia de Ddc2, a pesar de la presencia de DSBs sin reparar (Figura 12B). Como control, la deleción de SP011 también daba lugar a la ausencia de activación de Mek1, en este caso porque no se forman DSBs. Además, el mutante $d m c 1$ ddc2 también era defectivo en la señalización a dianas finales del checkpoint, como la inhibición de la producción de Cdc5 dependiente del factor de transcripción Ndt80. Mientras que en dmc1 se producia un retraso en la inducción de Cdc5, de acuerdo con la lenta progresión de la meiosis que presenta, el mutante $d m c 1 d d c 2$ presentaba la misma cinética en la inducción de Cdc5 que el silvestre o el mutante dmc1 spo11.

Horas en esporulación
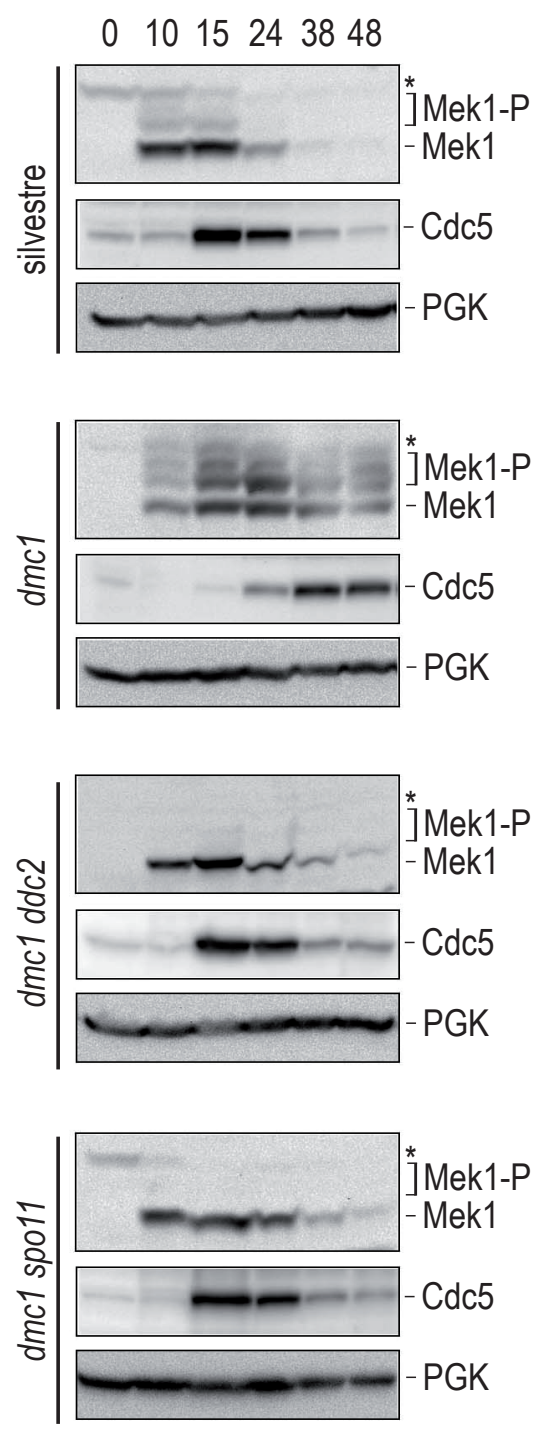

Figura 23. La activación del checkpoint de recombinación meiótica en el mutante dmc1 requiere Ddc2. Análisis mediante western blot de la fosforilación de Mek1 y la producción de Cdc5 como marcadores moleculares de la activación del checkpoint. Como control de carga se usó PGK. El gel de Mek1 contenía Phos-tag para resolver las bandas de fosforilación. El asterisco marca una banda inespecífica. Las cepas son DP455 (silvestre), DP467 (dmc1), DP468 (dmc1 ddc2) y DP466 (dmc1 spo11).

Para descartar que las diferencias observadas en el estudio de los marcadores moleculares de activación del checkpointfueran debidas a las diferentes cinéticas de progresión dela meiosis (por ejemplo, ddc2dmc1 progresa normalmente mientras que $d m c 1$ presenta un retraso en las divisiones meióticas), llevamos a cabo el análisis de la hiperfosforilación de Mek1 en condiciones en las que la meiosis se bloquea en profase independientemente del 
checkpoint, como ocurre en el mutante ndt80 (Xu et al., 1995; Hepworth et al., 1998). En este caso, utilizamos el mutante zip 1 para inducir el checkpoint de paquitene. Como se observa en la Figura 24A, en el mutante ndt80 zip1 se producía una fuerte activación del checkpoint de recombinación meiótica que se manifiesta por las presencia de múltiples formas de fosforilación de Mek1. En cambio, esta hiperfosforilación desaparecía tanto en el mutante ndt80 zip1 ddc2 como en el ndt80 zip1 mec1, carente del otro componente del complejo Mec1/Ddc2. Este resultado demuestra que Mec1 y Ddc2 son necesarias para la correcta activación del checkpoint de recombinación meiótica.

A

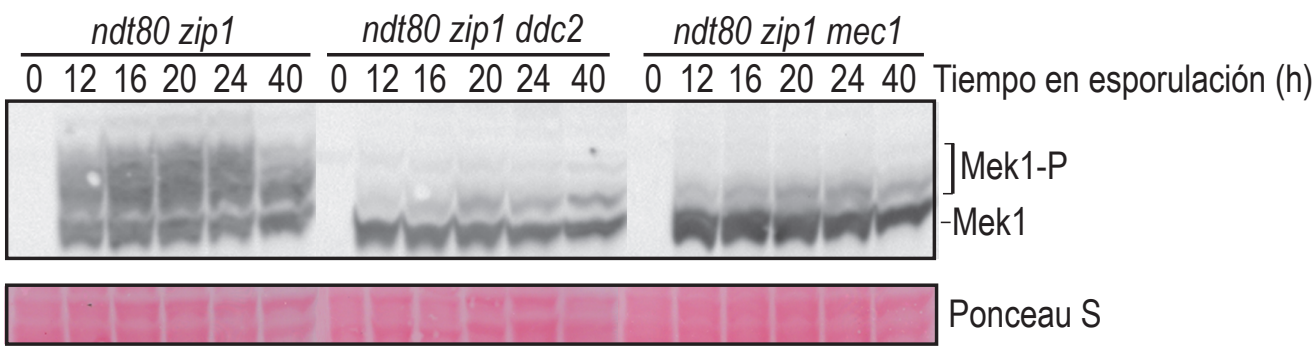

B

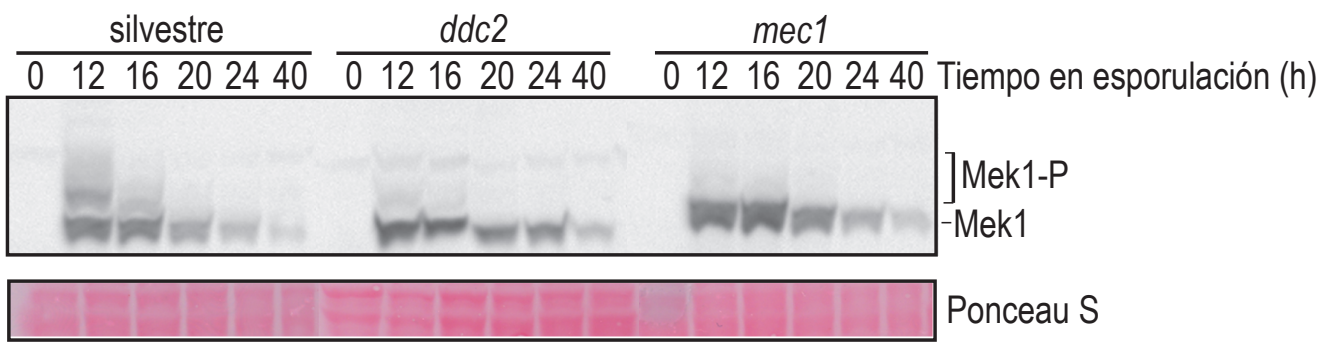

Figura 24. Mec1 y Ddc2 son necesarias para la correcta activación del checkpoint meiótico. (A y B) Análisis mediante western blot de la fosforilación de Mek1 utilizando Phos-tag para resolver las bandas de fosforilación. Como control de carga se muestra la tinción con Rojo Ponceau. Las cepas son DP455 (silvestre), DP454 (ddc2), DP566 (mec1), DP567 (ndt80 zip1), DP568 (ndt80 zip1 ddc2) y DP680 (ndt80 zip1 mec1).

Por último, también observamos que incluso en una meiosis sin perturbar en una cepa silvestre hay una ligera (pero detectable por la fosforilación de Mek1) activación del checkpoint de forma transitoria durante la profase cuando está ocurriendo la recombinación meiótica (ver t=10-15 h en Figuras 23 y 24B). Sin embargo, esta activación es prácticamente indetectable en ausencia de Ddc2 ó Mec1 (Figura 24B).

En conjunto, estos resultados indican que Ddc2 funciona en etapas tempranas de la ruta de checkpoint de paquitene, señalizando, junto con Mec1, la presencia de intermediarios de recombinación a componentes que están por debajo en la ruta de este checkpoint como la kinasa efectora Mek1.

\section{CAPÍTULO 2.- Interacción de Ddc2 con el huso meiótico}

\section{1.- Localización alternativa de $\mathrm{Ddc2}$ independiente de la recombinación meiótica}

Como se ha mostrado anteriormente, cuando observábamos la localización de Ddc2-GFP en mutantes carentes de recombinación meiótica (spo11), los focos múltiples de Ddc2 desaparecían y la señal de Ddc2-GFP se encontraba solamente en focos únicos (Figuras 19B y 20). Sin embargo, una observación detallada nos permitió apreciar que, en algunas células, esa señal discreta de Ddc2 no se concentraba en los típicos focos 
redondeados característicos de la presencia de daño (Lisby et al., 2004), sino que se encontraba en forma de una estructura alargada (Figura 20). La cuantificación exhaustiva del porcentaje de células que presentaban los focos redondos frente a la señal elongada de Ddc2 durante la meiosis mostró que, aunque esta última localización es más prominente en el mutante spo11, también se puede detectar en células silvestres (Figura 25A).

A

Morfología de focos sencillos de Ddc2-GFP

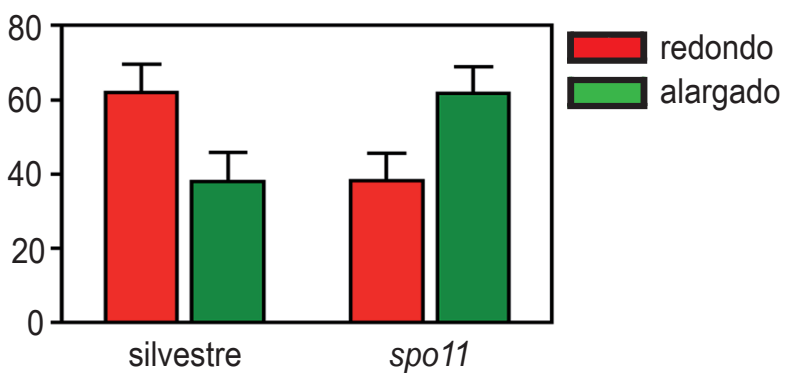

B

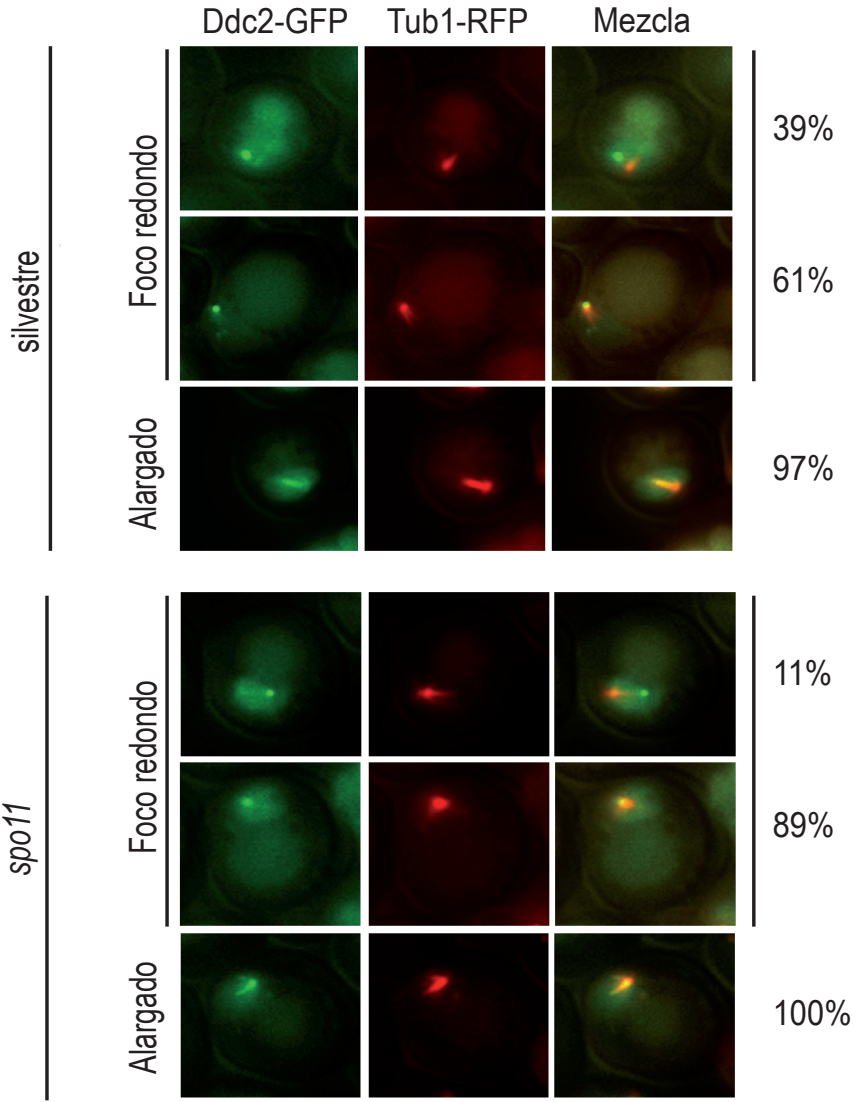

Figura 25. Localización de Ddc2 en el huso durante la profase meiótica. (A) Cuantificación del porcentaje de focos únicos de Ddc2 con morfología redonda o alargada. (B) Colocalización de Ddc2 y Tubulina en focos redondos o alargados. A la derecha se indica el porcentaje de colocalización. Se analizaron 104 células para la cepa silvestre y 228 células para la spo11. Las cepas son DP502 (silvestre) y DP504 (spo11).

\section{2.- Ddc2 colocaliza con el huso meiótico}

La localización de Ddc2 en un estructura alargada con forma de cometa es muy similar a la morfología que presenta el huso de microtúbulos durante la profase de la meiosis cuando los cuerpos polares del huso duplicados todavía no se han separado y los microtúbulos emanan de ellos en forma de haces (Hayashi et al., 1998). Por tanto, quisimos averiguar si estas formas elongadas de Ddc2 colocalizaban con el huso meiótico. 
Para ello, construimos cepas, tanto en fondo genético silvestre como spo11, portadoras en heterozigosis del gen TUB1 (que codifica la $\alpha$-tubulina) fusionado con la proteína roja fluorescente (RFP), y que también expresaban DDC2-GFP. A partir de cultivos meióticos de estas cepas se tomaron muestras para observar in vivo la localización de ambas proteínas mediante microscopía de fluorescencia. En la Figura 25B se puede apreciar que, cuando la señal de Ddc2-GFP es alargada, colocaliza en la práctica totalidad de las células con el huso profásico visualizado mediante Tub1-RFP tanto en la cepa silvestre como en el mutante spo11. Por su parte, cuando Ddc2-GFP se encuentra en un solo foco circular también existe un grado significativo de colocalización con Tub1-RFP, que es más acentuado en el mutante spo11 en comparación con la cepa silvestre. Por tanto, podemos concluir que la localización de Ddc2 en forma de cometa corresponde al huso de la profase meiótica. Además, los focos únicos redondeados de $\mathrm{Ddc2}$, probablemente procedentes de lesiones espontáneas, se encuentran frecuentemente en la vecindad del aparato de microtúbulos.

\section{3.- Ddc2 interacciona con el huso de la profase meiótica: ensayo BiFC}

Para comprobar si la colocalización entre las señales de Ddc2 y de Tub1 se corresponde con una interacción física entre ambas proteínas, llevamos a cabo un ensayo de complementación bimolecular fluorescente (BiFC), que permite detectar la asociación de dos proteínas in vivo (Sung and Huh, 2007). Este método consiste en fusionar cada una de las proteínas a estudiar con la mitad N-terminal y la mitad C-terminal, respectivamente, de una proteína fluorescente (en nuestro caso la variante Venus de la YFP) (Nagai et al., 2002). Si existe interacción entre ambas proteínas, se reconstituye la fluorescencia por proximidad física entre las dos mitades de la YFP y puede ser detectada mediante microscopía de fluorescencia.

Para nuestro estudio, marcamos $D D C 2$ con el epítopo VN, que corresponde al extremo $\mathrm{N}$-terminal de la proteína Venus, y TUB1 con elepítopoVC, correspondienteal extremo C-terminal de Venusyse capturaron imágenes al microscopio de fluorescencia para detectar la señal de YFP. Como se muestra en la Figura 26, pudimos observar que en células meióticas diploides expresando DDC2-VN y TUB1-VC simultáneamente se reconstituye la señal fluorescente de YFP que, además, muestra una morfología elongada. Como control, en las cepas que sólo poseen una de las dos proteínas marcada con el correspondiente epítopo, no aparece la señal de YFP. Por tanto, podemos concluirque las proteínas Ddc2 y Tub1 estáninteraccionandoentre síal menos en algunas células del cultivomeiótico.

\section{4.- La localización de Ddc2 en el huso depende de Mec1}

Ante lo inesperado de este resultado, para descartar que la presencia de Ddc2 que estábamos detectando asociada a los microtúbulos del huso de la profase pudiera ser debida a algún tipo de artefacto, estudiamos su localización en ausencia de Mec1, que forma complejo con Ddc2.

Mediante análisis de western blot a partir de muestras de cultivos en meiosis observamos que, aunque a un nivel ligeramente más bajo en comparación con el silvestre, la proteína Ddc2-GFP se sigue produciendo en el mutante mec1 (Figura 27A). Sin embargo, cuando analizamos las muestras mediante microscopía de fluorescencia encontramos que, en ausencia de Mec1, Ddc2-GFP se deslocaliza completamente y, a diferencia de la cepa silvestre, no aparece señal ni en los focos múltiples que representan intermediarios de recombinación meiótica (ver capítulo anterior; flechas blancas en Figura 27B), ni en las estructuras alargadas correspondientes al huso meiótico (Figura 27B, flechas rojas). 

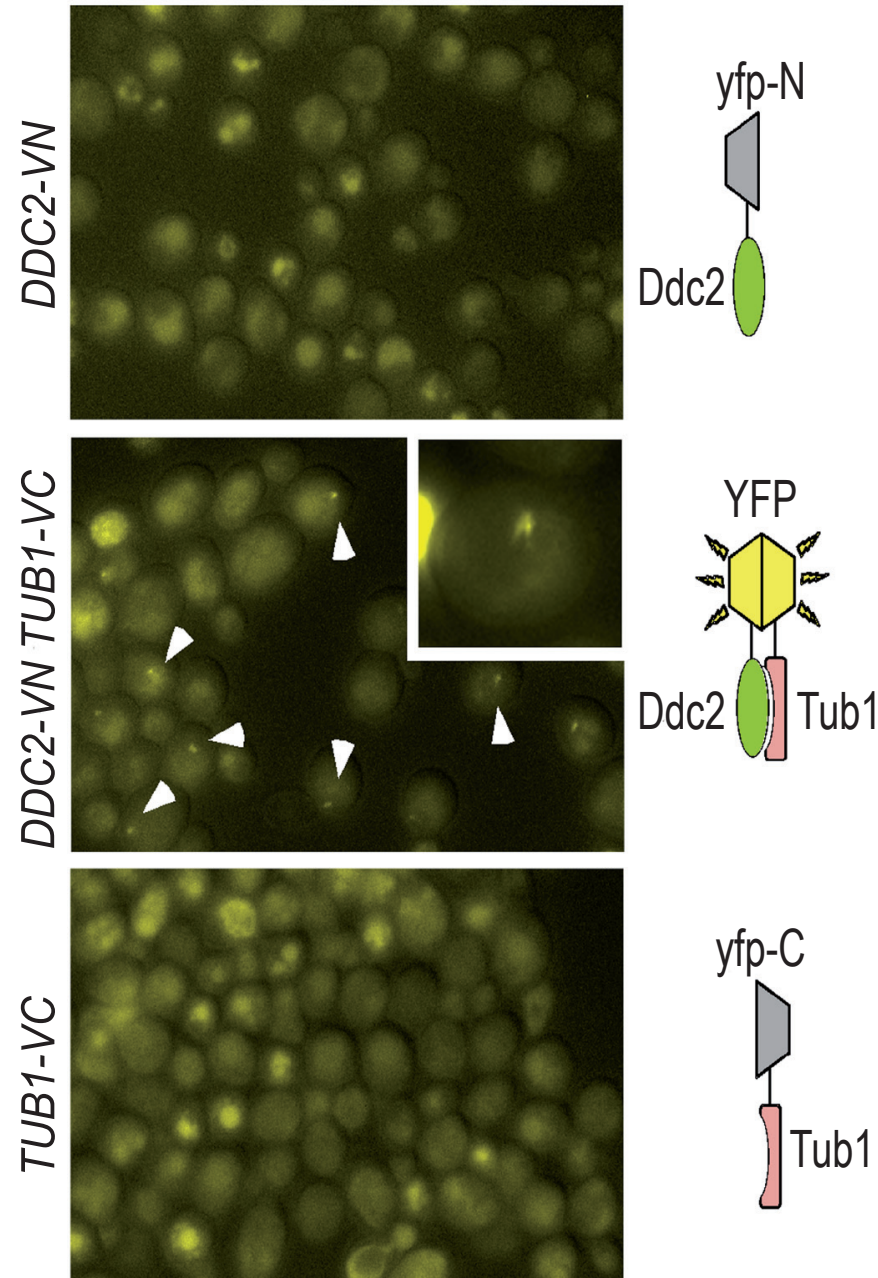

Figura 26. Interacción entre Ddc2 y Tubulina mediante el ensayo de BiFC. Las flechas señalan células que presentan la señal fluorescente que se genera específicamente cuando se expresan simultáneamente DDC2-VN y TUB1-VC. En el recuadro central se muestra una célula a mayor magnificación donde se aprecia que la señal fluorescente generada presenta la morfología del uso de la profase. Las cepas son DP594 (DDC2-VN), DP599 (DDC2-VN TUB1-VC) y DP601 (TUB1-VC). Las imágenes se tomaron a las 17 horas de la inducción de la meiosis.

Por tanto, el hecho de que la proteína Ddc2-GFP esté presente en las células, pero no sea capaz de localizarse correctamente en ausencia de Mec1 apoya que su presencia en el huso meiótico no es artefactual, sino que debe tener alguna implicación funcional. Como se observa en la Figura 27B, en un cultivo meiótico de una cepa silvestre pueden encontrarse células con múltiples focos de Ddc2 señalizando DSBs y células con Ddc2 en el huso, pero nunca observamos células en las que simultáneamente aparezca Ddc2 en ambas localizaciones.

Para investigar la dinámica temporal de la presencia de Ddc2 en ambas localizaciones (dependiente e independiente de la recombinación meiótica) llevamos a cabo estudios de time lapse en los que monitorizábamos la localización de Ddc2-GFP a lo largo del tiempo en células meióticas individuales. Para ello, se recogió una alícuota del cultivo en meiosis ( $\mathrm{t}=15 \mathrm{~h}$ ) de la cepa silvestre, se depositó sobre un porta como se describe en Materiales y Métodos, y mediante el microscopio de fluorescencia se tomaron imágenes a lo largo del tiempo de las células de un mismo campo. En estos estudios pudimos observar células en las que los múltiples focos de Ddc2 característicos de la señalización de intermediarios de recombinación terminaban confluyendo en una estructura alargada que, presumiblemente, corresponde al huso profásico (Figura 28). Sin embargo, nunca encontramos la situación contraria, es decir, que la localización en el huso preceda a los focos de recombinación. 
A

control

$\frac{\text { sin GFP }}{15} \frac{\text { silvestre }}{15 \quad 24} \frac{m e c 1}{15 \quad 24}$ Tiempo en meiosis $(h)$

-- Ddc2-GFP

Cuman- $-P G K$

B

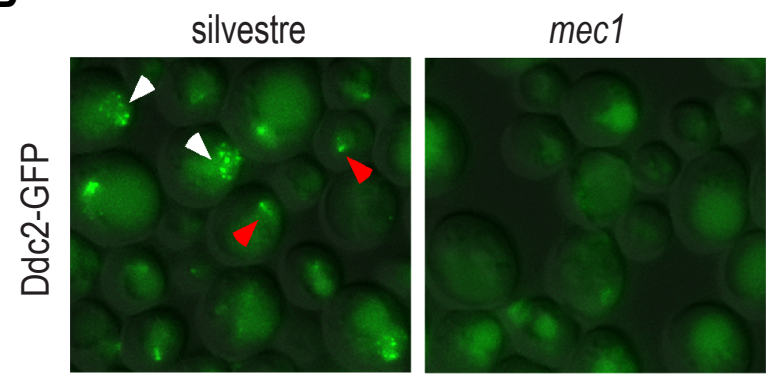

Figura 27. La localización de Ddc2 es dependiente de Mec1. (A) Análisis de la producción de Ddc2-GFP en el mutante mec1 mediante western blot. Como control de carga se utilizó PGK. El asterisco marca una banda inespecífica. (B) Localización de Ddc2-GFP en células vivas de la cepa silvestre y el mutante mec1. Las flechas blancas indican múltiples focos meióticos que representan intermediarios de recombinación. Las flechas rojas señalan células donde Ddc2 se encuentra en el huso profásico. Ambas localizaciones desaparecen en el mutante mec1. Las cepas son BR1919-2N (silvestre sin epítopo), DP448 (silvestre) y DP482 (mec1).

\section{5.- Los mutantes $d d c 2$ y mec1 presentan sensibilidad a benomilo}

Nuestro objetivo ahora era averiguar la posible relevancia biológica de la presencia de Ddc2 en el huso. Para ello, analizamos la sensibilidad de los mutantes ddc2 y mec1 a benomilo, que es una droga que provoca la despolimerización de los microtúbulos. Como control, utilizamos el mutante mad2que es defectivo en el denominado checkpoint de ensamblaje del huso (Li and Murray, 1991). Este checkpoint bloquea la progresión del ciclo celular en respuestaafallosenelensamblajedelhusomitóticooenlaunióndeloscromosomasaéste(Zhouetal.,2002;Musacchio and Salmon, 2007); por ello, mutaciones en componentes de este checkpoint dan lugar a sensibilidad a benomilo.

A partir de cultivos de células en fase exponencial de crecimiento, realizamos diluciones seriadas en placas con o sin benomilo que se incubaron a $30^{\circ} \mathrm{C}$. Observamos que tanto el mutante $d d c 2$ como mec1 eran sensibles al benomilo, al igual que el mutante mad2 (Figura 29). Además, construimos el doble mutante mad2 $d d c 2$ y comprobamos que su sensibilidad a benomilo era más acusada que la de los mutantes sencillos. Por tanto, estos resultados indican que el complejo Mec1/Ddc2 debe ejercer alguna función en el control de la dinámica de los microtúbulosyqueestepapelesindependientedelarutadelcheckpointdeensamblajedel husodependientedeMad2. 
A
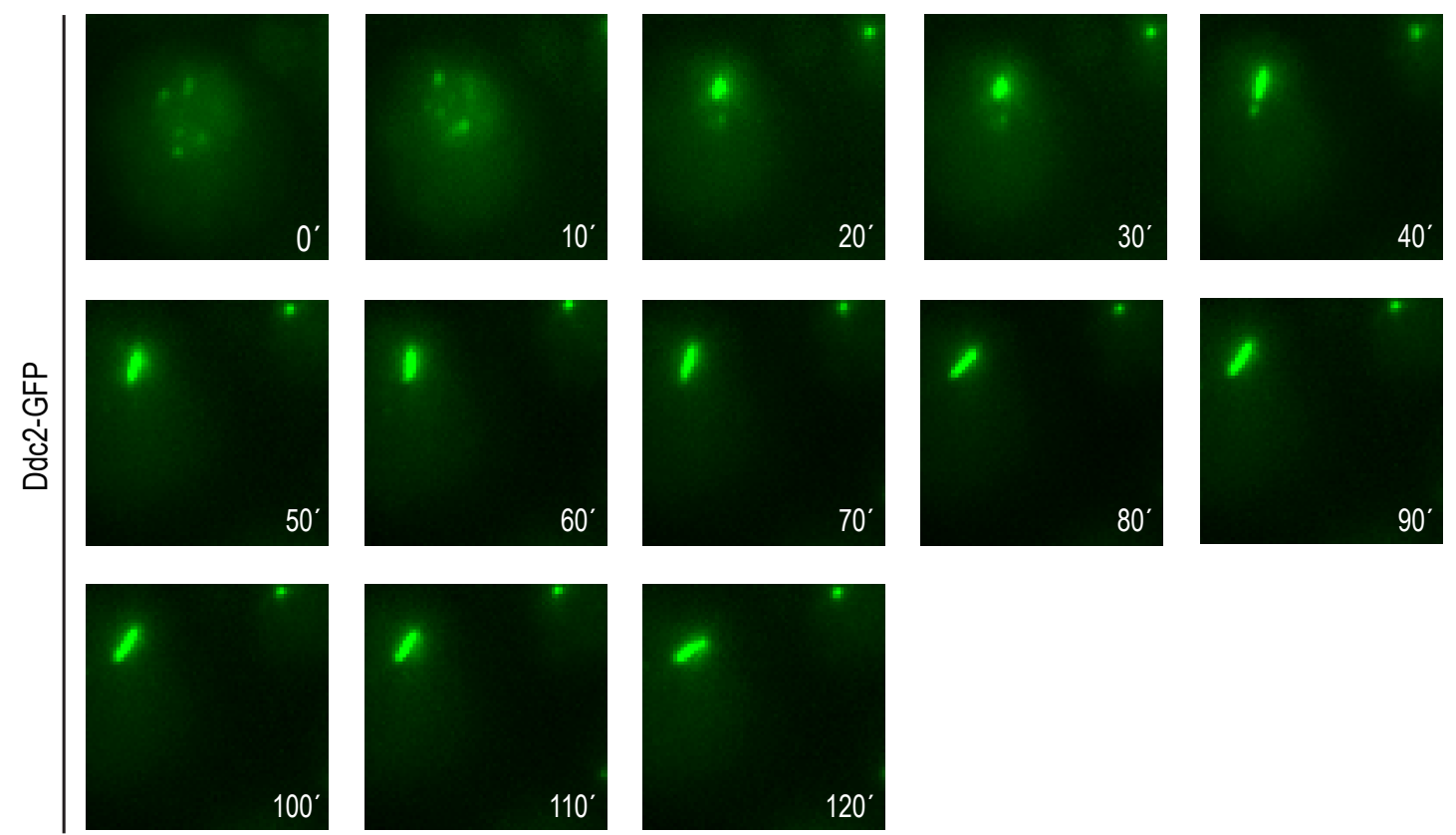

B
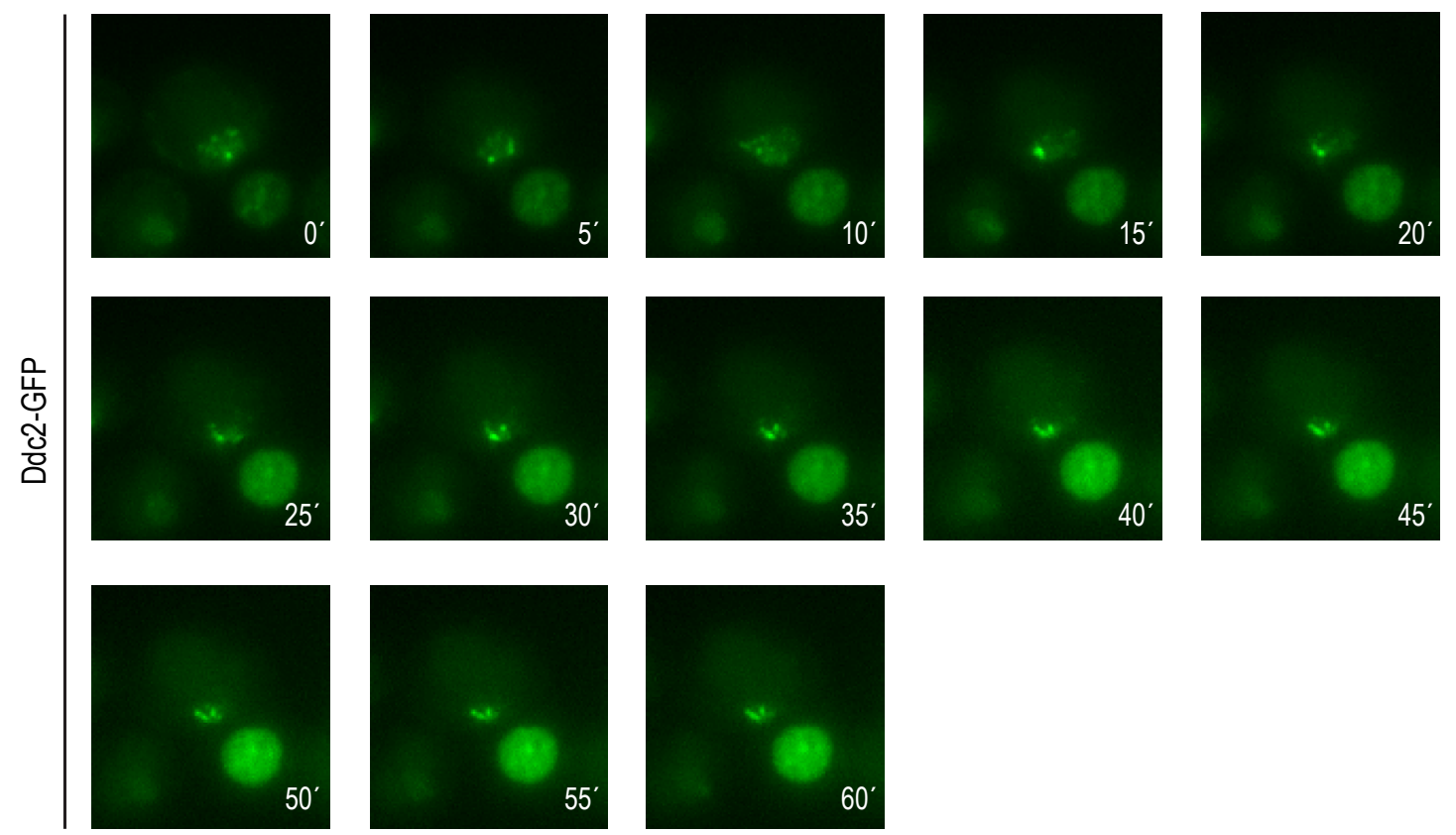

Figura 28. Los focos múltiples de Ddc2 confluyen en el huso durante la profase de la meiosis. Se realizaron varios experimentos de time-lapse en torno a las $15 \mathrm{~h}$ de meiosis y se muestran imágenes representativas de dos de ellos (A y B). Se indican los tiempos (minutos) a partir del momento en que se depositaron las células en el portaobjetos y se comenzó la observación. La cepa es DP448 (silvestre). 


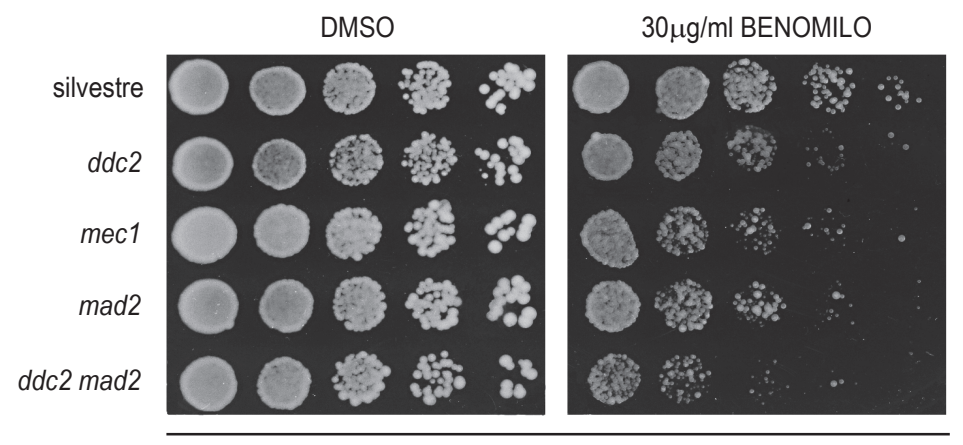

$72 \mathrm{~h}$

Figura 29. Los mutantes $d d c 2$ y mec1 presentan sensibilidad a benomilo. Se realizaron diluciones seriadas (1:5) de células creciendo exponencialmente y se sembraron en placas con o sin benomilo que posteriormente se incubaron a $30^{\circ} \mathrm{C}$ durante 3 días. Las cepas son YP853 (silvestre), YP852 (ddc2), YP937 (mec1), YP1622 (mad2), YP1594 (ddc2 mad2).

\section{CAPÍTULO 3.- Detección y señalización de los intermediarios de recombinación meiótica en el} mutante sae2

\section{1.- Localización de Ddc2 en el mutante sae2}

En el proceso de la recombinación meiótica, la proteína Sae2 es necesaria para eliminar Spo11 del extremo 5' de las DSBs generadas, permitiendo así su procesamiento a regiones de ssDNA (Keeney and Kleckner, 1995; McKee and Kleckner, 1997; Prinz et al., 1997).

Comoseaprecia en la Figura20, al igual queenotros mutantes que disparanel checkpointde recombinación meiótica, como dmc1 ó hop2, pero que están afectados en etapas más tardías de la recombinación, Ddc2 también se localiza en forma de focos múltiples en el mutante sae2, si bien los focos aparecen en menor número y, en algunos casos, con mayor intensidad. Puesto que, al menos en células vegetativas, el reclutamiento del complejo Mec1/Ddc2 a las DSBs depende de su previo procesamiento exonucleolítico a ssDNA y la unión de RPA, nos resultó sorprendente el detectar múltiples focos de Ddc2 en células meióticas de sae2 donde, supuestamente, no debería haber formación de ssDNA. Por tanto, nos decidimos a profundizar más acerca del tipo de intermediarios de recombinación meiótica generados en sae2 y cómo son detectados por Ddc2 para inducir el checkpoint meiótico.

En primer lugar, quisimos corroborar que los focos de Ddc2 que observamos en el mutante sae2 son focos meióticos, es decir, que su formación requiere el inicio de la recombinación con la formación de DSBs y no son consecuencia de otro tipo de lesiones que podrían generarse en este mutante durante la replicación. Para ello, se construyó una cepa spo11 sae2 y, como se observa en la Figuras 30A y 30B comprobamos que tanto la acumulación como el patrón de focos múltiples de Ddc2-GFP característico del mutante sae2, desaparecía si no se iniciaba la recombinación meiótica, puesto que en el doble mutante spo11 sae2 sólo se detectaban focos sencillos de Ddc2, en muchos casos correspondientes al huso.

Por otro lado, estudiamos mediante microscopía de fluorescencia si la localización de Ddc2 en el mutante sae2 depende de la presencia de Mec1. Como se muestra en la Figura 30C, tanto los focos sencillos como los múltiples de Ddc2-GFP desaparecían por completo en células meióticas del doble mutante sae2 mec1Por tanto, la acumulación de Ddc2 en forma de focos en sae2 precisa de los mismos requerimientos que en otros mutantes meióticos, es decir, la formación de DSBs dependientes de Spo11 y la integridad del complejo sensor Mec1/Ddc2. 
A

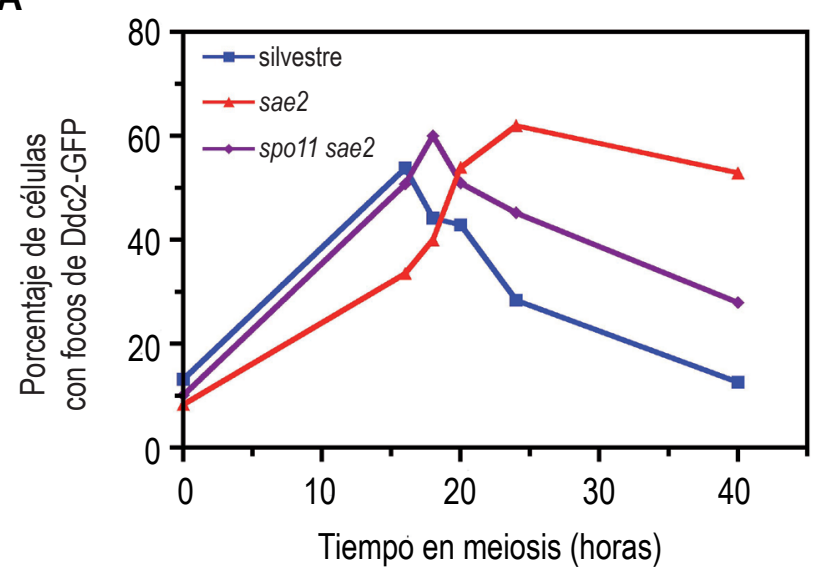

B

Patrón de focos de Ddc2-GFP

$\square$ un foco $\square$ focos múltiples

Ddc2-GFP
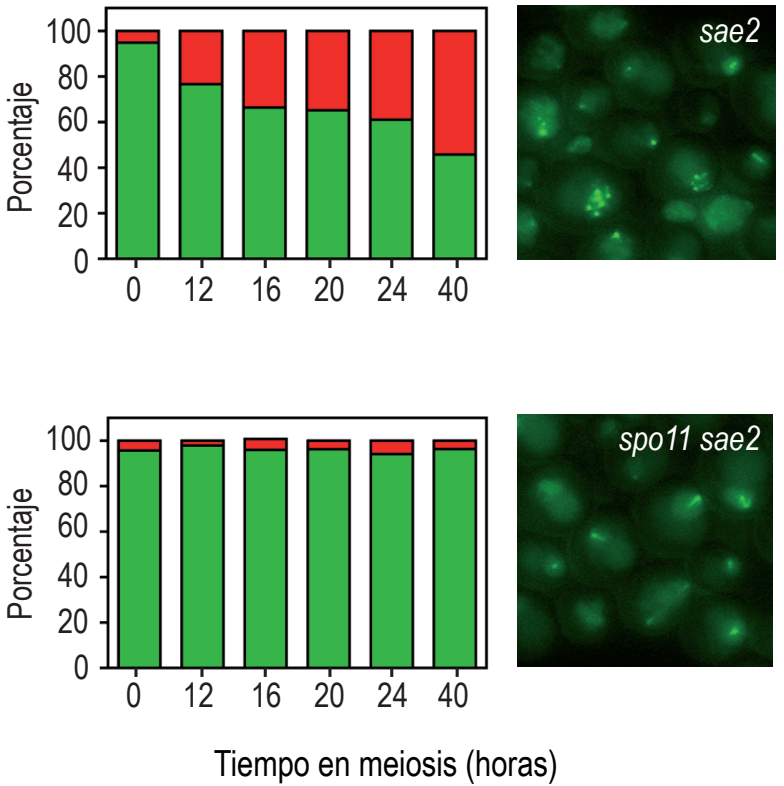

C

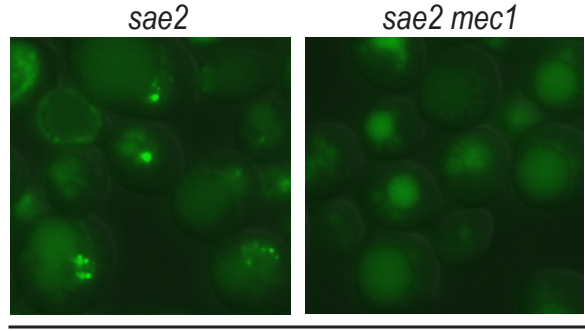

Ddc2-GFP

Figura 30. Análisis de la localización de Ddc2 en el mutante sae2. (A) Se representa el porcentaje de células que contienen señal de Ddc2-GFP a diferentes tiempos de la meiosis. Se analizaron entre 150-500 células por cada tiempo de meiosis y para cada cepa. (B) Se realizó un recuento del patrón de localización de Ddc2-GFP a lo largo de la meiosis (un solo foco o focos múltiples, como está indicado) en células que tenían señal de Ddc2-GFP. Las gráficas (paneles de la izquierda) representan el porcentaje de cada patrón de localización. También se muestran imágenes representativas de cada cepa (paneles de la derecha). (C) Imágenes representativas de microscopía de fluorescencia que muestran que los focos meióticos de Ddc2-GFP en el mutante sae2 dependen de Mec1. Las cepas son DP448 (silvestre), DP484 (sae2), DP550 (spo11 sae2) y DP486 (sae2 mec1). 


\subsection{Localización de Ddc2 en el mutante rad50S}

Para discernir si la localización de Ddc2 en forma de focos múltiples en sae2 es un fenómeno exclusivo de este mutante 0 se producía igualmente en otros mutantes alterados en el mismo paso de la recombinación meiótica, utilizamos el mutante rad50S que, al igual que sae2, acumula DSBs meióticas sin procesar (Alani et al., 1990; Keeney and Kleckner, 1995; McKee and Kleckner, 1997). Para ello, analizamos la localización de Ddc2 (en este caso marcada con YFP) durante la meiosis en el mutante rad50S y comprobamos que el patrón de focos era muy similar al que presentaba el mutante sae2. Además, observamos que en el doble mutante sae2 rad50S, Ddc2 sigue siendo capaz de localizarse en las células meióticas en forma de focos múltiples (Figura 31).

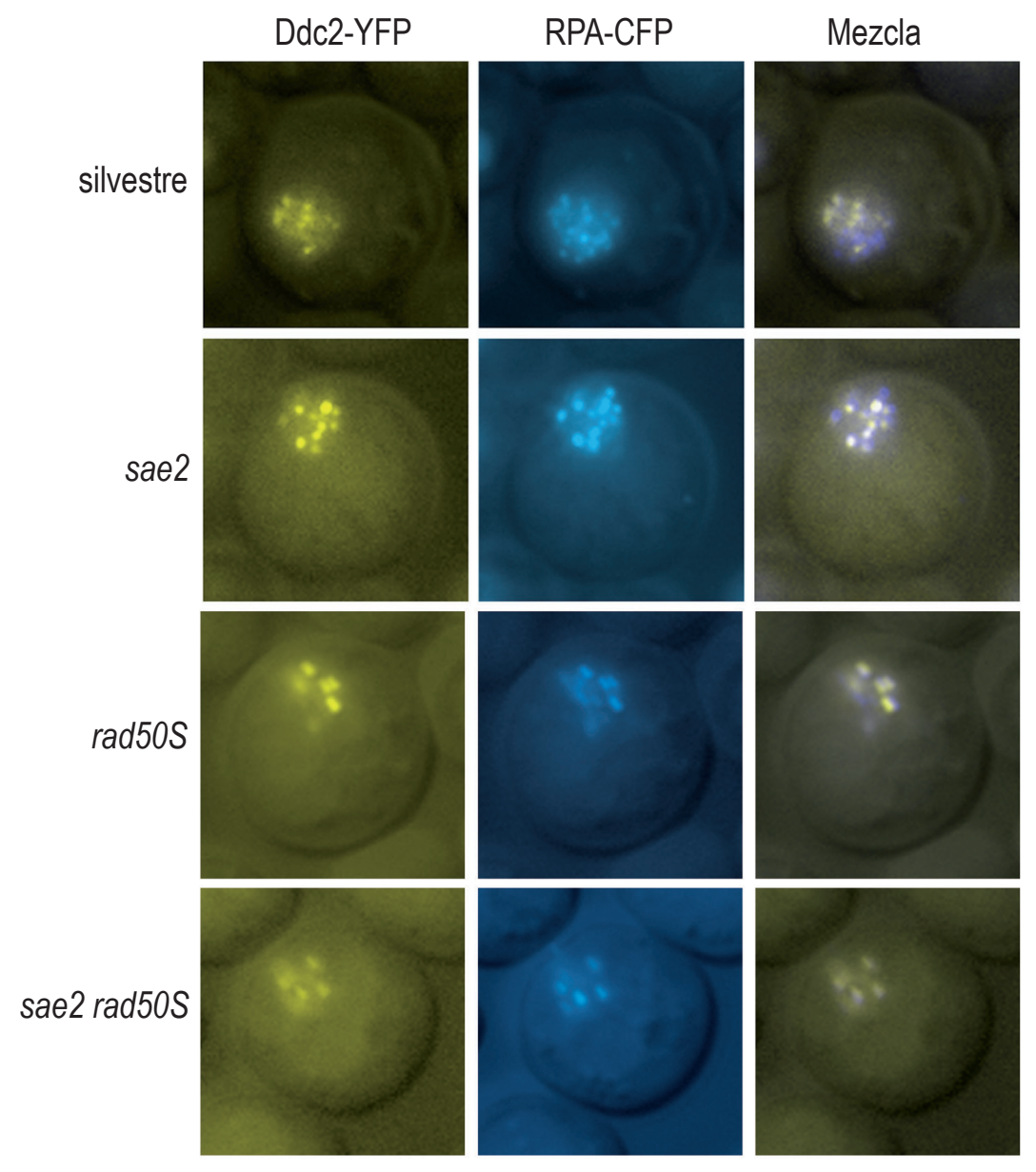

Figura 31. Colocalización de Ddc2 y RPA. Se muestran imágenes representativas de células en meiosis. Las cepas son DP524 (silvestre), DP525 (sae2), DP536 (rad50S) y DP542 (sae2 rad50S).

\subsection{Ddc2 colocaliza con RPA en los mutantes sae2 y rad50S.}

La inesperada formación de focos meióticos de Ddc2 en los mutantes sae2 y rad50S nos llevó a plantearnos dos alternativas: o bien el complejo Mec1/Ddc2 también es capaz de detectar DSBs sin que éstas hayan sido previamente procesadas a ssDNA, o bien que, a pesar de lo que está descrito, sí hay generación o exposición de regiones de ssDNA en estos mutantes que posibilitan el reclutamiento de Ddc2 y la consiguiente activación del checkpoint. Para distinguir entre estas posibilidades, utilizamos la formación de focos de RPA como indicador de la existencia de ssDNA, puesto que este complejo se une específicamente a estas regiones del genoma (Wold, 1997; Iftode et al., 1999). Para ello, construimos cepas diploides silvestre, 
sae2, rad50S y sae2 rad50S, portadoras de versiones de DDC2 y de RFA1 (una subunidad de RPA) marcadas con YFP y CFP, respectivamente, y las analizamos mediante microscopía de fluorescencia durante la meiosis.

Como se muestra en la Figura 31, se observaron focos meióticos de RPA no sólo en la cepa silvestre, si no también en los mutantes sae2, rad50S y sae2 rad50S. Además, existía una colocalización significativa entre la señal de Ddc2 y RPA, lo que apoya que Ddc2 está detectando regiones de ssDNA incluso en estos mutantes.

Por tanto, la colocalización observada de las proteínas Ddc2 y RPA en diferentes mutantes que acumulan DSBs sin procesar, nos está indicando que de alguna forma se está produciendo ssDNA, el cual, es necesario para que ambas proteínas se puedan unir al DNA.

\section{4.- En el mutante sae2 se genera ssDNA durante la meiosis}

Aunque la presencia de RPA es un indicador excelente de la existencia de ssDNA, no dejaba de ser una evidencia indirecta; por ello, nos planteamos la detección de ssDNA de un modo más directo empleando un anticuerpo anti-bromodeoxiuridina (BrdU) que reconoce específicamente este análogo de la timidina cuando está incorporado en ssDNA, pero no cuando se encuentra en DNA de cadena doble. Este anticuerpo permite detectar la incorporación de BrdU en el genoma durante la replicación del DNA (Gratzner, 1982; Vanderlaanand Thomas, 1985).

En primer lugar construimos cepas diploides capaces de incorporar BrdU en el genoma, puesto que las células de $S$. cerevisiae no lo hacen de modo natural. Para ello, en la cepa silvestre y los diferentes mutantes (spo11, dmc1 y sae2) se integró un plásmido portador del transportador de nucleósidos humano (hENT1) necesario para la toma de BrdU del medio y la enzima timidina kinasa del virus Herpes simplex (HSV-TK) necesaria para la incorporación de esta BrdU (Viggiani and Aparicio, 2006). Así, hacemos a las células de levadura competentes para la toma e incorporación de BrdU añadida al medio de cultivo. A continuación, se realizó un experimento de esporulación en líquido añadiendo la BrdU a las Oh, es decir, justo en el momento de inducir la meiosis para que este análogo se incorpore en el DNA durante la fase S premeiótica. En primer lugar, se comprobó mediante análisis de slot-blot con DNA genómico desnaturalizado que la incorporación de BrdU en el DNA era similar en todas las cepas construidas (silvestre, spo11, dmc1 y sae2) portadoras del cassette con la HSV-TK (Figura 32) y además se prepararon extensiones de núcleos a las 17h de meiosis, cuando gran parte de las células están en profase y tiene lugar la recombinación meiótica, y se analizaron mediante inmunofluorescencia en condiciones nativas empleando el anticuerpo anti-BrdU que detecta este nucleótido específicamente cuando está formando parte de ssDNA. Los resultados se muestran en la Figura 32. Como puede observarse, la cepa control que no incorpora BrdU no presentaba ningún foco, lo que valida la especificidad del anticuerpoen esta técnica. Para asegurar que la señal detectada marcaba exclusivamente regiones de ssDNA utilizamos los mutantes spo11 y dmc1 como controles negativo y positivo, respectivamente. En spo11 no se generan DSBs meióticas y, por tanto, no existen intermediarios de recombinación con ssDNA; de hecho, no se observaron focos de BrdU en este mutante. Por el contrario, el mutante dmc1 es defectivo en el paso de invasión de la cadena homóloga durante la recombinación meiótica y, por ello, acumula DSBs sin reparar con extenso procesamiento a ssDNA en sus extremos; de acuerdo con este fenotipo, encontramos numerosos focos de BrdU en dmc1. En la cepa silvestre sólo se detecta un número relativamente bajo de núcleos con señal BrdU, de acuerdo con el hecho de que los intermediarios de recombinación son transitorios y al repararse desaparecen las regiones de ssDNA. Por su parte, cuando analizamos el mutante sae2, encontramos múltiples focos de BrdU, aunque no tan abundantes como en dmc1. 
Por tanto, estos estudios demuestran la existencia de regiones de ssDNA durante la meiosis en sae2, lo que explica la presencia de focos de Ddc2 que colocalizan con RPA. No obstante, la generación de ssDNA en sae2 es más limitada que en el mutante dmc1.

A Patrón de focos de BrdU (ssDNA) en cromosomas meióticos ( $\mathrm{t}=17 \mathrm{~h})$

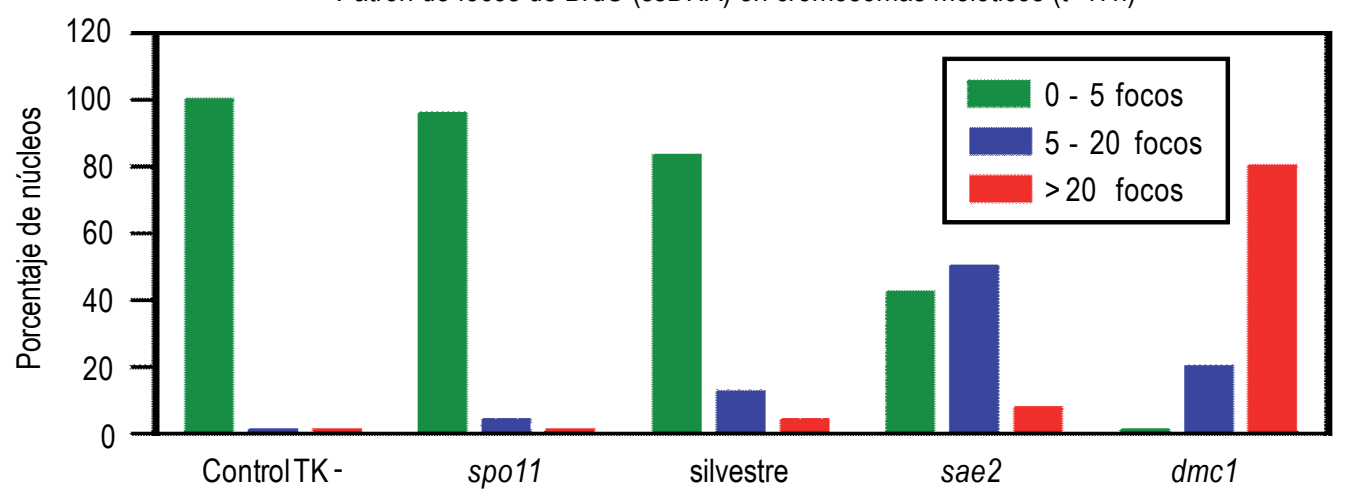

B
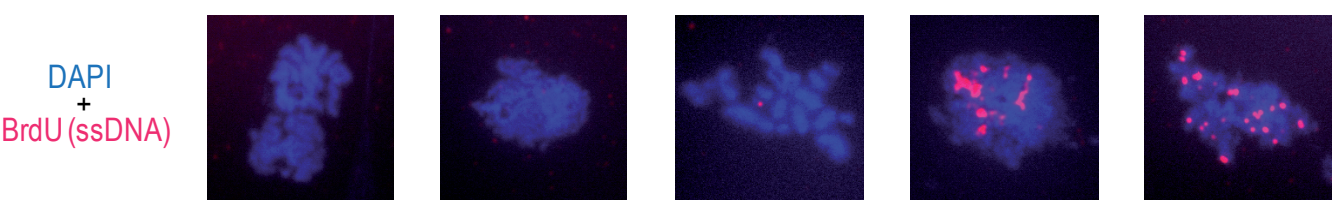

BrdU total incorporada (DNA desnaturalizado)
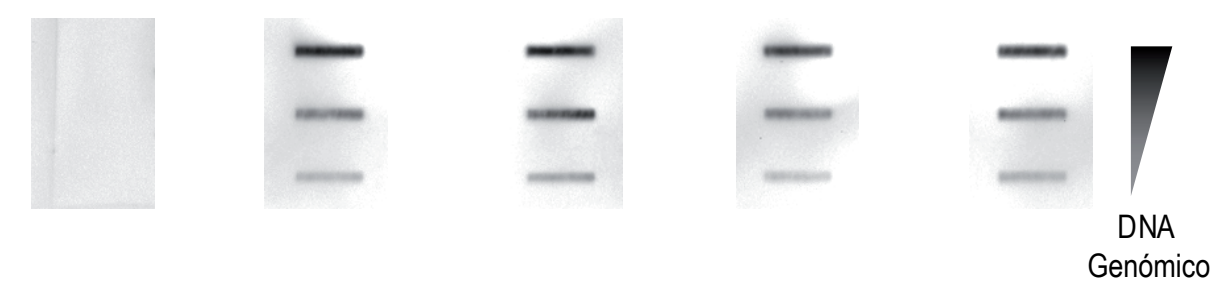

Figura 32. Análisis de la presencia de ssDNA durante la meiosis mediante marcaje con BrdU. (A) Se realizaron extensiones de cromosomas meióticos que se analizaron mediante inmunofluorescencia con anticueros que reconocen BrdU en regiones de ssDNA. Se representa el recuento de de focos de BrdU agrupando los núcleos en tres categorías: 0-5 focos, 5-20 focos y más de 20 focos. Se muestran imágenes representativas de núcleos de cada cepa analizada. Se analizaron entre 25 y 27 núcleos para cada cepa. (B) Análisis mediante slot blot de DNA genómico desnaturalizado para monitorizar la incorporación total de BrdU en las diferentes cepas. Las cepas son 1919-2N+pRS306 (Control TK-), DP592 (spo11), DP606 (silvestre), DP607 (sae2) y DP608 (dmc1).

\section{5.- El ssDNA generado en el mutante sae2 activa el checkpoint de recombinación meiótica}

Como ya se ha mostrado anteriormente (Figura 11B), en el mutante sae2 hay una fracción de células que, aunque con retraso, consiguen completar la meiosis. En estas células, el material genético aparece muy disgregado, probablemente debido a que eventualmente los cromosomas segregan aun habiendo DSBs sin reparar. Por ello, nos planteamos la posibilidad de que los focos de Ddc2 y el ssDNA detectados en sae2 pudieran reflejar la formación de roturas en el genoma producidas de modo mecánico al intentar segregar de modo aberrante los cromosomas durante las divisiones meióticas. Para investigar esta posibilidad, construimos una cepa ndt80 sae2 que se mantiene bloqueada en la profase independientemente del checkpoint porque, como ya se ha mencionado anteriormente, Ndt80 es un factor de transcripción necesario para la entrada en meiosis I. Como se muestra en las Figuras 33A y 33B, el doble mutante $n d t 80$ sae2 presenta el mismo patrón de acumulación de focos múltiples de Ddc2 que el mutante sae2, por lo que estos focos no se generan debido a roturas en el DNA producidas durante las segregaciones meióticas.

Como prueba adicional para demostrar que, al igual que ocurre en otros mutantes meióticos como $d m c 1$, Ddc2 también está señalizando la presencia de auténticos intermediarios de recombinación meiótica 


\section{B}

\section{A}
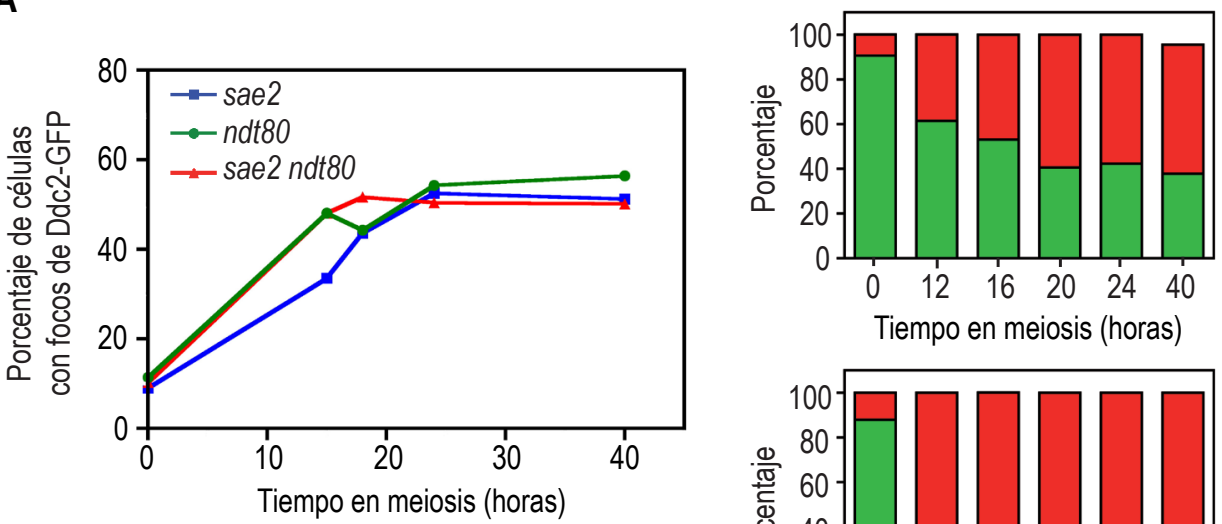

Ddc2-GFP
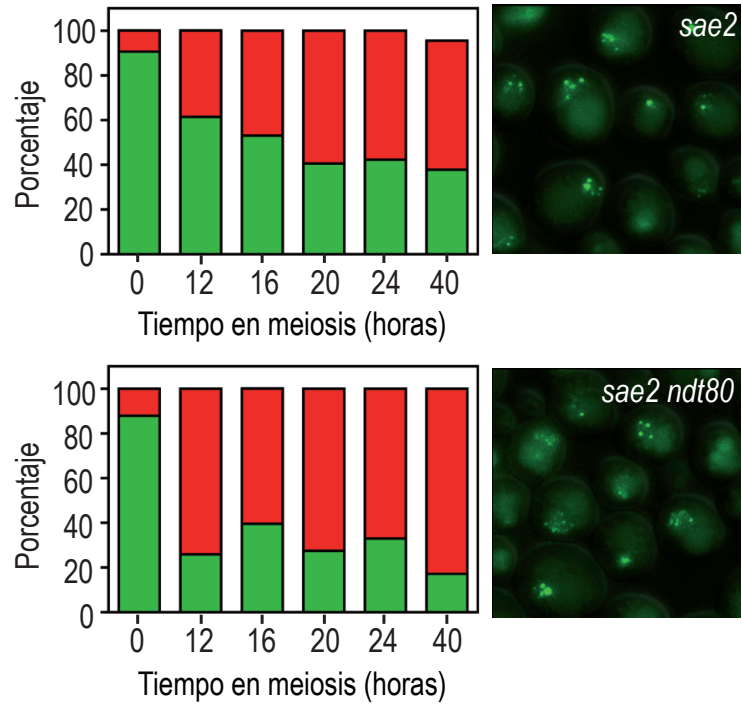

C
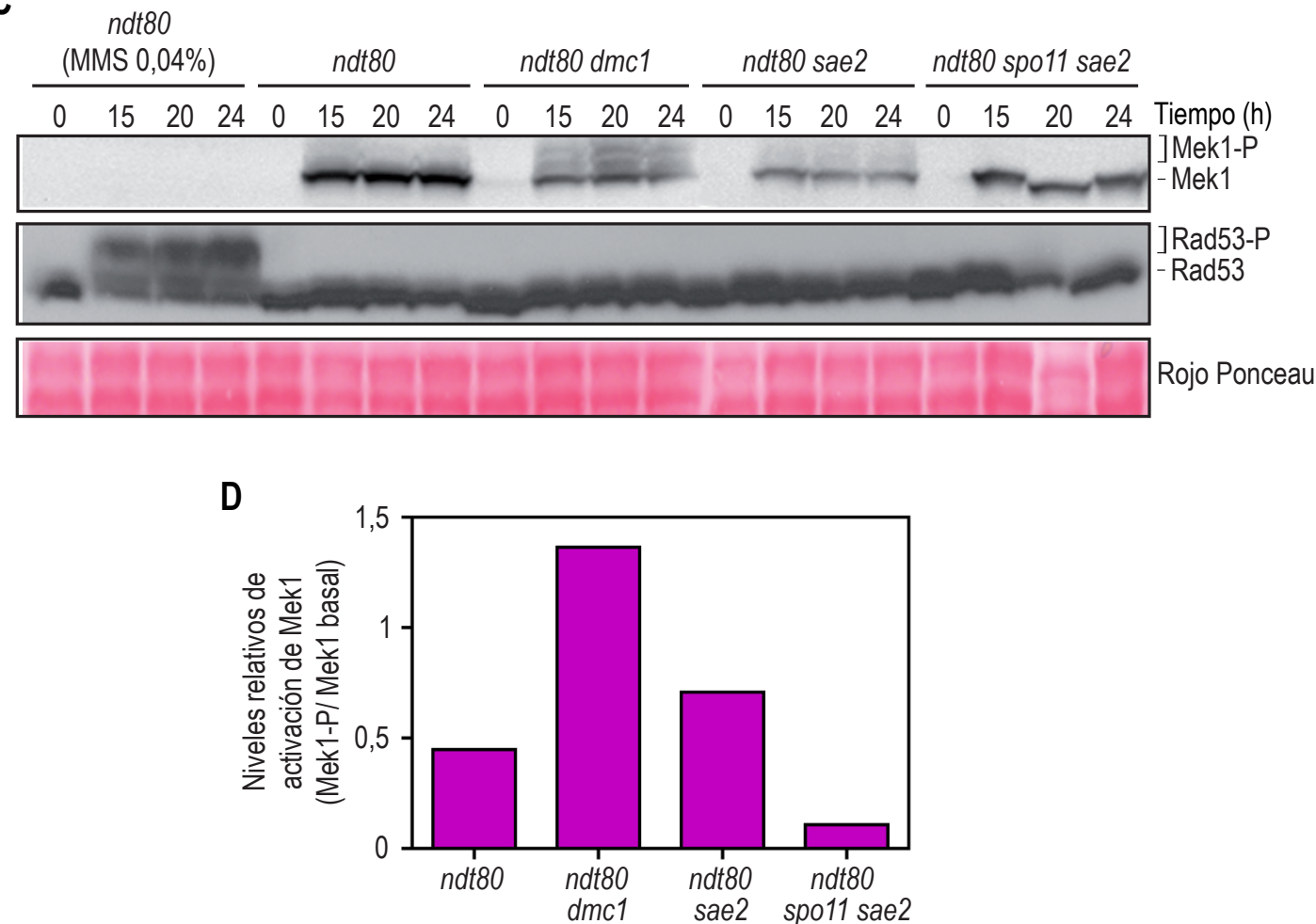

Figura 33. Activación del checkpoint de recombinación meiótica en el mutante sae2. En (A) y (B) se analiza la localización de Ddc2GFP en células vivas. (A) Porcentaje de células que contienen señal de Ddc2-GFP a diferentes tiempos de la meiosis. Se analizaron entre 150-500 células por cada tiempo de meiosis y para cada cepa. (B) Patrón de localización de Ddc2-GFP a lo largo de la meiosis (un solo foco o focos múltiples, como está indicado) en células que tenían señal de Ddc2-GFP. Las gráficas representan el porcentaje de cada patrón de localización. (C) Análisis de la activación de Mek1 y Rad53 mediante western blot. Se utilizó como control de carga la tinción con Rojo Ponceau. El gel de Mek1 contenía Phos-tag para resolver las bandas de fosforilación. (D) Cuantificación de la activación de Mek1 mediante el programa Quantity One (BioRad); se representan los niveles relativos de activación de Mek1 (Mek1-P) respecto a Mek1 basal. Las cepas son DP457 (ndt80), DP484 (sae2) y DP569 (sae2 ndt80) para (A) y (B), y DP691 (ndt80), DP693 (ndt80 dmc1), DP694 (ndt80 sae2) y DP695 (ndt80 spo11 sae2) para (C) y (D).

en sae2 y no de otro tipo de lesiones accidentales, analizamos la activación de las proteínas Rad53 y Mek1, que son las kinasas efectoras del checkpoint de daño en DNA (Pellicioli et al., 1999) y del checkpoint de 
recombinación meiótica (Bailis and Roeder, 2000), respectivamente. Este análisis se llevó a cabo tanto en la cepa silvestre como en diferentes mutantes meióticos, y todos ellos en fondo mutante ndt80 para bloquear todas las células en profase y que no hubiera diferencias debidas a la diferente cinética de progresión meiótica de las cepas analizadas. Como control positivo para la activación de Rad53 (que se pone de manifiesto por su hiperfosforilación) se añadió MMS al medio de esporulación en una cepa ndt80 a las 0h de meiosis. Por su parte, como control positivo para la activación de Mek1 empleamos el mutante dmc1 (ver Figuras 21C y 23).

Como se aprecia en la Figura 33C, sólo existía activación de Rad53 en la cepa tratada con MMS, pero no se producía dicha activación ni en la cepa sin tratar con MMS, ni en los mutantes dmc1 o sae2. Esto significa, que durante la profase meiótica, no se están produciendo roturas en el DNA que activen el checkpoint de daño en DNA mediado por Rad53. Por el contrario, cuando analizamos Mek1, observamos como tanto en el mutante dmc1 como en sae2, hay una activación de la kinasa Mek1, que se ve reflejada en las diferentes bandas de fosforilación de esta proteína. La cuantificación del nivel de activación de Mek1 en los diferentes mutantes se muestra en la Figura 33D. De forma consistente con los mayores niveles de ssDNA en dmc1 en comparación con sae2 (Figura 32), la activación de Mek1 también es más prominente (Figura 33D). Cabe destacar que la activación de Mek1 en sae2 se suprime totalmente en el doble mutante spo11 sae2 donde no hay DSBs meióticas. En conjunto, todos estos resultados indican que en el mutante sae2 se está produciendo una activación del checkpoint de recombinación meiótica mediado por la kinasa efectora Mek1 debido a la producción de DSBs meióticas que, de algún modo, generan ssDNA.

\section{6.- Spo11 y Ddc2 no colocalizan en el mutante sae2}

En principio, a pesar de que en ausencia de Sae2 (o en el mutante rad50S), Spo11 debe permanecer covalentemente unido a los extremos de las DSBs meióticas bloqueando su procesamiento exonucleolítico, nuestros resultados sugieren que, en al menos un subconjunto de todas las DSBs generadas, Spo11 debe estar liberándose en el mutante sae2 (o rad50S) posibilitando el procesamiento de esas roturas (Figura 34A; hipótesis 1). Alternativamente, podría ser posible que, en sae2, la proteína Spo11 permaneciese unida a los extremos de todas las DSBs y lo que estuviera ocurriendo, de algún modo, fuera una apertura o desenrollamiento de la doble hebra del DNA en los extremos de la rotura, exponiendo suficiente ssDNA como para que se pudiera reclutar RPA y posteriormente el complejo Mec1/Ddc2 activando el checkpoint a través de Mek1 (Figura 34A; hipótesis 2). Si la primera de las hipótesis fuera correcta, Spo11 no debería colocalizar con Ddc2, puesto que Ddc2 sólo aparecería en aquel conjunto de DSBs procesadas en las que Spo11 se ha eliminado (Figura 34A; hipótesis 1). Por el contario, si la segunda alternativa fuera cierta, la predicción sería que Spo11 colocalizaría con Ddc2 puesto que ambas proteínas coexistirían en los extremos de las DSBs desenrolladas pero sin procesar (Figura 34A; hipótesis 2).

Para dilucidar cuál de las dos situaciones está teniendo lugar realmente, se construyeron cepas que expresan desde su propio locus genómico una versión funcional de la proteína Spo11 marcada con GFP y, además la proteína Ddc2-HA descrita anteriormente. Mediante análisis de western blot, se observó que la producción de Spo11 se inducía en la fase temprana de la profase meiótica tanto en la cepa silvestre como en el mutante sae2. Sin embargo, mientras que en la cepa silvestre los niveles de Spo11 caían a medida que va progresando la meiosis, en el mutante sae2, se mantenían hasta tiempos más tardíos (Figura 34B). 
A

Mutante sae2

Hipótesis 1

Hipótesis 2
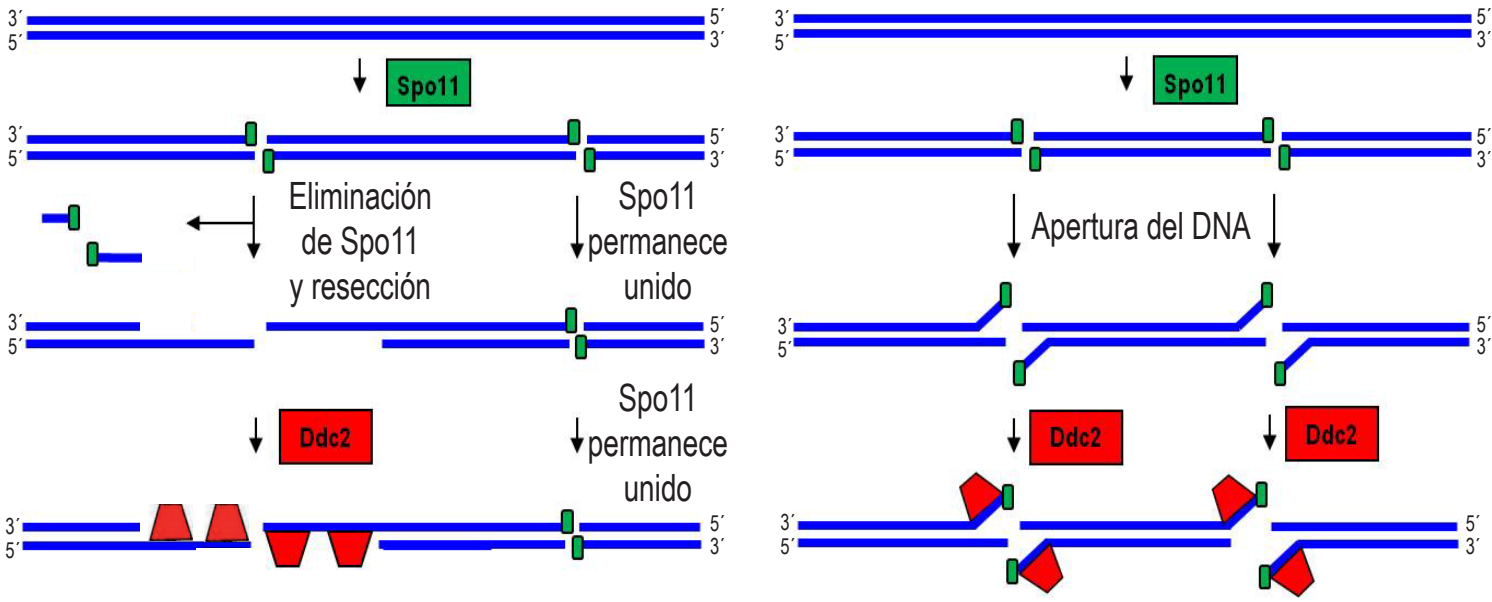

Spo11 y Ddc2 no colocalizarían

Spo11 y Ddc2 colocalizarían

B
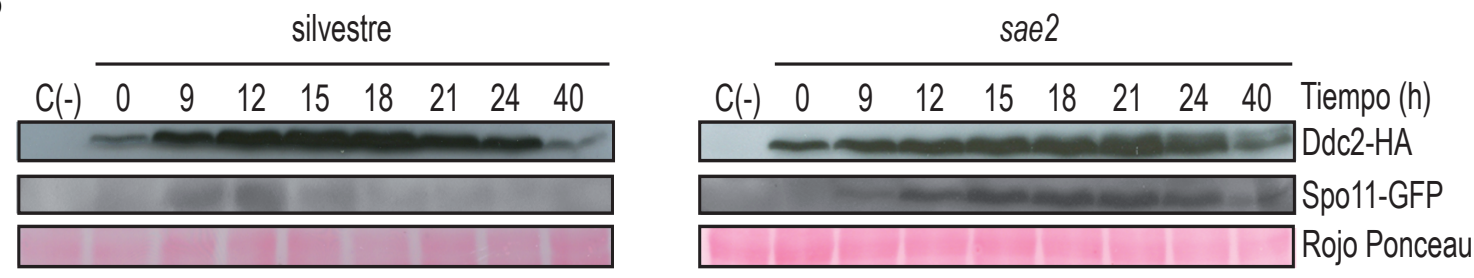

\section{C}

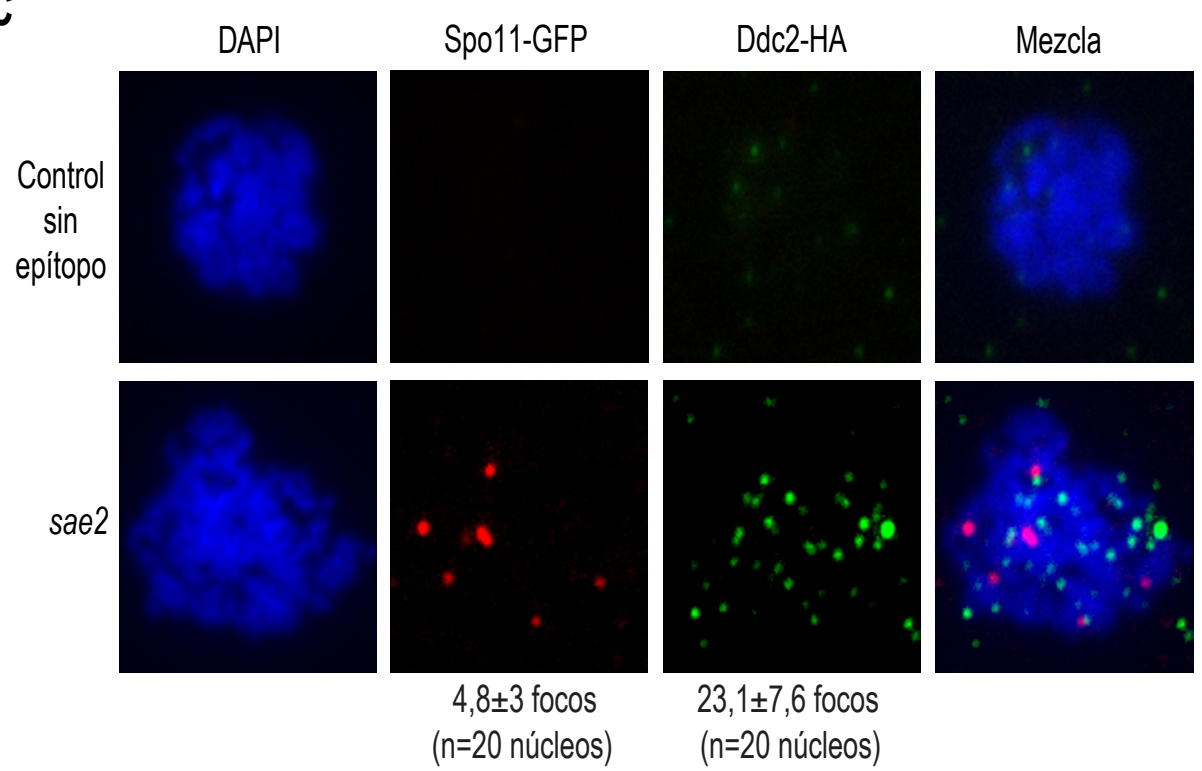

Figura 34. Análisis de la colocalización de Spo11 y Ddc2. (A) Esquema representativo de las hipótesis de trabajo planteadas (ver texto). (B) Análisis de Ddc2-HA y Spo11-GFP mediante western blot. Se utilizó como control de carga la tinción con Rojo Ponceau. (C) Inmunofluorescencia de extensiones de núcleos meióticos teñidos con DAPI (azul), y anticuerpos anti-GFP (rojo) y anti-HA (verde). Se muestran núcleos representativos a las 24h de meiosis. La cuantificación del número de focos de Spo11-GFP y Ddc2-HA se presenta debajo de las correspondientes imágenes. Las cepas son DP698 (sae2) y DP485 (control sin epítopo). 
De igual modo, Ddc2 permanece durante más tiempo en el mutante sae2, e incluso puede apreciarse, en este caso, una banda de menor movilidad electroforética indicativa de su activación por fosforilación (Figura 34B).

La localización de ambas proteínas se estudió mediante inmunofluorescencia en extensiones de cromosomas del mutante sae2 a las $24 \mathrm{~h}$ en meiosis. Se detectaron focos discretos de Spo11 y de Ddc2, pero que no colocalizaban, sino que más bien eran excluyentes (Figura 34C). Por tanto, este resultado apoya la primera hipótesis planteada, es decir, que incluso en ausencia de Sae2, la proteína Spo11 se elimina de los extremos de algunas DSBs permitiendo así el procesamiento a ssDNA, y su reconocimiento por Mec1/Ddc2.

\section{7.- En el mutante sae2 existe una leve acumulación de Ddc2 en algunas DSBs}

Mediante ChIP habíamos analizado la unión de Ddc2-HA a dos hotspots de DSBs meióticas (BUD23 y ERG1) y los resultados que obtuvimos revelaron que en el mutante $d m c 1$ se produce un enriquecimiento meiótico significativo de Ddc2 en estos hotspots (Figura 22). Para averiguar si en el mutante sae2 también se estaba produciendo la unión de Ddc2 a las DSBs meióticas, se realizaron experimentos de ChIP. Como se puede observar en los resultados que se muestran en la Figura 35, de los dos hotspots análizados, sólo en el ERG1 observamos un ligero enriquecimiento de Ddc2 en el mutante sae2, aunque mucho menor en comparación con el que se detecta en el mutante $d m c 1$. Por tanto, este resultado está de acuerdo con la hipótesis planteada anteriormente en la que argumentábamos que los focos de Ddc2 generados en el mutante sae2 podrían ser consecuencia de que Spo11 es liberado sólo de algunas DSBs permitiendo así su procesamiento a ssDNA.
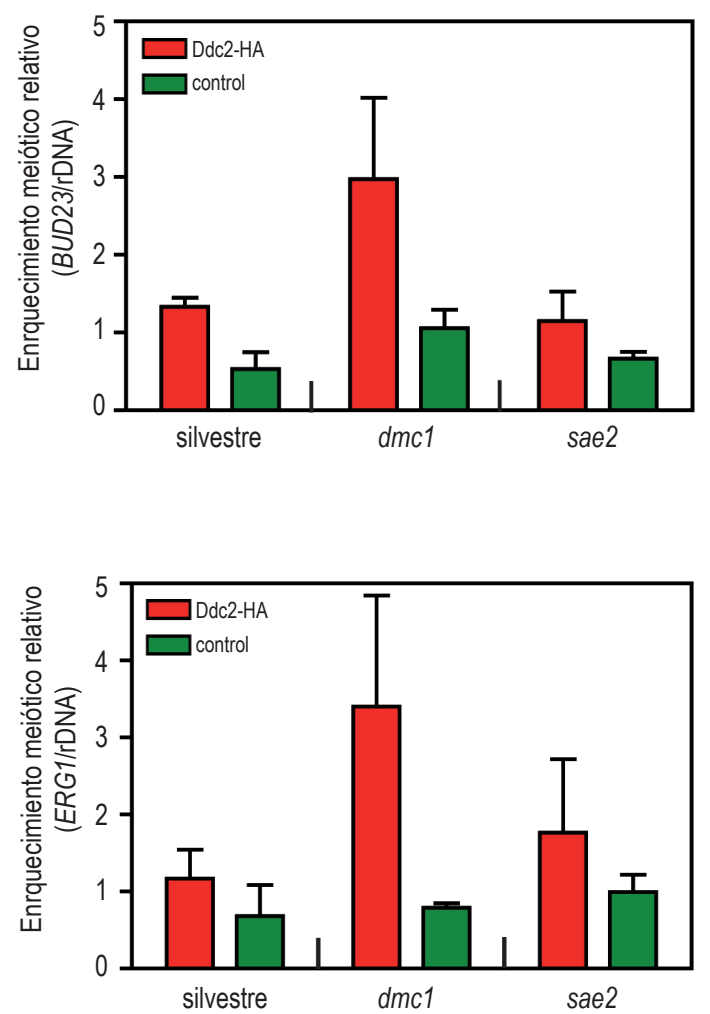

Figura 35. Ddc2 se une a los sitios de recombinación meiótica en el mutante sae2. Análisis por ChIP del reclutamiento de Ddc2 a los hotspots de DSBs BUD23 y ERG1 en las cepas silvestre (DP487) y sae2 (DP492) que expresan DDC2-HA, utilizando anticuerpos antiHA, como se describe en la Figura 17. Como comparación, se incluyen de nuevo los valores obtenidos para la cepa silvestre y el mutante dmc1 presentados en la Figura 23. 


\section{8.- Requerimientos genéticos para la localización de Ddc2 en sae2}

La proteína Exo1 es una exonucleasa 5'-3' y la proteína Sgs1 es una helicasa de DNA implicada en el mantenimiento de la integridad del genoma que, durante la meiosis, regula la sinapsis de los cromosomas y la formación de los entrecruzamientos meióticos (Rockmill et al., 2003).

Resultados recientes acerca de la resección de una DSB generada por la endonucleasa HO en células vegetativas han revelado una función clave para Exo1 y Sgs1 en este proceso (Mimitou and Symington, 2008; Zhu et al., 2008). Estos trabajos demuestran que el complejo MRX y la proteína Sae2 son importantes al inicio de la resección de la DSB para generar fragmentos cortos de SSDNA, que después son procesados en mucha mayor longitud por Exo1 y Sgs1 en colaboración con la nucleasa Dna2.

Para investigar la contribución de estas proteínas al procesamiento de DSBs meióticas e intentar determinar los requerimientos genéticos para la formación de ssDNA durante la recombinación meiótica, y en el mutante sae2 en particular, construimos los mutantes exo1, sgs1, exo1 sgs1 y exo1 sae2, y examinamos en ellos la localización de Ddc2 a lo largo de la meiosis (Figuras 36, 37). El mutante sencillo exo1 presenta una cinética de progresión de la meiosis similar a la cepa silvestre (Figura 37A). Asimismo, la aparición de células con focos de Ddc2 en el mutante exo1 muestra un pico durante la profase y después disminuye progresivamente (Figura 36A); además, el patrón de focos sencillos y múltiples de Ddc2 es similar al silvestre (Figuras 20 y 36B). Por tanto, la exonucleasa Exo1 es dispensable para el procesamiento y reparación de las DSBs meióticas.

Por su parte, en el doble mutante exo1 sae2 se siguen acumulando focos múltiples de Ddc2 (Figura 36), lo que implica que la generación de regiones de ssDNA en sae2 no depende, al menos exclusivamente, de Exo1. Por su parte, tanto el mutante sgs 1 como el doble mutante sgs 1 exo1 muestran un retraso en la progresión de la meiosis con respecto a la cepa silvestre y al mutante exo1 (Figura 37A) que, además, correlaciona con la acumulación de focos múltiples de Ddc2-GFP (Figuras 37B y 37C) de acuerdo con la existencia una recombinación meiótica defectiva en ausencia de Sgs1 (Rockmill et al., 2003). No obstante, la presencia de focos múltiples de Ddc2 en sgs1 exo1 indica que sigue habiendo resección de las DSBs meióticas en este doble mutante donde Sae2 está presente. Para determinar si la generación de ssDNA que observamos en ausencia de Sae2 depende de Sgs1, intentamos construir los mutantes sae2 sgs1 y sae2 sgs1 exo1, pero fue imposible debido a que existe letalidad sintética entre sae2 y sgs1. Por ello, decidimos generar un mutante "meiótico nulo" de SAE2, para inactivarlo exclusivamente durante la meiosis y poder así combinarlo con sgs1. Para ello, generamos cepas en las que el gen SAE2 se colocó bajo el control del promotor de CLB2 que se expresa durante el crecimiento mitótico pero se reprime durante la meiosis (Grandin and Reed, 1993; Lee and Amon, 2003). En primer lugar, analizamos mediante western blot la producción de Sae2 a partir de esta construcción p $^{\text {CLB2 }}$-SAE2, en la que, además, la proteína producida está marcada con tres copias del epítopo HA. En la Figura 38A se muestra que Sae2 está presente en las células vegetativas antes de entrar en meiosis $(t=0)$, pero después ya no se detecta a lo largo de la meiosis, lo que indicaba que esta construcción se estaba comportando del modo esperado. Sin embargo, encontramos que la cepa $\mathrm{p}^{C L B 2}$-SAE2 presentaba un fenotipo intermedio entre la cepa silvestre y el mutante sae2 en cuanto a la cinética de divisiones nucleares meióticas (Figura 38B) y, a diferencia de sae2, no mostraba una acumulación tan acusada de células con focos de Ddc2 (Figura 38C). El hecho de que el fenotipo meiótico conferido por $\mathrm{p}^{\mathrm{CLB2}-S A E 2}$ fuera menos fuerte que el de sae2 podría ser debido a que, o bien siguen 
existiendo ciertos niveles de Sae2 durante la meiosis no detectables por western, o bien la proteína que procede de las células vegetativas todavía es capaz de actuar en los tiempos iniciales del programa meiótico antes de desaparecer. En cualquier caso, se construyeron y analizaron las cepas $p^{\text {CLB2 }-S A E 2 ~ s g s 1 ~ y ~}$ p $^{\text {CB2 }}$-SAE2 sgs1 exo1, que mostraron un retraso meiótico más acusado (Figura 39A) y una mayor acumulación de células con señal de Ddc2 en comparación con p pLB2_SAE2 (Figura 39B). No obstante, se seguían observando focos múltiples de Ddc2 en estas estirpes (Figura 39C), lo que indica que sigue habiendo resección de las DSBs incluso en ausencia de Sgs1 y Exo1 y con la función de Sae2 disminuida. Sin embargo, un análisis más detallado nos permitió detectar que en $\mathrm{p}^{\text {CLB2}}$-SAE2 sgs1 y, sobre todo, en $\mathrm{p}^{\text {CLB2}-S A E 2 ~ s g s 1 ~ e x o 1, ~ e x i s t i ́ a ~ u n ~ p o r c e n t a j e ~ m a ́ s ~ e l e v a d o ~ d e ~}$

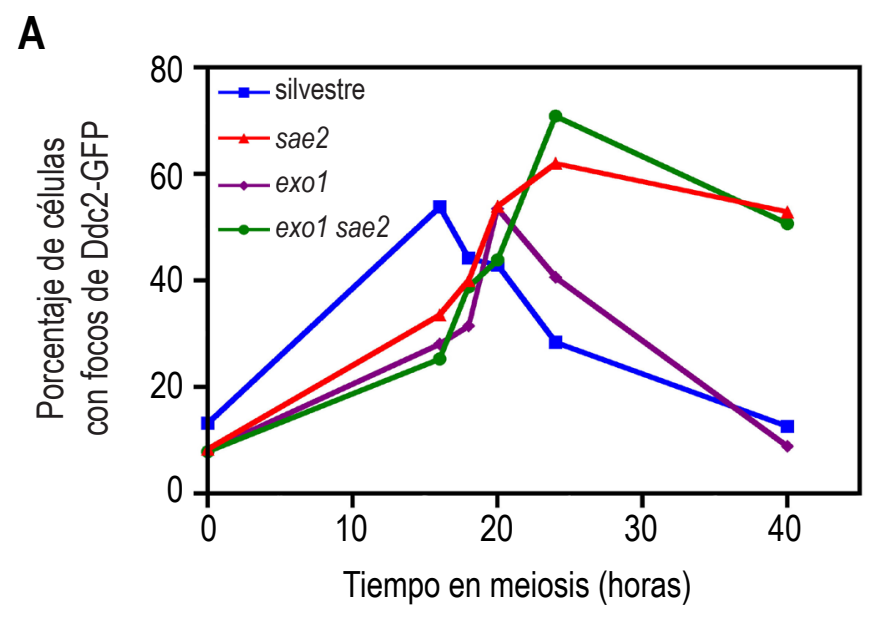

B

Patrón de focos de Ddc2-GFP
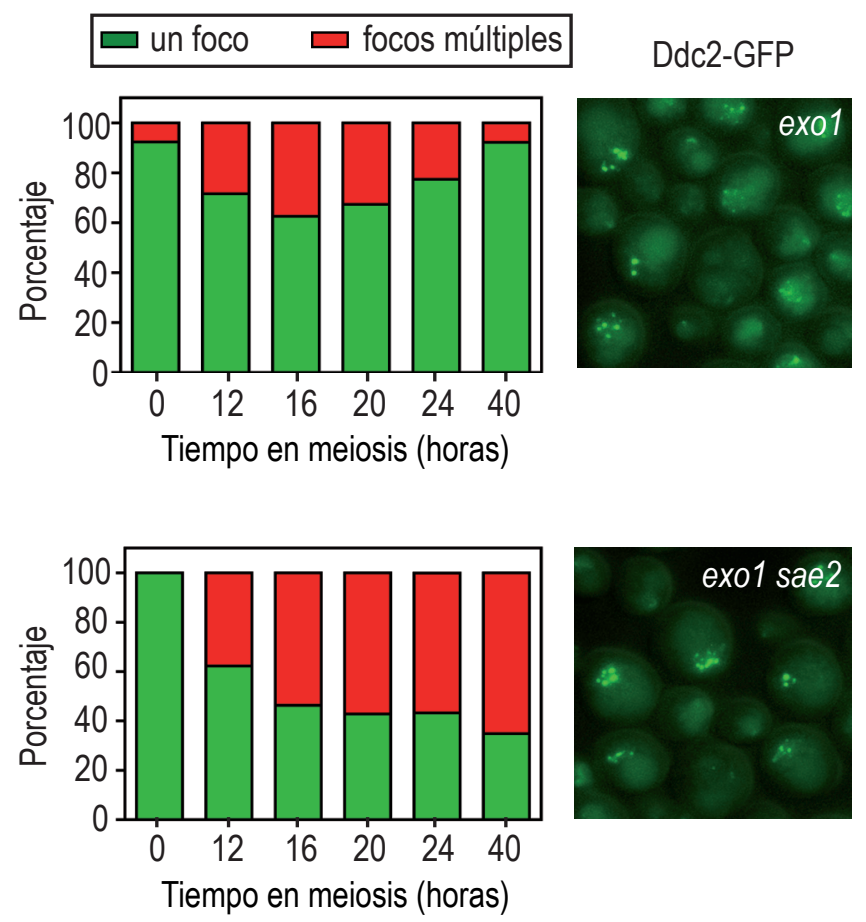

Figura 36. Análisis de la localización de Ddc2 en diferentes mutantes. (A) Se representa el porcentaje de células que contienen señal de Ddc2-GFP a diferentes tiempos de la meiosis. Se analizaron entre 150-500 células por cada tiempo de meiosis y para cada cepa. (B) Patrón de localización de Ddc2-GFP a lo largo de la meiosis (un solo foco o focos múltiples, como está indicado) en células que tenían señal de Ddc2-GFP. Las gráficas (paneles de la izquierda) representan el porcentaje de cada patrón de localización. También se muestran imágenes representativas de cada cepa (paneles de la derecha). Las cepas son DP448 (silvestre), DP484 (sae2), DP544 (exo1) y DP545 (exo1 sae2). 
A

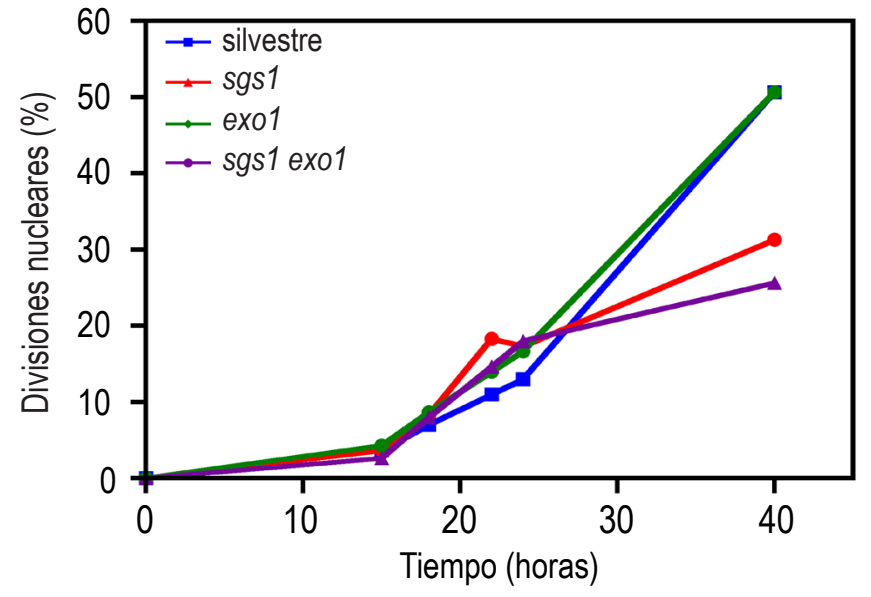

B

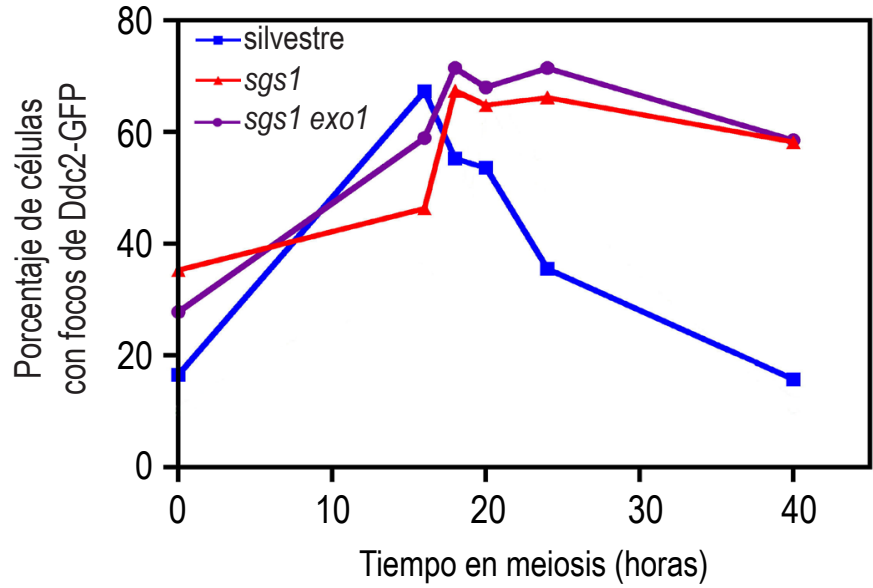

C

Patrón de focos de Ddc2-GFP

$\square$ un foco $\square$ focos múltiples

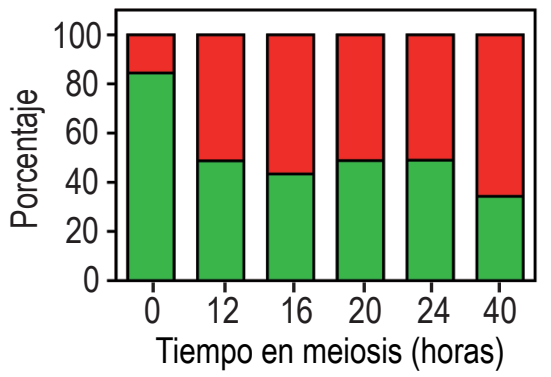

Ddc2-GFP
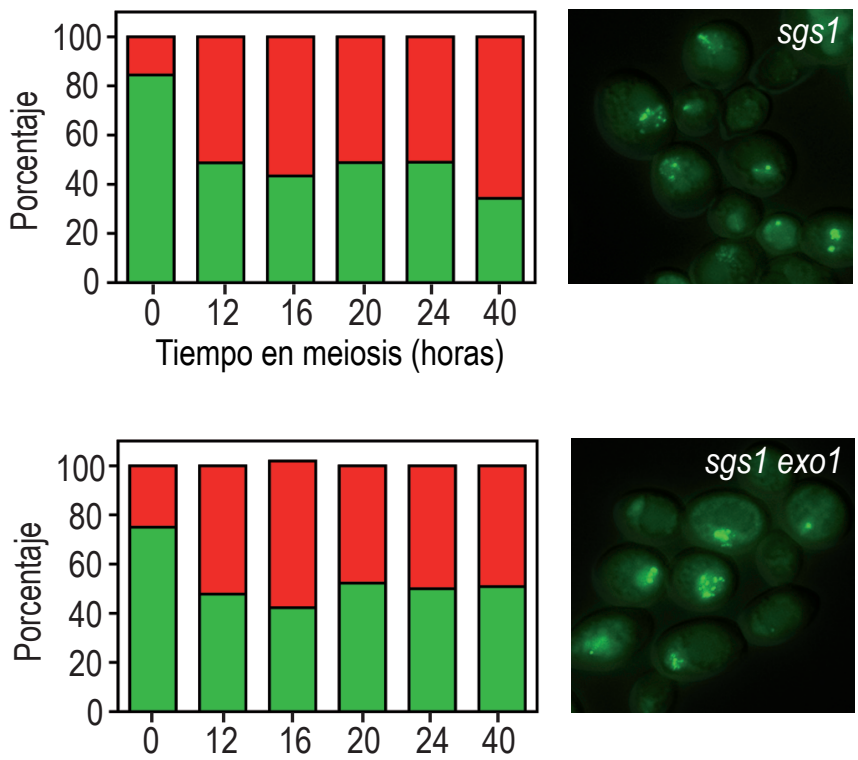

Figura 37. Análisis de la localización de Ddc2 en diferentes mutantes. (A) y (B) Se representa el porcentaje de células que contienen señal de Ddc2-GFP a diferentes tiempos de la meiosis. Se analizaron entre 150-500 células por cada tiempo de meiosis y para cada cepa. (C) Patrón de localización de Ddc2-GFP a lo largo de la meiosis (un solo foco o focos múltiples, como está indicado) en células que tenían señal de Ddc2-GFP. Las gráficas (paneles de la izquierda) representan el porcentaje de cada patrón de localización. También se muestran imágenes representativas de cada cepa (paneles de la derecha). Las cepas son DP448 (silvestre), DP609 (sgs1), DP544 (ex01) y DP610 (sgs1 ex01). 
células en las que las que Ddc2 se encuentra en el huso (Figura 40A), localización que, como se comentó en el apartado anterior, es independiente de la recombinación meiótica. Asimismo, contabilizamos el número de focos por célula y observamos que hay un ligera disminución tanto el mutante doble p $^{C L B 2}$-SAE2 sgs1 como en

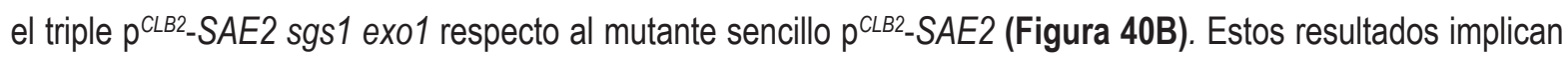
que la presencia de Ddc2 en los intermediarios de recombinación meiótica está de algún modo comprometida, aunque no eliminada, cuando la función de Sae2 está atenuada y las proteínas Sgs1 y Exo1 están ausentes.

A

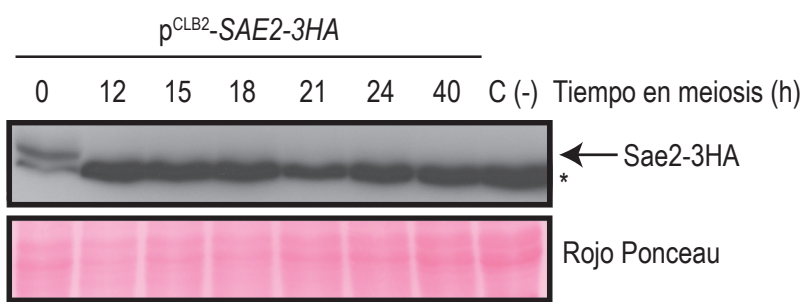

B

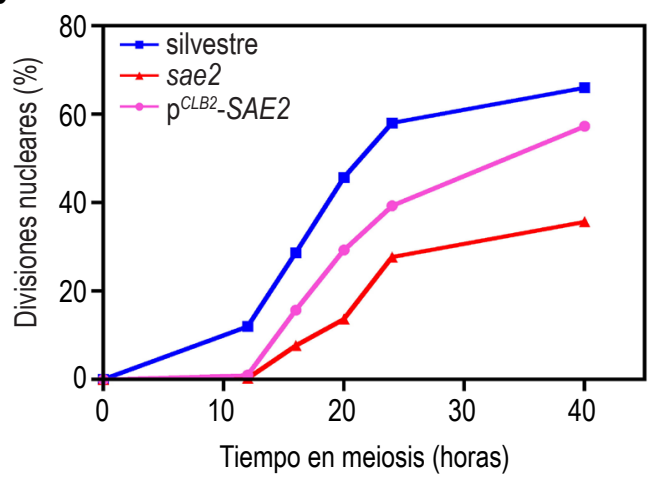

C

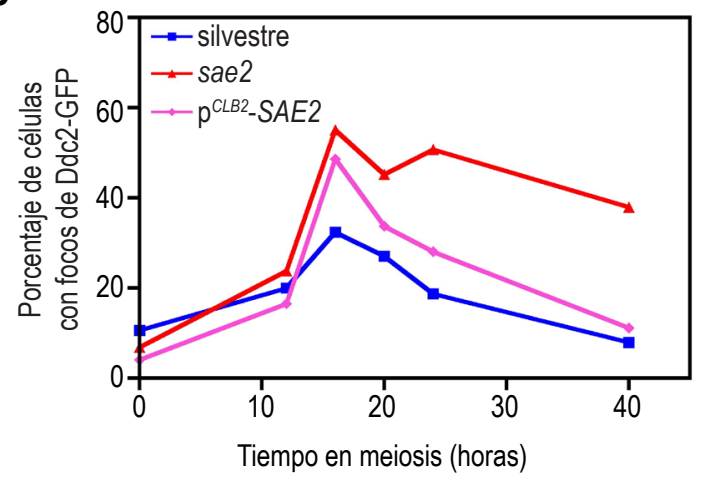

Figura 38. Análisis de un mutante meiótico nulo de SAE2 (p CLB2 $_{-}$SAE2). (A) Análisis mediante western blot de la desaparición de Sae2 al inducir la meiosis en el mutante $p^{C L B 2}-S A E 2-3 H A$. El asterisco marca una banda inespecífica (B) Se representan las cinéticas de las divisiones meióticas mediante el porcentaje de células que contienen más de dos núcleos. Se realizó un contaje de al menos 300 células para cada tiempo representado en la cinética. (C) Se representa el porcentaje de células que contienen señal de Ddc2-GFP a diferentes tiempos de la meiosis. Se analizaron entre 150-500 células por cada tiempo de meiosis y para cada cepa. Las cepas son DP448 (silvestre),

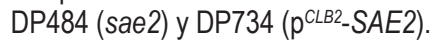


A

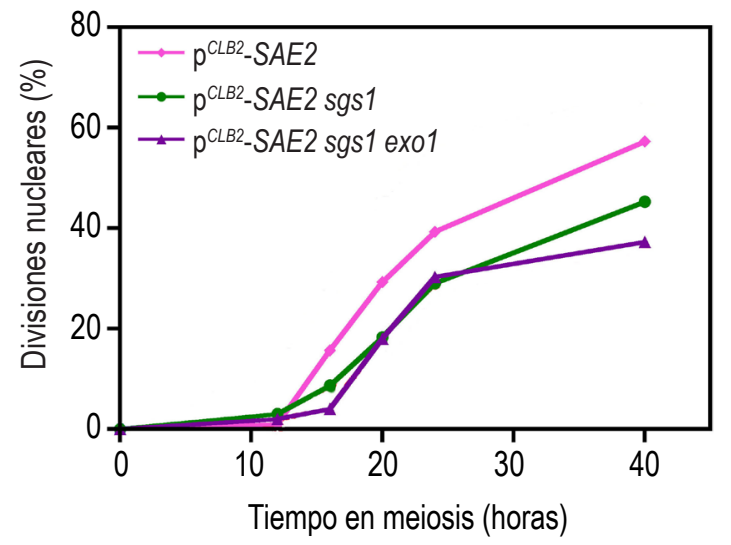

B

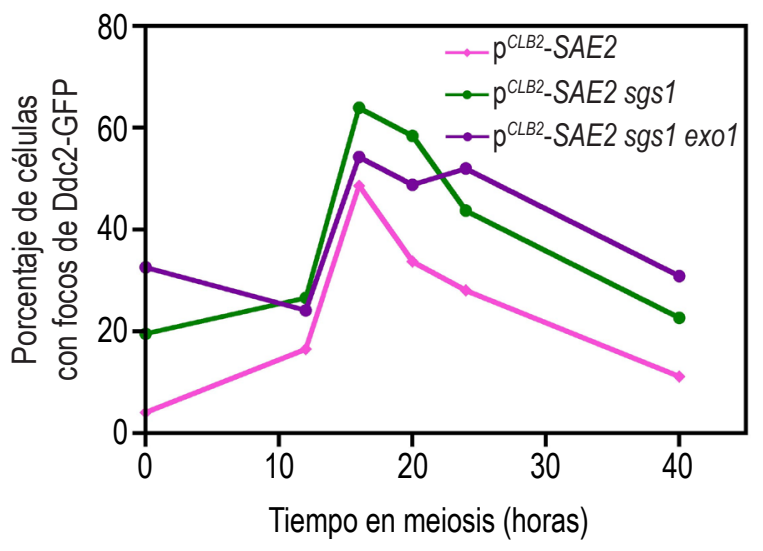

C

Patrón de focos de Ddc2-GFP

$\square$ un foco $\square$ focos múltiples Ddc2-GFP
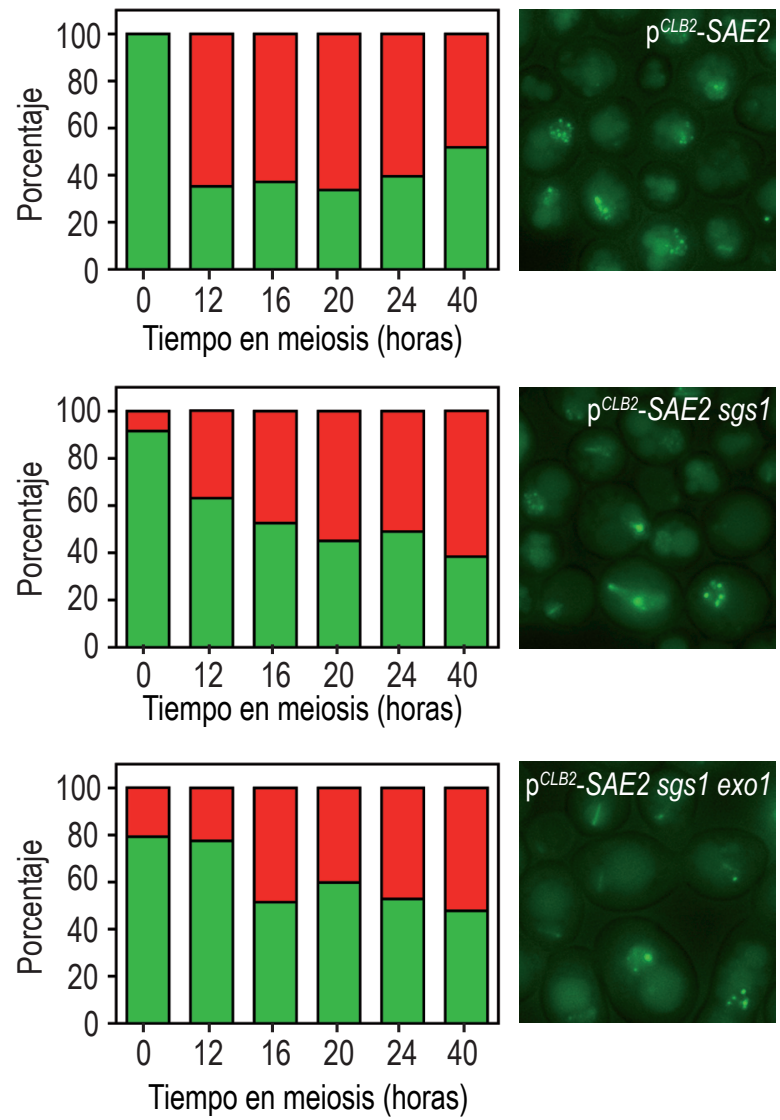

Figura 39. Localización de Ddc2 en diferentes mutantes. (A) Se representan las cinéticas de las divisiones meióticas mediante el porcentaje de células que contienen más de dos núcleos. Se realizó un contaje de al menos 300 células para cada tiempo. (B) Porcentaje de células que contienen señal de Ddc2-GFP a diferentes tiempos de meiosis. Se analizaron entre 150-500 células por cada tiempo y para cada cepa. (C) Patrón de localización de Ddc2-GFP a lo largo de la meiosis (un solo foco o focos múltiples, como está indicado) en células que tenían señal de Ddc2-GFP. Las gráficas (paneles de la izquierda) representan el porcentaje de cada patrón de localización. También se muestran imágenes representativas de cada cepa (paneles de la derecha). Las cepas son DP734 (p $p^{\text {CLB2 }}$-SAE2), DP735 (p ${ }^{\text {CLB2 }}$-SAE2

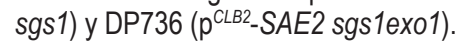


A

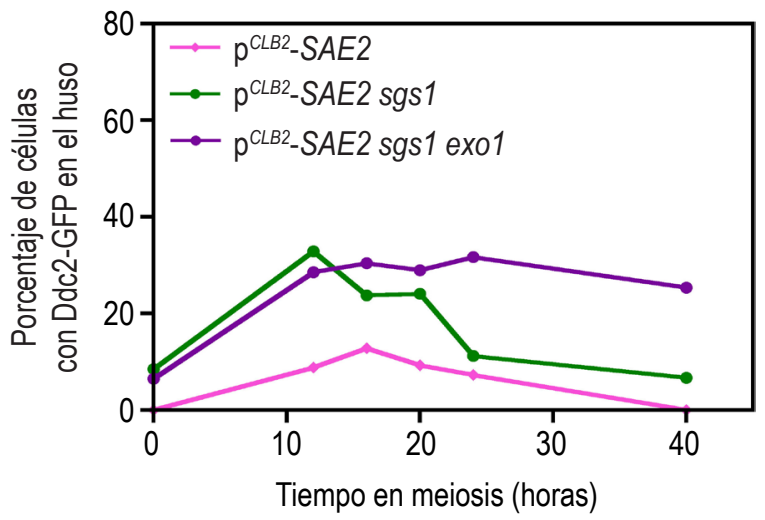

B

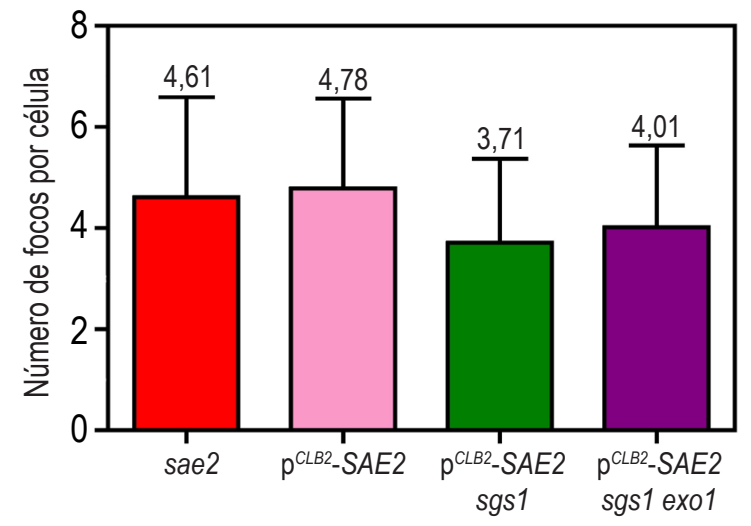

Figura 40. Análisis del patrón de localización de Ddc2 en diferentes mutantes. (A) Se representa el porcentaje de células que contienen señal alargada de Ddc2-GFP (huso meiótico; ver Figuras 26 y 27). Se analizaron entre 150-500 células por cada tiempo de la meiosis y para cada cepa. (B) Cuantificación del número de focos discretos de Ddc2 por cada célula. Se analizaron entre 200 y 500 células

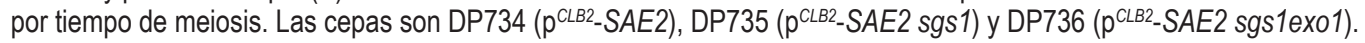


DISCUSIÓN 
Diferentes mutantes meióticos, tales como zip1, dmc1, hop2 o sae2, están alterados en varios aspectos de la recombinación y la dinámica de los cromosomas por lo que experimentan un retraso o bloqueo meiótico mediado por el checkpoint de recombinación meiótica. Para entender mejor como se activa el checkpoint en respuesta a la presencia de diferentes tipos de intermediarios de recombinación, hemos llevado a cabo una caracterización de la función meiótica de la proteína de checkpoint Ddc2 en S. cerevisiae.

\section{Función de Ddc2 en el checkpoint meiótico}

La deleción de DDC2 suprime el retraso meiótico de todos los mutantes analizados, lo que implica que, junto con Mec1 (Lydall et al., 1996; Usui et al., 2001), Ddc2 es un regulador clave en los mecanismos de vigilancia meióticos. El mayor defecto cromosómico del mutante zip1 es la ausencia de sinapsis, lo que resulta en fallos en la separación de los cromosomas homólogos durante la meiosis I (Sym and Roeder, 1994) y que se traduce en un patrón característico de muerte de las esporas con una predominancia de tétradas de 4-,2- y 0 esporas viables. Sin embargo, en el doble mutante zip1 $d d c 2$, la viabilidad de las esporas es aún menor y se pierde este patrón característico del mutante zip1 (Figura 7C), lo que sugiere que las células entran en meiosis con los intermediarios de recombinación sin resolver. Sin embargo, como ocurre en zip1, la mayoría de las ascas formadas en zip1 ddc2 son maduras y sus esporas contienen núcleos intactos, lo que es consistente con el hecho de que sólo una pequeña fracción de DSBs permanece sin reparar en el mutante zip1 (Storlazzi et al., 1996; Xu et al., 1997).

En el fondo genético BR utilizado en este trabajo, el mutante dmc1 muestra un marcado retraso en la meiosis, pero finalmente esporula y produce algunas esporas maduras con núcleos intactos. Esta observación sugiere que, durante el retraso meiótico de $d m c 1$, una fracción importante de DSBs se reparan, probablemente utilizando como molde la cromátida hermana. Confirmamos esta posibilidad cuando observamos que el mutante doble rad54 dmc1 presentaba un bloqueo más acusado. Por tanto, las diferencias que hay entre las cepas cepas SK1 utilizadas en otros estudios meióticos y las cepas BR respecto a la progresión de la meiosis en el mutante dmc1 (bloqueo en SK1 y retraso en BR) pueden deberse a que en las cepas BR, la barrera que impide la recombinación con la cromátida hermana sea más débil (Niu et al., 2009). En cualquier caso, la deleción de $D D C 2$ suprime el retraso o parada de $d m c 1$ y $d m c 1$ rad54, respectivamente, dando lugar a esporas inviables con el material genético fragmentado. Los mutantes hop2 ddc2 y sae2 ddc2 muestran el mismo tipo de productos meióticos aberrantes, es decir, esporas inviables e inmaduras con una distribución aberrante del material nuclear. El hecho de que, excepto para zip1, la deleción de DDC2 en dmc1, hop2 o sae2 no de como resultado una cinética de progresión meiótica como la del silvestre cuando se analizan las divisiones meióticas mediante tinción con DAPI se debe, probablemente, a la dificultad del contaje de las divisiones nucleares mediante DAPI cuando los núcleos están fragmentados como consecuencia de una segregación cromosómica con DSBs sin reparar. De hecho, el análisis de la separación de los polos del huso muestra que el bloqueo meiótico de dmc1 y hop2 se suprime completamente mediante la deleción de DDC2 (Figura 9).

\section{Regulación de Ddc2 durante la meiosis}

Hemos observado que durante una meiosis normal, la proteína Ddc2 alcanza sus máximos niveles durante la profase meiótica, coincidente con la presencia de intermediarios de recombinación, pero decae 
progresivamente a medida que la meiosis y la esporulación progresan. Por su parte, Ddc2 se acumula en mutantes bloqueados por el checkpoint, lo cual es consistente con un papel para Ddc2 detectando los intermediarios de recombinación meiótica. El daño en el DNA durante el ciclo celular mitótico estimula la fosforilación de Ddc2 (Paciotti et al., 2000); sin embargo, la contribución de estos eventos de fosforilación a la señalización del daño aún no está clara (Zou, 2007). Sorprendentemente, hemos encontrado que la mutación de Ddc2 en los tres sitios consenso S/T-Q para la fosforilación por Mec1, no confiere un defecto en el checkpoint ni en células mitóticas ni meióticas, lo cual indica que estos sitios potenciales de ser fosforilados no son relevantes para la función del Ddc2 en el checkpoint. De forma similar, en células somáticas de mamíferos, la fosforilación de ATRIP dependiente de ATR en los sitios consenso S/T-Q es prescindible en la respuesta al daño en el DNA (Itakura et al., 2004). También se ha mostrado esta falta de relevancia biológica para la fosforilación de los sitios S/T-Q en otras dianas de Mec1, tales como, Xrs2, Dun1 y Rfa2 (Mallory et al., 2003), indicando que quizás haya otros sitios (diferentes a los sitios consenso) para la fosforilación por Mec1 que sean los importantes, al menos para algunos de los substratos de Mec1.

\section{Ddc2 marca los intermediarios de recombinación}

En células vegetativas, el complejo Mec1-Ddc2 es un sensor primario del daño en el DNA (Kondo et al., 2001; Melo et al., 2001) y la formación de los focos de Ddc2 se utiliza frecuentemente como marcador de la presencia de daño en el DNA (Lisby et al., 2004). Aunque Mec1-Ddc2 puede reconocer diferentes tipos de estructuras de DNA aberrante o dañado, se ha determinado que la proteína Ddc2 reconoce el daño en el DNA al interaccionar con el ssDNA que está cubierto por la proteína RPA, permitiendo así la asociación del complejo Mec1-Ddc2 a los sitios de DNA dañado (Zou and Elledge, 2003; Nakada et al., 2005; Zou, 2007). En este trabajo mostramos evidencias que indican que Ddc2 también marca la presencia de intermediarios de recombinación durante la meiosis (Figura 41). La localización de Ddc2 en los cromosomas meióticos se correlaciona con la dinámica de la reparación de las DSBs durante la profase meiótica; hay muchos focos de Ddc2 en zigotene pero disminuyen en paquitene en las células silvestres. Por el contrario, el número de focos de Ddc2 continúa siendo muy elevado en mutantes dmc1 y hop2, los cuales acumulan DSBs sin reparar. El hecho de que el número de focos de Ddc2 que se observa $(\sim 30-60)$ es más bajo que el número total de DSBs meióticas que se generan $(\approx 200)$, puede reflejar que un foco sencillo representa varias DSBs sin reparar. Cabe mencionar que el número de focos y la cinética de distribución de la proteína del checkpoint Ddc1 en los cromosomas meióticos son parecidas a la que presenta Ddc2 (Hong and Roeder, 2002) a pesar de que ambas son reclutadas de forma independiente a las DSBs (Melo et al., 2001).

En células vegetativas, la presencia de DSBs induce la formación de los llamados "centros de reparación", en los cuales se concentran una serie de proteínas del checkpoint y de reparación del DNA, incluyendo Ddc2, que se pueden visualizar como focos nucleares discretos en células enteras (Lisby et al., 2004). Se ha comprobado que cada foco representa múltiples DSBs (Lisby et al., 2003b) y aunque se induzcan por daño en el DNA, los focos de reparación también aparecen ocasionalmente en células no sometidas a estrés genotóxico, como consecuencia de lesiones espontáneas que se generan durante la replicación del DNA (Lisby et al., 2003a). Nuestro análisis de la cinética que siguen los focos de Ddc2-GFP en células meióticas, es consistente con el papel de Ddc2 en señalizar los intermediarios de recombinación. En el silvestre, las células con focos de Ddc2 
alcanzan un máximo durante la profase meiótica para luego caer, mientras que en los mutantes defectivos en recombinación, el número de células con señal de Ddc2 se acumula. Cabe destacar que los focos de Ddc2-GFP aparecen con diferente morfología cuando se comparan células mitóticas y meióticas. En las células mitóticas, las DSBs múltiples dan lugar a uno o pocos centros de reparación que se identifican como focos brillantes, a los que son reclutados tanto proteínas del checkpoint como proteínas de reparación del DNA. Este número tan reducido de focos (1-3) se produce incluso cuando las células se exponen a altas dosis de radiación- $\gamma$ que producen unas 80 DSBs por célula (Lisby et al., 2003b). Por el contrario, en células meióticas observamos múltiples focos de Ddc2 que coinciden con la presencia de DSBs sin reparar. Este patrón tan diferente puede reflejar no sólo el gran número de DSBs generadas en cada célula meiótica, sino también la arquitectura cromosómica especializada en la cual tiene lugar la formación, la señalización y la reparación de las DSBs meióticas.

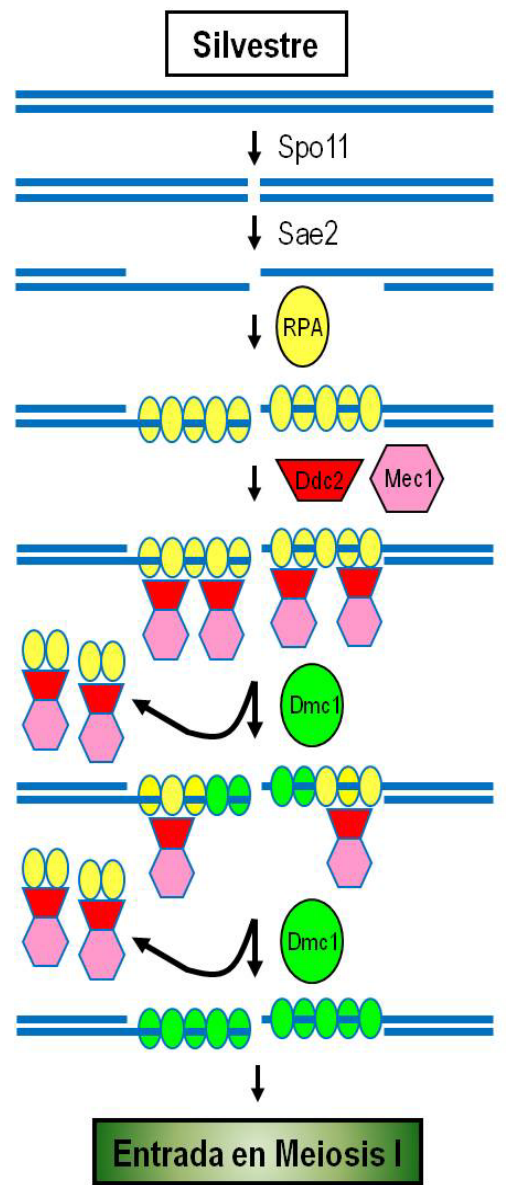

Esporas viables

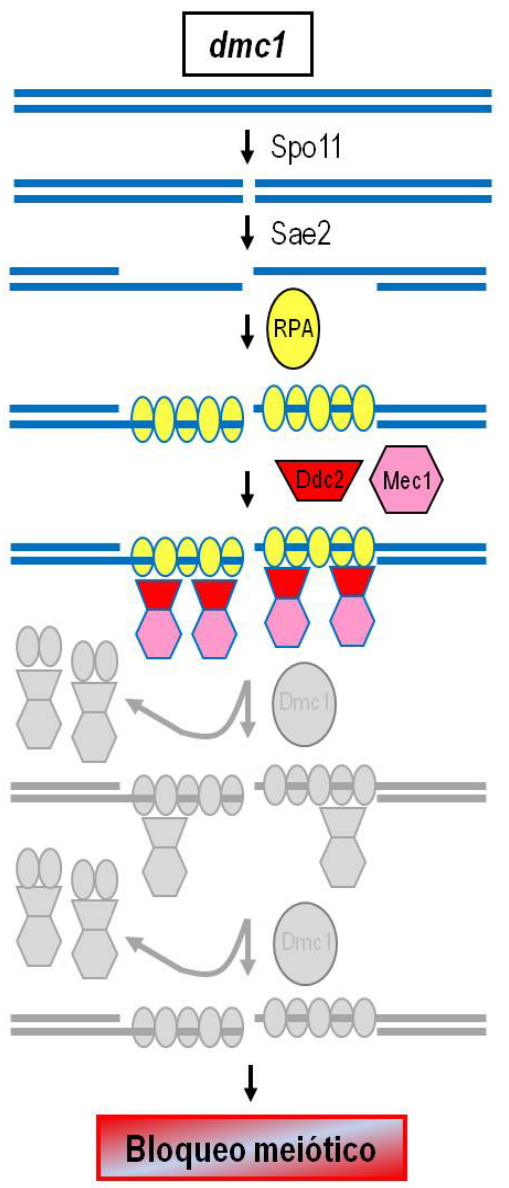

Bloqueo meiótico

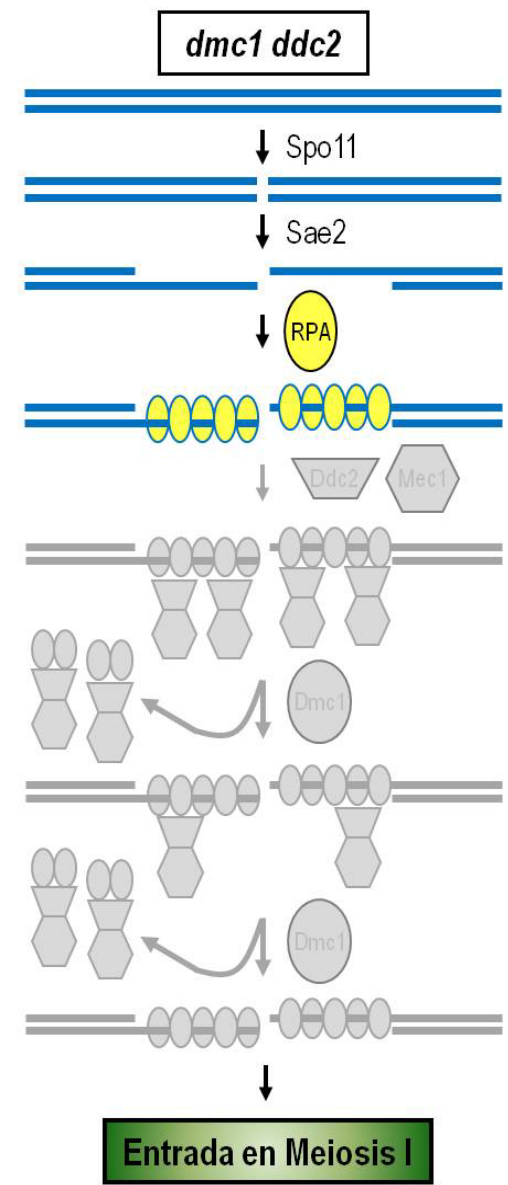

Esporas inviables

Figura 41. Ddc2 actúa como sensor en el checkpoint de recombinación meiótica. Modelo representativo del reclutamiento de diferentes proteínas a las DSBs meióticas. En la cepa silvestre, en primer lugar se produce el reclutamiento del complejo RPA al ssDNA generado dependiente de Sae2. A continuación, se reclutaría el complejo sensor del daño, formado por Mec1-Ddc2, mediante su unión a RPA, que es reemplazado gradualmente por Dmc1 promoviendo la reparación de las DSBs por recombinación y la desactivación del checkpoint. En el mutante dmc1, el complejo Mec1-Ddc2 permanece anclado a las DSBs procesadas a ssDNA señalizando la presencia de intermediarios de recombinación sin reparar y produciendo el bloqueo de las células en la profase meiótica. Por último, en el doble mutante $d m c 1 d d c 2$ no se detecta la existencia de DSBs sin reparar y las células entran en Meiosis I sin haber reparado el daño existente originando productos meióticos defectivos. 
Además, observamos diferentes morfologías en los focos de Ddc2 dependiendo del mutante analizado. El mutante sae2 muestra un menor número de focos de Ddc2-GFP pero de mayor intensidad que los mutantes dmc1 y hop2, lo que probablemente se deba a que estos mutantes se bloquean en diferentes pasos de la reparación de las DSBs. La observación de la formación de focos de Ddc2 en el mutante sae2 fue un resultado sorprendente porque Sae2 es necesaria para el procesamiento de las DSBs meióticas. Esta observación implica que, al menos en las cepas BR, se debe estar formando ssDNA incluso en ausencia de Sae2. En un apartado posterior se comentará más detalladamente este aspecto.

La formación de los focos de Ddc2 depende de Spo11, es decir, depende de la iniciación de la recombinación meiótica y, además, los focos de Ddc2 colocalizan parcialmente con Rad51, lo que indica que representan lugares donde está teniendo lugar la recombinación meiótica. En otros estudios también se ha encontrado que existe una colocalización limitada de focos de Rad51/Dmc1 con las proteínas del checkpoint ATR o TopBP1 en cromosomas meióticos de mamíferos (Moens et al., 1999; Perera et al., 2004b). El hecho de que sólo observemos una colocalización parcial de los focos de Ddc2 y Rad51 en las extensiones de cromosomas meióticos sugiere que su reclutamiento a los intermediarios de recombinación tiene lugar con una cinética diferente debido a que la recombinación meiótica es un proceso dinámico. Los análisis moleculares y bioquímicos de la reparación de DSBs por recombinación han demostrado que, durante la invasión de la cadena, Rad51 desplaza a RPA del ssDNA, lo cual, es consistente con la colocalización parcial que hemos observado (Kantake et al., 2003; Sugiyama and Kantake, 2009). Si Ddc2 se une preferentemente a los lugares cubiertos por RPA, como sugiere la falta de formación de focos de Ddc2 en células deficientes en RPA (Figura 21), esto explicaría la falta de colocalización total entre Ddc2 y Rad51, como ya ha sido descrito para las proteína Ddc1 y Rad51 (Hong and Roeder, 2002). La marcada variabilidad que se observa en la intensidad relativa de los focos de Ddc2 y Rad51 también es consistente con una dinámica diferente de la localización de las proteínas en los cromosomas. En cualquier caso, el análisis por ChIP de un mutante dmc1 revela una acumulación de Ddc2 específica de meiosis y dependiente de Spo11 en dos hotspots de DSBs, lo que corrobora la presencia de Ddc2 en los intermediarios de recombinación meiótica. Aunque el enriquecimiento de Ddc2 en las DSBs no es muy elevado, esto puede reflejar una menor actividad de los hotspots en las cepas BR, respecto de las cepas SK1 donde han sido caracterizados.

Estudios recientes en espermatocitos de ratón, que permiten una mayor resolución citológica, han revelado que la proteína homóloga a Ddc2 en mamíferos, denominada ATRIP, se localiza en los cromosomas meióticos durante los estadios de leptotene a paquitene (Refolio et al., 2011). Después, durante el diplotene, se acumula en el par XY que permanece sin hacer sinapsis y donde también se detectan numerosas proteínas de checkpoint (Keegan et al., 1996; Freire et al., 1998; Moens et al., 1999; Perera et al., 2004a; Roig et al., 2010). ATRIP también colocaliza con otras proteínas de checkpoint, como ATR y TopBP1 en aquellas regiones de los autosomas que no han establecido sinapsis, probablemente monitorizando los eventos de la profase meiótica para activar el checkpoint e impedir la progresión de la meiosis mientras no se complete la sinapsis y recombinación (Perera et al., 2004a). Por tanto, la localización de ATRIP durante la meiosis en mamíferos está de acuerdo con la función que hemos descrito en nuestros estudios de Ddc2 en levadura como sensor de los intermediarios de recombinación meiótica. En definitiva, nuestros resultados apoyan la existencia de una conservación evolutiva para la función biológica de Ddc2/ATRIP durante la gametogénesis. 


\section{Posible papel de Ddc2 en la dinámica del huso meiótico}

Uno de los resultados inesperados encontrados en este trabajo fue la localización de Ddc2 en células que carecen de recombinación meiótica (spo11). En el mutante spo11 no se lleva a cabo el inicio de la recombinación meiótica porque no se producen los DSBs y aunque tiene una progresión de la meiosis parecida a la de una cepa silvestre, al carecer de DSBs, los cromosomas segregan al azar con la consiguiente pérdida de la viabilidad de las esporas. En el mutante spo11 no se observan los focos múltiples de Ddc2 que representan DSBs meióticas sin reparar, pero la señal de Ddc2 no desaparece, sino que se concentra en una región discreta con una morfología que recuerda al haz de microtúbulos durante la profase meiótica. De hecho, hemos comprobado que Ddc2 colocaliza e interacciona con la tubulina en la mayoría de las células en las que la señal de Ddc2 es alargada. Además, esta colocalización de Ddc2 con la tubulina no sólo tiene lugar en un mutante spo11, sino que, también ocurre de forma significativa en una cepa silvestre aunque, eso sí, en menor medida. Esta sorprendente colocalización entre Ddc2 y Tubulina no ocurre exclusivamente cuando la señal de Ddc2 es alargada, sino que también tiene lugar frecuentemente cuando la señal de Ddc2 aparece como un único foco redondo típico. Esta observación sugiere que los focos o centros de reparación del daño espontáneo que se genera normalmente en la célula se localizan en regiones nucleares próximas al SPB desde donde se organizan los microtúbulos nucleares. El hecho de que la asociación de Ddc2 con estas estructuras dependa de Mec1 apoya la relevancia funcional de esta localización.

Esta localización alternativa de Ddc2 asociada al huso de la profase meiótica podría ser indicativa de un posible papel adicional de Ddc2 en algún aspecto relacionado con la dinámica de los mircrotúbulos, si bien no se puede descartar que represente un mero lugar de acumulación o almacenamiento de la proteína una vez finalizada su función de sensor cuando los intermediarios de recombinación ya se han reparado. De acuerdo con esta posibilidad, nuestros estudios de time-lapse muestran que en células que inicialmente presentan varios focos múltiples, a medida que pasa el tiempo, estos confluían en una estructura alargada que seguramente corresponda al huso meiótico en profase. También podría ocurrir que, de algún modo, Ddc2 permita la comunicación directa entre la maquinaria de reparación y/o señalización de las DSBs y los mecanismos responsables del metabolismo del huso, contribuyendo a bloquear el ensamblaje del huso metafásico mientras existan DSBs sin reparar.

Curiosamente, la localización de Ddc2 asociada a los microtúlbulos de la profase es especialmente evidente en el mutante spo11. Aunque en spo11 no se activa el checkpoint de paquitene, al no existir DSBs, sí que se activa el checkpoint de ensamblaje del huso (SAC). Al no haber recombinación meiótica en spo11, no se producen los entrecruzamientos que dan lugar a los quiasmas, responsables junto con los microtúbulos del huso tirando hacia polos opuestos, de la generación de la tensión adecuada para que los cromosomas segreguen correctamente. La falta de tensión en el huso en ausencia de quiasmas activa el SAC, lo que resulta en un ligero retraso meiótico en el mutante spo11 (Shonn, 2000). Estudios recientes han revelado que existe una estrecha relación funcional entre el checkpoint de daño en DNA y el SAC (Kim and Burke, 2008); por tanto, podría ocurrir que Ddc2 también participe en este otro mecanismo de vigilancia del ciclo celular, el SAC. De acuerdo con esta posibilidad, nuestros estudios preliminares muestran que los mutantes $d d c 2$ y mec1 presentan sensibilidad a benomilo. Estudios futuros, en los que se examine si la deleción de $D D C 2$ suprime el retraso meiótico del mutante spo11, nos permitirán investigar en más detalle la posibilidad de que Ddc2 sea necesario para el SAC durante la meiosis. 


\section{Intermediarios de recombinación detectados por Ddc2 en el mutante sae2}

Como ya se mencionó anteriormente, cuando analizamos la localización de Ddc2 en diversos mutantes alterados en diferentes pasos de la recombinación meiótica encontramos que, sorprendentemente, Ddc2 formaba múltiples focos en el mutante sae2. Este resultado fue totalmente inesperado porque la proteína Sae2 es necesaria para eliminar Spo11 de los extremos de las DSBs meióticas permitiendo así su resección (Keeney and Kleckner, 1995; McKee and Kleckner, 1997; Prinz et al., 1997). Por tanto, en sae2 no deben procesarse las DSBs a ssDNA por lo que no se reclutaría RPA y, consecuentemente, no deberían formarse focos de Ddc2. Puesto que la proteína Sae2 no es específica de meiosis sino que también juega un papel importante en el mantenimiento de la estabilidad genómica durante el ciclo mitótico (Clerici et al., 2005), podría ocurrir que los focos de Ddc2 que detectamos en sae2 no reflejaran DSBs meióticas sino fueran consecuencia de la acumulación de roturas espontáneas en el DNA producidas durante el crecimiento vegetativo previo a la meiosis, o incluso producidas de forma tardía durante las segregaciones cromosomales meióticas. No obstante, presentamos diversas evidencias que descartan esas posibilidades e indican que los focos de Ddc2 detectados en sae2 representan auténticos intermediarios de recombinación meiótica, puesto que: (a) dependen de Spo11 y de Mec1, (b) también se observan en un mutante rad50-S, (c) activan el checkpoint de recombinación meiótica dependiente de Mek1 y no el checkpoint de daño en el DNA dependiente de Rad53 como ocurría en caso de proceder de daño espontáneo y (d) el hecho de que en ausencia de Ndt80, que es necesaria para la salida de profase, se siga detectando la acumulación de focos de Ddc2 en sae2, confirma que se están produciendo durante la profase meiótica.

Por tanto, puesto que la función de Ddc2 es necesaria para promover el retraso meiótico de sae2, caben dos alternativas, o bien Mec1/Ddc2 también es capaz de señalizar DSBs sin procesar, o bien, de alguna manera se está generando ssDNA en el mutante sae2 que conduce a la activación del checkpoint meiótico dependiente de Mec1-Ddc2 y Mek1. Nuestros resultados apoyan la segunda posibilidad porque: (a) el complejo RPA de unión a ssDNA forma focos meióticos en los mutantes sae2 y rad50-S que colocalizan con Ddc2 y (b) empleando marcaje con BrdU, hemos detectado la presencia de ssDNA en núcleos meióticos de sae2.

En principio, la presencia de ssDNA en los intermediarios de recombinación acumulados en sae2 podría explicarse sin necesidad de que haya resección de las DSBs, si existiera cierto desenrollamiento de la doble cadena del DNA en los extremos de las DSBs de modo que quedaran expuestas regiones de ssDNA detectadas por Ddc2. En ese caso, cabría esperar que dicho desenrollamiento fuera llevado a cabo por una helicasa de DNA siendo Sgs1 el principal candidato ya que participa en la resección de DSBs mitóticas facilitando la acción de nucleasas (Mimitou and Symington, 2008; Zhu et al., 2008). Alternativamente, el ssDNA podría producirse por la resección de algunas DSBs tras la liberación de Spo11 de los extremos de las mismas por un mecanismo independiente de Sae2 (ver Figura 34). En este caso, la resección ocurriría sólo en un subconjunto de las DSBs generadas porque la proteína Spo11 permanece hasta tiempos tardíos en el mutante sae2 aunque no colocaliza con Ddc2, lo que apoya la segunda alternativa; es decir, que haya procesamiento de algunas DSBs. El hecho de que el número de focos de Ddc2 que se detecta en sae2 sea mucho menor que en los mutantes dmc1 o hop2 también está de acuerdo con que la resección no ocurra en todas las DSBs. Asimismo, nuestros estudios de ChIP en sae2 muestran un enriquecimiento diferencial para Ddc2 en diferentes hotspots.

Si la única función de Sae2 en la recombinación meiótica fuera la eliminación de Spo11, una vez que se produce el procesamiento de determinadas DSBs de forma independiente de Sae2 no cabría esperar ningún 
impedimento para que esas DSBs fueran reparadas. Sin embargo, el hecho de que se acumulen focos de Ddc2, indica que permanecen si reparar poniendo de manifiesto una función más tardía para Sae2 en el proceso de recombinación. Estudios en mutantes de C. elegans defectivos en el gen com-1 (homólogo de SAE2) también apuntan a la posibilidad de una función adicional de Sae2/Com1 en el proceso de invasión de la cadena homóloga, puesto que acumulan focos de Rad51 en gónadas irradiadas con rayos $\gamma$ (Penkner et al., 2007).

Puesto que el requerimiento de Sae2 para que se produzca el corte endonucleolítico que elimina Spo11 se ha estudiado detalladamente exclusivamente en cepas del fondo genético SK1 y en determinados hotspots de recombinación, no puede descartarse que en las cepas BR y W303 utlizadas en este trabajo existan nucleasas alternativas o adicionales que puedan colaborar con Sae2 en el procesamiento de las DSBs meióticas. Basándonos en los requerimientos descritos para el procesamiento de DSBs generadas por $\mathrm{HO}$ en células vegetativas (ver introducción) hemos analizado la contribución de la nucleasa Exo1 y la helicasa Sgs1 a la resección de DSBs meióticas empleando la formación de focos de Ddc2 como indicador de la presencia de ssDNA. En el caso de las DSBs mitóticas generadas por HO, aunque los mutantes sencillos exo1 y ssg1 son capaces de reclutar Ddc2 a las DSBs, en el doble mutante exo1 sgs1 no se forman focos de Ddc2 (Zhu et al., 2008). Sin embargo, en nuestros estudios durante la meiosis encontramos acumulación de focos meióticos de Ddc2 en el doble mutante sgs1 exo1, lo que pone de manifiesto la existencia de diferentes requerimientos genéticos para el procesamiento de las DSBs mitóticas y meióticas. Estas diferencias pueden estar relacionadas con el diferente contexto cromosomal en las que éstas últimas se producen, como son los bucles de cromatina anclados a los elementos axiales de los cromosomas (Panizza et al., 2011). No obstante, en estudios en los que se ha medido la formación de ssDNA mediante Southern blot en el hotspot adyacente al gen BUD23 en cepas SK1, se ha detectado un procesamiento muy limitado en el doble mutante ex01 sgs1 (Manfrini et al., 2010). Curiosamente, es en este mismo hotspot donde en nuestros análisis de ChIP (en cepas BR) no encontramos enriquecimiento de Ddc2.

En conjunto, todas estas observaciones permiten especular que, al menos en cepas BR de S. cerevisiae puedan existir dos tipos de DSBs meióticas con diferentes requerimientos para su procesamiento. En algunas de ellas, quizás la mayoría, la resección estaría mediada por el proceso canónico; es decir, eliminación de Spo11 de los extremos por MRX y Sae2 y posterior degradación a ssDNA mediante la acción de Exo1, Sgs1 y, probablemente, Dna2. Pero además, existiría un subconjunto de DSBs en las que la liberación de Spo11 y posterior resección no requiere, al menos exclusivamente, de Sae2, Exo1 y Sgs1. Estudios futuros encaminados a encontrar mutantes en los que se elimine la formación de focos de Ddc2 en sae2, posiblemente permitirán la identificación de nuevas funciones génicas implicadas en el procesamiento de las DSBs meióticas.

Es posible que las diferencias entre los dos tipos de DSBs pueda venir determinada por diferencias en la cromatina. Así, la metilación de la histona H3 en la lisina 4 (H3K4me) por Set1 está enriquecida en los sitios donde se producen DSBs de modo que el mutante set1 presenta niveles reducidos de DSBs, pero éstas no están completamente eliminadas (Borde et al., 2009). Puede especularse que las DSBs que se generan en un contexto no determinado por la metilación de H3K4 podrían tener diferentes requerimientos para su procesamiento. 
CONCLUSIONES 
1. La proteína Ddc2 participa en el checkpoint de recombinación meiótica ya que la deleción de DDC2 suprime el bloqueo meiótico que tienen mutantes de sinapsis y/o recombinación permitiendo la entrada en Meiosis I sin haber reparado los intermediarios de recombinación y generando productos meióticos aberrantes.

2. La producción de la proteína Ddc2 se induce en la profase meiótica y se acumula y fosforila en mutantes que activan el checkpoint meiótico.

3. La fosforilación de Ddc2 en los sitios consenso para Mec1 (S/T-Q) no es necesaria para su función de checkpoint.

4. Ddc2 se localiza en forma de focos cromosomales que se acumulan en diferentes mutantes meióticos de forma dependiente de RPA y marca la presencia de intermediarios de recombinación sin reparar.

5. En ausencia de recombinación meiótica, Ddc2 se asocia preferentemente al huso de la profase.

6. En el mutante sae2, Ddc2 forma focos que dependen del inicio de la recombinación meiótica, colocalizan con RPA y, presumiblemente, reflejan la existencia de ssDNA.

7. La localización de la proteína Ddc2 en el mutante sae2 depende de la proteína Mec1 pero es independiente de la nucleasa Exo1 y la helicasa Sgs1. 
MATERIALES

$Y$

MÉTODOS 


\section{1.- CONSTRUCCIÓN DE CEPAS DE Saccharomyces cerevisiae.}

Los genotipos de las cepas utilizadas en este trabajo se describen en las Tablas 3 y 4 . Las mayoría de los experimentos están realizados con estirpes construidas en el fondo genético BR1919 (Rockmill and Roeder, 1990), excepto en determinadas ocasiones que se utilizaron estirpes del fondo genético W303 (Thomas and Rothstein, 1989), según se indica para cada ensayo. Todas las cepas usadas y comparadas en cada experimento eran completamente isogénicas.

La construcción de cepas portadoras de deleciones de genes o de genes marcados con epítopos se llevó a cabo bien por transformación directa con fragmentos de plásmidos o con cassettes amplificados por PCR (ver explicación más adelante), o bien por cruces genéticos entre cepas isogénicas portadoras de las deleciones o marcajes de interés obtenidas previamente en este trabajo y/o procedentes de otros laboratorios (como se especifica en la Tabla 6). Para ello, las cepas parentales se cruzaron en placas de YPDA y se aislaron los diploides por micromanipulación de zigotos. A continuación, los diploides se pasaron a placas de medio de esporulación durante 2 - 3 días, se trataron las ascas con glusulasa (PerkinElmer; dilución 1:10) durante 30 min a temperatura ambiente y se diseccionaron las esporas con el micromanipulador (Singer Instruments) en placas de YPDA. Una vez que las esporas dieron lugar a colonias, se analizó su genotipo mediante réplicas a los distintos medios selectivos para seleccionar aquellas cepas que reunían las deleciones o marcaje con epítopos de interés en cada caso.

\section{1.- Deleción de genes.}

Las deleciones sml1::kanMX6, dmc1::kanMX6, sae2::kanMX6, sgs1::kanMX6, exo1::hphMX4, y mad2::hphMX4 se llevaron a cabo utilizando un procedimiento basado en la amplificación por PCR de un cassette de resistencia a G418 (kanMX6) o a higromicina ( $h p h M X 4$ ) flanqueado por 60 nucleótidos adyacentes al codón de inicio y de terminación de la ORF que se quiere delecionar, utilizando los plásmidos pFA6a-kanMX6 o pAG32, respectivamente (Longtine et al., 1998; Goldstein and McCusker, 1999).

La deleción sae2::natMX4 se generó por sustitución del marcador de selección kanMX6 por natMX4 al recombinar por las secuencias flanqueantes promotora y terminadora homólogas en ambos cassettes. Para ello, una cepa que ya contenía la deleción sae2::kanMX6 se transformó con el fragmento obtenido al digerir con Notl el plásmido pAG25 (Goldstein and McCusker, 1999) que contiene natMX4 y seleccionando las colonias con resistencia a nourseotricina y sensibilidad a G418 (geneticina).

Los plásmidos pFA6a-TRP1 y pUG72 (Longtine et al., 1998; Gueldener et al., 2002) fueron utilizados para generar ddc2::TRP1 y mec1::URA3, respectivamente. Estas deleciones se realizaron utilizando el procedimiento basado en la amplificación por PCR de cada fragmento, transformación y posterior selección de las colonias en medios sin el requerimiento nutricional correspondiente. Los diferentes oligonucleótidos y plásmidos que se han utilizado para la construcción de las cepas en este trabajo se muestran en las Tablas 5 y 6 , respectivamente.

Cepas haploides portadoras de la deleción de los siguientes genes se construyeron en trabajos anteriores a esta tesis y los plásmidos utilizados para ello fueron: pME302 para spo11::ADE2 (Engebrecht and Roeder, 1989), pTP89 para ndt80::LEU2 (Tung et al., 2000), pMB116 para zip1::LYS2 (Sym and Roeder, 1994), pEB30 para hop2::LEU2 (Hong and Roeder, 2002), pSM31 (procedente de D. Schild, Lawrence Berkeley Laboratories) para rad54::LEU2. 
Tabla 3. Cepas haploides de Sacccharomyces cerevisiae.

\begin{tabular}{|c|c|}
\hline Cepas & Genotipo \\
\hline BR1919a & MATa leu2-3,112 his4-260 ura3-1 ade2-1 thr1-4 trp1-289 \\
\hline BR1919 $\alpha$ & MAT $\alpha$ leu2-3,112 his4-260 ura3-1 ade2-1 thr1-4 trp1-289 \\
\hline S1561-D2 & BR1919a lys2 4 Nhel hop2::LEU2 \\
\hline YP307 & BR1919 $\alpha$ lys2 $\triangle$ Nhel zip1::LYS2 \\
\hline YP642 & BR1919a lys2 $\Delta$ Nhel \\
\hline YP712 & BR1919a lys2 4 Nhel zip1::LYS2 \\
\hline YP836 & BR1919 $\alpha$ lys2 $\triangle$ Nhel zip1::LYS2 sml1::kanMX6 \\
\hline YP838 & BR1919a lys2 4 Nhel DDC2-GFP::TRP1 \\
\hline YP839 & BR1919 $\alpha$ lys2 $\triangle$ Nhel DDC2-GFP::TRP1 \\
\hline YP843 & BR1919 $\alpha$ lys2 $\triangle$ Nhel DDC2-GFP::TRP1 dmc1::kanMX6 \\
\hline YP844 & BR1919 $\alpha$ lys2_Nhel zip1::LYS2 DDC2-GFP::TRP1 \\
\hline YP845 & BR1919a lys2 $\triangle$ Nhel zip1::LYS2 DDC2-GFP::TRP1 \\
\hline YP846 & BR1919a lys2_Nhel zip1::LYS2 sml1::kanMX6 \\
\hline YP848 & BR1919a lys2 4 Nhel zip1::LYS2 sml1::kanMX6 ddc2::TRP1 \\
\hline YP850 & BR1919 $\alpha$ lys2_Nhel zip1::LYS2 sml1::kanMX6 ddc2::TRP1 \\
\hline YP851 & BR1919 $\alpha$ lys2_Nhel sml1::kanMX6 ddc2::TRP1 \\
\hline YP852 & BR1919a lys2 ANhel sml1::kanMX6 ddc2::TRP1 \\
\hline YP853 & BR1919a lys2 ANhel sml1::kanMX6 \\
\hline YP854 & BR1919 $\alpha$ lys2 4 Nhel sml1::kanMX6 \\
\hline YP855 & BR1919a lys2 4 Nhel DDC2-GFP::TRP1 dmc1::kanMX6 \\
\hline YP860 & BR1919 $\alpha$ lys2_Nhel dmc1::kanMX6 \\
\hline YP861 & BR1919a lys2 4 Nhel dmc1::kanMX6 \\
\hline YP862 & BR1919a lys2 $\triangle$ Nhel DDC2-GFP::TRP1 ndt80::LEU2 \\
\hline YP863 & BR1919 $\alpha$ lys2 $\triangle$ Nhel DDC2-GFP::TRP1 ndt80::LEU2 \\
\hline YP870 & BR1919a lys2_Nhel spo11::ADE2 \\
\hline YP871 & BR1919 $\alpha$ lys2 4 Nhel spo11::ADE2 DDC2-GFP::TRP1 \\
\hline YP872 & BR1919 $\alpha$ lys2 4 Nhel spo11:::ADE2 dmc1::kanMX6 \\
\hline YP875 & BR1919a lys2_Nhel dmc1::kanMX6 sml1::kanMX6 \\
\hline YP876 & BR1919 $\alpha$ lys2 4 Nhel dmc1::kanMX6 sml1::kanMX6 \\
\hline YP877 & BR1919a lys2 ANhel dmc1::kanMX6 sml1::kanMX6 ddc2::TRP1 \\
\hline YP878 & BR1919 $\alpha$ lys2 4 Nhel dmc1::kanMX6 sml1::kanMX6 ddc2::TRP1 \\
\hline YP884 & BR1919a lys2 $\triangle$ Nhel spo11::ADE2 DDC2-GFP::TRP1 \\
\hline YP885 & BR1919a lys2 $\triangle$ Nhel spo11::ADE2 dmc1::kanMX6 \\
\hline YP890 & BR1919a lys2 4 Nhel spo11::ADE2 dmc1::kanMX6 DDC2-GFP::TRP1 \\
\hline YP891 & BR1919 $\alpha$ lys2 $\triangle$ Nhel spo11::ADE2 dmc1::kanMX6 DDC2-GFP::TRP1 \\
\hline YP896 & BR1919a lys2 $\triangle$ Nhel hop2::LEU2 \\
\hline YP897 & BR1919a lys24Nhel hop2::LEU2 sml1::kanMX6 \\
\hline YP898 & BR1919 $\alpha$ lys2 4 Nhel hop2::LEU2 sml1::kanMX6 \\
\hline YP899 & BR1919a lys2 $\triangle$ Nhel hop2::LEU2 sml1::kanMX6 ddc2::TRP1 \\
\hline
\end{tabular}


Tabla 3. Cepas haploides de Sacccharomyces cerevisiae (continuación).

\begin{tabular}{|c|c|}
\hline Cepas & Genotipo \\
\hline YP900 & BR1919 $\alpha$ lys2 $\triangle$ Nhel hop2::LEU2 sm11::kanMX6 ddc2::TRP1 \\
\hline YP901 & BR1919a rad54::LEU2 sml1::kanMX6 \\
\hline YP902 & BR1919 $\alpha$ rad54::LEU2 sml1::kanMX6 \\
\hline YP905 & BR1919a lys2 4 Nhel rad54::LEU2 sml1::kanMX6 dmc1::hphMX4 \\
\hline YP906 & BR1919 $\alpha$ rad54::LEU2 sml1::kanMX6 dmc1::hphMX4 \\
\hline YP915 & BR1919a lys2 $\triangle$ Nhel hop2::LEU2 DDC2-GFP::TRP1 \\
\hline YP916 & BR1919 $\alpha$ lys2 $\triangle$ Nhel hop2::LEU2 DDC2-GFP::TRP1 \\
\hline YP917 & BR1919a lys2 _Nhel rad54::LEU2 dmc1::hphMX4 sml1::kanMX6 ddc2::TRP1 \\
\hline YP918 & BR1919 $\alpha$ lys2 4 Nhel rad54::LEU2 dmc1::hphMX4 sml1::kanMX6 ddc2::TRP1 \\
\hline YP939 & BR1919a lys2 $\triangle$ Nhel sml1::kanMX6 mec1::URA3 DDC2-GFP::TRP1 \\
\hline YP940 & BR1919 $\alpha$ lys2 $\triangle$ Nhel sml1::kanMX6 mec1::URA3 DDC2-GFP::TRP1 \\
\hline YP949 & BR1919a lys2_Nhel sae2::kanMX6 DDC2-GFP::TRP1 \\
\hline YP950 & BR1919 $\alpha$ lys2 ANhel sae2::kanMX6 DDC2-GFP::TRP1 \\
\hline YP951 & BR1919a lys2_Nhel sml1::kanMX6 sae2::kanMX6 \\
\hline YP952 & BR1919 $\alpha$ lys2 $\Delta$ Nhel sml1::kanMX6 sae2::kanMX6 \\
\hline YP953 & BR1919a lys2 $\triangle$ Nhel sml1::kanMX6 mec1::URA3 sae2::kanMX6 DDC2-GFP::TRP1 \\
\hline YP954 & BR1919 $\alpha$ lys2 4 Nhel sml1::kanMX6 mec1::URA3 sae2::kanMX6 DDC2-GFP::TRP1 \\
\hline YP956 & BR1919a lys2 $\triangle$ Nhel DDC2-3HA::KanMX6 \\
\hline YP957 & BR1919 lys24Nhel DDC2-3HA::KanMX6 \\
\hline YP961 & BR1919a lys2 ANhel sml1::kanMX6 sae2::kanMX6 ddc2::TRP1 \\
\hline YP962 & BR1919 $\alpha$ lys2 4 Nhel sml1::kanMX6 sae2::kanMX6 ddc2::TRP1 \\
\hline YP964 & BR1919a lys2_Nhel dmc1::kanMX6 DDC2-3HA::KanMX6 \\
\hline YP965 & BR1919 $\alpha$ lys2 4 Nhel dmc1::kanMX6 DDC2-3HA::KanMX6 \\
\hline YP968 & BR1919a lys2 ANhel hop2::LEU2 DDC2-3HA::KanMX6 \\
\hline YP969 & BR1919 $\alpha$ lys2 4 Nhel hop2::LEU2 DDC2-3HA::KanMX6 \\
\hline YP970 & BR1919a lys2 4 Nhel sae2::kanMX6 DDC2-3HA::KanMX6 \\
\hline YP971 & BR1919 $\alpha$ lys2 $\triangle$ Nhel sae2::kanMX6 DDC2-3HA::KanMX6 \\
\hline YP1004 & BR1919a lys2 $\triangle$ Nhel TUB1-RFP::KanMX6 DDC2-GFP::TRP1 \\
\hline YP1006 & BR1919a lys2 $\triangle$ Nhel spo11::ADE2 TUB1-RFP::KanMX6 DDC2-GFP::TRP1 \\
\hline YP1115 & BR1919a lys2 $\triangle$ Nhel exo1::hphMX4 DCC2-GFP::TRP1 \\
\hline YP1116 & BR1919 $\alpha$ lys2 4 Nhel ex01::hphMX4 DCC2-GFP::TRP1 \\
\hline YP1117 & BR1919a sae2::kanMX6 exo1::hphMX4 DCC2-GFP::TRP1 \\
\hline YP1118 & BR1919 $\alpha$ lys2_Nhel sae2::kanMX6 exo1::hphMX4 DCC2-GFP::TRP1 \\
\hline YP1141 & BR1919a lys2_Nhel spo11::ADE2 sae2::kanMX6 DCC2-GFP::TRP1 \\
\hline YP1142 & BR1919 $\alpha$ lys2 $\triangle$ Nhel spo11::ADE2 sae2::kanMX6 DCC2-GFP::TRP1 \\
\hline YP1218 & BR1919a lys2 ANhel sae2::kanMX6 ndt80::LEU2 DDC2-GFP::TRP1 \\
\hline YP1219 & BR1919 $\alpha$ lys2 4 Nhel sae2::kanMX6 ndt80::LEU2 DDC2-GFP:::TRP1 \\
\hline YP1277 & BR1919 $\alpha$ lys2 4 Nhel p306-BrdU::URA3 spo11::ADE2 \\
\hline YP1284 & BR1919 $\alpha$ lys2 $\Delta$ Nhel DDC2-VN::TRP1 \\
\hline
\end{tabular}


Tabla 3. Cepas haploides de Sacccharomyces cerevisiae (continuación).

\begin{tabular}{|c|c|}
\hline Cepas & Genotipo \\
\hline YP1295 & BR1919a lys2 $\triangle$ Nhel TUB1-VC::KanMX6 \\
\hline YP1316 & BR1919 $\alpha$ lys2 4 Nhel DDC2-GFP::TRP1 p306-BrdU::URA3 \\
\hline YP1317 & BR1919 $\alpha$ lys2 $\triangle$ Nhel sae2::kanMX6 DDC2-GFP::TRP1 p306-BrdU::URA3 \\
\hline YP1318 & BR1919a lys2 $\triangle$ Nhel dmc1::hphMX4 DDC2-GFP::TRP1 p306-BrdU::URA3 \\
\hline YP1319 & BR1919 a lys2 4 Nhel dmc1::hphMX4 DDC2-GFP.:TRP1 \\
\hline YP1323 & BR1919a lys2_Nhel sgs1::KanMX6 DDC2-GFP::TRP1 \\
\hline YP1324 & BR1919 $\alpha$ lys2 $\Delta$ Nhel sgs1::KanMX6 DDC2-GFP::TRP1 \\
\hline YP1325 & BR1919a sgs1::KanMX6 exo1::hphMX4 DDC2-GFP::TRP1 \\
\hline YP1326 & BR1919 a sgs1::KanMX6 ex01::hphMX4 DDC2-GFP::TRP1 \\
\hline YP1494 & BR1919a lys2_Nhel ndt80::LEU2 zip1::LEU2 sml1::KanMX6 mec1::URA3 \\
\hline YP1495 & BR1919 $\alpha$ lys2 4 Nhel ndt80::LEU2 zip1::LEU2 sml1::KanMX6 mec1::URA3 \\
\hline YP1515 & BR1919a lys2_Nhel ndt80::LEU2 DDC2-3HA::KanMX6 \\
\hline YP1516 & BR1919 $\alpha$ lys2 $\triangle$ Nhel ndt80::LEU2 DDC2-3HA::KanMX6 \\
\hline YP1519 & BR1919a lys2 $\triangle$ Nhel ndt80::LEU2 dmc1::kanMX6 DDC2-3HA::KanMX6 \\
\hline YP1520 & BR1919 $\alpha$ lys2 $\triangle$ Nhel ndt80::LEU2 dmc1::kanMX6 DDC2-3HA::KanMX6 \\
\hline YP1521 & BR1919a lys2 4 Nhel ndt80::LEU2 sae2::kanMX6 DDC2-3HA::KanMX6 \\
\hline YP1522 & BR1919 $\alpha$ lys2 $\triangle$ Nhel ndt80::LEU2 sae2::kanMX6 DDC2-3HA::KanMX6 \\
\hline YP1523 & BR1919a lys2 $\triangle$ Nhel ndt80::LEU2 spo11::ADE2 dmc1::kanMX6 DDC2-3HA::KanMX6 \\
\hline YP1524 & BR1919 $\alpha$ lys2 4 Nhel ndt80::LEU2 spo11::ADE2 dmc1::kanMX6 DDC2-3HA::KanMX6 \\
\hline YP1537 & BR1919 $\alpha$ lys2DNhel SP011-GFP::KanMX6 DDC2-3HA::KanMX6 \\
\hline YP1538 & BR1919a lys2DNhel SP011-GFP::KanMX6 DDC2-3HA::KanMX6 \\
\hline YP1539 & BR1919a lys2DNhel sae2::natMX4 SP011-GFP::KanMX6 DDC2-3HA::KanMX6 \\
\hline YP1540 & BR1919a lys2DNhel sae2::natMX4 SP011-GFP::KanMX6 DDC2-3HA::KanMX6 \\
\hline YP1594 & BR1919a lys2DNhel mad2::hphMX4 sml1::KanMX6 ddc2::TRP1 \\
\hline YP1616 & BR1919a lys2DNhel KanMX6::pCLB2-SAE2-3HA DDC2-GFP::TRP1 \\
\hline YP1617 & BR1919 $\alpha$ lys2DNhel KanMX6::pCLB2-SAE2-3HA DDC2-GFP::TRP1 \\
\hline YP1618 & BR1919a lys2DNhel KanMX6::pCLB2-SAE2-3HA DDC2-GFP::TRP1 sgs1::KanMX4 \\
\hline YP1619 & BR1919 $\alpha$ lys2DNhel KanMX6::pCLB2-SAE2-3HA DDC2-GFP::TRP1 sgs1::KanMX4 \\
\hline YP1620 & $\begin{array}{l}\text { BR1919a lys2DNhel KanMX6:::pCLB2-SAE2-3HA DDC2-GFP::TRP1 } \\
\text { sgs1::KanMX4 ex01::hphMX4 }\end{array}$ \\
\hline YP1621 & $\begin{array}{l}\text { BR1919 a lys2DNhel KanMX6::pCLB2-SAE2-3HA DDC2-GFP::TRP1 } \\
\text { sgs1::KanMX4 ex01::hphMX4 }\end{array}$ \\
\hline YP1630 & BR1919a lys2DNhel sml1::KanMX6 mec1::URA3 \\
\hline YP1631 & BR1919 $\alpha$ lys2DNhel sml1::KanMX6 mec1::URA3 \\
\hline YP1632 & BR1919a lys2DNhel ndt80::LEU2 zip1::LYS2 sml1::KanMX6 \\
\hline YP1633 & BR1919 $\alpha$ lys2DNhel ndt80::LEU2 zip1::LYS2 sml1::KanMX6 \\
\hline YP1634 & BR1919a lys2DNhel ndt80::LEU2 zip1::LYS2 ddc2::TRP1 sml1::KanMX6 \\
\hline YP1635 & BR1919 $\alpha$ lys2DNhel ndt80::LEU2 zip1::LYS2 ddc2::TRP1 sml1::KanMX6 \\
\hline YP1732 & BR1919 $\alpha$ lys2DNhel sml1::kanMX6 TUB1-GFP::TRP1 \\
\hline YP1734 & BR1919 $\alpha$ lys2DNhel sml1::kanMX6 dmc1::kanMX6 TUB1-GFP.:TRP1 \\
\hline YP1736 & BR1919a lys2DNhel sml1::kanMX6 hop2::LEU2 TUB1-GFP::TRP1 \\
\hline
\end{tabular}


Tabla 3. Cepas haploides de Sacccharomyces cerevisiae (continuación).

\begin{tabular}{|c|c|}
\hline Cepas & Genotipo \\
\hline YP1738 & BR1919 $\alpha$ lys2DNhel sml1::kanMX6 dmc1::kanMX6 ddc2::hphMX4 TUB1-GFP::TRP1 \\
\hline YP1740 & BR1919 $\alpha$ lys2DNhel sm11::kanMX6 hop2::LEU2 ddc2::hphMX4 TUB1-GFP::TRP1 \\
\hline YP1741 & BR1919a lys2DNhel sml1::kanMX6dmc1::kanMX6 ddc2::hphMX4 \\
\hline YP1743 & BR1919a lys2DNhel sml1::kanMX6 hop2::LEU2 ddc2::hphMX4 \\
\hline W303-1A & MATa leu2-3,112 trp1-1 can1-100 ura3-1 ade2-1 his3-11,15 can1-100 rad5-G535R \\
\hline W303-1B & MAT $\alpha$ leu2-3,112 trp1-1 can1-100 ura3-1 ade2-1 his3-11,15 can1-100 rad5-G535R \\
\hline YJT130 & W303-1B sml1::URA3 DDC2-GFP::TRP1 \\
\hline YP749 & W303-1A sml1::URA3 DDC2-GFP.:TRP1 \\
\hline YP750 & W303-1A sml1::URA3 DDC2-GFP::TRP1 dmc1::KanMX6 \\
\hline YP751 & W303-1B sml1::URA3 DDC2-GFP.:TRP1 dmc1::KanMX6 \\
\hline YP1008 & W303-1A rfa-t11 dmc1::kanMX6 DDC2-GFP::TRP1 \\
\hline YP1009 & W303-1B rfa-t11 dmc1::kanMX6 DDC2-GFP::TRP1 \\
\hline YP1010 & W303-1A rfa-t11 DDC2-GFP::TRP1 \\
\hline YP1011 & W303-1B rfa-t11 DDC2-GFP::TRP1 \\
\hline YP1056 & W303-1A ADE2 RPA-CFP DDC2-YFP \\
\hline YP1057 & W303-1B ADE2 RPA-CFP DDC2-YFP \\
\hline YP1058 & W303-1A sae2::kanMX6 ADE2 RPA-CFP DDC2-YFP \\
\hline YP1059 & W303-1B sae2::kanMX6 ADE2 RPA-CFP DDC2-YFP \\
\hline YP1099 & W303-1A rad50- S::URA ADE2 RPA-CFP DDC2-YFP \\
\hline YP1100 & W303-1B rad50-S::URA ADE2 RPA-CFP DDC2-YFP \\
\hline YP1111 & W303-1A sae2::kanMX6 rad50-S::URA3 ADE2 RPA-CFP DDC2-YFP \\
\hline YP1112 & W303-1B sae2::kanMX6 rad50-S::URA3 ADE2 RPA-CFP DDC2-YFP \\
\hline
\end{tabular}

El alelo rad50-K181 (=rad50S) se generó por transformación con el fragmento obtenido del plásmido pNKY349 digerido con EcoRI-BamHI (Alani et al., 1990). Las cepas portadoras del alelo rfa1-t11 derivan de la cepa CY5467 (Lucca et al., 2004).

La comprobación de las deleciones se llevó a cabo mediante PCR utilizando parejas de oligonucleótidos correspondientes a las regiones $5^{\prime}$ y $3^{\prime}$ tanto del gen delecionado como del gen marcador introducido y comprobando en ambos extremos que aparecía la banda correspondiente a la deleción generada y desaparecía la correspondiente al alelo silvestre.

\section{2.- Marcaje de proteínas con epítopos.}

La proteína de fusión Ddc2-GFP se obtuvo insertando el epítopo GFP en el extremo 3' del gen DDC2 en su propio locus genómico. El epítopo GFP junto con el marcador auxotrófico TRP1 fueron amplificados por PCR a partir del plásmido pFA6a-GFP-TRP1 (Longtine et al., 1998). Estos oligonucleótidos fueron diseñados de forma que los veinte nucleótidos finales del extremo $3^{\prime}$ anillan en el plásmido y los nucleótidos restantes son las secuencias que quedan a ambos lados del codón de parada de DDC2. El fragmento de DNA generado, fue utilizado para transformar S. cerevisiae. Los transformantes obtenidos fueron comprobados mediante PCR. 
Tabla 4. Cepas diploides de Sacccharomyces cerevisiae. $\left({ }^{*}\right)$

\begin{tabular}{|c|c|c|}
\hline Cepas & Padres & Genotipo más relevante \\
\hline BR1919-2N & BR1919a x BR1919 $\alpha$ & $\begin{array}{l}\text { MATa/MAT } \alpha \text { leu2::3,112 his4::260 ura3::1 } \\
\text { ade2::1 thr1::4 trp1::289 }\end{array}$ \\
\hline DP421 & YP642 x BS200 & BR1919-2N lys2 $\Delta$ Nhel \\
\hline DP422 & YP712 x YP307 & DP421 zip1::LYS2 \\
\hline DP448 & YP838 x YP839 & DP421 DDC2-GFP::TRP1 \\
\hline DP449 & YP844 x YP845 & DP421 zip1::LYS2 DDC2-GFP::TRP1 \\
\hline DP450 & YP843 x YP855 & DP421 dmc1::kanMX6 DDC2-GFP::TRP1 \\
\hline DP451 & YP848 x YP850 & DP421 zip1::LYS2 ddc2::TRP1 sml1::kanMX6 \\
\hline DP452 & YP836 x YP846 & DP421 zip1::LYS2 sml1::kanMX6 \\
\hline DP454 & YP851 x YP852 & DP421 ddc2::TRP1 sml1::kanMX6 \\
\hline DP455 & YP853 x YP854 & DP421 sml1::kanMX6 \\
\hline DP456 & YP860 x YP861 & DP421 dmc1::kanMX6 \\
\hline DP457 & YP862 x YP863 & DP421 ndt80::LEU2 DDC2-GFP::TRP1 \\
\hline DP465 & YP871 x YP884 & DP421 sp011::ADE2 DDC2-GFP::TRP1 \\
\hline DP466 & YP872 x YP885 & DP421 spo11::ADE2 dmc1::kanMX6 \\
\hline DP467 & YP875 x YP876 & DP421 dmc1::kanMX6 sml1::kanMX6 \\
\hline DP468 & YP877 x YP878 & DP421 dmc1::kanMX6 ddc2::TRP1 sml1::kanMX6 \\
\hline DP469 & YP890 x YP891 & DP421 spo11::ADE2 dmc1::kanMX6 DDC2-GFP::TRP1 \\
\hline DP470 & S1561-D2 x YP896 & DP421 hop2::LEU2 \\
\hline DP471 & YP897 x YP898 & DP421 hop2::LEU2 sml1::kanMX6 \\
\hline DP472 & YP899 x YP900 & DP421 hop2::LEU2 ddc2::TRP1 sml1::kanMX6 \\
\hline DP473 & YP901 x YP902 & BR1919-2N rad54::LEU2 \\
\hline DP475 & YP905 x YP906 & $\begin{array}{l}\text { BR1919-2N lys2 } 4 \text { Nhel / LYS2 rad54::LEU2 } \\
\text { dmc1::hphMX4 sml1::kanMX6 }\end{array}$ \\
\hline DP480 & YP915 x YP916 & DP421 hop2::LEU2 DDC2-GFP::TRP1 \\
\hline DP481 & YP917 x YP918 & DP421 rad54::LEU2 dmc1::hphMX4 ddc2::TRP1 sml1::kanMX6 \\
\hline DP482 & YP939 x YP940 & DP421 mec1::URA3 DDC2-GFP::TRP1 sml1::kanMX6 \\
\hline DP484 & YP949 x YP950 & DP421 sae2::kanMX6 DDC2-GFP::TRP1 \\
\hline DP485 & YP951 x YP952 & DP421 sae2::kanMX6 sml1::kanMX6 \\
\hline DP486 & YP953 x YP954 & $\begin{array}{l}\text { DP421 mec1::URA3 sae2::KanMX6 } \\
\text { DDC2-GFP::TRP1 sml1::kanMX6 }\end{array}$ \\
\hline DP487 & YP956 x YP957 & DP421 DDC2-3HA::kanMX6 \\
\hline DP488 & YP964 x YP965 & DP421 dmc1::kanMX6 DDC2-3HA::kanMX6 \\
\hline DP489 & YP961 x YP962 & DP421 sae2::kanMX6 ddc2::TRP1 sml1::kanMX6 \\
\hline DP491 & YP968 x YP969 & DP421 hop2::LEU2 DDC2-3HA::kanMX6 \\
\hline DP492 & YP970 x YP971 & DP421 sae2::kanMX6 DDC2-3HA::kanMX6 \\
\hline
\end{tabular}


Tabla 4. Cepas diploides de Sacccharomyces cerevisiae (continuación).

\begin{tabular}{|c|c|c|}
\hline Cepas & Padres & Genotipo más relevante \\
\hline DP502 & YP1004 x YP839 & $\begin{array}{l}\text { DP421 DDC2-GFP:::TRP1 TUB1/ } \\
\text { DDC2-GFP::TRP1 TUB1-RFP::kanMX6 }\end{array}$ \\
\hline DP504 & YP1006 x YP871 & $\begin{array}{l}\text { DP421 TUB1 I } \\
\text { spo11::ADE2 DDC2-GFP::TRP1 TUB1-RFP::kanMX6 }\end{array}$ \\
\hline DP544 & YP1115 x YP1116 & DP421 exo1::hphMX4 DCC2-GFP.::TRP1 \\
\hline DP545 & YP1117 x YP1118 & DP421 sae2::kanMX6 exo1::hphMX4 DCC2-GFP::TRP1 \\
\hline DP550 & YP1141 x YP1142 & DP421 spo11::ADE2 sae2::kanMX6 DCC2-GFP::TRP1 \\
\hline DP566 & YP1630 x YP1631 & DP421 sml1::kanMX6 mec1::URA3 \\
\hline DP567 & YP1632 x YP1633 & DP421 ndt80::LEU2 zip1::LYS2 sml1::kanMX6 \\
\hline DP568 & YP1634 x YP1635 & DP421 ndt80::LEU2 zip1::LYS2 sml1::kanMX6 ddc2::TRP1 \\
\hline DP569 & YP1218 x YP1219 & DP421 sae2::kanMX6 ndt80::LEU2 DDC2-GFP::TRP1 \\
\hline DP592 & YP870 x YP1277 & DP421 spo11::ADE2/p306-BrdU::URA3 spo11::ADE2 \\
\hline DP594 & YP642 x YP1284 & DP421 DDC2/DDC2-VN::TRP1 \\
\hline DP599 & YP1284 x YP1295 & DP421 DDC2-VN::TRP1/TUB1-VC::kanMX6 \\
\hline DP601 & YP1295 x BS200 & DP421 TUB1-VC::kanMX6/TUB1 \\
\hline DP606 & YP838 x YP1316 & DP421 DDC2-GFP::TRP1/DDC2-GFP::TRP1 p306-BrdU::URA3 \\
\hline DP607 & YP949 x YP1317 & $\begin{array}{l}\text { DP421 sae2::KanMX6 DDC2-GFP::TRP1/ } \\
\text { sae2::kanMX6 DDC2-GFP::TRP1 p306-BrdU::URA3 }\end{array}$ \\
\hline DP608 & YP1318 x YP1319 & $\begin{array}{l}\text { DP421 dmc1::hphMX4 DDC2-GFP::TRP1/ } \\
\text { dmc1::hphMX4 DDC2-GFP:::TRP1 p306-BrdU::URA3 }\end{array}$ \\
\hline DP609 & YP1323 x YP1324 & DP421 sgs1::kanMX6 DDC2-GFP::TRP1 \\
\hline DP610 & YP1325 x YP1326 & DP421 sgs1::kanMX6 exo1::hphMX4 DDC2-GFP::TRP1 \\
\hline DP680 & YP1494 x YP1495 & DP421 ndt80::LEU2 zip1::LYS2 sml1::kanMX6 mec1::URA3 \\
\hline DP691 & YP1515 x YP1516 & DP421 ndt80::LEU2 DDC2-3HA::kanMX6 \\
\hline DP693 & YP1519 x YP1520 & DP421 ndt80::LEU2 dmc1::kanMX6 DDC2-3HA::kanMX6 \\
\hline DP694 & YP1521 x YP1522 & DP421 ndt80::LEU2 sae2::KanMX6 DDC2-3HA::kanMX6 \\
\hline DP695 & YP1523 x YP1524 & $\begin{array}{l}\text { DP421 ndt80::LEU2 spo11::ADE2 } \\
\text { dmc1::kanMX6 DDC2-3HA::kanMX6 }\end{array}$ \\
\hline DP697 & YP1537 x YP1538 & DP421 SP011-GFP.::kanMX6 DDC2-3HA::kanMX6 \\
\hline DP698 & YP1539 x YP1540 & DP421 sae2::natMX4 SP011-GFP::kanMX6 DDC2-3HA::kanMX6 \\
\hline DP734 & YP1616 x YP1617 & DP421 KanMX6:::pCLB2-SAE2-3HA DDC2-GFP:::TRP1 \\
\hline DP735 & YP1618 x YP1619 & $\begin{array}{l}\text { DP421 KanMX6::pCLB2-SAE2-3HA } \\
\text { DDC2-GFP:::TRP1 sgs1::kanMX6 }\end{array}$ \\
\hline DP736 & YP1620 x YP1621 & $\begin{array}{l}\text { DP421 KanMX6::pCLB2-SAE2-3HA DDC2-GFP::TRP1 } \\
\text { sgs1::kanMX6 ex01::hphMX4 }\end{array}$ \\
\hline DP778 & YP1732 x YP853 & DP421 TUB1-GFP::TRP1 sml1::kanMX6 \\
\hline DP779 & YP1734 x YP875 & DP421 dmc1::kanMX6 TUB1-GFP:::TRP1 sml1::kanMX6 \\
\hline
\end{tabular}


Tabla 4. Cepas diploides de Sacccharomyces cerevisiae (continuación).

\begin{tabular}{lll}
\hline Cepas & Padres & Genotipo más relevante \\
\hline DP780 & YP1736 x YP897 & DP421 hop2::LEU2 TUB1-GFP::TRP1 sml1::kanMX6 \\
DP781 & YP1738 x YP1741 & $\begin{array}{l}\text { DP421 dmc1::kanMX6 ddc2::hphMX4 } \\
\text { TUB1-GFP::TRP1 sml1::kanMX6 }\end{array}$ \\
DP782 & YP1740 x YP1743 & DP421 hop2::LEU2 ddc2::hphMX4 \\
& & TUB1-GFP:::TRP1 sml1::kanMX6 \\
W303-2N & W303-1A x W303-1B & MATa/ MAT $\alpha$ leu2::3,112 trp1::1 can1::100 ura3::1 \\
& & ade2::1 his3::11,15 can1::100 rad5::G535R \\
DP433 & YJT130 x YP749 & W303-2N sm11::URA3 DDC2-GFP:::TRP1 \\
DP434 & YP750 x YP751 & W303-2N sm11::URA3 dmc1:::kanMX6 DDC2-GFP::TRP1 \\
DP505 & YP1008 x YP1009 & W303-2N rfa-t11 dmc1::kanMX6 DDC2-GFP:::TRP1 \\
DP506 & YP1010 x YP1011 & W303-2N rfa-t11 DDC2-GFP:::TRP1 \\
DP524 & YP1056 x YP1057 & W303-2N ADE2 RPA-CFP DDC2-YFP \\
DP525 & YP1058 x YP1059 & W303-2N ADE2 sae2::kanMX6 RPA-CFP DDC2-YFP \\
DP536 & YP1099 x YP1100 & W303-2N ADE2 rad50-S::URA RPA-CFP DDC2-YFP \\
DP542 & YP1111 x YP1112 & W303-2N ADE2 sae2::kanMX6 rad50-S::URA3 RPA-CFP DDC2-YFP
\end{tabular}

$\left.{ }^{*}\right)$ Todas las cepas son homozigóticas para los marcadores a no ser que se indique lo contrario.

Para determinar si la fusión de GFP afectaba a la función de Ddc2, los clones positivos se analizaron en placas de metil-metano-sulfonato (MMS) y se comprobó que, a diferencia del mutante $d d c 2$, las cepas portadoras de DDC2-GFP no mostraban sensibilidad a este agente genotóxico, indicando que el epítopo GFP no afectaba a la función de la proteína. Además, también se comprobó la funcionalidad de la proteína Ddc2-GFP durante la meiosis gracias al seguimiento de las divisiones nucleares a lo largo de la meiosis mediante la tinción del DNA con DAPI.

Las cepas que expresan la proteína de fusión Ddc2-3HA se generaron del mismo modo descrito para Ddc2-GFP, pero utilizando el plásmido pFA6a-3HA-kanMX6 (Longtine et al., 1998). También se comprobó que la proteína Ddc2-3HA es funcional.

Para generar las cepas TUB1-GFP:::TRP1, se usó el plásmido pB237 (procedente de Beth Rockmill, Yale University) que fue digerido con la enzima Hindlll. La proteína de fusión Tub1-RFP se obtuvo insertando el epítopo RFP en el extremo 3' del gen TUB1 en su propio locus genómico. El epítopo RFP junto con el marcador de resistencia kanMX6 fue amplificado por PCR a partir del plásmido pFA6a-RFP-KanMX6. El protocolo utilizado para transformar S. cerevisiae y seleccionar los clones positivos se explicará posteriormente en el capítulo 3.

Para la construcción de las proteínas de fusión Ddc2-VN y Tub1-VC se amplificaron fragmentos de PCR a partir de los plásmidos pFA6a-VN-TRP1 y pFA6a-VC-kanMX6 (Sung and Huh, 2007) y se transformaron en S. cerevisiae. Los transformantes obtenidos fueron comprobados mediante PCR. También se comprobó que el marcaje no afectaba a la funcionalidad de las proteínas. 
Tabla 5.- Oligonucleótidos utilizados en este trabajo.

\begin{tabular}{|c|c|c|}
\hline Nombre & Secuencia $\left(5^{\prime}-3^{\prime}\right)$ & Aplicaciones \\
\hline SML1- L1 & $\begin{array}{l}\text { TGATCTTACGGTCTCACTAACCTC } \\
\text { TCTTCAACTGCTCAATAATTTCCC } \\
\text { GCTCAGCTGAAGCTTCGTACGC }\end{array}$ & Deleción de SML1 \\
\hline SML1- L2 & $\begin{array}{l}\text { ACAGAACTAGTGGGAAATGGAAAG } \\
\text { AGAAAAGAAAAGAGTATGAAAGGA } \\
\text { ACTGCATAGGCCACTAGTGGATCTG }\end{array}$ & Deleción de SML1 \\
\hline $\mathrm{DDC2}-\mathrm{K} 1$ & $\begin{array}{l}\text { CGCGATAGTGCACGAAACGTCAACA } \\
\text { CAATCATCAAACTCTTTTGCATATTTC } \\
\text { TATTATAGCGTACGCTGCAGGTCGAC }\end{array}$ & Deleción de $D D C 2$ \\
\hline $\mathrm{DDC2}-\mathrm{K} 2$ & $\begin{array}{l}\text { AATATTAAGCATTACAAGGTTTCTATA } \\
\text { AAGCGTTGACATTTTCCCCTTTTGAT } \\
\text { TGTTGCCATCGATGAATTCGAGCTCG }\end{array}$ & $\begin{array}{l}\text { Deleción y marcaje de DDC2 con } \\
\text { epítopos -GFP, -3HAy -VN }\end{array}$ \\
\hline DDC2- F2 & $\begin{array}{l}\text { AAATCATTCGATCTAACCACACTAGAG } \\
\text { GAGGCCGATTCATTATATATCTCAATG } \\
\text { GGACTGCGGATCCCCGGGTTAATTAA }\end{array}$ & $\begin{array}{c}\text { Marcaje de DDC2 con epítopos } \\
\text {-GFP, -3HA y -VN }\end{array}$ \\
\hline DMC1- D1 & $\begin{array}{l}\text { CACCCTTTTATATTTGCTGTAGTCTG } \\
\text { TTATGCCAATCAGGAAAGCATTTGA } \\
\text { ACAAATCGTACGCTGCAGGTCGAC }\end{array}$ & Deleción de DMC1 \\
\hline DMC1- D2 & $\begin{array}{l}\text { TAAAAGAAAAGTTTAATAAAGGAGC } \\
\text { AATGTCATCTTCATTAAAAAGTATAC } \\
\text { AAAAAATCGATGAATTCGAGCTCG }\end{array}$ & Deleción de DMC1 \\
\hline MEC1- L1 & $\begin{array}{l}\text { AGACAAAGTGAGGCTGGACAACAAGA } \\
\text { ACGACATACACCGCGTAAAGGCCCACA } \\
\text { AGACTGCCGGATCCCCGGGTTAATTAA }\end{array}$ & Deleción de MEC1 \\
\hline MEC1- L2 & $\begin{array}{l}\text { CCTGCAGTGATGGTTAGATCAAGAGG } \\
\text { AAGTTCGTCTGTTGCCGAAAATGGTG } \\
\text { GAAAGTCGATCGATGAATTCGAGCTCG }\end{array}$ & Deleción de MEC1 \\
\hline SAE2-D1 & $\begin{array}{l}\text { CGTTCACATACCTGCATTTCCATCCA } \\
\text { TGCTGTAAGCCATTAGGTGTTTGTAT } \\
\text { GTGAGCGTACGCTGCAGGTCGAC }\end{array}$ & Deleción de SAE2 \\
\hline SAE2-D2 & $\begin{array}{l}\text { ACCATACCAAAAAAAATGTATTTGAA } \\
\text { GTAATGAATAAAGAATGATGATCGCT } \\
\text { GGCGTATCGATGAATTCGAGCTCG }\end{array}$ & Deleción de SAE2 \\
\hline SAE2- F4 & $\begin{array}{l}\text { CGTTCACATACCTGCATTTCCATCCA } \\
\text { TGCTGTAAGCCATTAGGTGTTTGTAT } \\
\text { GTGAGGAATTCGAGCTCGTTTAAAC }\end{array}$ & Expresión de SAE2 bajo el promotor CLB2 \\
\hline SAE2-R3 & $\begin{array}{l}\text { CTGAGCTCCTTGAGAATGGATAAGCT } \\
\text { TGACTTTAGATACACATTTTCTTCACC } \\
\text { AGTCACGCACTGAGCAGCGTAATCTG }\end{array}$ & Expresión de $S A E 2$ bajo el promotor CLB2 \\
\hline
\end{tabular}


Tabla 5.- Oligonucleótidos utilizados en este trabajo (continuación).

\begin{tabular}{|c|c|c|}
\hline Nombre & Secuencia (5'-3') & Aplicaciones \\
\hline TUB1- K2 & $\begin{array}{l}\text { TTTTTTTACAATATACTTGAAATATAGA } \\
\text { AAGGATAAGGAGGTTGGGGGCGAGA } \\
\text { GTGAACCATCGATGAATTCGAGCTCG }\end{array}$ & Marcaje de TUB1 con epítopo -RFP \\
\hline TUB1- F2 & $\begin{array}{l}\text { GCTTTAGAAAGATTACATCGAAGTGG } \\
\text { GTGCCGACTCATACGCTGAGGAAGA } \\
\text { GGAATTTCGGATCCCCGGGTTAATTAA }\end{array}$ & Marcaje de TUB1 con epítopo -RFP y -VC \\
\hline TUB1- R1 & $\begin{array}{l}\text { TTTTTTTACAATATACTTGAAATATAGAA } \\
\text { AGGATAAGGAGGTTGGGGGCGAGAG } \\
\text { TGAACCGAATTCGAGCTCGTTTAAAC }\end{array}$ & Marcaje de TUB1 con epítopo -RFP y -VC \\
\hline EX01-K1 & $\begin{array}{l}\text { TGCTTTTTGGACCACATTAAAATAAAA } \\
\text { GGAGCTCGAAAAAACTGAAAGGCGTA } \\
\text { GAAAGGA CGTACGCTGCAGGTCGAC }\end{array}$ & Deleción de EX01 \\
\hline EX01-K2 & $\begin{array}{l}\text { TTTTCATTTGAAAAATATACCTCCGAT } \\
\text { ATGAAACGTGCAGTACTTAACTTTTA } \\
\text { TTTACCT ATCGATGAATTCGAGCTCG }\end{array}$ & Deleción de EX01 \\
\hline MAD2- up & $\begin{array}{l}\text { GTATTGAAAACCACTTCAAGGGGCC } \\
\text { CAATAGCACATTTACTCGAGGAGAA } \\
\text { CTTCTAGTA }\end{array}$ & Deleción de MAD2 \\
\hline MAD2- down & $\begin{array}{l}\text { TGGACTTCCGTCTTTTTTTTTTTTTTTT } \\
\text { GACTTGAATTCTAGCACCATATCGAC } \\
\text { TACGTCG }\end{array}$ & Deleción de MAD2 \\
\hline SP011- L2 & $\begin{array}{l}\text { ATGTAACCGTTTTCAATTCTTGAAAAA } \\
\text { CATTTTTTATAAAGCAACAGCTCCCAT } \\
\text { TCTTATCATAGGCCACTAGTGGATCTG }\end{array}$ & Marcaje de SP011 con epítopo -GFP \\
\hline SP011- F5 & $\begin{array}{l}\text { ATTTTTTTCCAAAAGAAAGCTGAAATG } \\
\text { AACGAGATTGATGCCAGAATTTTTGAA } \\
\text { TACAAAGGTGACGGTGCTGGTTTA }\end{array}$ & Marcaje de SP011 con epítopo -GFP \\
\hline rDNA- up & CTGATGTCTTCGGATGGATTTGAG & qPCR de ChIP \\
\hline rDNA- down & TTTCCTCTGGCTTCACCCTATTC & qPCR de ChIP \\
\hline qBUD23- up & TATGTCGTCCACCTGGTCGTCG & qPCR de ChIP \\
\hline qBUD23- down & TCCTAAACAGCGGTTGATGAGG & qPCR de ChIP \\
\hline qERG1- up & CAGTCATACCACCACCAGTCAATG & qPCR de ChIP \\
\hline qERG1-down & GCCAAACTCCTACTTGCCAGC & qPCR de ChIP \\
\hline
\end{tabular}


La cepas haploides originales con las proteínas Ddc2 y Rfa1 marcadas con los epítopos YFP y CFP, respectivamente, procedían del laboratorio de Rodney Rothstein (Columbia University) (Lisby et al., 2004).

\section{3.- Otras construcciones.}

Para la construcción de cepas capaces de incorporar BrdU se linearizó el plásmido p306-BrdU-Inc portador de la timidina kinasa del virus Herpes Simplex (HSV-TK) y el transportador de nucleósidos equilibrante de humanos (hENT1) con la enzima de restricción Stul para dirgir su integración al locus ura3 (Viggiani and Aparicio, 2006). Se comprobó la correcta integración del plásmido en los transformantes mediante PCR con una pareja de oligonucleótidos que anillan específicamente en la secuencia del plásmido y con otra pareja de oligonucleótidos que flanquean el gen URA3.

Para la construcción de cepas que expresan el gen SAE2 bajo el promotor de CLB2 se utilizó el plásmido pFA6a-KanMX6-pCLB2-3HA (pC797) para amplificar con los oligos correspondientes. Tras la transformación, se comprobó por PCR la correcta integración del promotor de CLB2 en el locus SAE2.

Para el estudio de los sitios consenso de fosforilación de la proteína Ddc2 por Mec1 en la respuesta a daño en el DNA en células vegetativas (Figura 15), las diferentes cepas de interés (zip1, ddc2 y zip1 ddc2) se transformaron con el vector vacío pRS316 o con los plásmidos pLCD1, pNML1 y pSS136 (Tabla 6). El gen DDC2 es un gen esencial para la célula. Para rescatar esta letalidad, las cepas se construyen sobre un fondo genético sml1. Para el estudio de los sitios consenso de fosforilación, las cepas llevaban el gen DDC2 en un plásmido (pLCD1, pNML1 o pSS136) cuyo marcador de selección era el gen URA3. Al llevar DDC2 en el plásmido, ya no era necesario que las células $d d c 2$ fueran además $s m l 1$ (el gen SML1 se delecionó utilizando el plásmido pFA6a-KanMX6). El ácido 5-fluoroacético o 5-FOA es usado en genética molecular de levaduras para detectar la expresión del gen URA3. El gen URA3 convierte el 5-FOA en el componente tóxico 5- fluorouracilo. Así, cuando diferentes células se crecen en medio 5-FOA, las células Ura+ mueren mientras que las Ura- son resistentes a este componente tóxico (Boeke et al., 1984). Para obtener cepas SML1 silvestres, se replicaron nuestras diferentes cepas de interés para este estudio (transformadas con los diferentes plásmidos que expresan el gen $D D C 2$ ), a placas con medio 5-FOA, placas con geneticina (G418) y placas de YPDA. Se seleccionaron de las placas de YPDA aquellas cepas de levadura que no crecían en 5-FOA y que eran sensibles a geneticina porque eran las que necesitaban el plásmido con la fuente de $D D C 2$ necesaria para poder ser viables y que eran además SML1 silvestres.

\section{2.- MEDIOS Y CONDICIONES DE CULTIVO.}

\section{1.- Medios de cultivo para Saccharomyces cerevisiae.}

Medios Líquidos:

- YPDA: Extracto de levadura 1\%, Peptona 2\%, Adenina 0,01\%, Glucosa 2\%.

- SC 2X: YNB sin aminoácidos (-aa) 0,7\%, Mezcla de aminoácidos (-LEU) de Formedium 0,138\%, Adenina 0,025\%, Leucina 0,02\%, Glucosa $2 \%$.

- SC-aa: YNB (-aa) 0,7\%, Glucosa 2\%. El YNB se suplementó con una Mezcla de aminóacidos (drop-out) que carece del aminoácido o aminoácidos necesarios, dependiendo de las auxotrofías de las cepas, 
pero al doble de la concentración recomendada por el fabricante.

- Esporulación: Acetato potásico (KAc) 2\%.

Medios Sólidos:

- YPDA: Extracto de levadura 1\%, Peptona 2\%, Adenina 0,01\%, Glucosa 2\% y Agar 2\%.

- SC-aa: YNB sin aminoácidos (-aa) 0,7\%, Glucosa 2\% y Agar 2\%. El YNB se suplementó con una Mezcla de aminóacidos (drop-out) que carece del aminoácido o aminoácidos necesarios, dependiendo de las auxotrofías de las cepas, pero al doble de la concentración recomendada por el fabricante.

- Esporulación: Extracto de levadura 0,1\%, KAc 1,5\%, Mezcla de aminoácidos (-ADE, -URA) de Formedium 0,185\%, Adenina 0,025\%, Uracilo 0,01\%, Glucosa 0,1\%, y Agar $2 \%$.

- Medio mínimo: YNB (-aa) $0,7 \%$, Glucosa $2 \%$ y Agar $2 \%$.

Medios de selección de resistencia a antibióticos:

Cuando fue necesario seleccionar clones de levadura resistentes a antibióticos, se suplementaron las placas de YPDA con $200 \mu \mathrm{g} / \mathrm{ml}$ de sulfato de geneticina (G418; Formedium), $300 \mu \mathrm{g} / \mathrm{ml}$ de higromicina (Formedium) ó $100 \mu \mathrm{g} / \mathrm{ml}$ de nourseotricina (clonNAT; Werner BioAgents).

\section{2.- Condiciones de crecimiento y esporulación para S. cerevisiae.}

El cultivo de S. cerevisiae se llevó a cabo en placas de medio sólido o en bien en medio líquido con una agitación de 200-250 rpm. Todos los cultivos su incubaron a una temperatura de $30^{\circ} \mathrm{C}$. El crecimiento en medio líquido se controló midiendo la turbidez del cultivo por su absorbancia a $600 \mathrm{~nm}\left(\mathrm{OD}_{600}\right)$.

Para inducir la meiosis en medio líquido, las diferentes cepas se estriaron en una placa de YPDA y se incubaron a $30^{\circ} \mathrm{C}$ durante 2-3 días. Se tocó con el palillo una colonia aislada que se incubó durante $20-24 \mathrm{~h}$ a $30^{\circ} \mathrm{C}$ en agitación en $3,5 \mathrm{ml}$ de medio líquido SC $2 \mathrm{X}$. A continuación, se recogieron las células y se incubaron en 2,5 ml de medio líquido YPDA (suplementado con $50 \mu \mathrm{l}$ de la una solución de Adenina 20mM y Uracilo $10 \mathrm{mM}$ ) a $30^{\circ} \mathrm{C}$ en agitación durante $8 \mathrm{~h}$ para saturar el cultivo y tener células en fase estacionaria. Se centrifugaron las células y se lavaron con $1 \mathrm{ml}$ de KAc $2 \%$ para eliminar los posibles restos de medio rico (YPDA). Se pasaron las células a un matraz de $100 \mathrm{ml}$ con $10 \mathrm{ml}$ de medio líquido de esporulación (KAc 2\%) y se incubaron en agitación a $30^{\circ} \mathrm{C}$. Según las necesidades, los volúmenes de los cultivos se aumentaron pero guardando siempre las mismas proporciones y tiempos de incubación. Para la incubación en KAc 2\% siempre se debe usar un matraz de un volumen al menos 10 veces superior al volumen de KAc $2 \%$ utilizado para que las células tengan una aireación adecuada.

Para inducir la esporulación en placa, se cultivaron los diploides en placas de YPDA durante $12 \mathrm{~h}$ y a continuación se replicaron a medio de esporulación donde se incubaron durante 3 días a $30^{\circ} \mathrm{C}$.

\section{3.- Ensayos de sensibilidad a MMS, luz UV y benomilo.}

Para analizar la sensibilidad a agentes genotóxicos, cultivos crecidos hasta saturación en YPDA se diluyeron en $5 \mathrm{ml}$ de YPDA fresco a una $\mathrm{OD}_{600} \sim 0,2$ y se incubaron hasta llegar a una $\mathrm{OD}_{600} \sim 1$. Se sembraron diluciones seriadas 1:10 ó diluciones seriadas 1:5 (igualando la $\mathrm{OD}_{600}$ inicial de todos los cultivos a 0,2 ) en placas de YPDA (control), en placas de YPDA con MMS 0,02\%, o en placas de YPDA que se irradiaron con luz UV 40J/ $\mathrm{m}^{2}$. Las placas de YPDA con MMS se prepararon el mismo día de su utilización. 
Para analizar la sensibilidad a benomilo las cepas se cultivaron en YPDA líquido como se ha descrito anteriormente y se sembraron en placas de YPDA suplementadas con diferentes concentraciones de benomilo a partir de una solución stock de $30 \mathrm{mg} / \mathrm{ml}$ en DMSO. Como control, se utilizó una placa de YPDA suplementada con la misma cantidad de DMSO presente en la placa con la mayor concentración de benomilo utilizada. Para la preparación de las placas que contienen benomilo es necesario que el medio YPDA fundido esté a una temperatura de $80-90^{\circ} \mathrm{C}$ en el momento de añadir el benomilo para que no precipite.

Tabla 6.- Plásmidos utilizados en este trabajo.

\begin{tabular}{|c|c|c|}
\hline Nombre & Aplicaciones & Procedencia/ Referencia \\
\hline pFA6a-kanMX6 & $\begin{array}{l}\text { Deleción de SML1, } \\
\text { DMC1 y SAE2 }\end{array}$ & Longtine et al., 1998. \\
\hline pFA6a-TRP1 & Deleción de $D D C 2$ & Longtine et al., 1998. \\
\hline pFA6a-GFP-TRP1 & Marcaje de DDC2 y SP011 & Longtine et al., 1998. \\
\hline pFA6a-3HA-kanMX6 & Marcaje de $D D C 2$ & Longtine et al., 1998. \\
\hline pFA6a-RFP-KanMX6 & Marcaje de TUB1 & Huh et al., 2003. \\
\hline pFA6a-VN-TRP1 & Marcaje de $D D C 2$ & Sung and Huh, 2007. \\
\hline pFA6a-VC-kanMX6 & Marcaje de TUB1 & Sung and Huh, 2007. \\
\hline pAG25 & Deleción de SAE2 & Goldstein and McCusker, 1999. \\
\hline pAG32 & Deleción de EX01 y MAD2 & Goldstein and McCusker, 1999. \\
\hline pUG72 & Deleción de MEC1 & Gueldener et al., 2002. \\
\hline p306-BrdU-Inc & Incorporación de BrdU & Viggiani and Aparicio, 2006. \\
\hline pLCD1 & Expresión de $D D C 2$ & S. Jackson (Univ. of Cambridge, UK) \\
\hline pNML1 & Expresión de DDC2-13myc & S. Jackson (Univ. of Cambridge, UK) \\
\hline pSS136 & Expresión de ddc2-3AQ-13myc & $\begin{array}{l}\text { R. Freire (Hospital Universitario Canarias) } \\
\text { P. San Segundo }\end{array}$ \\
\hline pNKY349 & Introducción del alelo rad50-S & N. Kleckner (Harvard University, USA) \\
\hline pB237 & Integración de TUB1-GFP::TRP1 & B. Rockmill (Yale University, USA) \\
\hline pC797 & Introducción del promotor CLB2 & $\begin{array}{l}\text { D. Dawson } \\
\text { (Oklahoma Medical Research Foundation, USA) } \\
\text { AM. Neiman } \\
\text { (Stony Brook University, USA) }\end{array}$ \\
\hline
\end{tabular}




\section{4.- Cultivos de Escherichia coli.}

La bacteria E. coli se cultivó tanto en medio LB líquido (extracto de levadura 0,5\%, triptona $1 \%$ y $\mathrm{NaCl}$ $1 \%$ ), como en placas de LB suplementado con $100 \mu \mathrm{g} / \mathrm{ml}$ de ampicilina (Sambrook y Russel, 2001). En ambos casos la temperatura de incubación fue de $37^{\circ} \mathrm{C}$. Para el mantenimiento y obtención de plásmidos se utilizó la cepa DH5a de E. coli. Las células competentes se generaron en el Servicio General del Instituto de Microbiología Bioquímica siguiendo el protocolo descrito por (Kushner, 1978).

\section{3.- TÉCNICAS DE TRANSFORMACIÓN.}

\section{1.- Transformación de S. cerevisiae.}

Para transformar S. cerevisiae se siguió básicamente el protocolo descrito por (Gietz et al., 1995). Para ello, células crecidas en YPDA hasta saturación se diluyeron en $5 \mathrm{ml}$ de YPDA fresco a una concentración de $5 \times 10^{6}$ células $/ \mathrm{ml}\left(\mathrm{OD}_{600} \sim 0,25\right)$, se incubaron a $30^{\circ} \mathrm{C}$ durante $\sim 3 \mathrm{~h}$ hasta una concentración de $2 \times 10^{7}$ células/ $\mathrm{ml}\left(\mathrm{OD}_{600} \sim 1\right)$, se recogieron por centrifugación y se lavaron primero con el mismo volumen de agua estéril y a continuación con $1 \mathrm{ml}$ de acetato de litio (AcLi) $100 \mathrm{mM}$. Una vez retirado el sobrenadante, se añadieron $240 \mu \mathrm{l}$ de Polietilenglicol (PEG) 3350 al 50\%, $36 \mu \mathrm{l}$ de AcLi 1M, $25 \mu \mathrm{l}$ de DNA desnaturalizado de esperma de salmón a una concentración de $2 \mathrm{mg} / \mathrm{ml}$ y $50 \mu \mathrm{l}$ de la solución que contenía el DNA a transformar. Las células se resuspendieron mediante agitación en vortex, se incubaron a $30^{\circ} \mathrm{C}$ durante $30-60$ min con agitación y, a continuación, se sometieron a un pulso de calor de $15 \mathrm{~min}$ a $42^{\circ} \mathrm{C}$. Finalmente, las células se centrifugaron y se resuspendieron en $100 \mu \mathrm{l}$ de agua para sembrarlas en placas de medio selectivo. Cuando el marcador de selección fue la resistencia a los antibióticos $\mathrm{G} 418$, higromicina o nourseotricina, después del pulso de calor las células se incubaron en YPDA líquido durante 2 - $3 \mathrm{~h}$ antes de sembrarlas en las placas que contenían el antibiótico. Las células transformadas se incubaron a $30^{\circ} \mathrm{C}$ durante 2 - 3 días.

\section{2.- Transformación de E. coli.}

Para transformar E. coli con plásmidos se siguió el protocolo descrito por Golub, 1988. Para ello, se descongelaron las células competentes en hielo y se les añadió $1 \mu$ lde DNA procedente de minipreparaciones de DNA plasmídico por cada $75 \mu \mathrm{l}$ de células competentes. Seguidamente se dio a las células un pulso de calor durante $1 \mathrm{~min}$ a $42^{\circ} \mathrm{C}$, se añadieron $100 \mu \mathrm{l}$ de LB y se sembraron en placas de LB con ampicilina que se incubaron durante $12-18 \mathrm{~h}$ a $37^{\circ} \mathrm{C}$.

\section{4.- MICROSCOPÍA.}

\section{1.- Microscopía de contraste de fases.}

Para el seguimiento rutinario del crecimiento celular, la formación de zigotos, el contaje de ascas, etc., se utilizó un microscopio Nikon Eclipse 50i equipado con objetivos 20X y 40X de contraste de fases.

\section{2.- Microscopía de fluorescencia y de contraste interferencial (DIC).}

Se utilizó un microscopio de fluorescencia Nikon Eclipse 90i equipado con una cámara CCD Orca-AG 
(Hamamatsu) y objetivos 63X o 100X de apertura numérica 1,4. Las diferentes características de los prismas ópticos, espejos dicroicos selectivos y filtros de excitación y emisión están reflejadas en la Tabla 7. Para seguir la formación de focos de la proteína Ddc2-GFP, la colocalización de ésta con la proteina Tub1-RFP, la interacción entre las proteínas Ddc2-VN y Tub1-VC y el estudio de la formación de focos de RPA-CFP y Ddc2-YFP a lo largo de la meiosis, se capturaron imágenes a diferentes tiempos a lo largo de la meiosis. Cuando se analizaron focos de Ddc2-GFP, para cada campo se realizaron once capturas en el eje $Z$ a intervalos de 0,4 $\mu$ m y con un tiempo de exposición de 1000 miliseg cada una. Para obtener la proyección máxima de los planos capturados, las imágenes se procesaron con el programa informático ImageJ (http:// rsb.info.nih.gov/ij/). De cada plano también se obtuvo una imagen de DIC de las células analizadas. Para el resto de focos analizados (Ddc2-YFP, RPA-CFP...) se tomaron varias imágenes de cada tiempo de meiosis en un solo plano.

Tabla 7.- Características de los filtros utilizados en microscopía de fluorescencia.

\begin{tabular}{lccc}
\hline Fluoróforos & $\begin{array}{c}\text { Filtro de excitación } \\
(\mathrm{nm})\end{array}$ & $\begin{array}{c}\text { Filtro de emisión } \\
(\mathrm{nm})\end{array}$ & $\begin{array}{c}\text { Espejo dicroico selectivo } \\
(\mathrm{nm})\end{array}$ \\
\hline GFP y AF488 & $450-490$ & $500-550$ & 495 \\
YFP y Venus & $490-510$ & $520-550$ & 515 \\
RFPy AF594 & $530-550$ & $590-650$ & 570 \\
CFP & $426-446$ & $460-500$ & 455 \\
DAPI & $340-380$ & 425 & 400 \\
\hline
\end{tabular}

Para realizar el contaje de las divisiones nucleares a lo largo de la meiosis se capturaron imágenes de las células teñidas con DAPI usando un microscopio Leica DMRXA equipado con una cámara CCD Orca-AG (Hamamatsu) y un objetivo 63X de apertura numérica 1,4.

Para los experimentos de time-lapse de Ddc2-GFP se utilizó el microscopio de fluorescencia DeltaVision equipado con una cámara CoolSNAP HQ2 (Photometrics). Para la toma de imágenes se usó un objetivo 100X Olympus UPLSAPO de apertura numérica 1,4, un filtro de excitación de 440-470 nm y un filtro de emisión de 525$550 \mathrm{~nm}$. La temperatura del microscopio se ajustó a $30^{\circ} \mathrm{C}$ la noche anterior al experimento. La preparación de las muestras se llevó a cabo del siguiente modo. Se colocó un porta cóncavo (EMS, Electron Microscopy Science) y un porta normal en un bloque térmico que está a una temperatura de $37^{\circ} \mathrm{C}-42^{\circ} \mathrm{C}$ durante aproximadamente 5 minutos para que cuando se añada la solución de $K A c$ al $2 \%$ + agarosa al $1,2 \%$, ésta no se solidifique inmediatamente. Durante esos 5 minutos, se hierve una solución de KAc al 2\% + agarosa al 1,2\% repartida en diferentes eppendorfs y guardada a $4^{\circ} \mathrm{C}$. Cuando la solución esté líquida se deja a $70^{\circ} \mathrm{C}$ para que no se vuelva a solidificar. A continuación, se recogen $100 \mu \mathrm{l}$ de células en meiosis, se centrifugan y se concentran en un volumen final de $15 \mu \mathrm{l}$. Se añaden $50 \mu$ de la solución de KAc al $2 \%$ con agarosa al 1,2\% en el porta cóncavo e inmediatamente colocamos encima el porta normal y se deja solidificar a temperatura ambiente durante 5 minutos. Pasado este tiempo se retira el porta normal se añaden $7 \mu \mathrm{l}$ de las células concentradas encima de la solución solidificada y se coloca un cubre encima. Para cada tiempo analizado (cada 5 ó 10 minutos) se 
realizaron once capturas en el eje $Z$ a intervalos de 0,4 $\mu \mathrm{m}$ y con un tiempo de exposición de 500 miliseg cada una. Para obtener la proyección máxima de los planos capturados y la posterior reconstrucción de la película con todos los tiempos, las imágenes se procesaron con el programa informático ImageJ (http:// rsb.info.nih.gov/ij/).

\section{5.- ANÁLISIS DE ÁCIDOS NUCLEICOS.}

\section{1.- Extracción de DNA plasmídico de E. coli.}

Para la purificación de DNA plasmídico a pequeña escala de E. coli se usaron las columnas Wizard Plus SV Minipreps (Promega) siguiendo el protocolo del fabricante basado en el método de lisis alcalina.

\section{2.- Extracción de DNA total de S. cerevisiae.}

Para usar el DNAgenómico como molde para PCR se empleó el protocolo que se describe a continuación. Se recogieron por centrifugación de 1,5 a $3 \mathrm{ml}$ de un cultivo saturado de la cepa de interés. Las células se resuspendieron en $735 \mu \mathrm{l}$ de una solución de sorbitol 0,9 M y EDTA 0,1 M. Se añadieron $45 \mu \mathrm{l}$ de zimoliasa $20 \mathrm{~T}$ a $10 \mathrm{mg} / \mathrm{ml}$ y $1 \mu \mathrm{l}$ de $\beta$-mercaptoetanol y se incubaron a $37^{\circ} \mathrm{C}$ durante 1 hora agitando ocasionalmente. A continuación se centrifugaron las células a máxima velocidad y se retiró el sobrenadante. Los esferoplastos formados se resuspendieron en $304 \mu \mathrm{l}$ de TE, $32 \mu \mathrm{l}$ de EDTA 0,5 M (pH 8), $32 \mu \mathrm{l}$ de Tris-HCl $1 \mathrm{M}(\mathrm{pH}$ 7,5) y $16 \mu \mathrm{l}$ de SDS $10 \%$. Después de incubar durante $30 \mathrm{~min}$ a $65^{\circ} \mathrm{C}$ para lisar completamente las células, se añadieron 80 $\mu \mathrm{l}$ de acetato potásico $5 \mathrm{M}$, se mezcló por inversión varias veces y se incubó en hielo durante 30 - 60 min para precipitar las proteínas. A continuación, se centrifugó a 15000 x g durante 3 min y el sobrenadante se decantó sobre un tubo con $1 \mathrm{ml}$ de etanol 100\% para precipitar los ácidos nucleicos. El precipitado resultante de la centrifugación durante 3 min a 15000 x g se resuspendió en $200 \mu$ de TE, se añadieron $2 \mu$ de RNasa A 10 mg/ $\mathrm{ml}$ y se incubó a $37^{\circ} \mathrm{C}$ durante $30 \mathrm{~min}$. El DNA genómico se precipitó de nuevo añadiendo $200 \mu \mathrm{l}$ de isopropanol y centrifugando durante 2 min a $15000 \mathrm{x}$ g. Finalmente, el precipitado se lavó con etanol al 70\% y, una vez seco, se resuspendió en 20-50 $\mu$ le TE.

\section{3.- Digestión de moléculas de DNA con enzimas de restricción.}

La digestión de moléculas de DNA se llevó a cabo utilizando endonucleasas de restricción de Fermentas. Las soluciones tampón empleadas y la temperatura a la que se realizaron las digestiones fueron en cada caso las recomendadas por el fabricante. Las reacciones se llevaron a cabo en un volumen de 20 a $60 \mu$ l durante un tiempo de 2 - $4 \mathrm{~h}$

\section{4.- Separación de moléculas de DNA en geles de agarosa.}

La separación por tamaños de las moléculas de DNA procedentes de PCR o digestiones con endonucleasas de restricción se llevó a cabo mediante electroforesis en geles de agarosa. Dependiendo del tamaño de las moléculas a separar, se usaron geles del $0,8 \%$ al $2 \%$ de agarosa (Seakem LE) preparados en TAE (Tris-acetato 40 mM, EDTA $1 \mathrm{mM} \mathrm{pH} \mathrm{8,0)} \mathrm{y} \mathrm{conteniendo} \mathrm{bromuro} \mathrm{de} \mathrm{etidio} \mathrm{a} \mathrm{una} \mathrm{concentración} \mathrm{de} \mathrm{0,5} \mathrm{\mu g/}$ ml. Para visualizar el DNA mediante iluminación con luz UV, se utilizó un equipo Gel Doc XR (Bio-Rad) equipado con una cámara CCD para la captura de imágenes. Los tamaños de las moléculas se estimaron comparando 
con el marcador de tamaño molecular $1 \mathrm{~Kb}$ Plus DNA ladder (Invitrogen). Las separaciones electroforéticas se realizaron a voltaje constante (50-120 V) en tampón TAE.

\section{5.- Amplificación de DNA: reacción en cadena de la polimerasa (PCR).}

Para amplificar fragmentos de DNA de forma rutinaria se usaron Taq polimerasas de 5-Prime o Promega, a una concentración de $0,05 \mathrm{U} / \mu \mathrm{l}$ junto con las soluciones tampón recomendadas por el fabricante. Las reacciones se llevaron a cabo en un volumen de $50 \mu \mathrm{l}$ conteniendo $1 \mu \mathrm{M}$ de oligonucleótidos sintetizados por Isogen Life Science o Thermo Scientific y dNTPs 0,4 mM de 5-Prime. Como DNA molde se utilizaron cantidades variables de DNA genómico, plásmido o directamente una pequeña cantidad de biomasa de células de $S$. cerevisiae tomada de una placa de YPDA. La reacción de amplificación se realizó en un termociclador MJ Mini (Bio-Rad). La longitud de los ciclos de extensión y la temperatura de anillamiento, fue variable dependiendo del tamaño del fragmento a amplificar y de la Tm de los oligonucleótidos, respectivamente.

Para amplificar fragmentos de DNA que llevan epítopos para el marcaje de genes, se utilizó una polimerasa de alta fidelidad (Expand High Fidelity PCR System).

\section{6.- Inmunoprecipitación de cromatina y PCR cuantitativa.}

Se recogieron $16 \mathrm{ml}$ de células en $\mathrm{KAc} 2 \%$ a $\mathrm{OD}_{600} \approx 6$ (8 $\mathrm{ml}$ de células por cada inmunoprecipitación= IP). Las células se trataron con $1 \%$ de formaldehído (Merck) durante 10 min a temperatura ambiente en agitación suave. La fijación se detuvo con glicina $125 \mathrm{mM}$ durante 5 min a temperatura ambiente en agitación suave.

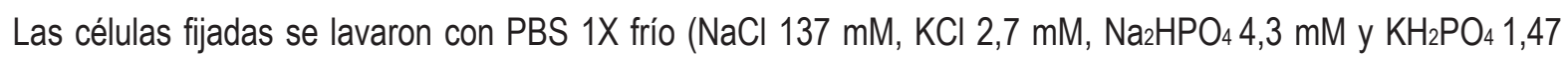
$\mathrm{mM}$ ), se eliminó el PBS 1X, se dividieron las células en 2 tubos de 1,7 ml (low binding, COSTAR) por separado para realizar con mayor eficacia una posterior rotura y sonicación de las mismas. Las células se congelaron inmediatamente en hielo seco para seguidamente guardarlas a $-80^{\circ} \mathrm{C}$.

Las células guardadas a $-80^{\circ} \mathrm{C}$ se descongelaron en hielo y se resuspendieron en $500 \mu$ de tampón de lisis (Hepes $\mathrm{KOH}$ pH=7,550mM, EDTA $5 \mathrm{mM}, \mathrm{NaCl} 140 \mathrm{mM}$, TRITÓN X-100 al 1\%, deoxicolato sódico al 0,1\%). Se añadió PMSF $1 \mathrm{mM}$ y una tableta de cocktail inhibidor de proteasas (Roche) por cada $50 \mathrm{ml}$ de tampón de lisis o una mini tableta de cocktail inhibidor de proteasas (Roche) por cada $10 \mathrm{ml}$ de tampón de lisis. Las células se rompieron en una FastPrep (Qbiogene) con bolitas de vidrio (Sigma) que cubrían el volumen de cada muestra, con 3 pulsos de agitación de 20 seg a una potencia de 5,5 (las células se dejaron reposando en hielo 1 minuto entre cada pulso). Se pasó la muestra a un tubo BD Falcon de $15 \mathrm{ml}$ haciendo un agujero en el tubo eppendorf con una aguja (100 STERICAN 21Gx1", BRAUN) y centrifugando a 1000 rpm durante 2 min.

Posteriormente, mediante una sonda que se ajusta perfectamente al tubo BD Falcon de $15 \mathrm{ml}$, se fragmentó la cromatina hasta un tamaño medio de aproximadamente 200-500 pb con un Bioruptor (Diagenode) refrigerado con agua y hielo. Se aplicaron 3 ciclos de sonicación a potencia máxima de 10 min cada uno y con intervalos de 30 seg encendido y 1 minuto apagado (cambiando el agua y añadiendo más hielo entre cada pulso para evitar el calentamiento de la muestra).

A continuación, se pasó la muestra sonicada a un nuevo tubo eppendorf de 1,7 ml y se centrifugó a $16100 \mathrm{x} \mathrm{g} \mathrm{a} 4^{\circ} \mathrm{C}$ durante $10 \mathrm{~min}$ recogiendo el sobrenadante en otro tubo eppendorf de 1,7 ml. En este paso se juntaron los sobrenadantes correspondientes a la misma muestra (Volumen $\square 1000 \mu l$ ) que se incubaron 
durante 1 hora en rotor a $4^{\circ} \mathrm{C}$ con $80 \mu$ de Dynabeads de proteína $A$ + proteína $\mathrm{G}$ (Invitrogen) que habían sido previamente bloqueadas durante $30 \mathrm{~min}$ a temperatura ambiente con $100 \mu \mathrm{g} / \mathrm{ml}$ de BSA (SIGMA-ALDRICH, A7906) y $75 \mathrm{ng} / \mu \mathrm{l}$ ssDNA de esperma de salmón (se prepararon $120 \mu \mathrm{l}$ de dynabeads $(60 \mu \mathrm{l}$ de proteína $\mathrm{A}+60 \mu \mathrm{l}$ de proteína G) por cada IP que se realizó). Se recuperó el sobrenadante mediante el uso de un imán que retiene las Dynabeads.

Se reservaron $40 \mu \mathrm{l}$ de este sobrenadante como input y el resto, que se usó para hacer las IPs, se dividió a la mitad en 2 tubos de 1,7 ml. A una mitad se añadieron 10 $\mu \mathrm{g}$ de anticuerpo anti-HA (clon 12CA5, Roche) y a la otra, $10 \mu \mathrm{g}$ de anticuerpo anti-myc (Santa Cruz, sc-40), éste último se usó como uno de los controles negativos del experimento. Tanto los inputs como los IPs se incubaron $2 \mathrm{~h}$ en rotor a $4^{\circ} \mathrm{C}$. A continuación, a los IPs se les añadió otros $50 \mu \mathrm{l}$ de dynabeads y se incubaron durante toda la noche en rotor a $4^{\circ} \mathrm{C}$.

Los inputs se trataron con RNAasa a $10 \mu \mathrm{g} / \mu \mathrm{l}$ (DNAasa free; $500 \mu \mathrm{g} / \mu \mathrm{l}$; ROCHE) durante 30 min a $37^{\circ} \mathrm{C}$. A continuación, se les añadió proteinasa $\mathrm{K}$ a $0,2 \mu \mathrm{g} / \mu \mathrm{l}$ y se incubaron durante 30 min a $55^{\circ} \mathrm{C}$. Se centrifugaron $100 \mu \mathrm{l}$ de la resina Chelex al 10\% (Chelex 100, Biorad) y se eliminó el sobrenadante. Se añadieron los $40 \mu \mathrm{l}$ del input (previamente tratado con RNAasa y proteinasa K) a las bolitas de Chelex secas. Se mezclaron bien por vortex y se hirvieron durante 10 min en agitación. Centrifugamos y recogimos, sin apurar, el sobrenadante en un eppendorf nuevo. Se añadieron $120 \mu l$ de agua libre de DNAsas, RNAsas y Proteasas (5-Prime) a las bolitas de Chelex mezclando bien en vortex. Se centrifugaron de nuevo para juntar el sobrenadante con el anterior previamente recogido.

Las IPs incubadas junto con el anticuerpo y las dynabeads se lavaron 6 veces con $1 \mathrm{ml}$ de tampón de lisis (sin inhibidores de proteasas ni PMSF), 1 vez con tampón de lavado 1 (Hepes $\mathrm{KOH} 50 \mathrm{mM} \mathrm{pH=7,5,} \mathrm{EDTA}$ $5 \mathrm{mM}, \mathrm{NaCl}$ 0,5 mM, TRITON X-100 al 1\%, deoxicolato sódico al 0,1\%), 1 vez con tampón de lavado 2 (Lic. 0,25M, TE 1X, NP-40\% al 0,5\% y deoxicolato sódico al 0,5\%) y un último lavado con $1 \mathrm{ml}$ de TE $1 \mathrm{X}$ (Tsukuda et al., 2009).

Se añadieron $100 \mu \mathrm{l}$ de Chelex al $100 \%$ a las dynabeads (sin restos del último lavado con TE 1X). Las dynabeads con las bolitas de Chelex al 10\% se mezclaron bien en vortex. Se hirvieron durante $10 \mathrm{~min}$ en agitación (aquí se revirtió el crosslink quedando atrapadas las proteínas y los anticuerpos en las bolitas de Chelex). Se dejaron enfriar las muestras y se añadieron RNAasa y proteinasa $\mathrm{K}$ del mismo modo en que se hizo con los inputs. Se volvieron a hervir las muestras durante $10 \mathrm{~min}$. Se centrifugaron durante 1 minuto a 12000 x g y se recogió el sobrenadante sin apurar en un nuevo eppendorf. Se añadieron $120 \mu$ de agua libre de DNAasas, RNAasas y proteasas a las bolitas de Chelex y mezclamos bien en vortex. Se centrifugaron de nuesvo para juntar el sobrenadante con el anterior previamente recogido. Todas las muestras de DNA (inputs y IPs) se congelaron a $-20^{\circ} \mathrm{C}$ hasta el momento de hacer la PCR cuantitativa ( $q P C R$ ).

Para una mejor cuantificación del DNA obtenido, los inputs se diluyeron 100 veces en agua libre de DNAasas, RNAasas y proteasas. El DNA se analizó por PCR cuantitativa en un equipo ABI7000 (Applied Biosystems) usando diferentes parejas de oligonucleótidos que se describen en la Tabla 5. Para cada reacción de PCR se añadió $1 \mu \mathrm{l}$ de DNA, 0,75 $\mu \mathrm{l}(100 \mu \mathrm{M})$ de una mezcla de cada pareja de oligonucleótidos, 0,4 $\mu \mathrm{l}$ de ROX Dye, 8,35 $\mu \mathrm{l}$ de agua libre de DNasa, RNAasa free y $10 \mu \mathrm{l}$ de la mezcla preparada comercialmente (Takara SYBR Premix Ex Taq, Perfect Real Time) que contiene la polimerasa, los nucleótidos y SYBR Green. Para conseguir mayor reproducibilidad se prepararon mezclas de reacción comunes para cada DNA molde, y 
cada muestra se analizó por triplicado,. El termociclador ABI7000 fue programado del siguiente modo: paso n⿳01.Desnaturalización inicial del DNA: 10 seg a $95^{\circ} \mathrm{C}$, paso $n^{\circ} 2$.- PCR: 5 seg a $95^{\circ} \mathrm{C}, 31$ seg a $60^{\circ} \mathrm{C}$ durante 40 ciclos y paso $n^{03}$.- Disociación: $15 \mathrm{seg}$ a $95^{\circ} \mathrm{C}, 1$ minuto a $60^{\circ} \mathrm{C}$ y 15 seg a $95^{\circ} \mathrm{C}$. En cada placa de reacción de PCR se introdujeron también por triplicado muestras de diluciones seriadas de DNA genómico sonicado de S. cerevisiae de tamaño medio de $500 \mathrm{pb}$, a las que se dieron unos valores arbitrarios referentes a la cantidad de $\operatorname{DNA}\left(1,10^{-1}\right.$, $\left.10^{-2}, 0\right)$. Con estos datos se realizó una recta patrón representando el ciclo umbral de amplificación exponencial (Ct) frente a la cantidad relativa de DNA. Esta recta sirvió para determinar la cantidad relativa de DNA presente en cada muestra analizada de acuerdo con los valores de Ct obtenidos para cada una. Los valores obtenidos para cada hotspot analizado (BUD23 y ERG1) se normalizaron con los correspondientes al rDNA (donde no se generan DSBs meióticas) de este modo: (IPDSB/NNPUT ${ }^{\mathrm{DSB}}$ ) / (IPrDNA/INPUT'DNA). Para calcular el enriquecimiento relativo de Ddc2-3HA reclutado a los hotspots durante la meiosis, los valores obtenidos para la muestras de $24 \mathrm{~h}$ (roturas meióticas) se dividieron por los valores obtenidos para el $\mathrm{t}=0$ (sin roturas meióticas).

\section{7.- Tinción de DNA con DAPI.}

Se recogieron alícuotas de $300 \mu \mathrm{l}$ de células de los cultivos en KAc $2 \%$ a diferentes tiempos a lo largo de la meiosis y se añadieron $700 \mu \mathrm{l}$ de etanol $100 \%$. Las células fijadas se almacenaron a $4^{\circ} \mathrm{C}$. Para teñir los núcleos con DAPI (4'-6-diamidino-2-fenilindol), se tomaron $200 \mu$ le las células fijadas, se centrifugaron durante 2 min a 16100 x g, se eliminó el sobrenadante y se lavaron con $100 \mu \mathrm{l}$ de PBS 1X. Una vez eliminado el sobrenadante, se añadieron $100 \mu \mathrm{l}$ de una solución de DAPI $1 \mu \mathrm{g} / \mathrm{ml}$ y se incubaron las células durante 10-15 min a temperatura ambiente. A continuación, se centrifugaron de nuevo las células ya teñidas durante 2 min a 16100 $x \mathrm{~g}$, se desechó el sobrenadante y se resuspendieron en $100 \mu$ de PBS 1X. Alícuotas $(7 \mu \mathrm{l})$ se depositaron en portas para su análisis mediante microscopía de fluorescencia. Para representar la cinética de la progresión de la meiosis, en cada tiempo se realizó un contaje de al menos 300 células.

\section{8.- Análisis de incorporación de BrdU.}

Para determinar la incorporación de BrdU durante el crecimiento vegetativo, se cultivaron las células en $5 \mathrm{ml}$ de YPDA líquido hasta fase exponencial a $30^{\circ} \mathrm{C}$ y se les añadió $400 \mu \mathrm{g} / \mathrm{ml}$ de BrdU (5-Bromo-2' deoxyuridine $\geq 99 \%$ HPLC, Sigma-Aldrich). Depués de una hora, se recogieron las células, se lavaron con agua estéril y se extrajo su DNA genómico mediante la técnica descrita anteriormente.

A continuación, cuantificamos la cantidad de DNA de cada cepa mediante espectroscopía (Nanodrop ND-1000, Nanodrop Technologies, Inc). Para comprobar que la incorporación de BrdU era la misma en todas las cepas, se emplearon diferentes diluciones de DNA (5ng, 10ng, 25ng y 100ng) con SSC $5 x$ en un volumen final de $500 \mu \mathrm{l}$ y se desnaturalizaron a $95^{\circ} \mathrm{C}$ durante $10 \mathrm{~min}$. Las muestras de DNA se enfriaron inmediatamente en un baño de agua helada para evitar su renaturalización y se añadieron mediante vacio a una membrana de nylon (Hybond $\mathrm{N}^{+}$, GE Healthcare) equilibrada en SSC $5 x$ usando un apararato de slot blot (Bio-Dot SF; BioRad). Posteriormente, la muestra de DNA fue fijada a la membrana mediante la aplicación de luz UV $\left(1.2 \times 10^{5} \mu \mathrm{J}\right)$. La membrana fue bloqueada con leche al $5 \%$ en TBS conteniendo Tween-20 al 0,1\% e incubada con un anticuerpo anti-BrdU durante $30 \mathrm{~min}$. Después de lavar la membrana, se incubó con un anticuerpo secundario anti-IgG de ratón durante 30 min. y se reveló con el reactivo ECL plus (GE Healthcare) La quimioluminiscencia se detectó 
usando un equipo Chemidoc (Bio-Rad) y la cuantificación de las bandas se realizó mediante el software de Quantity One.

Cuando comprobamos que las cepas haploides de diferentes genotipos portadoras del cassette p306BrdU-Inc incorporaban cantidades similares de BrdU, construimos las correspondientes cepas diploides para llevar a cabo el experimento de detección de BrdU en meiosis. En este caso, la BrdU se añadió al pasar la células al medio líquido de esporulación ( $\mathrm{t}=0$ ) para que se incorpore durante la fase $\mathrm{S}$ premeiótica. Asimismo, siguiendo el mismo procedimiento descrito anteriormente, también comprobamos que los diferentes diploides mutantes construidos incorporaban la misma cantidad de BrdU durante la meiosis para que los resultados obtenidos en las extensiones de núcleos fueran comparables.

Para detectar la BrdU en extensiones de cromosomas (condiciones nativas), a partir de cultivos meióticos en presencia de $\mathrm{BrdU}$ añadida a $\mathrm{t}=0$, se tomaron muestras a las $17 \mathrm{~h}$ de meiosis para realizar extensiones de núcleos y la posterior detección de BrdU en regiones de ssDNA mediante inmunofluorescencia utilizando el procedimiento descrito en el apartado 6.5.

\section{6.- ANÁLISIS DE PROTEÍNAS}

\section{1.- Obtención de extractos proteicos en condiciones desnaturalizantes.}

La células procedentes de $5-10 \mathrm{ml}$ de cultivos en meiosis se recogieron, se lavaron en el mismo volumen de agua y se resuspendieron inmediatamente en $1 \mathrm{ml}$ de ácido tricloroacético (TCA) al 20\%. A continuación, se centrifugaron las células, se eliminó el sobrenadante y se pesó la biomasa presente. Para romper las células, se resuspendieron en $100 \mu \mathrm{l}$ de TCA $20 \%$, se añadieron $500 \mu \mathrm{l}$ de bolitas de vidrio y se dieron tres pulsos de agitación de $15 \mathrm{seg}$ cada uno a una potencia de 5 en una FastPrep (Bio101, Inc.) a $4^{\circ} \mathrm{C}$ (dejando las células 1 min de reposo en hielo entre cada pulso). Se recogió el lisado de células, las bolitas de vidrio se lavaron dos veces con $100 \mu \mathrm{l}$ de TCA $5 \%$ y todo el lisado celular reunido se centrifugó durante 5 min a $16100 \mathrm{x}$ g. Se eliminó el sobrenadante y el precipitado perteneciente a la muestra que menos biomasa poseía se resuspendió en $100 \mu \mathrm{l}$ de tampón Laemmli 2X (Tris-HCl 100 mM pH 6,8, glicerol 20\%, SDS 2,5\%, DTT 5\% y trazas de azul de bromofenol). El resto de muestras se resuspendió en la cantidad de tampón Laemmli $2 X$ proporcional a la biomasa que poseían para igualar la cantidad de proteína presente en todas las muestras a analizar simultáneamente. Una vez resuspendidos los precipitados, se añadieron $50 \mu \mathrm{l}$ de Tris Base 2M para cada $100 \mu \mathrm{l}$ de Laemmli 2X (o la cantidad proporcional para cada muestra) y se hirvieron durante 5 min. Finalmente, se centrifugaron las muestras a $16100 \mathrm{x} g$ durante 5 min y se recogieron los sobrenadantes en tubos nuevos que se congelaron a $-80^{\circ} \mathrm{C}$.

\section{2.- Separación de proteínas en geles de poliacrilamida.}

Las proteínas se separaron por tamaños en geles de poliacrilamida desde el 8\% al 15\% (relación acrilamida: bisacrilamida de 37,5:1 ó 37,5:0,5). Se cargaron $10 \mu$ de los extractos obtenidos y se llevó a cabo la electroforesis utilizando cubetas Mini-Protean III (Bio-Rad) a voltaje constante de $150 \mathrm{~V}$ durante 1,5 h y usando

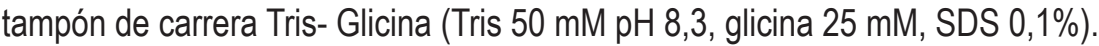

Para resolver las diferentes formas resultantes de la fosforilación de la proteína Mek1 se utilizaron geles en los que se añadió el ligando Phos-tag (NARD Institute) a una concentración de $37,5 \mu \mathrm{M}$ y $\mathrm{MnCl}_{2}$ a una 
concentración de $75 \mathrm{mM}$ (relación acrilamida:bisacrilamida de 29:1). Las electroforesis se realizaron durante $3 \mathrm{~h}$ en hielo a $100 \mathrm{~V}$ constantes.

\section{3.- Transferencia de proteínas tipo western.}

Tras la electroforesis, las proteínas fueron transferidas a membranas de PVDF (Immobilon-P; Millipore) previamente activadas con metanol y equilibradas en tampón de transferencia, mediante el sistema de transferencia húmeda Mini-Transfer (Bio-Rad) aplicando un amperaje constante de $275 \mathrm{~mA}$ durante $2 \mathrm{~h}$ o bien a $100 \mathrm{~V}$ constantes durante 40 min empleando el sistema Criterion Blotter (Biorad). El tampón de transferencia fue Tris $25 \mathrm{mM}$, glicina $200 \mathrm{mM}$ y $20 \%$ de metanol. En el caso de los geles con Phos-tag, antes de transferir las proteínas a la membrana se hicieron dos lavados del gel durante 10 min en agitación suave, el primer lavado se hizo con tampón de transferencia y EDTA $1 \mathrm{mM}$ (para eliminar el ión $\mathrm{Mn}^{2+}$ ) y el segundo lavado con tampón de transferencia sin EDTA. Para monitorizar la transferencia y estimar si la carga de proteína era equivalente en los diferentes carriles se tiñeron las membranas con Ponceau-S y seguidamente se bloquearon en una solución de TBS-T (Tris-HCl 10 mM pH 7,6, NaCl 150 mM y Tween-20 0,1\%) con 5\% de BSA (Sigma A7906) o leche desnatada (Sveltesse; Nestlé) durante 1 hora a temperatura ambiente. A continuación las membranas se incubaron en la solución de bloqueo con los anticuerpos primarios durante $12-16 \mathrm{~h}$ a $4^{\circ} \mathrm{C}$ ó $2 \mathrm{~h}$ a temperatura ambiente. Se lavaron las membranas con TBS-T durante $30 \mathrm{~min}$ (tres lavados de $10 \mathrm{~min}$ cada uno) y se incubaron con el anticuerpo secundario diluido en TBS-T con BSA $5 \%$ o leche durante 45 - 60 min a temperatura ambiente. Nuevamente se lavaron las membranas y se revelaron empleando el reactivo de ECL ó ECL+ (GE Healthcare). La señal de quimioluminiscencia emitida se detectó con películas Hyperfilm ECL (GE Healthcare) o en un equipo Molecular Imager Chemi-Doc XRS (Biorad) equipado con una cámara CCD para la captura de imágenes. Los anticuerpos primarios y secundarios utilizados se describen en la Tabla 8.

\section{4.- Inmunoprecipitación de proteínas y tratamiento con $\lambda$-fosfatasa.}

Se prepararon los extractos de proteína con TCA, como se ha explicado anteriormente. A continuación, se guardó una alícuota de 10-20 $\mu$ l en un nuevo eppendorf y el resto del extracto se diluyó 10 veces con tampón de lisis (SDS al 0,01\%, Triton X-100 al 1,1\%, Tris-HCl 16,7mM, EDTA 1,2mM y NaCl 167mM) con $3 \mu$ de cocktail de inhibidor de proteasas (SIGMA, P8215). Se añadieron $10 \mu \mathrm{g}$ de anticuerpo primario y se incubó durante 1 hora rotando a $4{ }^{\circ} \mathrm{C}$. En este intervalo de tiempo se preparó la proteína-G sepharosa del siguiente modo: se equilibraron 70-80 $\mu \mathrm{l}$ de proteína-G sepharosa con $1 \mathrm{ml}$ de tampón de lisis, se centrifugaron a $12000 \mathrm{x} \mathrm{g}$ durante 1 min y se resuspendieron en el mismo volumen de tampón de lisis. Añadimos los $80 \mu$ de proteína-G sepharosa al extracto incubado con el anticuerpo primario y se incubaron durante $1 \mathrm{~h}$ rotando a $4^{\circ} \mathrm{C}$. Después se centrifugó la muestra a 12000 x g durante 1 min y se eliminó el sobrenadante. Se realizaron 3 lavados de las bolitas de proteína G-sepharosa con PBS1X. Seguidamente, se resuspendió en $90 \mu$ de PBS 1X y se dividió el volumen en 3 alícuotas: una llevará muestra sin tratar, otra tratada con la enzima $\lambda$-fosfatasa y la útlima tratada con $\lambda$-fosfatasa e inhibidores de la enzima. A la muestra sin tratar con $\lambda$-fosfatasa se le añadió $20 \mu l$ de tampón 10X de $\lambda$-fosfatasa, (New England Biolabs), $20 \mu \mathrm{l} \mathrm{de} \mathrm{CIMn}_{2}$ y $130 \mu \mathrm{l}$ de agua. La segunda muestra se trató con 2 $\mu \mathrm{l}$ de $\lambda$-fosfatasa (New England Biolabs), $20 \mu \mathrm{l}$ de tampón 10X de $\lambda$-fosfatasa, $20 \mu \mathrm{l}$ de $\mathrm{CIMn}_{2}$ y $128 \mu \mathrm{l}$ de agua. La última muestra se trató con $2 \mu \mathrm{l}$ de $\lambda$-fosfatasa, $10 \mu \mathrm{l}$ de ortovanadato $0,2 \mathrm{M}, 10 \mu \mathrm{l}$ de NaF 1M, $20 \mu \mathrm{l}$ de EDTA 
Tabla 8.- Anticuerpos utilizados en este trabajo.

\begin{tabular}{|c|c|c|c|c|}
\hline Anticuerpo & Organismo & Tipo & Condiciones & Procedencia \\
\hline anti-GFP & conejo & policlonal & $\begin{array}{l}\text { WB } 1: 2000 \\
\text { IF } 1: 160\end{array}$ & R. Freire \\
\hline anti-HA & ratón & monoclonal & $\begin{array}{l}\text { WB 1:2000 } \\
\text { IF } 1: 200\end{array}$ & Covance \\
\hline anti-HA & ratón & monoclonal & $\begin{array}{l}\text { WB 1:2000 } \\
\text { ChIP } 10 \mu \mathrm{g}\end{array}$ & Roche; 12CA5 \\
\hline anti-HA & conejo & policlonal & IF $1: 200$ & Abcam; ab9110 \\
\hline anti-Myc & ratón & monoclonal & WB $1: 1000$ & Covance \\
\hline anti-Myc & ratón & monoclonal & ChIP $10 \mu \mathrm{g}$ & Santa Cruz; sc-40 \\
\hline anti-Rad53 & conejo & policlonal & WB 1:1000 & Santa Cruz; sc-6749 \\
\hline anti-Cdc5 & cabra & policlonal & WB 1:1000 & Santa Cruz; sc-6733 \\
\hline anti-PGK & ratón & monoclonal & WB 1:5000 & $\begin{array}{l}\text { Molecular Probes; } \\
\text { 22C5, A-6457 }\end{array}$ \\
\hline anti-Tat1 & ratón & monoclonal & WB $1: 5000$ & K. Gull lab \\
\hline anti-Mek1 & conejo & policlonal & WB 1:2000 & R. Freire \\
\hline anti-Rad51 & conejo & policlonal & IF $1: 750$ & D. Bishop \\
\hline anti-Zip1 & conejo & policlonal & IF 1:100 & S. Roeder \\
\hline anti-BrdU & ratón & monoclonal & $\begin{array}{l}\text { SB } 1: 50 \\
\text { IF } 1: 20\end{array}$ & Becton Dickinson; 347583 \\
\hline anti-lgG conejo-HRP & burro & policlonal & WB 1:5000 & GE-Healthcare; NA934 \\
\hline anti-lgG ratón-HRP & oveja & policlonal & WB 1:5000 & GE-Healthcare; NA931 \\
\hline anti-lgG cabra-HRP & burro & policlonal & WB 1:5000 & Santa Cruz; sc-2020 \\
\hline anti-lgG de conejo-AF488 & cabra & policlonal & IF 1:200 & Invitrogen; A11034 \\
\hline anti-IgG de ratón-AF488 & cabra & policlonal & IF $1: 200$ & Invitrogen; A11029 \\
\hline anti-lgG de conejo-AF594 & cabra & policlonal & IF 1:200 & Invitrogen; A11012 \\
\hline anti-IgG de ratón-AF594 & cabra & policlonal & IF 1:200 & Invitrogen; A11032 \\
\hline
\end{tabular}

WB: Western Blot

IF: Inmunofluorescencia

ChIP: Inmunoprecipitación de cromatina

SB: Slot Blot 
0,5M, $20 \mu \mathrm{l}$ de tampón $10 \mathrm{X}, 20 \mu \mathrm{l}$ de $\mathrm{CIMn}_{2}$ y $88 \mu \mathrm{l}$ de agua. Las tres muestras se incubaron a $30^{\circ} \mathrm{C}$ durante $30 \mathrm{~min}$. A continuación, se centrifugaron a $12000 \mathrm{x}$ g durante 2 min y se eliminó el sobrenadante. Las bolitas de proteína-G sepharosa se lavaron 3 veces con PBS 1X y se resuspendieron en 20-40 $\mu$ l de Laemnli Sample Buffer $1 X$. Se hirvieron durante 5 min y se centrifugaron a máxima velocidad durante $10 \mathrm{~min}$. Se recogieron los sobrenadantes y se congelaron a $-20^{\circ} \mathrm{C}$ antes de ser analizados mediante western blot.

\section{5.- Inmunofluorescencia de extensiones de núcleos.}

Las extensiones de núcleos y las inmunofluorescencias se llevaron a cabo siguiendo un protocolo descrito para S. cerevisiae (Sym et al., 1993; San-Segundo and Roeder, 1999).

Las extensiones de núcleos se hicieron a partir de $10 \mathrm{ml}$ de células recogidas a diferentes tiempos de meiosis. En primer lugar, se hicieron esferoplastos de las células, para lo cual se resuspendieron en $1 \mathrm{ml}$ de KAc $2 \%$, Sorbitol $1 \mathrm{M} \mathrm{pH} 7$ al que se le ha añadido además DTT 10mM, 0,5 mg/ml de Zimoliasa 20T (Seikagaku Corporation) y $0,005 \%$ de glusulasa (Perkin Elmer). Transcurridos 30 min de incubación en agitación suave a $30^{\circ} \mathrm{C}$ se comprobó al microscopio si se habían formado esferoplastos. Una vez formados, se centrifugaron a 1000 rpm durante 2 min y se eliminó el sobrenadante volteando el tubo con cuidado. Seguidamente, se añadió $1 \mathrm{ml}$ de MES-sorbitol enfriado en hielo (MES 0,1 M, EDTA $1 \mathrm{mM}, \mathrm{MgCl}_{2}$ 0,5 mM, pH 6,4, sorbitol $1 \mathrm{M}$ ) resbalando por las paredes del tubo. Las células se resuspendieron agitando suavemente el tubo con la mano, sin usar vortex ni pipeta. A continuación, se centrifugaron de nuevo a 1000 rpm durante 2 min y se desechó el sobrenadante volteando el tubo con cuidado. Para romper la células y fijar los núcleos inmediatamente, se colocó el tubo en posición horizontal y se pusieron $200 \mu \mathrm{l}$ de MES enfriado en hielo, ahora sin sorbitol, sobre la pared del tubo, cerca de la boca: se añadieron $720 \mu \mathrm{l}$ de paraformaldehído enfriado en hielo al $4 \%$ sobre los $200 \mu \mathrm{l}$ de MES, y se inclinó el tubo para que ambas soluciones cayeran suavemente sobre los esferoplastos. Para mezclar las células con la solución de fijación, se agitó el tubo suavemente con la mano, sin usar vortex ni pipeta. Una vez resuspendidos los esferoplastos, se vertió la mezcla sobre dos o tres portas (Superfrost Plus, $25 \times 75 \times 1,0 \mathrm{~mm}$; Thermo Scientific) y se colocó sobre cada uno de ellos un cubre $(24 \times 50 \mathrm{~mm})$. Tras $30 \mathrm{~min}$ de reposo, al inclinar los portas se retiraron los cubres y el exceso de líquido. Se dejaron reposar 2 min y, seguidamente, se lavaron con 1-2 ml de Photo-Flo 200 (Kodak) al 0,4\%. Para hacer este lavado, se fue vertiendo la solución de Photo-Flo sobre los portas inclinados, dejando que resbalara suavemente sobre ellos. Se dejaron inclinados a temperatura ambiente hasta que se secaron. Si no iban a ser procesados para inmunofluorescencia inmediatamente, se guardaron a $-20^{\circ} \mathrm{C}$.

La solución de paraformaldehído al 4\% utilizada para la fijación se preparó añadiendo $1 \mathrm{~g}$ del compuesto (Sigma-Aldrich P6148) a $25 \mathrm{ml}$ de agua y calentando la mezcla a $50-55^{\circ} \mathrm{C}$. Para facilitar la disolución del paraformaldehído se añadió $1 \mu \mathrm{l}$ de $\mathrm{NaOH} 5 \mathrm{~N}$. Una vez disuelto, se comprobó que su pH estaba entre 7-8, se filtró y se guardó a $4^{\circ} \mathrm{C}$ para ser utilizada durante los días siguientes.

Para llevar a cabo las inmunofluorescencias se lavaron los portas con PBS 1X durante 3 min usando una "Copling jar". Una vez eliminado el exceso de PBS se añadieron $200 \mu \mathrm{l}$ de solución de bloqueo (suero bovino fetal; Gibco) sobre cada porta, se puso un cubre de $24 \times 50 \mathrm{~mm}$ sobre cada uno de ellos y se incubaron a temperatura ambiente durante $1 \mathrm{~h}$ en una cámara húmeda. Transcurrido este tiempo, se eliminó la solución de 
bloqueo inclinando el porta y dejando que escurriera el exceso de líquido. Se preparó una dilución apropiada del anticuerpo primario en PBS con BSA al 3\%. Se añadieron $75 \mu$ lde solución de anticuerpo sobre cada porta. Se puso encima de cada porta un cubre de $24 \times 50 \mathrm{~mm}$ y se incubaron con los anticuerpos toda la noche a $4^{\circ} \mathrm{C}$ en una cámara húmeda. Posteriormente, se hicieron tres lavados de 5 min con PBS 1X en una "Copling jar". Las diluciones de los anticuerpos secundarios se hicieron en PBS con BSA al 3\%. Se utilizaron $75 \mu$ lde solución de anticuerpo secundario para cada porta. Esta incubación fue de $2 \mathrm{~h}$ a temperatura ambiente en cámara húmeda. Transcurrido este tiempo, se lavaron con PBS 1 X 3 veces durante 5 min, se eliminó el exceso de líquido y se añadieron $15 \mu$ de solución de montaje (VECTASHIELD Mounting Medium with DAPI). Por último, se colocaron los cubres, se sellaron con laca de uñas y se observaron al microscopio de fluorescencia o se guardaron a $-20^{\circ} \mathrm{C}$. Los anticuerpos primarios y secundarios utilizados se muestran en la Tabla 8.

\section{7.- OTRAS TÉCNICAS.}

\section{1.- Estudios de ditirosina.}

Para realizar el ensayo de fluorescencia de ditirosina como marcador semicuantitativo de la formación de esporas maduras (Briza et al., 1986), se sembraron las cepas de interés en una placa de YPDA durante la noche y a la mañana siguiente, se replicaron sobre una placa de medio de esporulación que llevaba un filtro de nitrocelulosa (Protran BA85, Whatman) y que se incubó a $30^{\circ} \mathrm{C}$. A los 2 y 3 días, la placa conteniendo el filtro de nitrocelulosa se irradió con luz UV de $302 \mathrm{~nm}$ procedente de una lámpara de mano (Model UVM-57, UVP) y se tomaron imágenes mediante un equipo Gel Doc XR (Bio-Rad) equipado con una cámara CCD.

\section{2.- Cálculos de estadística.}

Para calcular si las diferencias entre determinados valores eran estadísticamente significativas se utilizó un test $t$-Student. Los valores $P$ fueron calculados usando el software GraphPad Prism 4.0. Se consideraron significativos los resultados con $P<0,01$. 
Acosta, I., Ontoso, D. and San-Segundo, P. A. (2011). The budding yeast polo-like kinase Cdc5 regulates the Ndt80 branch of the meiotic recombination checkpoint pathway. Mol Biol Cell 22, 3478-90.

Alani, E., Padmore, R. and Kleckner, N. (1990). Analysis of wild-type and rad50 mutants of yeast suggests an intimate relationship between meiotic chromosome synapsis and recombination. Cell 61, 419-36.

Aguilera, A. and Gomez-Gonzalez, B. (2008). Genome instability: a mechanistic view of its causes and consequences. Nat Rev Genet 9, 204-17.

Alcasabas, A. A., Osborn, A. J., Bachant, J., Hu, F., Werler, P. J., Bousset, K., Furuya, K., Diffley, J. F., Carr, A. M. and Elledge, S. J. (2001). Mrc1 transduces signals of DNA replication stress to activate Rad53. Nat Cell Biol 3, 958-65.

Alexandru, G., Zachariae, W., Schleiffer, A. and Nasmyth, K. (1999). Sister chromatid separation and chromosome reduplication are regulated by different mechanisms in response to spindle damage. EMBO J 18, 2707-21

Allers, T. and Lichten, M. (2001). Differential timing and control of noncrossover and crossover recombination during meiosis. Cell 106, 47-57.

Amon, A. (1999). The spindle checkpoint. Curr Opin Genet Dev 9, 69-75.

Araki, H., Leem, S. H., Phongdara, A. and Sugino, A. (1995). Dpb11, which interacts with DNA polymerase II(epsilon) in Saccharomyces cerevisiae, has a dual role in S-phase progression and at a cell cycle checkpoint. Proc Natl Acad Sci U S A 92, 11791-5.

Arbel, A., Zenvirth, D. and Simchen, G. (1999). Sister chromatid-based DNA repair is mediated by RAD54, not by DMC1 or TID1. EMBO J 18, 2648-58.

Bailis, J. M. and Roeder, G. S. (1998). Synaptonemal complex morphogenesis and sister-chromatid cohesion require Mek1dependent phosphorylation of a meiotic chromosomal protein. Genes Dev 12, 3551-63.

Bailis, J. M. and Roeder, G. S. (2000). Pachytene exit controlled by reversal of Mek1-dependent phosphorylation. Cell 101, 211-21.

Ball, H. L., Ehrhardt, M. R., Mordes, D. A., Glick, G. G., Chazin, W. J. and Cortez, D. (2007). Function of a conserved checkpoint recruitment domain in ATRIP proteins. Mol Cell Biol 27, 3367-77.

Barlow, J. H., Lisby, M. and Rothstein, R. (2008). Differential regulation of the cellular response to DNA double-strand breaks in G1. Mol Cell 30, 73-85.

Bassing, C. H., Suh, H., Ferguson, D. O., Chua, K. F., Manis, J., Eckersdorff, M., Gleason, M., Bronson, R., Lee, C. and Alt, F. W. (2003). Histone H2AX: a dosage-dependent suppressor of oncogenic translocations and tumors. Cell 114, 359-70.

Baudat, F. and Nicolas, A. (1997). Clustering of meiotic double-strand breaks on yeast chromosome III. Proc Natl Acad Sci U S A 94, 5213-8.

Benjamin, K. R., Zhang, C., Shokat, K. M. and Herskowitz, I. (2003). Control of landmark events in meiosis by the CDK Cdc28 and the meiosis-specific kinase Ime2. Genes Dev 17, 1524-39.

Bernard, P., Maure, J. F. and Javerzat, J. P. (2001). Fission yeast Bub1 is essential in setting up the meiotic pattern of chromosome segregation. Nat Cell Biol 3, 522-6.

Bishop, D. K., Park, D., Xu, L. and Kleckner, N. (1992). DMC1: a meiosis-specific yeast homolog of E. coli recA required for recombination, synaptonemal complex formation, and cell cycle progression. Cell 69, 439-56.

Bishop, D. K. (1994). RecA homologs Dmc1 and Rad51 interact to form multiple nuclear complexes prior to meiotic chromosome synapsis. Cell 79, 1081-92. 
Boeke, J. D., LaCroute, F. and Fink, G. R. (1984). A positive selection for mutants lacking orotidine-5'-phosphate decarboxylase activity in yeast: 5-fluoro-orotic acid resistance. Mol Gen Genet 197, 345-6.

Bonilla, C. Y., Melo, J. A. and Toczyski, D. P. (2008). Colocalization of sensors is sufficient to activate the DNA damage checkpoint in the absence of damage. Mol Cell 30, 267-76.

Borde, V., Goldman, A. S. and Lichten, M. (2000). Direct coupling between meiotic DNA replication and recombination initiation. Science 290, 806-9.

Borde, V., Robine, N., Lin, W., Bonfils, S., Geli, V. and Nicolas, A. (2009). Histone H3 lysine 4 trimethylation marks meiotic recombination initiation sites. EMBO J 28, 99-111.

Borner, G. V., Kleckner, N. and Hunter, N. (2004). Crossover/noncrossover differentiation, synaptonemal complex formation, and regulatory surveillance at the leptotene/zygotene transition of meiosis. Cell 117, 29-45.

Bostelman, L. J., Keller, A. M., Albrecht, A. M., Arat, A. and Thompson, J. S. (2007). Methylation of histone H3 lysine-79 by Dot1p plays multiple roles in the response to UV damage in Saccharomyces cerevisiae. DNA Repair (Amst) 6, 383-95.

Briza, P., Winkler, G., Kalchhauser, H. and Breitenbach, M. (1986). Dityrosine is a prominent component of the yeast ascospore wall. A proof of its structure. J Biol Chem 261, 4288-94.

Budd, M. E. and Campbell, J. L. (2009). Interplay of Mre11 nuclease with Dna2 plus Sgs1 in Rad51-dependent recombinational repair. PLoS One 4, e4267.

Buhler, C., Borde, V. and Lichten, M. (2007). Mapping meiotic single-strand DNA reveals a new landscape of DNA doublestrand breaks in Saccharomyces cerevisiae. PLoS Biol 5, e324.

Buhler, C., Shroff, R. and Lichten, M. (2009). Genome-wide mapping of meiotic DNA double-strand breaks in Saccharomyces cerevisiae. Methods Mol Biol 557, 143-64.

Carballo, J. A., Johnson, A. L., Sedgwick, S. G. and Cha, R. S. (2008). Phosphorylation of the axial element protein Hop1 by Mec1/Tel1 ensures meiotic interhomolog recombination. Cell 132, 758-70.

Caspari, T. and Carr, A. M. (2002). Checkpoints: how to flag up double-strand breaks. Curr Biol 12, R105-7.

Cejka, P., Cannavo, E., Polaczek, P., Masuda-Sasa, T., Pokharel, S., Campbell, J. L. and Kowalczykowski, S. C. (2010). DNA end resection by Dna2-Sgs1-RPA and its stimulation by Top3-Rmi1 and Mre11-Rad50-Xrs2. Nature 467, 112-6.

Celeste, A., Difilippantonio, S., Difilippantonio, M. J., Fernandez-Capetillo, O., Pilch, D. R., Sedelnikova, O. A., Eckhaus, M., Ried, T., Bonner, W. M. and Nussenzweig, A. (2003). H2AX haploinsufficiency modifies genomic stability and tumor susceptibility. Cell 114, 371-83.

Cejka, P., Cannavo, E., Polaczek, P., Masuda-Sasa, T., Pokharel, S., Campbell, J. L. and Kowalczykowski, S. C. (2010). DNA end resection by Dna2-Sgs1-RPA and its stimulation by Top3-Rmi1 and Mre11-Rad50-Xrs2. Nature 467, 112-6.

Clerici, M., Mantiero, D., Lucchini, G. and Longhese, M. P. (2005). The Saccharomyces cerevisiae Sae2 protein promotes resection and bridging of double strand break ends. J Biol Chem 280, 38631-8.

Clyne, R. K., Katis, V. L., Jessop, L., Benjamin, K. R., Herskowitz, I., Lichten, M. and Nasmyth, K. (2003). Polo-like kinase Cdc5 promotes chiasmata formation and cosegregation of sister centromeres at meiosis I. Nat Cell Biol 5, 480-5.

Cohen-Fix, O. and Koshland, D. (1997). The anaphase inhibitor of Saccharomyces cerevisiae Pds1p is a target of the DNA damage checkpoint pathway. Proc Natl Acad Sci U S A 94, 14361-6.

Conde, F. and San-Segundo, P. A. (2008). Role of Dot1 in the response to alkylating DNA damage in Saccharomyces cerevisiae: regulation of DNA damage tolerance by the error-prone polymerases Polzeta/Rev1. Genetics 179, 1197-210.

Conde, F., Refolio, E., Cordon-Preciado, V., Cortes-Ledesma, F., Aragon, L., Aguilera, A. and San-Segundo, P. A. (2009). The Dot1 histone methyltransferase and the Rad9 checkpoint adaptor contribute to cohesin-dependent double-strand break repair by sister chromatid recombination in Saccharomyces cerevisiae. Genetics 182, 437-46. 
Cortes-Ledesma, F. and Aguilera, A. (2006). Double-strand breaks arising by replication through a nick are repaired by cohesin-dependent sister-chromatid exchange. EMBO Rep 7, 919-26.

Cheng, L., Collyer, T. and Hardy, C. F. (1999). Cell cycle regulation of DNA replication initiator factor Dbf4p. Mol Cell Biol 19, 4270-8.

Cheslock, P. S., Kemp, B. J., Boumil, R. M. and Dawson, D. S. (2005). The roles of MAD1, MAD2 and MAD3 in meiotic progression and the segregation of nonexchange chromosomes. Nat Genet 37, 756-60.

Chu, S. and Herskowitz, I. (1998). Gametogenesis in yeast is regulated by a transcriptional cascade dependent on Ndt80. Mol Cell 1, 685-96.

de los Santos, T. and Hollingsworth, N. M. (1999). Red1p, a MEK1-dependent phosphoprotein that physically interacts with Hop1p during meiosis in yeast. J Biol Chem 274, 1783-90.

de los Santos, T., Loidl, J., Larkin, B. and Hollingsworth, N. M. (2001). A role for MMS4 in the processing of recombination intermediates during meiosis in Saccharomyces cerevisiae. Genetics 159, 1511-25.

De Massy, B., Baudat, F. and Nicolas, A. (1994). Initiation of recombination in Saccharomyces cerevisiae haploid meiosis. Proc Natl Acad Sci U S A 91, 11929-33.

Dirick, L., Goetsch, L., Ammerer, G. and Byers, B. (1998). Regulation of meiotic S phase by Ime2 and a Clb5,6-associated kinase in Saccharomyces cerevisiae. Science 281, 1854-7.

Eichinger, C. S. and Jentsch, S. (2010). Synaptonemal complex formation and meiotic checkpoint signaling are linked to the lateral element protein Red1. Proc Natl Acad Sci U S A 107, 11370-5.

Engebrecht, J. and Roeder, G. S. (1989). Yeast mer1 mutants display reduced levels of meiotic recombination. Genetics 121, 237-47.

Falck, J., Coates, J. and Jackson, S. P. (2005). Conserved modes of recruitment of ATM, ATR and DNA-PKcs to sites of DNA damage. Nature 434, 605-11.

Feng, Q., Wang, H., Ng, H. H., Erdjument-Bromage, H., Tempst, P., Struhl, K. and Zhang, Y. (2002). Methylation of H3lysine 79 is mediated by a new family of HMTases without a SET domain. Curr Biol 12, 1052-8.

Fesquet, D., Fitzpatrick, P. J., Johnson, A. L., Kramer, K. M., Toyn, J. H. and Johnston, L. H. (1999). A Bub2p-dependent spindle checkpoint pathway regulates the Dbf2p kinase in budding yeast. EMBO J 18, 2424-34.

Fraschini, R., Formenti, E., Lucchini, G. and Piatti, S. (1999). Budding yeast Bub2 is localized at spindle pole bodies and activates the mitotic checkpoint via a different pathway from Mad2. J Cell Biol 145, 979-91.

Freire, R., Murguia, J. R., Tarsounas, M., Lowndes, N. F., Moens, P. B. and Jackson, S. P. (1998). Human and mouse homologs of Schizosaccharomyces pombe rad1(+) and Saccharomyces cerevisiae RAD17: linkage to checkpoint control and mammalian meiosis. Genes Dev. 12, 2560-73.

Game, J. C., Williamson, M. S., Spicakova, T. and Brown, J. M. (2006). The RAD6/BRE1 histone modification pathway in Saccharomyces confers radiation resistance through a RAD51-dependent process that is independent of RAD18. Genetics 173, 1951-68.

Gellert, M. (1996). A new view of V(D)J recombination. Genes Cells 1, 269-75.

Giannattasio, M., Lazzaro, F., Plevani, P. and Muzi-Falconi, M. (2005). The DNA damage checkpoint response requires histone H2B ubiquitination by Rad6-Bre1 and H3 methylation by Dot1. J Biol Chem 280, 9879-86.

Gietz, R. D., Schiestl, R. H., Willems, A. R. and Woods, R. A. (1995). Studies on the transformation of intact yeast cells by the LiAc/SS-DNA/PEG procedure. Yeast 11, 355-60. 
Gilbertson, L. A. and Stahl, F. W. (1994). Initiation of meiotic recombination is independent of interhomologue interactions. Proc Natl Acad Sci U S A 91, 11934-7.

Golub, E. I. (1988). 'One minute' transformation of competent E.coli by plasmid DNA. Nucleic Acids Res 25, 1641.

Goldstein, A. L. and McCusker, J. H. (1999). Three new dominant drug resistance cassettes for gene disruption in Saccharomyces cerevisiae. Yeast 15, 1541-53.

Gravel, S., Chapman, J. R., Magill, C. and Jackson, S. P. (2008). DNA helicases Sgs1 and BLM promote DNA doublestrand break resection. Genes Dev 22, 2767-72.

Grandin, N. and Reed, S. I. (1993). Differential function and expression of Saccharomyces cerevisiae B-type cyclins in mitosis and meiosis. Mol Cell Biol 13, 2113-25.

Gratzner, H. G. (1982). Monoclonal antibody to 5-bromo- and 5-iododeoxyuridine: A new reagent for detection of DNA replication. Science $\mathbf{2 1 8 , 4 7 4 - 5 .}$

Grushcow, J. M., Holzen, T. M., Park, K. J., Weinert, T., Lichten, M. and Bishop, D. K. (1999). Saccharomyces cerevisiae checkpoint genes MEC1, RAD17 and RAD24 are required for normal meiotic recombination partner choice. Genetics 153 , 607-20.

Gueldener, U., Heinisch, J., Koehler, G. J., Voss, D. and Hegemann, J. H. (2002). A second set of loxP marker cassettes for Cre-mediated multiple gene knockouts in budding yeast. Nucleic Acids Res 30, e23.

Haber, J. E. (1998). Mating-type gene switching in Saccharomyces cerevisiae. Annu Rev Genet 32, 561-99.

Harrison, J. C. and Haber, J. E. (2006). Surviving the breakup: the DNA damage checkpoint. Annu Rev Genet 40, 209-35.

Hartwell, L. H. and Weinert, T. A. (1989). Checkpoints: controls that ensure the order of cell cycle events. Science 246, 629-34.

Hayashi, A., Ogawa, H., Kohno, K., Gasser, S. M. and Hiraoka, Y. (1998). Meiotic behaviours of chromosomes and microtubules in budding yeast: relocalization of centromeres and telomeres during meiotic prophase. Genes Cells 3, 587-601.

Henderson, K. A., Kee, K., Maleki, S., Santini, P. A. and Keeney, S. (2006). Cyclin-dependent kinase directly regulates initiation of meiotic recombination. Cell 125, 1321-32.

Hepworth, S. R., Friesen, H. and Segall, J. (1998). NDT80 and the meiotic recombination checkpoint regulate expression of middle sporulation-specific genes in Saccharomyces cerevisiae. Mol Cell Biol 18, 5750-61.

Hochwagen, A. and Amon, A. (2006). Checking your breaks: surveillance mechanisms of meiotic recombination. Curr Biol 16, R217-28.

Hollingsworth, N. M. and Ponte, L. (1997). Genetic interactions between HOP1, RED1 and MEK1 suggest that MEK1 regulates assembly of axial element components during meiosis in the yeast Saccharomyces cerevisiae. Genetics 147, 3342.

Hong, E. J. and Roeder, G. S. (2002). A role for Ddc1 in signaling meiotic double-strand breaks at the pachytene checkpoint. Genes Dev 16, 363-76.

Hoyt, M. A. (2000). Exit from mitosis: spindle pole power. Cell 102, 267-70.

Huh, W. K., Falvo, J. V., Gerke, L. C., Carroll, A. S., Howson, R. W., Weissman, J. S. and O'Shea, E. K. (2003). Global analysis of protein localization in budding yeast. Nature $425,686-91$.

Hunter, N. and Kleckner, N. (2001). The single-end invasion: an asymmetric intermediate at the double-strand break to double-holliday junction transition of meiotic recombination. Cell 106, 59-70. 
Jordan, P., Copsey, A., Newnham, L., Kolar, E., Lichten, M. and Hoffmann, E. (2009). Ipl1/Aurora B kinase coordinates synaptonemal complex disassembly with cell cycle progression and crossover formation in budding yeast meiosis. Genes Dev 23, 2237-51.

Iftode, C., Daniely, Y. and Borowiec, J. A. (1999). Replication protein A (RPA): the eukaryotic SSB. Crit Rev Biochem Mol Biol 34, 141-80.

Itakura, E., Umeda, K., Sekoguchi, E., Takata, H., Ohsumi, M. and Matsuura, A. (2004). ATR-dependent phosphorylation of ATRIP in response to genotoxic stress. Biochem Biophys Res Commun 323, 1197-202.

Kamimura, Y., Masumoto, H., Sugino, A. and Araki, H. (1998). Sld2, which interacts with Dpb11 in Saccharomyces cerevisiae, is required for chromosomal DNA replication. Mol Cell Biol 18, 6102-9.

Kantake, N., Sugiyama, T., Kolodner, R. D. and Kowalczykowski, S. C. (2003). The recombination-deficient mutant RPA (rfa1-t11) is displaced slowly from single-stranded DNA by Rad51 protein. J Biol Chem 278, 23410-7.

Katis, V. L., Galova, M., Rabitsch, K. P., Gregan, J. and Nasmyth, K. (2004). Maintenance of cohesin at centromeres after meiosis I in budding yeast requires a kinetochore-associated protein related to MEI-S332. Curr Biol 14, 560-72.

Keegan, K. S., Holtzman, D. A., Plug, A. W., Christenson, E. R., Brainerd, E. E., Flaggs, G., Bentley, N. J., Taylor, E. M., Meyn, M. S., Moss, S. B. et al. (1996). The Atr and Atm protein kinases associate with different sites along meiotically pairing chromosomes. Genes Dev. 10, 2423-37.

Keeney, S. and Kleckner, N. (1995). Covalent protein-DNA complexes at the 5' strand termini of meiosis-specific doublestrand breaks in yeast. Proc Natl Acad Sci U S A 92, 11274-8.

Keeney, S., Giroux, C. N. and Kleckner, N. (1997). Meiosis-specific DNA double-strand breaks are catalyzed by Spo11, a member of a widely conserved protein family. Cell 88, 375-84.

Keeney, S. (2001). Mechanism and control of meiotic recombination initiation. Curr Top Dev Biol 52, 1-53.

Kim, H. S. and Brill, S. J. (2001). Rfc4 interacts with Rpa1 and is required for both DNA replication and DNA damage checkpoints in Saccharomyces cerevisiae. Mol Cell Biol 21, 3725-37.

Kim, E. M. and Burke, D. J. (2008). DNA damage activates the SAC in an ATM/ATR-dependent manner, independently of the kinetochore. PLoS Genet 4, e1000015.

Kitajima, T. S., Kawashima, S. A. and Watanabe, Y. (2004). The conserved kinetochore protein shugoshin protects centromeric cohesion during meiosis. Nature 427, 510-7.

Klein, F., Mahr, P., Galova, M., Buonomo, S. B., Michaelis, C., Nairz, K. and Nasmyth, K. (1999). A central role for cohesins in sister chromatid cohesion, formation of axial elements, and recombination during yeast meiosis. Cell 98, 91-103.

Kondo, T., Wakayama, T., Naiki, T., Matsumoto, K. and Sugimoto, K. (2001). Recruitment of Mec1 and Ddc1 checkpoint proteins to double-strand breaks through distinct mechanisms. Science 294, 867-70.

Lee, B. H. and Amon, A. (2003). Role of Polo-like kinase CDC5 in programming meiosis I chromosome segregation. Science $300,482-6$.

Lee, S. J., Schwartz, M. F., Duong, J. K. and Stern, D. F. (2003). Rad53 phosphorylation site clusters are important for Rad53 regulation and signaling. Mol Cell Biol 23, 6300-14.

Lengsfeld, B. M., Rattray, A. J., Bhaskara, V., Ghirlando, R. and Paull, T. T. (2007). Sae2 is an endonuclease that processes hairpin DNA cooperatively with the Mre11/Rad50/Xrs2 complex. Mol Cell 28, 638-51.

Leu, J. Y., Chua, P. R. and Roeder, G. S. (1998). The meiosis-specific Hop2 protein of S. cerevisiae ensures synapsis between homologous chromosomes. Cell 94, 375-86. 
Leu, J. Y. and Roeder, G. S. (1999). The pachytene checkpoint in S. cerevisiae depends on Swe1-mediated phosphorylation of the cyclin-dependent kinase Cdc28. Mol Cell 4, 805-14.

Li, R. (1999). Bifurcation of the mitotic checkpoint pathway in budding yeast. Proc Natl Acad Sci U S A 96, 4989-94.

Li, R. and Murray, A. W. (1991). Feedback control of mitosis in budding yeast. Cell 66, 519-31.

Liang, F. and Wang, Y. (2007). DNA damage checkpoints inhibit mitotic exit by two different mechanisms. Mol Cell Biol 27, 5067-78.

Liao, S., Toczylowski, T. and Yan, H. (2008). Identification of the Xenopus DNA2 protein as a major nuclease for the 5' $>3^{\prime}$ strand-specific processing of DNA ends. Nucleic Acids Res 36, 6091-100.

Lichten, M. and Goldman, A. S. (1995). Meiotic recombination hotspots. Annu Rev Genet 29, 423-44.

Lin, F. M., Lai, Y. J., Shen, H. J., Cheng, Y. H. and Wang, T. F. (2010). Yeast axial-element protein, Red1, binds SUMO chains to promote meiotic interhomologue recombination and chromosome synapsis. EMBO J 29, 586-96.

Lindgren, A., Bungard, D., Pierce, M., Xie, J., Vershon, A. and Winter, E. (2000). The pachytene checkpoint in Saccharomyces cerevisiae requires the Sum1 transcriptional repressor. EMBO J 19, 6489-97.

Lisby, M., Antunez de Mayolo, A., Mortensen, U. H. and Rothstein, R. (2003a). Cell cycle-regulated centers of DNA double-strand break repair. Cell Cycle 2, 479-83.

Lisby, M., Mortensen, U. H. and Rothstein, R. (2003b). Colocalization of multiple DNA double-strand breaks at a single Rad52 repair centre. Nature Cell Biology 5, 572-7.

Lisby, M., Barlow, J. H., Burgess, R. C. and Rothstein, R. (2004). Choreography of the DNA damage response: spatiotemporal relationships among checkpoint and repair proteins. Cell 118, 699-713.

Longhese, M. P., Mantiero, D. and Clerici, M. (2006). The cellular response to chromosome breakage. Mol Microbiol 60, 1099-108.

Longhese, M. P., Guerini, I., Baldo, V. and Clerici, M. (2008). Surveillance mechanisms monitoring chromosome breaks during mitosis and meiosis. DNA Repair (Amst) 7, 545-57.

Longtine, M. S., McKenzie, A., 3rd, Demarini, D. J., Shah, N. G., Wach, A., Brachat, A., Philippsen, P. and Pringle, J. R. (1998). Additional modules for versatile and economical PCR-based gene deletion and modification in Saccharomyces cerevisiae. Yeast 14, 953-61.

Lucca, C., Vanoli, F., Cotta-Ramusino, C., Pellicioli, A., Liberi, G., Haber, J. and Foiani, M. (2004). Checkpoint-mediated control of replisome-fork association and signalling in response to replication pausing. Oncogene 23, 1206-13.

Lydall, D., Nikolsky, Y., Bishop, D. K. and Weinert, T. (1996). A meiotic recombination checkpoint controlled by mitotic checkpoint genes. Nature 383, 840-3.

Lydall, D. (2003). Hiding at the ends of yeast chromosomes: telomeres, nucleases and checkpoint pathways. J Cell Sci 116, 4057-65.

Maizels, N. (2005). Immunoglobulin gene diversification. Annu Rev Genet 39, 23-46.

Majka, J. and Burgers, P. M. (2003). Yeast Rad17/Mec3/Ddc1: a sliding clamp for the DNA damage checkpoint. Proc Natl Acad Sci U S A 100, 2249-54.

Majka, J., Binz, S. K., Wold, M. S. and Burgers, P. M. (2006). Replication protein A directs loading of the DNA damage checkpoint clamp to 5'-DNA junctions. J Biol Chem 281, 27855-61.

Mantiero, D., Clerici, M., Lucchini, G. and Longhese, M. P. (2007). Dual role for Saccharomyces cerevisiae Tel1 in the checkpoint response to double-strand breaks. EMBO Rep 8, 380-7. 
Marston, A. L. and Amon, A. (2004). Meiosis: cell-cycle controls shuffle and deal. Nat Rev Mol Cell Biol 5, 983-97.

Mallory, J. C., Bashkirov, V. I., Trujillo, K. M., Solinger, J. A., Dominska, M., Sung, P., Heyer, W. D. and Petes, T. D. (2003). Amino acid changes in Xrs2p, Dun1p, and Rfa2p that remove the preferred targets of the ATM family of protein kinases do not affect DNA repair or telomere length in Saccharomyces cerevisiae. DNA Repair (Amst) 2, 1041-64.

Manfrini, N., Guerini, I., Citterio, A., Lucchini, G. and Longhese, M. P. (2010). Processing of meiotic DNA double strand breaks requires cyclin-dependent kinase and multiple nucleases. J Biol Chem 285, 11628-37.

Marston, A. L., Tham, W. H., Shah, H. and Amon, A. (2004). A genome-wide screen identifies genes required for centromeric cohesion. Science 303, 1367-70.

McGowan, C. H. (2002). Checking in on Cds1 (Chk2): A checkpoint kinase and tumor suppressor. Bioessays 24, 502-11.

McKee, A. H. and Kleckner, N. (1997). A general method for identifying recessive diploid-specific mutations in Saccharomyces cerevisiae, its application to the isolation of mutants blocked at intermediate stages of meiotic prophase and characterization of a new gene SAE2. Genetics 146, 797-816.

Melo, J. A., Cohen, J. and Toczyski, D. P. (2001). Two checkpoint complexes are independently recruited to sites of DNA damage in vivo. Genes Dev 15, 2809-21.

Melo, J. and Toczyski, D. (2002). A unified view of the DNA-damage checkpoint. Curr Opin Cell Biol 14, 237-45.

Michaelis, C., Ciosk, R. and Nasmyth, K. (1997). Cohesins: chromosomal proteins that prevent premature separation of sister chromatids. Cell 91, 35-45.

Mimitou, E. P. and Symington, L. S. (2008). Sae2, Exo1 and Sgs1 collaborate in DNA double-strand break processing. Nature 455, 770-4.

Mimitou, E. P. and Symington, L. S. (2011). DNA end resection--unraveling the tail. DNA Repair (Amst) 10, 344-8.

Moens, P. B. and Pearlman, R. E. (1988). Chromatin organization at meiosis. Bioessays 9, 151-3.

Moens, P. B., Tarsounas, M., Morita, T., Habu, T., Rottinghaus, S. T., Freire, R., Jackson, S. P., Barlow, C. and WynshawBoris, A. (1999). The association of ATR protein with mouse meiotic chromosome cores. Chromosoma 108, 95-102.

Monje-Casas, F., Prabhu, V. R., Lee, B. H., Boselli, M. and Amon, A. (2007). Kinetochore orientation during meiosis is controlled by Aurora B and the monopolin complex. Cell 128, 477-90.

Morales, M., Theunissen, J. W., Kim, C. F., Kitagawa, R., Kastan, M. B. and Petrini, J. H. (2005). The Rad50S allele promotes ATM-dependent DNA damage responses and suppresses ATM deficiency: implications for the Mre11 complex as a DNA damage sensor. Genes Dev 19, 3043-54.

Moreno-Borchart, A. C. and Knop, M. (2003). Prospore membrane formation: how budding yeast gets shaped in meiosis. Microbiol Res 158, 83-90.

Murakami, H., Borde, V., Shibata, T., Lichten, M. and Ohta, K. (2003). Correlation between premeiotic DNA replication and chromatin transition at yeast recombination initiation sites. Nucleic Acids Res 31, 4085-90.

Musacchio, A. and Salmon, E. D. (2007). The spindle-assembly checkpoint in space and time. Nat Rev Mol Cell Biol 8, 379-93.

Nagai, T., Ibata, K., Park, E. S., Kubota, M., Mikoshiba, K. and Miyawaki, A. (2002). A variant of yellow fluorescent protein with fast and efficient maturation for cell-biological applications. Nat Biotechnol 20, 87-90.

Nakada, D., Hirano, Y., Tanaka, Y. and Sugimoto, K. (2005). Role of the C terminus of Mec1 checkpoint kinase in its localization to sites of DNA damage. Mol Biol Cell 16, 5227-35. 
Navadgi-Patil, V. M. and Burgers, P. M. (2008). Yeast DNA replication protein Dpb11 activates the Mec1/ATR checkpoint kinase. J Biol Chem 283, 35853-9.

Neiman, A. M. (2005). Ascospore formation in the yeast Saccharomyces cerevisiae. Microbiol Mol Biol Rev 69, 565-84.

Ng, H. H., Feng, Q., Wang, H., Erdjument-Bromage, H., Tempst, P., Zhang, Y. and Struhl, K. (2002). Lysine methylation within the globular domain of histone $\mathrm{H} 3$ by Dot1 is important for telomeric silencing and Sir protein association. Genes Dev $16,1518-27$.

Nicolette, M. L., Lee, K., Guo, Z., Rani, M., Chow, J. M., Lee, S. E. and Paull, T. T. (2010). Mre11-Rad50-Xrs2 and Sae2 promote 5' strand resection of DNA double-strand breaks. Nat Struct Mol Biol 17, 1478-85.

Niu, H., Li, X., Job, E., Park, C., Moazed, D., Gygi, S. P. and Hollingsworth, N. M. (2007). Mek1 kinase is regulated to suppress double-strand break repair between sister chromatids during budding yeast meiosis. Mol Cell Biol 27, 5456-67.

Niu, H., Wan, L., Busygina, V., Kwon, Y., Allen, J. A., Li, X., Kunz, R. C., Kubota, K., Wang, B., Sung, P. et al. (2009). Regulation of meiotic recombination via Mek1-mediated Rad54 phosphorylation. Molecular Cell 36, 393-404.

Nyberg, K. A., Michelson, R. J., Putnam, C. W. and Weinert, T. A. (2002). Toward maintaining the genome: DNA damage and replication checkpoints. Annu Rev Genet 36, 617-56.

Ogiwara, H., Ui, A., Onoda, F., Tada, S., Enomoto, T. and Seki, M. (2006). Dpb11, the budding yeast homolog of TopBP1, functions with the checkpoint clamp in recombination repair. Nucleic Acids Res 34, 3389-98.

Osborn, A. J. and Elledge, S. J. (2003). Mrc1 is a replication fork component whose phosphorylation in response to DNA replication stress activates Rad53. Genes Dev 17, 1755-67.

Paciotti, V., Clerici, M., Lucchini, G. and Longhese, M. P. (2000). The checkpoint protein Ddc2, functionally related to S. pombe Rad26, interacts with Mec1 and is regulated by Mec1-dependent phosphorylation in budding yeast. Genes Dev 14, 2046-59.

Padmore, R., Cao, L. and Kleckner, N. (1991). Temporal comparison of recombination and synaptonemal complex formation during meiosis in S. cerevisiae. Cell 66, 1239-56.

Pak, J. and Segall, J. (2002). Role of Ndt80, Sum1, and Swe1 as targets of the meiotic recombination checkpoint that control exit from pachytene and spore formation in Saccharomyces cerevisiae. Mol Cell Biol 22, 6430-40.

Panizza, S., Mendoza, M. A., Berlinger, M., Huang, L., Nicolas, A., Shirahige, K. and Klein, F. (2011). Spo11-accessory proteins link double-strand break sites to the chromosome axis in early meiotic recombination. Cell 146, 372-83.

Pellicioli, A., Lucca, C., Liberi, G., Marini, F., Lopes, M., Plevani, P., Romano, A., Di Fiore, P. P. and Foiani, M. (1999). Activation of Rad53 kinase in response to DNA damage and its effect in modulating phosphorylation of the lagging strand DNA polymerase. EMBO J 18, 6561-72.

Pellicioli, A. and Foiani, M. (2005). Signal transduction: how rad53 kinase is activated. Curr Biol 15, R769-71.

Penkner, A., Portik-Dobos, Z., Tang, L., Schnabel, R., Novatchkova, M., Jantsch, V. and Loidl, J. (2007). A conserved function for a Caenorhabditis elegans Com1/Sae2/CtIP protein homolog in meiotic recombination. EMBO J 26, 5071-82.

Perera, D., Perez-Hidalgo, L., Moens, P. B., Reini, K., Lakin, N., Syvaoja, J. E., San-Segundo, P. A. and Freire, R. (2004). TopBP1 and ATR colocalization at meiotic chromosomes: role of TopBP1/Cut5 in the meiotic recombination checkpoint. Molecular Biology of the Cell 15, 1568-79.

Petronczki, M., Siomos, M. F. and Nasmyth, K. (2003). Un menage a quatre: the molecular biology of chromosome segregation in meiosis. Cell 112, 423-40. 
Petronczki, M., Matos, J., Mori, S., Gregan, J., Bogdanova, A., Schwickart, M., Mechtler, K., Shirahige, K., Zachariae, W. and Nasmyth, K. (2006). Monopolar attachment of sister kinetochores at meiosis I requires casein kinase 1. Cell 126, 1049-64.

Pierce, M., Benjamin, K. R., Montano, S. P., Georgiadis, M. M., Winter, E. and Vershon, A. K. (2003). Sum1 and Ndt80 proteins compete for binding to middle sporulation element sequences that control meiotic gene expression. Mol Cell Biol 23, 4814-25.

Prado, F., Cortes-Ledesma, F., Huertas, P. and Aguilera, A. (2003). Mitotic recombination in Saccharomyces cerevisiae. Curr Genet 42, 185-98.

Prinz, S., Amon, A. and Klein, F. (1997). Isolation of COM1, a new gene required to complete meiotic double-strand breakinduced recombination in Saccharomyces cerevisiae. Genetics 146, 781-95.

Rabitsch, K. P., Petronczki, M., Javerzat, J. P., Genier, S., Chwalla, B., Schleiffer, A., Tanaka, T. U. and Nasmyth, K. (2003). Kinetochore recruitment of two nucleolar proteins is required for homolog segregation in meiosis I. Dev Cell 4, 53548.

Refolio, E., Cavero, S., Marcon, E., Freire, R. and San-Segundo, P. A. (2011). The Ddc2/ATRIP checkpoint protein monitors meiotic recombination intermediates. J Cell Sci 124, 2488-500.

Richardson, C., Horikoshi, N. and Pandita, T. K. (2004). The role of the DNA double-strand break response network in meiosis. DNA Repair (Amst) 3, 1149-64.

Rockmill, B. and Roeder, G. S. (1990). Meiosis in asynaptic yeast. Genetics 126, 563-74.

Rockmill, B. and Roeder, G. S. (1991). A meiosis-specific protein kinase homolog required for chromosome synapsis and recombination. Genes Dev 5, 2392-404.

Rockmill, B., Sym, M., Scherthan, H. and Roeder, G. S. (1995). Roles for two RecA homologs in promoting meiotic chromosome synapsis. Genes Dev 9, 2684-95.

Rockmill, B., Fung, J. C., Branda, S. S. and Roeder, G. S. (2003). The Sgs1 helicase regulates chromosome synapsis and meiotic crossing over. Curr Biol 13, 1954-62.

Roeder, G. S. (1997). Meiotic chromosomes: it takes two to tango. Genes Dev 11, 2600-21.

Roeder, G. S. and Bailis, J. M. (2000). The pachytene checkpoint. Trends Genet 16, 395-403.

Roig, I., Dowdle, J. A., Toth, A., de Rooij, D. G., Jasin, M. and Keeney, S. (2010). Mouse TRIP13/PCH2 is required for recombination and normal higher-order chromosome structure during meiosis. PLoS Genet. 6.

Rouse, J. and Jackson, S. P. (2002). Lcd1p recruits Mec1p to DNA lesions in vitro and in vivo. Mol Cell 9, 857-69.

Sakaguchi, K., Ishibashi, T., Uchiyama, Y. and Iwabata, K. (2009). The multi-replication protein A (RPA) system--a new perspective. FEBS J 276, 943-63.

San-Segundo, P. A. and Roeder, G. S. (1999). Pch2 links chromatin silencing to meiotic checkpoint control. Cell 97, 313-24.

San-Segundo, P. A. and Roeder, G. S. (2000). Role for the silencing protein Dot1 in meiotic checkpoint control. Mol Biol Cell 11, 3601-15.

Schwartz, M. F., Duong, J. K., Sun, Z., Morrow, J. S., Pradhan, D. and Stern, D. F. (2002). Rad9 phosphorylation sites couple Rad53 to the Saccharomyces cerevisiae DNA damage checkpoint. Mol Cell 9, 1055-65.

Segal, M. and Bloom, K. (2001). Control of spindle polarity and orientation in Saccharomyces cerevisiae. Trends Cell Biol $11,160-6$.

Segurado, M. and Diffley, J. F. (2008). Separate roles for the DNA damage checkpoint protein kinases in stabilizing DNA replication forks. Genes Dev 22, 1816-27. 
Shiloh, Y. and Kastan, M. B. (2001). ATM: genome stability, neuronal development, and cancer cross paths. Adv Cancer Res 83, 209-54.

Shiloh, Y. (2003). ATM and related protein kinases: safeguarding genome integrity. Nat Rev Cancer 3, 155-68.

Shim, E. Y., Chung, W. H., Nicolette, M. L., Zhang, Y., Davis, M., Zhu, Z., Paull, T. T., Ira, G. and Lee, S. E. (2010). Saccharomyces cerevisiae Mre11/Rad50/Xrs2 and Ku proteins regulate association of Exo1 and Dna2 with DNA breaks. EMBO J 29, 3370-80.

Shonn, M. A. (2000). Requirement of the spindle checkpoint for proper chromosome segregation in budding yeast meiosis. Science 289, 300-3.

Shonn, M. A., McCarroll, R. and Murray, A. W. (2002). Spo13 protects meiotic cohesin at centromeres in meiosis I. Genes Dev 16, 1659-71.

Shonn, M. A., Murray, A. L. and Murray, A. W. (2003). Spindle checkpoint component Mad2 contributes to biorientation of homologous chromosomes. Curr Biol 13, 1979-84.

Shubassi, G., Luca, N., Pak, J. and Segall, J. (2003). Activity of phosphoforms and truncated versions of Ndt80, a checkpointregulated sporulation-specific transcription factor of Saccharomyces cerevisiae. Mol Genet Genomics 270, 324-36.

Sidorova, J. M. and Breeden, L. L. (1997). Rad53-dependent phosphorylation of Swi6 and down-regulation of CLN1 and CLN2 transcription occur in response to DNA damage in Saccharomyces cerevisiae. Genes Dev 11, 3032-45.

Smith, K. N., Penkner, A., Ohta, K., Klein, F. and Nicolas, A. (2001). B-type cyclins CLB5 and CLB6 control the initiation of recombination and synaptonemal complex formation in yeast meiosis. Curr Biol 11, 88-97.

Smits, G. J., van den Ende, H. and Klis, F. M. (2001). Differential regulation of cell wall biogenesis during growth and development in yeast. Microbiology 147, 781-94.

Sourirajan, A. and Lichten, M. (2008). Polo-like kinase Cdc5 drives exit from pachytene during budding yeast meiosis. Genes Dev 22, 2627-32.

Stegmeier, F. and Amon, A. (2004). Closing mitosis: the functions of the Cdc14 phosphatase and its regulation. Annu Rev Genet 38, 203-32.

Stewart, G. S., Maser, R. S., Stankovic, T., Bressan, D. A., Kaplan, M. I., Jaspers, N. G., Raams, A., Byrd, P. J., Petrini, J. H. and Taylor, A. M. (1999). The DNA double-strand break repair gene hMRE11 is mutated in individuals with an ataxiatelangiectasia-like disorder. Cell 99, 577-87.

Storlazzi, A., Xu, L., Schwacha, A. and Kleckner, N. (1996). Synaptonemal complex (SC) component Zip1 plays a role in meiotic recombination independent of SC polymerization along the chromosomes. Proc Natl Acad Sci U S A 93, 9043-8.

Stuart, D. and Wittenberg, C. (1998). CLB5 and CLB6 are required for premeiotic DNA replication and activation of the meiotic S/M checkpoint. Genes Dev 12, 2698-710.

Sugiyama, T. and Kantake, N. (2009). Dynamic regulatory interactions of Rad51, Rad52, and replication protein-a in recombination intermediates. Journal of Molecular Biology 390, 45-55.

Sun, Z., Hsiao, J., Fay, D. S. and Stern, D. F. (1998). Rad53 FHA domain associated with phosphorylated Rad9 in the DNA damage checkpoint. Science 281, 272-4.

Sung, M. K. and Huh, W. K. (2007). Bimolecular fluorescence complementation analysis system for in vivo detection of protein-protein interaction in Saccharomyces cerevisiae. Yeast 24, 767-75.

Sweeney, F. D., Yang, F., Chi, A., Shabanowitz, J., Hunt, D. F. and Durocher, D. (2005). Saccharomyces cerevisiae Rad9 acts as a Mec1 adaptor to allow Rad53 activation. Curr Biol 15, 1364-75. 
Sym, M., Engebrecht, J. A. and Roeder, G. S. (1993). ZIP1 is a synaptonemal complex protein required for meiotic chromosome synapsis. Cell 72, 365-78.

Sym, M. and Roeder, G. S. (1994). Crossover interference is abolished in the absence of a synaptonemal complex protein. Cell 79, 283-92.

Szostak, J. W., Orr-Weaver, T. L., Rothstein, R. J. and Stahl, F. W. (1983). The double-strand-break repair model for recombination. Cell 33, 25-35.

Szyjka, S. J., Viggiani, C. J. and Aparicio, O. M. (2005). Mrc1 is required for normal progression of replication forks throughout chromatin in S. cerevisiae. Mol Cell 19, 691-7.

Toh, G. W., O'Shaughnessy, A. M., Jimeno, S., Dobbie, I. M., Grenon, M., Maffini, S., O'Rorke, A. and Lowndes, N. F. (2006). Histone H2A phosphorylation and H3 methylation are required for a novel Rad9 DSB repair function following checkpoint activation. DNA Repair (Amst) 5, 693-703.

Toth, A., Rabitsch, K. P., Galova, M., Schleiffer, A., Buonomo, S. B. and Nasmyth, K. (2000). Functional genomics identifies monopolin: a kinetochore protein required for segregation of homologs during meiosis i. Cell 103, 1155-68.

Thomas, B. J. and Rothstein, R. (1989). Elevated recombination rates in transcriptionally active DNA. Cell 56, 619-30.

Treuner, K., Helton, R. and Barlow, C. (2004). Loss of Rad52 partially rescues tumorigenesis and T-cell maturation in Atmdeficient mice. Oncogene 23, 4655-61.

Tsubouchi, T., Macqueen, A. J. and Roeder, G. S. (2008). Initiation of meiotic chromosome synapsis at centromeres in budding yeast. Genes Dev 22, 3217-26.

Tsukuda, T., Trujillo, K. M., Martini, E. and Osley, M. A. (2009). Analysis of chromatin remodeling during formation of a DNA double-strand break at the yeast mating type locus. Methods 48, 40-5.

Tung, K. S., Hong, E. J. and Roeder, G. S. (2000). The pachytene checkpoint prevents accumulation and phosphorylation of the meiosis-specific transcription factor Ndt80. Proc Natl Acad Sci U S A 97, 12187-92.

UhImann, F. (2003). Chromosome cohesion and separation: from men and molecules. Curr Biol 13, R104-14.

Usui, T., Ogawa, H. and Petrini, J. H. (2001). A DNA damage response pathway controlled by Tel1 and the Mre11 complex. Mol Cell 7, 1255-66.

Vanderlaan, M. and Thomas, C. B. (1985). Characterization of monoclonal antibodies to bromodeoxyuridine. Cytometry 6 , $501-5$.

van Leeuwen, F., Gafken, P. R. and Gottschling, D. E. (2002). Dot1p modulates silencing in yeast by methylation of the nucleosome core. Cell 109, 745-56.

Viggiani, C. J. and Aparicio, O. M. (2006). New vectors for simplified construction of BrdU-Incorporating strains of Saccharomyces cerevisiae. Yeast 23, 1045-51.

Viscardi, V., Clerici, M., Cartagena-Lirola, H. and Longhese, M. P. (2005). Telomeres and DNA damage checkpoints. Biochimie 87, 613-24.

Visintin, R., Craig, K., Hwang, E. S., Prinz, S., Tyers, M. and Amon, A. (1998). The phosphatase Cdc14 triggers mitotic exit by reversal of Cdk-dependent phosphorylation. Mol Cell 2, 709-18.

Wan, L., de los Santos, T., Zhang, C., Shokat, K. and Hollingsworth, N. M. (2004). Mek1 kinase activity functions downstream of RED1 in the regulation of meiotic double strand break repair in budding yeast. Mol Biol Cell 15, 11-23.

Wang, H., Liu, D., Wang, Y., Qin, J. and Elledge, S. J. (2001). Pds1 phosphorylation in response to DNA damage is essential for its DNA damage checkpoint function. Genes Dev 15, 1361-72. 
Ward, I. M., Minn, K., van Deursen, J. and Chen, J. (2003). p53 Binding protein 53BP1 is required for DNA damage responses and tumor suppression in mice. Mol Cell Biol 23, 2556-63.

Wold, M. S. (1997). Replication protein A: a heterotrimeric, single-stranded DNA-binding protein required for eukaryotic DNA metabolism. Annu Rev Biochem 66, 61-92.

Wu, H. Y. and Burgess, S. M. (2006). Two distinct surveillance mechanisms monitor meiotic chromosome metabolism in budding yeast. Curr Biol 16, 2473-9.

Wysocki, R., Javaheri, A., Allard, S., Sha, F., Cote, J. and Kron, S. J. (2005). Role of Dot1-dependent histone H3 methylation in G1 and S phase DNA damage checkpoint functions of Rad9. Mol Cell Biol 25, 8430-43.

Xie, J., Pierce, M., Gailus-Durner, V., Wagner, M., Winter, E. and Vershon, A. K. (1999). Sum1 and Hst1 repress middle sporulation-specific gene expression during mitosis in Saccharomyces cerevisiae. EMBO J 18, 6448-54.

Xu, L., Ajimura, M., Padmore, R., Klein, C. and Kleckner, N. (1995). NDT80, a meiosis-specific gene required for exit from pachytene in Saccharomyces cerevisiae. Mol Cell Biol 15, 6572-81.

Xu, L., Weiner, B. M. and Kleckner, N. (1997). Meiotic cells monitor the status of the interhomolog recombination complex. Genes Dev 11, 106-18.

Yu, H. G. and Koshland, D. (2007). The Aurora kinase Ipl1 maintains the centromeric localization of PP2A to protect cohesin during meiosis. J Cell Biol 176, 911-8.

Zhao, X., Muller, E. G. and Rothstein, R. (1998). A suppressor of two essential checkpoint genes identifies a novel protein that negatively affects dNTP pools. Mol Cell 2, 329-40.

Zhou, J., Yao, J. and Joshi, H. C. (2002). Attachment and tension in the spindle assembly checkpoint. J Cell Sci 115, 354755.

Zhu, Z., Chung, W. H., Shim, E. Y., Lee, S. E. and Ira, G. (2008). Sgs1 helicase and two nucleases Dna2 and Exo1 resect DNA double-strand break ends. Cell 134, 981-94.

Zierhut, C., Berlinger, M., Rupp, C., Shinohara, A. and Klein, F. (2004). Mnd1 is required for meiotic interhomolog repair. Curr Biol 14, 752-62.

Zou, L. and Elledge, S. J. (2003). Sensing DNA damage through ATRIP recognition of RPA-ssDNA complexes. Science $300,1542-8$.

Zou, L. (2007). Single- and double-stranded DNA: building a trigger of ATR-mediated DNA damage response. Genes and Development 21, 879-85. 


\begin{tabular}{|c|c|c|}
\hline ARSs & Secuencias de replicación autónomas & Autonomously Replicating Sequence \\
\hline ATM & Ataxia telangiectasia mutada & Ataxia Telangiectasia Mutated \\
\hline BSA & Seroalbúmina bovina & Bovine Serum Albumin \\
\hline BRCT & Extremo carboxilo de BRCA1 & BRCA1 C-Terminus \\
\hline BrdU & 5-bromo-2'-deoxiuridina & 5-bromo-2'-deoxyuridine \\
\hline CDK & Kinasa dependiente de Ciclina & 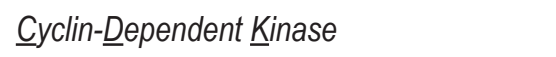 \\
\hline ChIP & Inmunoprecipitación de cromatina & Chromatin ImmunoPrecipitation \\
\hline DIC & Contraste interferencial & Differential Interference Contrast \\
\hline DMSO & Dimetil sulfóxido & \\
\hline DNA & Ácido desoxirribonucleico & \\
\hline DSB & Rotura de doble cadena & Double-Strand Break \\
\hline DSBR & Reparación de roturas de doble cadena & Double-Strand Break Repair \\
\hline FEAR & Liberación de Cdc14 en anafase temprana & cdc Fourteen Early Anaphase Release \\
\hline FHA & Asociado a Forkhead & ForkHead-Associated \\
\hline GAP & Proteína activadora de la actividad GTPasa & GTPase-Activating Proteins \\
\hline GFP & Proteína fluorescente Verde & Green Fluorescent Protein \\
\hline h & Horas & \\
\hline HA & Hemaglutinina & Haemaglutinin \\
\hline HJ & Unión de Holliday & Holliday Junction \\
\hline HR & Recombinación homóloga & Homologous Recombination \\
\hline HRP & Peroxidasa de rábano & HorseRadish Peroxidase \\
\hline HSV-TK & Timidina kinasa del virus del Herpes Simplex & \\
\hline kb & Kilobase & \\
\hline MEN & Red de salida de mitosis & Mitotic Exit Network \\
\hline $\min$ & Minutos & \\
\hline MMC & Complejo del chekpoint mitótico & Mitotic Checkpoint Complex \\
\hline MMS & Metil-metanosulfonato & \\
\hline MSE & Elemento de esporulación mediano & Middle Sporulation Element \\
\hline MRX & Complejo Mre11/Rad50/Xrs2 & \\
\hline NHEJ & Unión de extremos no homólogos & Non-Homologous End-Joining \\
\hline OD & Densidad óptica & Optical Density \\
\hline ORF & Marco abierto de lectura & Open Reading Frame \\
\hline pb & pares de bases & \\
\hline PCNA & Antígeno nuclear de células proliferantes & Proliferating Cell Nuclear Antigen \\
\hline PCR & Reacción en cadena de la polimerasa & Polymerase Chain Reaction \\
\hline PGK & Fosfoglicerato kinasa & Phosphoglycerate kinase \\
\hline PI3KK & Kinasas parecidas a las 3 ' fosfatidil inositol kinasas & Phosphatidyl-Inositol-3' Kinase-like Kinase \\
\hline PSMs & Membranas de las pro-esporas & ProSpore Membranes \\
\hline rDNA & DNA ribosómico & ribosomal DNA \\
\hline RFC & Factor de replicación C & Replication Factor C \\
\hline RFP & Proteina flurorescente roja & Red Flurescent Protein \\
\hline RPA & Proteína A de replicación & Replication Protein A \\
\hline SAC & Checkpoint de esamblaje del huso & Spindle Assembly Checkpoint \\
\hline SC & Complejo sinaptonémico & Synaptonemal Complex \\
\hline SCR & Recombinación entre cromátidas hermanas & Sister Chromatid Recombination \\
\hline SPBs & Cuerpos polares del huso & Spindle Pole Body \\
\hline SPOC & Checkpoint de posicionamiento del huso & 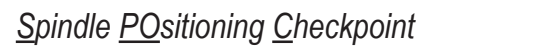 \\
\hline
\end{tabular}




$\begin{array}{lll}\text { SSBs } & \text { Roturas de cadena sencilla } & \text { Single-Strand Breaks } \\ \text { ssDNA } & \text { DNA de cadena sencilla } & \text { single-stranded DNA } \\ \text { TCA } & \text { Ácido Tricloroacético } & \text { TriChloroacetic Acid } \\ \text { UV } & \text { Ultravioleta } & \\ \text { YFP } & \text { Proteína fluorescente amarilla } & \text { Yellow Fluorescent Protein } \\ \text { YH2A } & \text { Histona H2A fosforilada en el residuo S129 } & \end{array}$

